\title{
COMPOSITION PLAN
}

(faillissementsakkoord)

LEHMAN BROTHERS TREASURY CO. B.V. in bankruptcy

(“LBT”)

This Composition Plan is primarily addressed to Direct Participants and Other Ordinary Creditors

Direct Participants are defined in Section $C$ as persons or entities that are shown in the records of a Clearing System as holders of particular nominal amounts of Notes issued by LBT

Beneficial owners of Notes that do not qualify as a Direct Participant are recommended to contact the Direct Participant or Intermediary Institution through which their Notes are held and to consult the "UBO Information Memorandum" available on the LBT Website 
This Composition Plan is offered pursuant to article 138 of the Dutch Bankruptcy Act ("DBA") to ordinary non-preferred Creditors of LBT ("Ordinary Creditors"), being:

(i) "Noteholders" as defined in the Consent Solicitation Memorandum (Annex I); and

(ii) creditors holding an unsecured non-preferred claim against LBT, other than a claim arising from Notes ("Other Ordinary Creditors").

Only Ordinary Creditors are requested to file claims and participate in the voting procedures as set forth herein and in the Consent Solicitation Memorandum.

Conditional upon the acceptance of the Composition Plan by the required majority of the Ordinary Creditors that participate in the filing and voting procedures, and subject to the confirmation of the Composition Plan by the Dutch court, once the Composition Plan becomes effective, distributions will be made to Direct Participants for the benefit of all Noteholders and Other Ordinary Creditors in accordance with the provisions of the Composition Plan.

Direct Participants will be responsible for allocating distributions that they receive under the Composition Plan to Noteholders.

Unless otherwise defined, capitalised terms have the meanings ascribed to them in Section $\underline{\mathrm{C}}$ of this Composition Plan. 


\section{SECTION A: EXPLANATORY STATEMENT TO THE COMPOSITION PLAN}

\section{INTRODUCTION}

LBT presents this draft Composition Plan (ontwerp-faillissementsakkoord) pursuant to Title I, Chapter 6 DBA to its Ordinary Creditors.

Explicit reference is made to the Public Reports that have been published since the Bankruptcy Date and that are available on the website of LBT: www.lehmanbrotherstreasury.com (the "LBT Website").

Prior to its Bankruptcy, LBT issued securities (notes and certificates, all referred to as: "Notes") to professional and retail investors under the following programs: the USD 100,000,000,000 Euro Medium Term Note Program (the "EMTN Program"), the USD 4,000,000,000 German Note Issuance Program (the "German Note Program"), the (Swiss) Certificates Program (the "Swiss Program") and the (Italian) Inflation Linked Notes Program (the "Italian Program").

At the Bankruptcy Date, 3,789 Series of Notes were outstanding. The vast majority $(3,655$ Series) of the outstanding Notes were issued under the EMTN Program. 67 Notes were issued under the Swiss Program and 66 Notes under the German Note Program. The Italian Program only consists of one Series.

The characteristics of these Notes vary from relatively simple to extremely complex. With respect to almost all Notes, both the nominal amount invested, as well as any return (if applicable) on such nominal, are synthetically linked to movements of specific underlying elements, such as equity prices, stock indices and commodity prices. LBT hedged the risks related to underlying elements of Notes by entering into numerous swap agreements with affiliated entities.

LBT on-lent the proceeds from the Note issuance programs to Lehman Brothers Holdings Inc. ("LBHI") for purposes of funding the activities of the Lehman Brothers group.

Pursuant to a settlement agreement executed on August 30, 2011 and amended on January 27, 2012 and on December 5, 2012, between the Bankruptcy Trustees and LBHI and certain of its affiliates (the "Settlement Agreement", attached as Annex I), among other things, (i) the intercompany claims of LBT against LBHI have been agreed to and allowed by LBHI under the confirmed Third Amended Joint Chapter 11 Plan of Lehman Brothers Holdings Inc. and its affiliated debtors (the "Confirmed Chapter 11 Plan") for an amount of USD 
$34,548,000,000$ as a class $4 A$ senior affiliate claim as defined in the Confirmed Chapter 11 Plan (the "LBT Intercompany Claim"); and (ii) the Bankruptcy Trustees have agreed to and allowed a claim of Lehman Brothers Special Financing Inc. in the amount of USD $1,022,992,712$ and a claim of Lehman Brothers Commodities Services Inc. in the amount of USD 43,507,736 (jointly referred to as: "Allowed U.S. Debtor Claims").

On April 17, 2012, LBT received a first distribution of $4.62 \%$ on the LBT Intercompany Claim from LBHI; on October 1, 2012, LBT received a second distribution of $3.11 \%$. The Confirmed Chapter 11 Plan provides for LBHI to make further distributions to its creditors, including to LBT on account of the LBT Intercompany Claim, on or about March 30 and September 30 of each year, as and to the extent sufficient cash becomes available.

\section{PURPOSE OF THE COMPOSITION PLAN}

The Composition Plan will allow LBT to make distributions to Direct Participants for the benefit of Noteholders and to Other Ordinary Creditors in the most efficient and expedient manner by establishing:

(i) the LBT Note Valuations as a fair and equitable basis for the pro rata entitlement of Noteholders to distributions from LBT and binding all Ordinary Creditors thereto; and

(ii) a distribution method that enables LBT to make distributions to Direct Participants by means of and subject to the existing payment and settlement systems.

Other Ordinary Creditors whose claims have been or will be acknowledged by the Bankruptcy Trustees will receive payments pursuant to the provisions of the Composition Plan.

The Composition Plan will be put to a vote of Ordinary Creditors. The filing and voting procedures applicable to Noteholders are set forth in the Consent Solicitation Memorandum, which is attached to this Composition Plan as Annex II. The filing of Noteholders' claims and the collection of voting instructions from Noteholders, is directed through Direct Participants.

\section{NOTEHOLDERS ARE REQUESTED TO READ CAREFULLY THE CONSENT SOLICITATION MEMORANDUM}

This Composition Plan is primarily addressed to Direct Participants and Other Ordinary Creditors. Beneficial owners of Notes that do not qualify as a Direct Participant are recommended to contact the Direct Participant or Intermediary Institution through which their Notes are held 
The Supervisory Judge has approved the filing and voting procedures as described and laid down in the Consent Solicitation Memorandum.

Other Ordinary Creditors are required to file claims and are entitled to vote in accordance with the applicable provisions of Dutch bankruptcy law.

\section{NEED FOR AND BACKGROUND OF THE COMPOSITION PLAN}

The demise of the Lehman Brothers Group is without precedent in terms of scope, amounts at stake and financial complexity.

The specific complexities related to the calculation and valuation of sophisticated financial instruments were at the centre of LBT's operations: the issuance of thousands of Notes with payments linked to specific underlyings and the conclusion of as many individual hedges with affiliates.

In order to make distributions, the Series of Notes needed to be properly and irrevocably valued taking into account each Note's respective Conditions as well as the applicable requirements of Dutch law. The number of UBOs that hold Notes runs into the tens of thousands. Some of these UBOs are sophisticated and large institutional investors, others are private individuals. The rights of UBOs and their respective entitlements to payments are effected through Direct Participants and through Intermediary Institutions active in Europe, Asia and the U.S.

Because of the immense number of UBOs and the complexity and potential subjectivity related to the valuation of each of the Notes, the LBT estate has, since July 2009, in consultation with many large UBOs, been working towards a framework in which the valuation of the Notes is undertaken using Valuation Principles that are fair and equitable, and that respect the Conditions of each Note as well as Dutch (bankruptcy) law.

Provisional Valuation Principles were announced in the third Public Report of July 22, 2009; more detail and explanation were provided in the fourth and fifth Public Report of November 3, 2009 and March 12, 2010.

Following discussions with and communications from large UBOs, the Provisional Valuation Principles were further refined. Ultimately, the Definitive Valuation Principles were promulgated in the tenth Public Report of November 11, 2011. Given the importance of reaching as many Noteholders as possible, the publication of the tenth Public Report was

This Composition Plan is primarily addressed to Direct Participants and Other Ordinary Creditors. Beneficial owners of Notes that do not qualify as a Direct Participant are recommended to contact the Direct Participant or Intermediary Institution through which their Notes are held 
announced by communications sent through the communication channels of the Clearing Systems.

From December 2011, the LBT Estate and its financial advisors started the calculations of each Series of Notes by applying the Definitive Valuation Principles. On January 31, 2012, Provisional Admissible Amounts related to the first batch of 484 Series were made public on the LBT website, followed by a second batch of 1,109 Series on March 12, 2012, a third batch of 278 Series on May 1, 2012, a fourth batch of 854 Series on June 28, 2012, a fifth batch of 790 Series on July 25, 2012 and lastly, on September 27, 2012, the final list of Outstanding Series containing the final valuation of 3,789 Series of Notes was made public.

From the publication of the first batch on, UBOs were given the opportunity to lodge Manifest Error Notifications with the LBT Estate with respect to self-evident errors in an LBT Note Valuation. The possibility of making Manifest Error Notifications, as well as the requirements for such a valid Manifest Error Notification, were communicated in the tenth Public Report. The Manifest Error Bar Date was set at October 29, 2012 at 5pm CET. As a result of Manifest Error Notifications received, a limited number of LBT Note Valuations were amended and, as of December 5, 2012, twelve LBT Note Valuations remain the subject of discussion or are in the process of resolution.

The Definitive Valuation Principles are actively supported by a number of large UBOs representing a significant number of Notes, both in number of discrete Notes held and in amount. This support has materialised in the execution of Valuation Support Agreements ("VSAs") between the LBT estate and these UBOs. Each VSA expresses the respective UBOs written support for the Definitive Valuation Principles. Annex III contains a list of large UBOs that have executed VSAs.

The U.S. Debtors that hold Other Ordinary Claims against LBT and that are holding claims arising from Notes have expressed their support for the Composition Plan and will vote in favor of the Composition Plan subject to the Settlement Agreement. Reference is made to Annex IV (U.S. Debtors' statement dated December 5, 2012).

The final list of LBT Note Valuations as of the date of this Composition Plan is attached as Annex V.

A draft of the Composition Plan dated November 30, 2012 was made available as an attachment to the fourteenth (interim) Public Report of the same date. This draft is superseded in all aspects by this Composition Plan.

This Composition Plan is primarily addressed to Direct Participants and Other Ordinary Creditors. Beneficial owners of Notes that do not qualify as a Direct Participant are recommended to contact the Direct Participant or Intermediary Institution through which their Notes are held 


\section{RECOMMENDATION}

The Composition Plan provides Noteholders as well as Other Ordinary Creditors with a mechanism to receive distributions on their admitted claims against LBT in the quickest and most efficient manner.

The Definitive Valuation Principles have been formulated with the equitable treatment of claims as the base principle and in accordance with the principles of the DBA, whilst taking the Conditions of each Note as the starting point. UBOs have had and have taken the opportunity to communicate their views on the Definitive Valuation Principles and the published valuations. The process of valuing each Note has been performed by valuation professionals who have applied a robust process with appropriate internal checks and balances. As such, subject to Manifest Errors, the Bankruptcy Trustees will at the Claims Admission Meeting only recognise (Series of) Notes for their respective LBT Note Valuation.

\section{IMPLEMENTATION OF THE COMPOSITION PLAN IS IN THE BEST INTEREST OF ALL ORDINARY CREDITORS. LBT AND THE BANKRUPTCY TRUSTEES THEREFORE STRONGLY RECOMMEND NOTEHOLDERS AND OTHER ORDINARY CREDITORS TO ACCEPT THE COMPOSITION PLAN BY VOTING IN FAVOR OF THE COMPOSITION PLAN.}

Under Dutch Bankruptcy law, a composition plan can only be offered once to creditors. Should the Composition Plan not be accepted, the Bankruptcy Trustees will seek to allow Noteholders' claims in the LBT bankruptcy based on the Definitive Valuation Principles. This scenario would potentially expose all Ordinary Creditors to severe delays in receiving distributions. Such a claims allowance process can, particularly in light of the complexity of the Notes, lead to complicated and protracted litigation, which could force the LBT estate to maintain significant distribution reserves.

[remainder of the page intentionally left blank] 


\section{SECTION B: PROVISIONS OF THE COMPOSITION PLAN}

\section{Article 1, Recognition of Outstanding Series of Notes and Other Ordinary Claims}

1.1. As of the "Effective Date" (as defined in Section C), the Outstanding Series of Notes are irrevocably recognised by LBT in accordance with the LBT Note Valuations included in Annex $\mathbf{V}$. Distributions on Outstanding Series of Notes will be made solely in accordance with Article 3.

1.2. As of the Effective Date, each Other Ordinary Claim that is recognised by the Bankruptcy Trustees at the Claims Admission Meeting is irrevocably recognised by LBT for the value attributed to such claim according to the List of Admitted Claims. Annex VI, which includes the Acknowledged U.S. Debtor Claims, provides a list of submitted and provisionally admitted or disputed Other Ordinary Claims which list shall be updated from time to time.

1.3. As of the Effective Date, each Other Ordinary Claim that is submitted to LBT after the Claims Admission Meeting and each Disputed Claim, shall, for the purposes of distributions pursuant to this Composition Plan, only be recognised by LBT for either (a) the value decided upon in a Final Order; or (b) the value determined in a settlement agreement between the relevant holder of such claim and LBT. As of the Effective Date, LBT has full and absolute discretion to enter into settlement agreements with Ordinary Creditors in order to either settle Disputed Claims or to recognise Other Ordinary Claims.

1.4. Claims arising out of the Outstanding Series of Notes, which, except for the (pro rata) entitlement to distributions provided for in this Composition Plan, remain subject to the applicable Conditions and related legal provisions and other arrangements related or applicable to the holding or trading of Notes, and that are or will be recognised pursuant to Article 1.1 and Article 1.3, are defined as "Acknowledged Noteholder Claims". All Other Ordinary Claims that are recognised pursuant to Article 1.2 and Article 1.3 are defined as "Acknowledged Other Ordinary Claims". The Acknowledged Noteholders Claims and Acknowledged Other Ordinary Claims together are defined as "Acknowledged Claims".

1.5. All Acknowledged Claims rank pari passu for the value attributed to such claims.

This Composition Plan is primarily addressed to Direct Participants and Other Ordinary Creditors. Beneficial owners of Notes that do not qualify as a Direct Participant are recommended to contact the Direct Participant or Intermediary Institution through which their Notes are held 


\section{Article 2, Binding nature of the values attributed to Acknowledged Claims}

2.1. As of the Effective Date, each Ordinary Creditor is bound by the value attributed to the Acknowledged Claims pursuant to Article 1 above, regardless of whether such Ordinary Creditor has filed a claim in the bankruptcy of LBT, or has voted against or in favor of this Composition Plan or has abstained from voting.

2.2. Except for the entitlement to receive distributions on Acknowledged Claims as provided for in this Composition Plan, nothing in the Composition Plan should be construed as providing holders of Acknowledged Claims with any other rights or entitlements that as of the Effective Date do not exist under the applicable Conditions or any other legal or other provisions - including those provisions related to the holding or trading of Notes through the Clearing systems - that are applicable to the Acknowledged Claims.

\section{Article 3, Distributions to Ordinary Creditors}

3.1. Each time that "Available Cash" (as defined in Section $\mathrm{C}$ ) is available for distribution to Ordinary Creditors, LBT shall make a distribution in accordance with this Article 3 and with Article 4. To the extent reasonably possible, LBT will make such distributions within 13 business days after receipt of any payments from LBHI on the LBT Intercompany Claim, which payments are expected to take place semi-annually on March 30 and September 30 of each year as provided in the Confirmed Chapter 11 Plan. In principle, LBT shall not make distributions that are in the aggregate less than USD $100,000,000$, except for a final distribution.

3.2. LBT will receive cash distributions on the LBT Intercompany Claim in U.S. Dollars. Currency conversions shall only be made as provided in Article 4.

3.3. In accordance with the Conditions and existing legal provisions of the applicable Note documentation and other provisions related or applicable to the holding or trading of Notes, as well as the legal and operating arrangements between LBT and the Distribution Agent (collectively referred to as the "Distribution Provisions"), LBT will make distributions on the Outstanding Series of Notes by instructing the Distribution Agent to transfer the "Pro Rata Share" (as defined in Section C) of Available Cash applicable to such Outstanding Series of Notes to the relevant Clearing System or, to the extent applicable, to the entities designated by the relevant Clearing System for onward payment to the relevant Direct Participants. Direct Participants will be responsible for allocating distributions to Noteholders.

3.4. Each time LBT intends to make a distribution in accordance with the Distribution Provisions, such intention, including the date on which the Distribution Agent expects to make distributions as described in Article 3.3 (the "Distribution Date") shall be 
communicated on the LBT Website and by means of a notice to be sent via the communication channels of the relevant Clearing System, no later than 3 business days before the Distribution Date.

3.5. LBT will on or promptly after the Distribution Date make distributions to the holders of Acknowledged Other Ordinary Claims by paying each such Other Ordinary Creditor, as indicated in the records of LBT, its Pro Rata Share of Available Cash on the bank account provided by the holder of such Acknowledged Other Ordinary Claim.

3.6. If an Other Ordinary Claim is transferred after the Effective Date, such transfer shall only be recognised by LBT for the purpose of distributions pursuant to this Composition Plan upon written confirmation by LBT of receipt of a notice of transfer. The notice of transfer needs to be signed by both the transferor and the transferee, and must clearly state the date upon which the transfer of the relevant Other Ordinary Claim has become effective. The transferee of the Other Ordinary Claim will be bound by the Composition Plan, and will only be entitled to receive any distributions from LBT that fall due after the date of the aforementioned written confirmation by LBT.

3.7. Any distributions made pursuant to this Article 3 are made free of withholding tax, unless such withholding is required by applicable law, rule, regulation or practice. Clearing Systems, Direct Participants, Noteholders, Intermediary Institutions, or as the case may be, UBOs and holders of Acknowledged Ordinary Claims or any other party entitled to any distributions from LBT, are and will at all times, remain responsible for any and all tax consequences in any applicable jurisdiction related to the direct or indirect receipt of, or entitlement to distributions from LBT. For the avoidance of doubt, such responsibility could include, without limitation, any tax under applicable tax laws in any applicable jurisdiction due upon direct or indirect receipt of, or entitlement to, any distributions made by LBT or any tax required to be withheld under applicable tax laws in any applicable jurisdiction on any payments made as a direct or indirect consequence of any distributions made by LBT.

\section{Article 4, Currency of distributions}

4.1. On each Distribution Date, LBT will make distributions in accordance with Article 3 in the currency in which the relevant Outstanding Series or Other Ordinary Claim is denominated (the "Original Currency").

4.2. For each distribution, the Pro Rata Share of Available Cash payable on any Acknowledged Claim that is denominated in a currency other than U.S. Dollars shall be converted from U.S. Dollars (being the currency in which distributions on the LBT Intercompany Claim are received) into the Original Currency of such claim at

This Composition Plan is primarily addressed to Direct Participants and Other Ordinary Creditors. Beneficial owners of Notes that do not qualify as a Direct Participant are recommended to contact the Direct Participant or Intermediary Institution through which their Notes are held 
conversion rates determined by reference to prevailing spot exchange rates approximately 5 business days before each Distribution Date. The conversion rates applicable to each non-U.S. Dollar denominated Series will be communicated on, or one business day before, each Distribution Date on the LBT Website and, if and to the extent reasonably possible, communicated via the communication channels of the Clearing Systems.

\section{Article 5, Modification of the Composition Plan}

5.1. After the Effective Date, LBT may amend or modify the Composition Plan, or remedy any omission or inconsistency in the Composition Plan, in such a manner that may be considered necessary to carry out the purpose and intent of the Composition Plan, provided that any such amendment, modification or remedy does not materially change the Composition Plan. LBT will publish any proposed amendment, modification or remedy 15 business days prior to its effect on the LBT Website.

\section{Article 6, Post Effective Date Provisions}

6.1. As of the Effective Date, the bankruptcy proceedings related to LBT shall end in accordance with article 161 DBA, and LBT shall continue to exist for the purpose of fulfillment of its obligations under the Composition Plan as an entity in liquidation as provided in Article 6.3.

6.2. As of the Effective Date, each Ordinary Creditor is bound by this Composition Plan, whether or not such Ordinary Creditor has filed a claim in the bankruptcy of LBT or voted in favor or against the Composition Plan.

6.3. On or immediately after the Effective Date, Stichting Lehman Brothers Treasury (the "Stichting") as the sole shareholder of LBT, shall pass a resolution to liquidate LBT in accordance with article 2:19 of the Dutch Civil Code ("DCC") with the appointment of the Bankruptcy Trustees as liquidators (vereffenaars) of LBT (the "Liquidators").

6.4. LBT acknowledges that it shall be fully bound by any obligation assumed by and any agreement entered into by the Bankruptcy Trustees on behalf of the LBT estate.

6.5. LBT shall continue to exist for the purpose of fulfilling all its obligations under the Composition Plan and will act for the benefit of the Ordinary Creditors, and in accordance with articles 2:23b and 2:19 DCC, will only cease to exist once LBT has no more assets to distribute. The Liquidators shall be authorised to represent and bind LBT for any and all matters related to the fulfillment of LBT's obligations existing under the Composition Plan. The articles of association of LBT shall be amended to the extent required for the fulfillment of the Composition Plan. 
6.6. As of the Effective Date, LBT will publish quarterly reports on the LBT Website presented in the same format as the Public Reports.

6.7. As of the Effective Date, LBT shall indemnify and hold harmless the "Indemnified Parties" (as defined in Section C) against any and all liabilities, claims, actions, acts, omitted or taken, or damages incurred or asserted against, in connection with, or arising out of the suspension of payment and bankruptcy proceedings related to LBT, the Composition Plan, its formulation, preparation and its fulfillment, including, but not limited to the determination of claims arising from Notes, the management of LBT's cash, and any distributions made as provided for under the Composition Plan, provided however, that nothing in this Article 6.7 shall affect the liability of any person that otherwise would result from any act or omission that is determined by a Final Order to have constituted willful misconduct or gross negligence (opzet of grove schuld).

\section{Article 7, Notices}

7.1. As of the Effective Date, any notice or request in connection with this Composition Plan shall be in writing and made by courier or certified mail to the attention of: Lehman Brothers Treasury Co. B.V. in liquidatie, attn. R.J. Schimmelpenninck and F. Verhoeven, vereffenaars, c/o Houthoff Buruma, PO Box 75505, NL-1070 AM, Amsterdam, the Netherlands.

\section{Article 8, Releases}

8.1. As of the Effective Date, each and every Ordinary Creditor shall release or shall be deemed to have released the "Released Parties" (as defined in Section C) from, and none of the Released Parties shall have or incur any liability for, any claim for, cause of action for or other assertion of liability, for any act taken or omitted to be taken during the provisional suspension of payment and bankruptcy proceedings of LBT, and until LBT ceases to exist, in connection with, or arising out of, the LBT provisional suspension of payment and bankruptcy proceedings, the formulation or administration of the Composition Plan, including but not limited to, the manner in which any cash is or will be distributed under the Composition Plan, or any other act or omission in connection with the LBT provisional suspension of payment or bankruptcy proceedings, the Composition Plan and any annexes or documentation and communication related thereto, the Public Reports and any annexes thereto, the VSAs, the LBT Note Valuations and any information whether in writing or orally provided in connection therewith, or any contract, instrument or other document related thereto; provided however, that nothing in this Article 8.1 shall affect the obligations of LBT under the Composition Plan, and that nothing in this Article 8.1

This Composition Plan is primarily addressed to Direct Participants and Other Ordinary Creditors. Beneficial owners of Notes that do not qualify as a Direct Participant are recommended to contact the Direct Participant or 
shall affect the liability of any person that otherwise would result from an act or omission that is determined by a Final Order to have constituted willful misconduct or gross negligence (opzet of grove schuld).

8.2. As of the Effective Date, each and every Ordinary Creditor shall waive any and all claims, rights, remedies and actions against the Released Parties and (other) Ordinary Creditors with respect to the valuation, recognition and settlement of any Acknowledged Claim, including but not limited to the Acknowledged U.S. Debtor Claims and the Settlement Agreement.

8.3. Upon the date that all distributions under the Composition Plan have been made, each Ordinary Creditor shall have waived, released and discharged, to the extent applicable, the Released Parties of and from any and all claims, rights and liabilities arising under or related to the Composition Plan or the implementation or performance thereof or to any distributions made or not made thereunder.

\section{Article 9, Annexes}

9.1. The Annexes to this Composition Plan, including their respective annexes and appendices, form an integral part of the Composition Plan for all intents and purposes.

\section{Article 10, Settlement Agreement}

10.1. The Settlement Agreement is incorporated by reference herein. Notwithstanding anything to the contrary in this Composition Plan, nothing herein shall constitute an amendment to or modification of the Settlement Agreement.

\section{Article 11, Miscellaneous}

11.1. In the event that prior to or after the Effective Date, it appears that - either by a Final Order or otherwise - any provision or Article of the Composition Plan is invalid, void or unenforceable, LBT shall be authorised to alter such provision or Article to make it valid or enforceable, consistent with such provision and the purpose of the Composition Plan. Notwithstanding any such alteration, the remainder of the Composition Plan is and shall in no way be affected by such alteration.

11.2. The headings used in this Composition Plan are for convenience of reference only and shall not be taken into consideration in interpreting this Composition Plan.

11.3. In this Composition Plan, unless stated otherwise: (i) a reference to the singular includes the plural and vice versa, and (ii) other grammatical forms of a defined term 
have a corresponding meaning. All references to any provision of law shall also be deemed to refer to any modification thereof.

\section{Article 12, Governing law and court of competent jurisdiction}

12.1. The Composition Plan, as well as all rights and obligations arising out of or in connection with this Composition Plan, shall be governed by the laws of the Netherlands.

12.2. Any dispute arising out of the Composition Plan or in connection with the Composition Plan or any act, agreement or engagement arising out of the Composition Plan, shall be exclusively submitted to the District Court of Amsterdam, the Netherlands.

[remainder of the page intentionally left blank] 


\section{SECTION C: LIST OF DEFINITIONS}

\author{
Acknowledged Noteholder \\ Claim
}

Acknowledged Claim with respect to a particular Outstanding Series of Notes, the Noteholder's claim arising out of such Outstanding Series of Notes, which claim, except for the (pro rata) entitlement to distributions under this Composition Plan, remains subject to the applicable Conditions and related legal provisions and other arrangements related or applicable to the holding and trading of Notes, and which are or will be recognised pursuant to Article 1.1 and Article 1.3 of this Composition Plan

an Acknowledged Noteholder Claim or an Acknowledged Other Ordinary Claim, provided however, that a claim that is allowed for voting purposes only on the basis of Article 125 DBA (voorwaardelijke toelating) is not considered an "Acknowledged Claim"

an Other Ordinary Claim (i) that is included on the List of Admitted Claims for the value included therein; or (ii) for the value decided upon after the Effective Date by a court of competent jurisdiction following a claims referral proceeding (renvooiprocedures), or, as the case may be, (iii) for the value as determined after the Effective Date in a settlement agreement between the relevant holder of such Other Ordinary Claim and LBT 
Acknowledged U.S. Debtor Claims

\section{Admissible Amounts}

Article

Available Cash

Bankruptcy (Date)

Bankruptcy Trustees the claims of Lehman Brothers Special Financing Inc. in the amount of USD 1,022,992,712 and the claim of Lehman Brothers Commodities Services Inc. in the amount of USD 43,507,736, respectively, both allowed by the Bankruptcy Trustees as Acknowledged Other Ordinary Claims pursuant to the Settlement Agreement

the LBT Note Valuation attributable to a particular ISIN expressed in EUR

an article of the Composition Plan

all cash LBT receives by way of distributions on the LBT Intercompany Claim (which distributions are made in USD) or otherwise, including any interest made on invested cash, less the amount of cash needed to cover (at any time) actual and expected Expenses and the amount of cash needed to fund the projected costs required to finance the execution of the Composition Plan and the amount of cash needed for reservations for Disputed Claims

October 8, 2008

R.J. Schimmelpenninck and F. Verhoeven, appointed by the Amsterdam District Court, solely acting in their capacity of bankruptcy trustees (curatoren) of LBT, without personal liability 
Claims Admission Meeting

Claims Filing Date

Clearing System(s)

Composition Plan the meeting chaired by the Supervisory Judge, in which each of the claims of Ordinary Creditors that have been validly filed by or on behalf of Ordinary Creditors will either be admitted (erkend) or disputed (betwist), which meeting is scheduled for March 7 , 2013

the date for the filing of claims in the bankruptcy of LBT as set by the Supervisory Judge in accordance with Article 108 DBA, which is also the Expiration Date as defined in the Consent Solicitation Memorandum being January 25, 2013

the central securities depositories Euroclear Bank S.A. I N.V. (Brussels), Clearstream Banking S.A. (Luxembourg), the Depository Trust Company, SIX SIS Ltd, Clearstream Banking AG (Frankfurt am Main), Monte Titoli S.p.A., Verdipapirsentralen ASA, VP Securities A/S, Euroclear Sweden AB, Euroclear Finland Ltd and Computershare Investor Services Pty Ltd, as well as any other entity or institution that takes on a similar role

this composition plan (faillissementsakkoord) including all annexes thereto offered by LBT to its Ordinary Creditors in accordance with the DBA 
Conditions

Confirmed Chapter 11 Plan

Consent Solicitation

Memorandum

DBA

DCC

Definitive Valuation Principles

Direct Participant the terms and conditions of the Notes, which are contained in the respective prospectuses in relation to the Programs, and all documents in relation to each issue of a Series of Notes, amending and finalising the Conditions and of which the Conditions form part

the Third Amended Joint Chapter 11 Plan of Lehman Brothers Holdings Inc. and its affiliated debtors confirmed by the United States Bankruptcy Court Southern District of New York on December 6, 2011

the procedures related to the filing of claims with the Bankruptcy Trustees and the casting of votes at the Claims Admission Meeting for the acceptance of the Composition Plan by Noteholders as described in the document (including its annexes and sections) attached as Annex II

Dutch Bankruptcy Act (Faillissementswet)

\section{Dutch Civil Code}

the valuation principles set out in paragraph six of the tenth public report

each person or entity who is shown in the records of a Clearing System as a holder of a particular nominal amount of Notes 
Disputed Claim

Distribution Agent

Distribution Date

Distribution Provisions any Noteholder claim whether submitted in accordance with the Consent Solicitation Memorandum or otherwise, as well as any claim submitted by an Other Ordinary Creditor, that - either in whole or in part - is disputed (betwist) by the Bankruptcy Trustees at the Claims Admission Meeting and which at the Claims Admission Meeting is referred to the District Court for claim referral proceedings (renvooiprocedures); a list of provisionally disputed claims will be made available for inspection at the registry of the Amsterdam District Court at least for a period of 8 days before the Claims Admission Meeting

Deutsche Bank AG, London branch or any other party engaged by LBT to make distributions in accordance with Article 3

each date at which LBT instructs the Distribution Agent to make distributions of Available Cash as provided for in Articles 3 and 4

the Conditions and other existing legal provisions of the applicable Note documentation and other provisions related to or applicable to the holding or trading of Notes, as well as the legal and operating arrangements between LBT and the Distribution Agent as described in Article 3.3 
Effective Date

Expenses

Final Order

Indemnified Parties the date at which the Composition Plan becomes effective and binding on all Ordinary Creditors, this date being the date at which the confirmation decision (homologatiebeslissing) of the Amsterdam District Court is no longer subject to appeal

any and all outstanding costs made by the LBT estate and its advisors and agents, and, as of the Effective Date, LBT and the Liquidators and their respective advisors and agents, related to LBT's bankruptcy proceedings, including, without limitation, the formation of this Composition Plan and the fulfillment of LBT's obligations as set out, following from or related to this Composition Plan

a judgment of a court of competent jurisdiction that is no longer open to appeal or cassation

LBT, its current and future directors, the Liquidators, the Bankruptcy Trustees, Stichting, the current and future directors or liquidators of Stichting, Houthoff Buruma Coöperatief U.A. and its affiliates as well as their respective present or former, partners or employees 
Intermediary Institution

ISIN

LBHI

LBT

LBT estate

LBT Website

LBT Intercompany claim any depositary bank, commercial bank, broker, dealer, custodian, trust company or other financial institution or intermediary party who has indirect access to the Clearing Systems through its own account with a Direct Participant or (if there are multiple layers) through its own account with the next (final) Intermediary Institution who holds an account with a Direct Participant

an Outstanding Series of Notes as identified by its International Securities Identification Number; for the purpose of the Consent Solicitation Memorandum, "holding an ISIN" means holding an interest in a Series (of Notes) as identified by its International Securities Identification Number

Lehman Brothers Holdings Inc.

Lehman Brothers Treasury Co. B.V.

the bankruptcy estate (faillissementsboedel) of LBT

www.lehmanbrotherstreasury.com

LBT's intercompany claim of USD 34,548,000,000 against LBHI, allowed as a Class $4 \mathrm{~A}$ claim under the Confirmed Chapter 11 Plan pursuant to the Settlement Agreement 


\section{LBT Note Valuation}

List of Admitted Claims

List of Provisionally Admitted

Claims the value of an ISIN established in accordance with the Definitive Valuation Principles; all LBT Note Valuations are expressed in Euros using exchange rates as of the Bankruptcy Date of LBT (see Annex $\underline{\mathbf{V}}$ for the valuation of each ISIN)

the final list of claims filed with and acknowledged by the Bankruptcy Trustees and not disputed by Ordinary Creditors, as evidenced by the court minutes of the Claims Admission Meeting (procesverbaal van de verificatievergadering) as referred to in Article 121 DBA

the list of provisionally admitted claims filed by Ordinary Creditors which will be made available for inspection at the registry of the Amsterdam District Court at least for a period of 8 days before the Claims Admission Meeting; Annex VI is a list of submitted and provisionally admitted or disputed Other Ordinary Claims which list shall be updated from time to time

R.J. Schimmelpenninck and F. Verhoeven, or any other person appointed as liquidator (vereffenaar) of LBT by Stichting 
Manifest Error

Manifest Error Notification

Noteholder(s)

Notes

Ordinary Creditors

Original Currency

Other Ordinary Claims a self-evident, inconsistent or erroneous application of the Definitive Valuation Principles, or an application of the Definitive Valuation Principles to a situation obviously not contemplated by the Definitive Valuation Principles, or a self-evident material mistake in the application or interpretation of the Conditions or in the use of relevant, observable and objective data

a request to the Bankruptcy Trustees to reconsider the LBT Note Valuation for reasons of Manifest Error filed in accordance with the conditions specified in paragraph 6.8 of the tenth Public Report

has the meaning assigned thereto in each applicable market section included in the Consent Solicitation Memorandum (Annex II)

notes and certificates issued by LBT under the issuance Programs

all ordinary non-preferred unsecured creditors, being (i) Noteholders as defined in the Consent Solicitation Memorandum and (ii) Other Ordinary Creditors

the currency in which a Series of Notes is denominated upon issuance or the currency in which an Other Ordinary Claim is denominated

all unsecured non-preferred claims other than claims arising out of Notes 
Other Ordinary Creditors

Outstanding Series (of Notes)

Pro Rata Share creditors holding an unsecured non-preferred claim against LBT, other than a claim arising out of Notes

the Series (of Notes) that are outstanding at Bankruptcy Date as set forth in Annex V

with respect to each ISIN: the proportion, expressed as a percentage, that the LBT Note Valuation of the ISIN bears to the sum of (i) the LBT Note Valuations of all ISINs that are not treated as Disputed Claims (meaning that if a Disputed Claim relates to a part of the Admissible Amount pertaining to an ISIN, the undisputed part of such Admissible Amount will be taken into account), (ii) all Acknowledged Other Ordinary Claims and (iii) all Disputed Claims (for the avoidance of doubt, excluding any undisputed parts of Disputed Claims);

with respect to each Acknowledged Other Ordinary Claim: the proportion, expressed as a percentage, that the amount of such claim bears to the sum of (i) the LBT Note Valuations of all ISINs that are not treated as Disputed Claims (meaning that if a Disputed Claim relates to a part of the Admissible Amount pertaining to an ISIN, the undisputed part of such Admissible Amount will be taken into account), (ii) all Acknowledged Other Ordinary Claims and (iii) all Disputed Claims (for the avoidance of doubt, excluding any undisputed parts of Disputed Claims);

the Pro Rata Share is calculated by denominating all relevant claims in Euros using exchange rates as of the Bankruptcy Date 
Programs

Provisional Admissible

Amounts

Provisional Valuation Principles

Public Report the provisional valuation principles set out in paragraph 6 of the fourth public report and further explained in paragraph 6 of the fifth public report

the Euro Medium Term Note Program, the German Note Issuance Program, the (Swiss) Certificates Program and the (Italian) Inflation Linked Notes Program

Admissible Amounts related to each Series of Notes published on the LBT Website on a provisional basis prior to the publication of the final list of all Admissible Amounts on September 27, 2012

the public reports (openbare verslagen) published by the Bankruptcy Trustees available on the LBT Website 


\section{Released Parties}

Series (of Notes)

\section{Settlement Agreement}

\section{Stichting}

LBT, its current and future directors, the Liquidators, the Bankruptcy Trustees, Stichting, the current and future directors or liquidators of Stichting, Houthoff Buruma Coöperatief U.A. and its affiliates as well as their respective present or former, partners, employees, agents, officers, directors or principles, officers, as well as any advisor, lawyer, accountant, valuation expert, agent, officer or person engaged or hired by any of the aforementioned entities or persons and regardless of whether such engagement has been terminated, is ongoing or shall be entered into, included but not limited to, PricewaterhouseCoopers Accountants N.V. and its affiliates, as well as the Consent Agent, the Distribution Agent and their respective affiliates, and all advisors, officers, employees retained by such entities or persons

the entirety of Notes of a single issuance of Notes, which may be comprised of one or more tranches issued on different issue dates. The Notes of each Series of Notes are subject to identical terms, except that the issue date, the issue price and the amount of the first payment of interest may be different in respect of different tranches

the agreement entered into between certain U.S. Debtors and the LBT estate on August 30, 2011 and amended on January 27, 2012 and December 5, 2012 attached as Annex I

Stichting Lehman Brothers Treasury 
UBO(s)

U.S. Debtors

VSA

This Composition Plan is primarily addressed to Direct Participants and Other Ordinary Creditors. Beneficial owners of Notes that do not qualify as a Direct Participant are recommended to contact the Direct Participant or Intermediary Institution through which their Notes are held 


\title{
SECTION D: LIST OF ANNEXES
}

\author{
Annex I: $\quad$ Settlement Agreement \\ Annex II: $\quad$ Consent Solicitation Memorandum \\ Annex III: $\quad$ List of VSA signatories \\ Annex IV: $\quad$ Statement of U.S. Debtors \\ Annex V: $\quad$ Final List of LBT Note Valuations \\ Annex VI: List of submitted Other Ordinary Claims
}


ANNEX I 


\section{SETTLEMENT AGREEMENT}

This Settlement Agreement (the "Agreement") is made and entered into as of August 30, 2011 (the "Execution Date"), by and among Debtors" and Rutger J. Schimmelpenninck and Frédéric Verhoeven, in their capacity as bankruptcy trustees (curatoren) (the "LBT Trustees") for Lehman Brothers Treasury Co. B.V. (such estate and corporate entity, collectively, "LBT"). The Debtors and the LBT Trustees shall each be referred to individually as a "Party" and collectively as the "Parties." For the avoidance of doubt, whenever LBT is required hereunder to take any actions or assume any obligations, the LBT Trustees shall cause LBT to take such actions or assume such obligations.

\section{RECITALS}

WHEREAS, on September 15, 2008 and on various dates thereafter, each of the Debtors commenced a voluntary case under chapter 11 of title 11 of the United States Code (the "Bankruptcy Code") in the United States Bankruptcy Court for the Southern District of New York (the "Bankruptcy Court"), which cases are being jointly administered under Case Number 08-13555 (JMP) (the "Chapter 11 Cases" and each a "Chapter 11 Case");

WHEREAS, LBT was declared bankrupt (in staat van faillissement) by the Amsterdam District Court on October 8, 2008 with the appointment of Rutger J. Schimmelpenninck as bankruptcy trustee (curator) for LBT. On October 13, 2009, the Amsterdam District Court appointed Frédéric Verhoeven as bankruptcy trustee (curator);

WHEREAS, the LBT Trustees have, on behalf of LBT, filed the proofs of claim listed on Schedule A attached hereto against certain Debtors (collectively, the "Proofs of Claim") for amounts that the LBT Trustees assert are due and owing to LBT;

WHEREAS, certain Debtors have asserted amounts due and owing to them from LBT (the "Liquidation Claims");

WHEREAS, LBT issued notes and certificates jointly (the "LBT Notes") pursuant to, among other issuance programs, the Euro Medium-Term Note Program;

WHEREAS, holders of LBT Notes (the "LBT Noteholders") have filed proofs of claim against LBHI based upon an asserted guarantee that runs in favor of LBT Noteholders (the "LBT Noteholder Claims");

WHEREAS, the Parties are desirous of resolving potential disputes and all other outstanding issues between the Parties and avoiding extensive and expensive litigation;

\footnotetext{
As used herein, the "Debtors" means Lehman Brothers Holdings Inc. ("LBHI"); Lehman Brothers Special Financing Inc. ("LBSF"); Lehman Commercial Paper Inc.; Lehman Brothers Commercial Corporation ("LBCC"); Lehman Brothers Financial Products Inc.; Lehman Brothers OTC Derivatives Inc.; Lehman Brothers Derivative Products Inc.; Lehman Brothers Commodity Services Inc. "LBCS"); Lehman Scottish Finance L.P.; CES Aviation LLC; CES Aviation V LLC; CES Aviation IX LLC; East Dover Limited; Luxembourg Residential Properties Loan Finance S.a.r.l; BNC Mortgage LLC; Structured Asset Securities Corporation; LB Rose Ranch LLC; LB 2080 Kalakaua Owners LLC; Merit LLC; LB Somerset LLC; LB Preferred Somerset LLC; LB 745 LLC; PAMI Statler Arms LLC.
} 
WHEREAS, on August 24, 2011, the Debtors filed the Revised Second Amended Joint Chapter 11 Plan of Lehman Brothers Holdings Inc. and its Affiliated Debtors [ECF No. 19482] (the "Plan") and the Debtors' Disclosure Statement for the Revised Plan [ECF No. 19484] (the "Disclosure Statement"); and

WHEREAS, each of the Debtors, either individually or jointly, will file an amendment, modification and/or supplement to the Plan that will incorporate the terms and conditions of this Agreement (the "Amended Plan");

WHEREAS, the LBT Trustees have executed this Agreement subject to the approval by the Supervisory Judge (rechter-commissaris) and to the extent applicable, hereof by a Final Order in the LBT Case (as defined below);

WHEREAS, the LBT Trustees may request LBHI to cause a transfer of the shares of LBT to the Entity (as defined below) controlled by the LBT Trustees for the purpose of advancing the administration of the LBT Case;

NOW, THEREFORE, in consideration of the recitals stated above, the agreements, promises and warranties set forth below and other good and valuable consideration, the receipt and sufficiency of which is hereby acknowledged, the Parties agree as follows:

\section{Definitions}

Except as otherwise specified herein or as the context may otherwise require, the following terms have the respective meanings set forth below for all purposes of this Agreement.

"Affiliate" shall have the meaning set forth in section 101(2) of the Bankruptcy Code.

"Agreement" has the meaning ascribed to it in the Preamble.

"Allowed LBSF Claim" has the meaning ascribed to it in Section 2.2(a)(i).

"Allowed LBT Claim" has the meaning ascribed to it in Section 2.1(a).

"Allowed US Claims" has the meaning ascribed to it in Section 2.2(a)(ii).

"Alternative Plan" means a chapter 11 plan or plans, proposed by parties other than the Debtors.

"Amended Disclosure Statement" means the Disclosure Statement as amended, modified and/or supplemented to incorporate the terms of the Amended Plan.

"Amended Plan" has the meaning ascribed to it in the Recitals.

"Assigned LBCC Claim" has the meaning ascribed to it in Section 2.1(b).

"Bankruptcy Code" has the meaning ascribed to it in the Recitals.

"Bankruptcy Court" has the meaning ascribed to it in the Recitals.

"Business Day" means any day on which commercial banks in both New York, New York and the Netherlands are open for business. 
"Chapter 11 Case" has the meaning ascribed to it in the Recitals.

"Confirmation Order" means an order of the Bankruptcy Court (i) confirming the Amended Plan pursuant to section 1129 of the Bankruptcy Code; (ii) approving, pursuant to Rule 9019 of the Federal Rules of Bankruptcy Procedure and applicable provisions of the Bankruptcy Code, the terms of this Agreement; and (iii) authorizing the Debtors to take all necessary corporate actions to consummate the transactions contemplated by this Agreement.

"Disclosure Statement" has the meaning ascribed to it in the Recitals.

"Disputed Portion" has the meaning ascribed to it in Section 2.2(a)(3).

"Effective Date" means the date that the Amended Plan becomes effective as provided for therein.

"Entity" has the meaning ascribed to it in Section 3(a)(2).

"Execution Date" has the meaning ascribed to it in the Preamble.

"Final Order" means, with respect to any proceeding in either the Netherlands or the United States, an order entered in such proceeding as to which the time to appeal or seek other review has expired or which remains in full force and effect after all appeals or other review have been taken.

"LBCS ISDA Master Agreement" means that certain ISDA Master Agreement, dated as of August 8, 2006, between LBCS and LBT.

"LBSF ISDA Master Agreement" means, as amended, that certain ISDA Master Agreement, dated as of May 11, 1995, between LBSF and LBT.

"LBT" has the meaning ascribed to it in the Preamble.

"LBT Avoidance Actions" means all avoidance actions and causes of action against Lehman US pursuant to sections 42 and 47 of the Dutch Insolvency Act and 6:162 of the Dutch Civil Code.

"LBT Case" means the bankruptcy case of LBT that was commenced on October 8, 2008 by the Amsterdam District Court.

"LBT Composition Plan" means the composition plan ("akkoord") in the LBT Case, if any, that is endorsed by the LBT Trustees.

"LBT Noteholder Claims" has the meaning ascribed to it in the Recitals.

"LBT Noteholders" has the meaning ascribed to it in the Recitals.

"LBT Notes" has the meaning ascribed to it in the Recitals.

"LBT Trustees" has the meaning ascribed to it in the Preamble.

"Lehman Tax Affiliate" means (a) any person or entity which directly or indirectly holds ten percent of the vote or value of a Debtor, or (b) any person or entity in which, directly or indirectly, a Debtor owns ten percent of the vote or value.

"Liquidation Claims" has the meaning ascribed to it in the Recitals. 
"Parties" has the meaning ascribed to it in the Preamble.

"Party" has the meaning ascribed to it in the Preamble.

"Pending Claim Objection" means an action by a creditor in the LBT Case, as a result of which the Supervisory Judge directs or applicable law requires the LBT Trustees to withhold a distribution on all or a portion of the Allowed US Claims.

"Plan" has the meaning ascribed to it in the Recitals.

"Plan Support Agreements" shall have the meaning ascribed to it in the Amended Plan.

"Proofs of Claim" has the meaning ascribed to it in the Recitals.

"Reserve Amount" has the meaning ascribed to it in Section 2.2(a)(3).

"Supervisory Judge" means the judge presiding in the LBT Case.

"US Avoidance Actions" means all actions under chapter 5 of the Bankruptcy Code or similar actions under applicable state law.

"Valuation" has the meaning ascribed to it in Section 6.6 of this Agreement.

"Voting Deadline" means the date set by the Bankruptcy Court by which creditors must vote to accept or reject the Amended Plan.

\section{Settlement of Claims.}

\subsection{The LBT Proofs of Claim.}

(a) LBT Intercompany Claim Against LBHI. LBT will have an allowed, senior, nonpriority, non-subordinated general unsecured claim against LBHI in an amount equal to $\$ 34,548,000,000$ in respect of proof of claim number 58612 (the "Allowed LBT Claim").

(b) LBT Claim Against LBCC. As of the Effective Date, LBT assigns to LBHI all of its rights, title and interests in, arising under or related to proof of claim number 58645 against $L B C C$ (the "Assigned LBCC Claim"). The Assigned LBCC Claim shall be allowed as a non-priority, nonsubordinated general unsecured claim against LBCC in an amount to be determined by LBHI and LBCC.

(c) Other than the Allowed LBT Claim and the Assigned LBCC Claim, all other claims or receivables asserted or held by LBT against the Debtors will be deemed fully and forever expunged, extinguished, disallowed and released.

(d) The Allowed LBT Claim as set forth in this Section 2.1 shall not be subject to any objections or defenses, whether by way of netting, set off, recoupment, counterclaim or otherwise, or any claim under section 510 of the Bankruptcy Code or otherwise which would have the effect of subordinating such claims to the claims of other general unsecured creditors; and to the extent that the Debtors now have or become legally entitled to be subrogated to the rights of any creditor of LBT, the Debtors agree not to assert any right as subrogee of such creditor against LBT, to the extent such right is permitted by applicable law. 
(e) Plan Exceptions for LBT. Sections 8.10, 8.14, 8.15, and 13.8 of the Plan shall not apply to LBT or to the Allowed LBT Claim. In addition, section 8.13(e) of the Plan shall not apply to the LBT Noteholder Claims.

\subsection{The Debtors' Liquidation Claims}

(a) Claims Against LBT.

(i) LBSF will have an allowed, non-priority, non-senior, non-subordinated general unsecured claim against LBT in an amount equal to $\$ 1,022,992,712$ (the "Allowed LBSF Claim").

(ii) LBCS will have an allowed, non-priority, non-senior, non-subordinated general unsecured claim against LBT in an amount equal to $\$ 43,507,736$ (the "Allowed LBCS Claim" and together with the Allowed LBSF Claim, the "Allowed US Claims").

(iii) If at any time when a distribution is to be made on the Allowed US Claims, there is a Pending Claim Objection to the allowance (in whole or in part) of an Allowed US Claim, then the LBT Trustees shall establish a reserve containing the distribution (the "Reserve Amount") that would otherwise be allocated to the disputed portion of such Allowed US Claim (the "Disputed Portion"), provided that the LBT Trustees shall make distributions on any undisputed portion of the Allowed US Claims to the holders of the Allowed US Claims. Upon resolution of the Pending Claim Objection in favor of allowance of the Disputed Portion (either through withdrawal of the Pending Claim Objection, determination by the Amsterdam District Court to allow the Allowed US Claim that is the subject of the Pending Claim Objection, or agreement among the parties), then the LBT Trustees shall promptly distribute the Reserve Amount (together with any interest earned thereon unless prohibited by applicable law) to the holder of such Allowed US Claim. To the extent that all or part of the Disputed Portion is disallowed (either through determination by the Amsterdam District Court or agreement by the parties), then the LBT Trustees shall distribute the Reserve Amount attributable to the disallowed Disputed Portion of the Allowed US Claim to admitted creditors in the LBT Case, including any holder of an Allowed US Claim to the extent such holder is an admitted creditor, and any remainder to the holder of the Allowed US Claim. The LBT Trustees shall promptly inform the Debtors if there is a Pending Claim Objection to the allowance of any Allowed US Claim and shall comply with their obligations in Section $3(\mathrm{~b})(6)$ of this Agreement.

(b) Other than the Allowed US Claims, all other claims or receivables asserted or held by the Debtors against LBT will be deemed fully and forever expunged, extinguished, disallowed and released.

(c) The Allowed US Claims as set forth in this Section 2.2 shall not be subject to further objections or defenses, whether by way of netting, set off, recoupment, counterclaim or otherwise, or any other claim which would have the effect of subordinating such claims to the claims of other unsecured creditors; and to the extent that LBT now has or becomes legally entitled to be subrogated to the rights of any creditor of the Debtors, the LBT Trustees agree not to assert any right as subrogee of such creditor against the Debtors, to the extent such right is permitted by applicable law.

2.3. Claims Register. In order to reflect the entry into this Agreement, upon the Effective Date, the Parties hereto acknowledge and agree that (i) the Proofs of Claim and the Allowed US Claims shall be deemed amended to the extent necessary to reflect the terms of the settlement reached in this Agreement and/or to reflect the reconciliation of such claims that has been ongoing amongst the Parties, (ii) they shall execute and submit joint instructions to Epiq Bankruptcy Solutions, LLC requesting

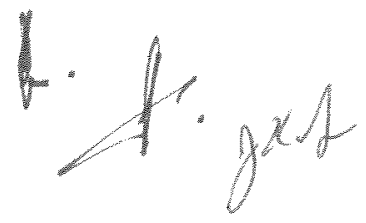


that the claims register in the Chapter 11 Cases be amended to reflect $(A)$ the allowance of proof of claim number 58612 in the amount of $\$ 34,548,000,000$, (B) the assignment of proof of claim number 58645 to LBHI, and (C) the disallowance of the remaining Proofs of Claim on Schedule A of this Agreement, and (iii) to the extent necessary, they shall execute and file a notice of transfer of proof of claim number 58645 by LBT to LBHI in accordance with the Federal Rules of Bankruptcy Procedure.

\section{Amended Plan and Related Support.}

\section{(a) The Debtors' Obligations.}

(1) Within a reasonable period of time following the Execution Date, the Debtors will (i) file the Amended Plan to incorporate this Agreement and seek approval of the Amended Disclosure Statement and voting procedures with respect thereto, and (ii) prosecute the Amended Plan and seek entry of a Confirmation Order. If the Bankruptcy Court allows other parties to solicit acceptances of any Alternative Plan or Alternative Plans and subject to LBT's obligations in Section 3(b)(5) below, the Debtors agree not to object to LBT voting to accept any Alternative Plan or Alternative Plans in the amounts set forth on Schedule A with respect to each Proof of Claim.

(2) As may be requested by the LBT Trustees, in order to assist the LBT Trustees in the administration and resolution of the LBT Case, upon the request of the LBT Trustees, which request shall be made no later than ten days prior to the Effective Date, LBHI shall as soon as reasonably practicable after receipt of such request, but no later than one day prior to the Effective Date, cause the transfer of the shares of LBT in exchange for no consideration to an entity designated by the LBT Trustees to be incorporated under Dutch law (the "Entity"). The Entity shall not own any interest, directly or indirectly, in any Debtor or Lehman Tax Affiliate (other than LBT), nor shall any Debtor or Lehman Tax Affiliate be a direct or indirect beneficiary or owner of the Entity. The LBT Trustees shall cause the Entity to be formed prior to the date of the transfer of the LBT shares.

(3) Provided that (a) the Debtors are afforded an opportunity to review a draft of the LBT Composition Plan for a reasonable period of time, but not less than 30 days prior to publication of a draft LBT Composition Plan to LBT's creditors and (b) the LBT Composition Plan is consistent with the terms of this Agreement and treats the Allowed US Claims the same as other similar claims to the extent permitted by Dutch law, the Debtors holding Allowed US Claims shall (i) vote for the LBT Composition Plan, (ii) support approval of the LBT Composition Plan, (iii) neither join in nor support any objection to the LBT Composition Plan, and (iv) seek authority, to the extent necessary, from the Bankruptcy Court, to perform all of the foregoing prior to the deadline for the voting on the LBT Composition Plan.

(4) Notwithstanding Section 3(a)(3)(i), if there is an alternative to the LBT Composition Plan in the Netherlands that has not been proposed by or formulated with the Debtors, then LBSF or LBCS, in their capacity as creditors of LBT, may support the approval of such alternative if and only if such alternative provides LBSF or LBCS, respectively, with an equal or greater economic recovery than the LBT Composition Plan, provided that LBSF or LBCS, as applicable, shall also (i) vote to accept the LBT Composition Plan to the extent LBSF or LBCS is permitted to vote in favor of the LBT Composition Plan while supporting approval of an alternative and (ii) comply with its obligations in Sections 3(a)(3)(ii) - (iv) and Section 3(a)(5) of this Agreement.

(5) Subject to Section 6.6 of this Agreement, which the Parties agree applies to the valuation of the Allowed US Claims, the Debtors acknowledge that LBT may adopt principles for valuing claims in the LBT Case that are different from the principles adopted in the Chapter 11 Cases and the Debtors holding Allowed US Claims will not object to those principles if the principles have not been

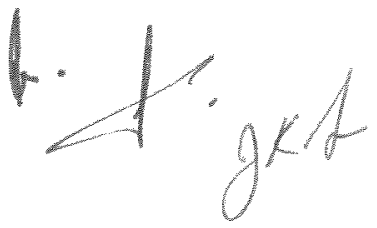


objected to by LBT Noteholders holding two thirds in nominal amount and a majority in number of all LBT Notes that are subject to Plan Support Agreements that have not been terminated.

(6) The Debtors acknowledge and agree that Rutger J. Schimmelpenninck may refuse to serve as a member of the Director Selection Committee (as defined in the Amended Plan) or as a trustee of the Plan Trust (as defined in the Amended Plan), or may resign from either position at any time, for any reason or for no reason, and in his sole and absolute discretion, and no provision of this Agreement, the Plan Trust Agreement (as defined in the Amended Plan) or the Amended Plan shall limit his right to do so or shall condition any treatment of LBT or LBT Noteholders upon his refusal or resignation.

(b) LBT's Obligations. LBT agrees to perform and comply with the following obligations as to the Amended Plan, which obligations shall become effective as set forth in Section 11 below:

(1) LBT shall (i) support approval of the Amended Disclosure Statement, (ii) neither oppose nor object to the Amended Disclosure Statement, and (iii) neither join in nor support any objection to the Amended Disclosure Statement.

(2) If the Bankruptcy Court allows the Debtors to solicit acceptances of the Amended Plan before acceptances are solicited for any Alternative Plan or Alternative Plans, and provided that LBT has been solicited pursuant to section 1125 of the Bankruptcy Code, LBT shall (i) timely vote to accept the Amended Plan in the amounts set forth on Schedule A with respect to each Proof of Claim, and not thereafter withdraw or change such vote, and (ii) support approval and confirmation of the Amended Plan.

(3) LBT shall not oppose or object to the Amended Plan or the solicitation of the Amended Plan, or join in or support any objection to the Amended Plan or the solicitation of the Amended Plan.

(4) LBT shall not (i) participate in the formulation of, file, or prosecute any Alternative Plan (ii) join in or support any Alternative Plan, including, without limitation, express support in writing of, or enter into any form of plan support agreement with respect to any Alternative Plan, or (iii) subject to Section 3(b)(5) below, take any action to alter, delay or impede the confirmation and consummation of the Amended Plan; provided that, a vote on an Alternative Plan or Plans shall not constitute an action to delay or impede the confirmation or consummation of the Amended Plan. The foregoing does not prohibit the LBT Trustees from responding to inquiries of creditors of LBT regarding an Alternative Plan, provided that such discussions are neither solicited nor initiated by the LBT Trustees.

(5) If the Bankruptcy Court allows other parties to solicit acceptances of any Alternative Plan or Alternative Plans at the same time as the Amended Plan, LBT may vote to accept any Alternative Plan or Alternative Plans, only if such Alternative Plan or Alternative Plans provide LBT with an equal or greater economic recovery than the Amended Plan, provided, however, that LBT shall also (i) timely vote to accept the Amended Plan, and not thereafter withdraw or change such vote, (ii) comply with the provisions of Section 3(b)(3) and 3(b)(4) above except to the extent 3(b)(4)(iii) is subject to this 3(b)(5), and (ii) support approval and confirmation of the Amended Plan, and indicate a preference for the Amended Plan on its voting ballot, if the Amended Plan provides LBT and its creditors with an equal or greater economic recovery compared with any Alternative Plan that LBT votes to accept. Notwithstanding anything contained in this section, LBT shall not indicate a preference on its voting ballots for any Alternative Plan. 
(6) The LBT Trustees shall take reasonable actions consistent with Dutch law to support (i) the allowance of the Allowed US Claims in the LBT Case, including, without limitation, by supporting the applicable holder of the Allowed US Claim in its defense of any Pending Claim Objection, and (ii) the payment of distributions on the Allowed US Claims from LBT, including under the LBT Composition Plan, in each case, so long as the Debtors are not in breach of their representations and warranties in Section 6.6 of this Agreement.

(7) If LBT submits a LBT Composition Plan, (i) the LBT Trustees will provide the Debtors an opportunity to review a draft LBT Composition Plan at least 30 days prior to publication of a draft LBT Composition Plan to LBT's creditors and (ii) the LBT Composition Plan will be consistent with the terms of this Agreement and treat the Allowed US Claims the same as other similar claims to the extent permitted by Dutch law.

(c) Solicitation Required in Connection with Amended Plan. Notwithstanding anything contained in this Section 3 or elsewhere in this Agreement, this Agreement is not, and shall not be deemed to be, a solicitation of a vote for the acceptance of the Amended Plan pursuant to section 1125 of the Bankruptcy Code, or rejection of any Alternative Plan. Acceptance of the Amended Plan will not be solicited until the Bankruptcy Court has approved the Amended Disclosure Statement and related ballots, and such Amended Disclosure Statement and ballots have been transmitted to parties entitled to receive the same in accordance with an order of the Bankruptcy Court.

4. The LBT Trustees' Representations and Warranties. In order to induce the Debtors to enter into and perform their obligations under this Agreement, the LBT Trustees hereby represent, warrant and acknowledge as follows:

4.1. Authority. (i) Subject to the approval by the Supervisory Judge, and, to the extent applicable, obtaining a Final Order, the LBT Trustees have the power and authority to execute, deliver and perform their obligations under this Agreement, and to consummate the transactions contemplated herein; and (ii) subject to the approval by the Supervisory Judge, and, to the extent applicable, obtaining a Final Order, the execution, delivery and performance by the LBT Trustees of this Agreement and the consummation of the transactions contemplated herein have been duly authorized by all necessary action on the part of LBT and no other proceedings on the part of LBT are necessary to authorize and approve this Agreement or any of the transactions contemplated herein.

4.2. Validity. Subject to the approval by the Supervisory Judge, and, to the extent applicable, obtaining a Final Order, this Agreement has been duly executed and delivered by the LBT Trustees and constitutes the legal, valid and binding agreement of the LBT Trustees, enforceable against the LBT estate in accordance with its terms.

4.3. Authorization of Governmental Authorities and Creditors. Subject to the approval by the Supervisory Judge, and, to the extent applicable, obtaining a Final Order, no action by (including any authorization, consent or approval), in respect of, or filing with, any governmental authority is required for, or in connection with, the valid and lawful authorization, execution, delivery and performance by LBT pursuant to this Agreement.

4.4. No Reliance. The LBT Trustees (i) are in their capacity as bankruptcy trustees sophisticated parties with respect to the subject matter of this Agreement, (ii) have been represented and advised by legal counsel in connection with this Agreement, (iii) have adequate information concerning the matters that are the subject of this Agreement, and (iv) have independently and without reliance upon any Debtor or any of the Debtors' Affiliates, or any officer, employee, agent or representative thereof, and based on such information as LBT has deemed appropriate, made their own analysis and decision to enter 
into this Agreement, except that the LBT Trustees have relied upon each Debtor's express representations, warranties and covenants in this Agreement, and the LBT Trustees acknowledge that they have entered into this Agreement voluntarily and of their own choice and not under coercion or duress.

4.5. Title. Subject to the effectiveness of this Agreement, LBT owns and has good title to its Proofs of Claim, free and clear of any and all liens, claims (other than on account of claims against the assets of LBT), set-off rights of third parties, security interests, participations, or encumbrances created or incurred by or against LBT as of the Execution Date and has not transferred or assigned to any other person any of the claims or receivables that are the subject of this Agreement, in whole or in part.

4.6. Transactions covered by Valuation. The LBT Trustees have no knowledge that the Transactions (as defined in the applicable ISDA Master Agreement) covered by the Valuation do not constitute all valid, binding and enforceable Transactions by and between LBT, on the one hand, and LBSF and LBCS, on the other hand, outstanding as of September 12, 2008.

5. No Transfer of Claims. LBT may not transfer any of the claims or receivables that are the subject of this Agreement, or any rights or interests arising thereunder or related thereto, in whole or in part, prior to the Effective Date; provided, however, that LBT may pledge or otherwise encumber up to $\$ 500$ million of the Allowed LBT Claim to obtain financing in connection with the LBT Case so long as the secured party agrees in writing that in the event that such secured party ever forecloses the Allowed LBT Claim up to the aforementioned maximum amount of $\$ 500$ million or otherwise becomes the holder of the Allowed LBT Claim, such secured party and its successors or assigns shall be bound by Sections $3(\mathrm{~b})(1)-(4)$ hereto.

6. The Debtors' Representations and Warranties. In order to induce LBT and the LBT Trustees to enter into and perform its obligations under this Agreement, each Debtor hereby represents, warrants and acknowledges as follows:

6.1. Authority. Subject to Bankruptcy Court approval to the extent necessary, (i) each Debtor has the power and authority to execute, deliver and perform its obligations under this Agreement, and to consummate the transactions contemplated herein and (ii) the execution, delivery and performance by such Debtor of this Agreement and the consummation of the transactions contemplated herein have been duly authorized by all necessary action on the part of such Debtor and no other proceedings on the part of such Debtor are necessary to authorize and approve this Agreement or any of the transactions contemplated herein.

6.2. Validity. Subject to Bankruptcy Court approval to the extent necessary, this Agreement has been duly executed and delivered by each Debtor and constitutes the legal, valid and binding agreement of each Debtor, enforceable against each Debtor in accordance with its terms.

6.3. Authorization of Governmental Authorities. No action by (including any authorization, consent or approval), in respect of, or filing with, any governmental authority is required for, or in connection with, the valid and lawful authorization, execution, delivery and performance by each Debtor of this Agreement, other than entry of the Confirmation Order.

6.4. No Reliance. Each Debtor (i) is a sophisticated party with respect to the matters that are the subject of this Agreement, (ii) has had the opportunity to be represented and advised by legal counsel in connection with this Agreement, (iii) has adequate information concerning the matters that are the subject of this Agreement, and (iv) has independently and without reliance upon the LBT Trustees, and based on such information as such Debtor has deemed appropriate, made its own analysis and 
decision to enter into this Agreement, except that such Debtor has relied upon the LBT Trustees' express representations, warranties and covenants in this Agreement, which it enters, or as to which it acknowledges and agrees, voluntarily and of its own choice and not under coercion or duress.

6.5. Title. Each Debtor owns and has good title to its respective Liquidation Claims, free and clear of any and all liens, claims (other than on account of claims against the assets of such Debtor), set-off rights of third parties, security interests, participations, or encumbrances created or incurred by or against any such Debtor as of the Execution Date, and has not transferred or assigned to any other person any of the claims or receivables that are the subject of this Agreement.

6.6. Amount of Allowed US Claims. The amounts of the Allowed LBSF Claim and Allowed LBCS Claim have been determined by LBSF and LBCS respectively in good faith and in a commercially reasonable manner pursuant to section 6(e)(i)(4) of the LBSF ISDA Master Agreement and of the LBCS ISDA Master Agreement respectively as of December 12, 2008 (the "Valuation"), and further that:

(a) The Valuation has been conducted on a Transaction (as defined in the applicable ISDA Master Agreement) by Transaction basis using valuation models and techniques generally accepted in the financial community.

(b) The amount of the Allowed US Claims is based on LBSF's and LBCS's respective commercially reasonable and good faith determinations of each such Transaction's fair market value as of December 12, 2008 adjusted to take into account unperformed obligations (assuming the satisfaction of applicable conditions precedent) on or before December 12, 2008 and based on mid-market valuation parameters. The Valuation does not take into account (i) any cost of funding, (ii) any loss or cost incurred as a result of terminating, liquidating, obtaining or reestablishing any hedge or related trading position, and/or (iii) any bid-ask or bid-offer spread or allowance, and no adjustment has been made to the Valuation to account for the applicable parties' credit standing. No additional loss or damages (including, without limitation, any special, incidental, indirect or consequential loss or damages) has been factored into the amount of the Allowed US Claims. The Valuation also does not include any of LBSF's or LBCS's respective fees, costs or expenses in connection with the termination of the applicable ISDA Master Agreement.

(c) LBSF and LBCS have no knowledge that (i) the Transactions covered by the Valuation do not constitute all valid, binding and enforceable Transactions by and between LBT, on the one hand, and LBSF and LBCS, on the other hand, outstanding as of September 12, 2008 or (ii) any collateral was posted by any party with respect to any Transaction covered by the Valuation.

7. No Transfer of Claims. Each Debtor entity may not transfer any of the Liquidation Claims, or any rights or interests arising thereunder or related thereto, in whole or in part, prior to the Effective Date.

8. Surviving Contracts. The contracts and any non-binding agreements listed in Schedule B shall survive the execution and consummation of this Agreement. All executory contracts between the Debtors and LBT that are not included on Schedule B shall be rejected pursuant to section 365 of the Bankruptcy Code in accordance with the Amended Plan. Any claims that arise from the rejection of prepetition executory contracts between the Debtors and LBT are deemed to be satisfied in full by the claims allowed pursuant to Section 2 hereof. 
9. Cooperation. The Parties will continue to exchange data relating to the respective bankruptcy cases and insolvency proceedings based on the data-sharing agreement and the cross border international protocol in order to assist each other in resolving claims of Affiliates and other creditors.

\section{Releases.}

10.1. Debtors' Releases. Upon the occurrence of the Effective Date, and except as to (i) the allowed claims set forth in Section 2 hereof, (ii) the Debtors' distribution entitlements in the LBT Case, (iii) the agreements, promises, settlements, representations and warranties set forth in this Agreement, (iv) the performance of the obligations set forth herein, and (v) the claims, if any, arising under the surviving contracts set forth on Schedule B, provided that the foregoing exception shall not apply to the personal liability of the LBT Trustees, and subject to the effectiveness of this Agreement in accordance with Section 11 below, and in consideration of the foregoing and the LBT Trustees' execution of this Agreement, each Debtor on behalf of itself, its estate, and its successors and assigns, will fully and forever release, discharge and acquit LBT, the LBT estate and the LBT Trustees (in their personal and professional capacities), and their respective successors, assigns, officers, directors, employees, agents, representatives, consultants, financial advisors, accountants and attorneys, from all manners of action, causes of action, judgments, executions, debts, demands, rights, damages, costs, expenses, and claims of every kind, nature, and character whatsoever existing as of the date hereof, whether at law or in equity, whether based on contract (including, without limitation, quasi-contract or estoppel), statute, regulation, tort (excluding intentional torts, fraud, recklessness, gross negligence or willful misconduct) or otherwise, accrued or unaccrued, known or unknown, matured or unmatured, liquidated or unliquidated, certain or contingent, including, without limitation, all US Avoidance Actions.

10.2. LBT'S Releases. Upon the occurrence of the Effective Date, and except as to (i) the allowed claims set forth in Section 2 hereof, (ii) LBT's distribution entitlements in the Chapter 11 Cases, (iii) the agreements, promises, settlements, representations and warranties set forth in this Agreement, (iv) the performance of the obligations set forth herein, and (v) the claims, if any, arising under the surviving contracts set forth on Schedule B, and subject to the effectiveness of this Agreement in accordance with Section 11 below, and in consideration of the foregoing and each Debtor's execution of this Agreement, the LBT Trustees on behalf of the LBT estate, and its successors and assigns, will fully and forever release, discharge and acquit each Debtor and Alvarez and Marsal North America, LLC, and their respective successors, assigns, officers, directors, employees, agents, representatives, consultants, financial advisors, accountants and attorneys, from all manners of action, causes of action, judgments, executions, debts, demands, rights, damages, costs, expenses, and claims of every kind, nature, and character whatsoever existing as of the date hereof, whether at law or in equity, whether based on contract (including, without limitation, quasi-contract or estoppel), statute, regulation, tort (excluding intentional torts, fraud, recklessness, gross negligence or willful misconduct) or otherwise, accrued or unaccrued, known or unknown, matured or unmatured, liquidated or unliquidated, certain or contingent, including, without limitation, (i) any administrative expense claims arising under section 503 of the Bankruptcy Code, and (ii) LBT Avoidance Actions.

\section{Effectiveness of Agreement.}

11.1. Sections 3 (except 3(b)(2)), 5, 7,9 and 11 through 27 of this Agreement shall be effective upon the Execution Date.

11.2. Section 3(b)(2) of this Agreement shall be effective upon entry of a Final Order from the Supervisory Judge approving this Agreement, provided that if such Final Order from the Supervisory Judge is appealed against or if a creditor takes other action, Section 3(b)(2) of this 
Agreement shall only be effective upon entry of a Final Order from the Amsterdam District Court, the Amsterdam Court of Appeals or the Supreme Court in the Hague.

11.3. All other provisions of this Agreement shall be effective upon approval of this Agreement by the Bankruptcy Court and the occurrence of the Effective Date.

\section{Termination.}

12.1. Automatic Termination. This Agreement shall automatically terminate on any date on which the Bankruptcy Court denies the motion seeking the Confirmation Order with prejudice.

12.2. Debtors' Right to Terminate. Each Debtor shall have the right, at its election, to terminate this Agreement by written notice to the LBT Trustees if (a) there is a breach, in any material respect, of the representations, warranties and/or covenants of the LBT Trustees hereunder, taken as a whole, and the LBT Trustees shall fail to cure such breach within ten (10) days following written notice of such breach from any of the Debtors, or (b) other than as set forth herein, the LBT Trustees allow and provide for materially different treatment of claims held by other creditors of LBT that are legally similar to the Allowed US Claims that results in such other creditors having a recovery entitlement in respect of said claims that is materially higher than the recovery entitlement in respect of the Allowed US Claims.

12.3. The LBT Trustees' Right to Terminate. The LBT Trustees shall have the right, at its election, to terminate this Agreement by written notice to the Debtors if (a) the Debtors file or support a chapter 11 plan that provides for the substantive consolidation of one or more Debtor or Affiliate and LBT, commences any proceeding for similar relief, or joins with any other party in any proceeding seeking similar relief; (b) an order confirming the Amended Plan, in a form and substance reasonably satisfactory to the LBT Trustees, is not entered by the Bankruptcy Court on or before February 29, 2012; (c) there is a breach, in any material respect, of the representations, warranties and/or covenants of the Debtors hereunder, taken as a whole, and the Debtors fail to cure such breach within ten (10) days following written notice of such breach from the LBT Trustees; (d) Debtors make any changes or amendments to the Amended Plan or Amended Disclosure Statement, or the Debtors take any other action (including, without limitation, with respect to claims, asset transfers or allocations) in each case, that, individually or, in the aggregate together with all other such changes, amendments, actions and agreements, will, if the Amended Plan were to be consummated, materially and adversely affect the treatment of, estimated recoveries by, or distribution to, or proportionate share of the Debtors' assets that are distributed pursuant to the Amended Plan to, the Allowed LBT Claim; or (e) a majority in number of the holders of LBT Notes who signed Plan Support Agreements (or their successors and assigns) holding two-thirds in amount of LBT Notes subject to Plan Support Agreements, have terminated their Plan Support Agreements; provided, however, that with respect to Section 12.3(d), (i) the Debtors are not guaranteeing or committing to any specific recovery amount under the Amended Plan and (ii) modifications to the projected recovery amounts set forth in the disclosure statement approved by the Bankruptcy Court with respect to the Amended Plan that are based upon revised projections of asset values shall not constitute material modifications to the Amended Plan; and provided further that unless the Debtors agree otherwise, the LBT Trustees must exercise any right to terminate this Agreement under Sections 12 (d) and (e) by giving written notice of termination to the Debtors no later than the close of business of the tenth Business Day after and excluding the day on which the LBT Trustees receive written notice of the event creating such right of termination.

12.4. Effect of Termination. In the event that this Agreement is terminated, then neither this Agreement, nor any motion or other pleading filed in the Bankruptcy Court with respect to the approval of this Agreement or confirmation of the Amended Plan, shall have any res judicata or collateral estoppel effect or be of any force or effect, each of the Parties' respective interests, rights, remedies and

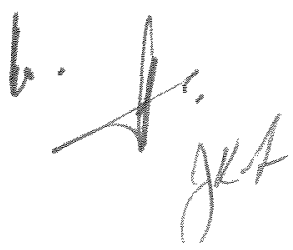


defenses shall be restored without prejudice as if this Agreement had never been executed and the Parties hereto shall be automatically relieved of any further obligations hereunder. Except as expressly provided herein, this Agreement and all communications and negotiations among the Parties with respect hereto or any of the transactions contemplated hereunder are without waiver of or prejudice to the Parties rights and remedies and the Parties hereby reserve all claims, defenses and positions that they may have with respect to each other.

13. Withholding Rights and Allocation of Payments. Each Party shall be entitled to deduct and withhold from the amounts otherwise payable to any other Party pursuant to this Agreement such amounts as it is required to deduct and withhold with respect to the making of such payment under any requirement of any applicable tax law. Any amounts so withheld shall be treated for all purposes of this Agreement as having been paid to such Party in respect of the allowed claim for which such deduction and withholding is made. The Parties agree that any payments made by LBT and the Debtors on account of the claims and receivables that are the subject of this Agreement shall be allocated for all purposes, including but not limited to US federal income tax and Dutch tax purposes, first to the principal portion of such claims and receivables, and, only after the principal portion of such respective claims and receivables is satisfied in full, to any portion of such claims and receivables comprising interest accruing prior to the filing of each Debtor's Chapter 11 Case (but solely to the extent that interest is an allowable portion of such claims and receivables).

\section{Venue and Choice of Law.}

14.1. Venue. To the maximum extent permissible by law, the Parties expressly consent and submit to the exclusive jurisdiction of the Bankruptcy Court over any actions or proceedings relating to the enforcement or interpretation of this Agreement and any Party bringing such action or proceeding shall bring such action or proceeding in the Bankruptcy Court; provided that the Parties may appear before another court of competent jurisdiction if a non Party brings any action relating to this Agreement before such other court of competent jurisdiction, provided, further, that any actions or proceedings arising out of disputes in the amount or validity of the Liquidation Claims shall be within the exclusive jurisdiction of the Amsterdam District Court. Each of the Parties agrees that a final judgment in any such action or proceeding, including all appeals, shall be conclusive and may be enforced in other jurisdictions (including any foreign jurisdictions) by suit on the judgment or in any other manner provided by applicable law. If the Bankruptcy Court refuses or abstains from exercising jurisdiction over the enforcement of this Agreement and/or any actions or proceedings arising hereunder or thereunder, then the Parties agree that venue shall be in any other state or federal court located within the County of New York in the State of New York having proper jurisdiction. Each Party hereby irrevocably and unconditionally waives, to the fullest extent it may legally and effectively do so, (i) any objection which it may now or hereafter have to the laying of venue of any suit, action or proceeding arising out of or relating to this Agreement with the Bankruptcy Court or with any other state or federal court located within the County of New York in the State of New York, or with the Amsterdam District Court or other court of competent jurisdiction as described above solely relating to any actions or proceedings arising out of disputes in the amount or validity of the Liquidation Claims and (ii) the defense of an inconvenient forum to the maintenance of such action or proceeding in any such court. Each Party irrevocably consents to service of process at the addresses set forth in Section 15 hereof. Nothing in this Agreement will affect the right, or requirement, of any Party to this Agreement to serve process in any other manner permitted or required by applicable law.

14.2. Choice of Law. This Agreement and all claims and disputes arising out of or in connection with this Agreement, shall be governed by and construed in accordance with the laws of the State of New York and the Bankruptcy Code, without regard to choice of law principles to the extent such principles would apply a law other than that of the State of New York or the Bankruptcy Code; provided,

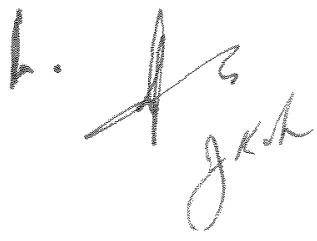


however, that any claims and disputes arising out of the Liquidation Claims shall be governed by and construed in accordance with Dutch law except as otherwise provided in the underlying agreements.

15. Notices. All notices and other communications given or made pursuant to this Agreement shall be in writing and shall be deemed effectively given: (a) upon personal delivery to the party to be notified, (b) when sent by confirmed electronic mail or facsimile if sent during normal business hours of the recipient, and if not so confirmed, then on the next Business Day, (c) three days after having been sent by registered or certified mail, return receipt requested, postage prepaid, or (d) one Business Day after deposit with a nationally recognized overnight courier, specifying next day delivery, with written verification of receipt. All communications shall be sent:

\section{To the Debtors at:}

1271 Avenue of the Americas, 39th Floor

New York, New York 10020

U.S.A.

Attn: John Suckow and Daniel J. Ehrmann

Facsimile: (646) 834-0874

jsuckow@alvarezandmarsal.com and dehrmann@alvarezandmarsal.com

With a copy (which shall not constitute notice) to:

Weil, Gotshal \& Manges LLP

767 Fifth Avenue

New York, New York 10153

U.S.A.

Attn: Alfredo R. Pérez, Esq. and Lori R. Fife, Esq.

Facsimile: (212) 310-8007

Alfredo.perez@weil.com and lori.fife@weil.com

\section{To the LBT Trustees at:}

Rutger J. Schimmelpenninck and Frédéric Verhoeven, curatoren van Lehman Brothers Treasury Co. B.V.

Houthoff Buruma

PO Box 75505

NL-1070 AM Amsterdam

the Netherlands

Facsimile: +31 (0) 206056708

r.schimmelpenninck@houthoff.com and f.verhoeven@houthoff.com

With a copy (which shall not constitute notice) to:

Kramer Levin Naftalis \& Frankel LLP

1177 Avenue of Americas

New York, New York 10036

Attn: Thomas Moers Mayer and Daniel M. Eggermann

Facsimile (212) 715-8000

tmayer@kramerlevin.com and deggermann@kramerlevin.com 
or to such other address as may have been furnished by a Party to each of the other Parties by notice given in accordance with the requirements set forth above.

16. Expenses. The fees and expenses incurred by each Party (including the fees of any attorneys, accountants, investment bankers, financial advisors or any other professionals engaged by such Party) in connection with this Agreement and the transactions contemplated hereby, whether or not the transactions contemplated hereby are consummated, will be paid by such Party.

17. No Admission of Liability. Each Party acknowledges that this Agreement effects a settlement of potential claims and counterclaims that might be denied and contested, and that nothing contained herein shall be construed as an admission of liability or wrongdoing.

18. Entire Agreement. This Agreement constitutes the entire and only agreement of the Parties concerning the subject matter hereof. This Agreement supersedes and replaces any and all prior or contemporaneous verbal or written agreements between the Parties concerning the subject matter hereof, and to the extent of any conflicts between the Amended Plan and the terms of this Agreement, the terms of this Agreement shall control. The Parties acknowledge that this Agreement is not being executed in reliance on any verbal or written agreement, promise or representation not contained herein.

19. No Oral Modifications. This Agreement may not be modified or amended orally. This Agreement only may be modified or amended by a writing signed by a duly authorized representative of each Party hereto. Any waiver of compliance with any term or provision of this Agreement on the part of the Debtors must be provided in a writing signed by the LBT Trustees. Any waiver of compliance with any term or provision of this Agreement on the part of LBT or the LBT Trustees must be provided in a writing signed by each Debtor. No waiver of any breach of any term or provision of this Agreement shall be construed as a waiver of any subsequent breach.

20. Construction. This Agreement constitutes a fully negotiated agreement among commercially sophisticated parties and therefore shall not be construed or interpreted for or against any Party, and any rule or maxim of construction to such effect shall not apply to this Agreement.

21. Binding Effect; Successor and Assigns. Any declaration, representation, or statement of the LBT Trustees shall only be made in their capacity and function as bankruptcy trustees of LBT, and shall in no circumstance be construed as being a declaration, representation, or statement of the LBT Trustees on their own and personal behalf. This Agreement shall inure to the benefit of and be binding upon the Parties and the LBT estate and their respective successors and permitted assigns; provided, however, that subject to Section 5 and 7 above, no Party may assign its rights or obligations under this Agreement without the written consent of the other Party, which consent shall not be unreasonably withheld or delayed, and any assignment not in accordance with the terms hereof shall be null and void $a b$ initio.

22. Counterparts. This Agreement may be executed in counterparts, each of which constitutes an original, and all of which, collectively, constitute only one agreement. The signatures of all of the Parties need not appear on the same counterpart.

23. Headings; Schedules and Exhibits. The headings utilized in this Agreement are designed for the sole purpose of facilitating ready reference to the subject matter of this Agreement. Said headings shall be disregarded when resolving any dispute concerning the meaning or interpretation of any language contained in this Agreement. References to sections, unless otherwise indicated, are references to sections of this Agreement. All Schedules to this Agreement are hereby made a part hereof and 
incorporated herein by reference for all purposes. Reference to any Schedule herein shall be to the Schedules attached hereto.

24. No Personal Liability. The Parties acknowledge, accept, and agree that this Agreement and all actions and measures contained herein or following herefrom do not and will not give rise to any personal liability on the part of the LBT Trustees, their firm and its partners and employees, and their representatives or other professional advisors, and to the extent any such personal liability existed, the Parties explicitly waive any and all potential rights and claims against them, their firm and its partners and employees, and their representatives and other professional advisors, personally. The LBT Trustees further acknowledge, accept, and agree that this Agreement and all transactions and measures contained herein do not give rise to any personal liability on the part of any of the officers, directors, employees, members, consultants, asset managers, representatives or professional advisors of the Debtors and to the extent any such personal liability existed, the LBT Trustees explicitly waive any and all potential rights and claims against all of the aforementioned persons. Any claim by a Party against the LBT Trustees or LBT arising under or relating to this Agreement shall only be satisfied out of the assets of the insolvency estate of LBT, and any claim by a Party against any of the Debtors arising under or relating to this Agreement shall only be satisfied out of the assets of such Debtor.

25. Severability and Construction. If any provision of this Agreement shall be held by a court of competent jurisdiction to be illegal, invalid or unenforceable, the remaining provisions shall remain in full force and effect if the essential terms and conditions of this Agreement for each Party remain valid, binding, and enforceable.

26. Waiver of Jury Trial. EACH OF THE PARTIES HERETO HEREBY AGREE NOT TO ELECT A TRIAL BY JURY OF ANY ISSUE TRIABLE OF RIGHT BY JURY, AND HEREBY KNOWINGLY, VOLUNTARILY, INTENTIONALLY, UNCONDITIONALLY AND IRREVOCABLY WAIVES ANY RIGHT TO TRIAL BY JURY FULLY TO THE EXTENT THAT ANY SUCH RIGHT SHALL NOW OR HEREAFTER EXIST WITH REGARD TO THIS AGREEMENT OR ANY CLAIM, COUNTERCLAIM OR OTHER ACTION ARISING IN CONNECTION THEREWITH OR IN RESPECT OF ANY COURSE OF CONDUCT, COURSE OF DEALING, STATEMENT (WHETHER VERBAL OR WRITTEN) OR ACTION OF ANY PARTY OR ARISING OUT OF ANY EXERCISE BY ANY PARTY OF ITS RESPECTIVE RIGHTS UNDER THIS AGREEMENT OR IN ANY WAY RELATING TO THE TRANSACTIONS CONTEMPLATED HEREBY (INCLUDING, WITHOUT LIMITATION, WITH RESPECT TO ANY ACTION TO RESCIND OR CANCEL THIS AGREEMENT AND WITH RESPECT TO ANY CLAIM OR DEFENSE ASSERTING THAT THIS AGREEMENT WAS FRAUDULENTLY INDUCED OR IS OTHERWISE VOID OR VOIDABLE). THIS WAIVER OF RIGHT TO TRIAL BY JURY IS INTENDED TO ENCOMPASS INDIVIDUALLY EACH INSTANCE AND EACH ISSUE AS TO WHICH THE RIGHT TO A TRIAL BY JURY WOULD OTHERWISE ACCRUE. EACH OF THE PARTIES HERETO IS HEREBY AUTHORIZED TO FILE A COPY OF THIS SECTION 26 IN ANY PROCEEDING AS CONCLUSIVE EVIDENCE OF THIS WAIVER. THIS WAIVER OF JURY TRIAL IS A MATERIAL INDUCEMENT FOR THE PARTIES HERETO TO ENTER INTO THIS AGREEMENT.

27. Disclosure. Neither the Debtors nor the LBT Trustees are under any obligation to hold confidential and not disclose this Agreement, so that it may be disclosed generally or to individual parties as each side may see fit. Without limiting the rights of any party under the preceding sentence, the Debtors and the LBT Trustees shall work together to disclose this Agreement by a public filing or filings at a time and in a manner acceptable and convenient to both. 
IN WTNESS WHEREOF, each Party by his or its duly authorized representative has exeeted this Agreement as of the date first written above:

LEHMAN BROTHERS HOLDINGS INC., LEHMAN COMMERCIAL PAPER INC. LEHMAN BROTHERS COMMODITY SERVICES INC, LEHMAN BROTHERS SPECIAL. FINANCINGINC., LEHMAN BROTHERS OTC DERTVATIVES INC., LEIMAN BROTIERS COMMERCIAL CORPORATION, LB 745 LLC, PAMI STATLER ARMS LLC. CES AVIATION LLC. CES AVIATION V LLC, CES AVIATION IX LLC, LEHMAN SCOTTISH FINANCE L.P., BNC MORTGAGE LLC, LB ROSE RANCH LLC. STRUCTURED ASSET SECURITIES CORPORATION, LB 2080 KALAKAUA OWNERS LLC, MERIT LLC, LB PREFERRED SOMERSET LLC, LB SOMERSET LLC, as Debtors and Debtors in Possession

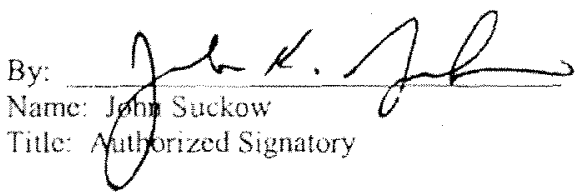

LEHMAN BROTHERS DERIVATIVES

PRODUCTS INC. LEHMAN BROTHERS

FINANCIAL PRODUCTS INC., EAST DOVER

LIMTED, LUXEMBOURG RESIDENTIAL

PROPERTIES LOAN FINANCE S.A.R.L., as

Debtors and Debtors in Possession

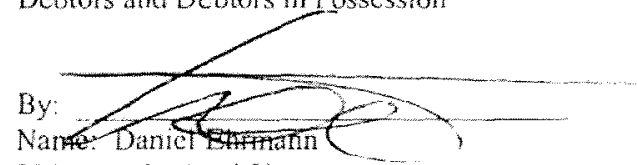

Tille: Authorized Signatory
Rutger J. Schimmelpenninck and Frederic Verhoeven, in their capacity of banknuptcy trustees (curatoren) of LEHMAN BROTHERS TREASURY CO. B.V.

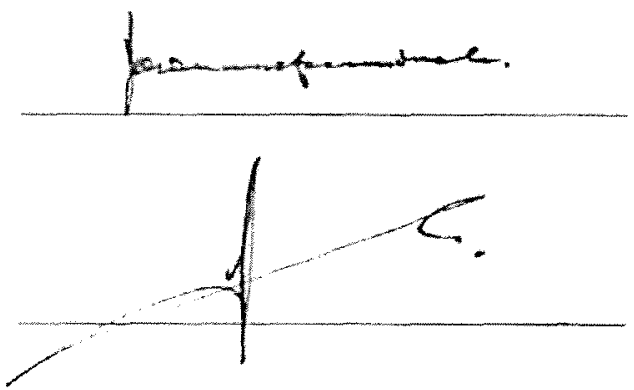

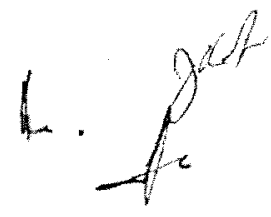




\section{Lehman Brothers Treasury Settlement Agreement Proofs of Claim (\$ in actual)}

\section{Schedule A}

\begin{tabular}{|c|c|c|}
\hline Claim Number & Debtor & $\begin{array}{l}\text { Amount } \\
\text { (USD) }\end{array}$ \\
\hline 58610 & Lehman Brothers Holdings Inc. & $37,566,349$ \\
\hline 58611 & Lehman Brothers Holdings Inc. & $38,413,247$ \\
\hline 58612 & Lehman Brothers Holdings Inc. & $34,820,143,375$ \\
\hline 58613 & Lehman Brothers Holdings Inc. & $34,820,990,272$ \\
\hline 58623 & Lehman Brothers Holdings Inc. & - \\
\hline 58624 & LB Rose Ranch LLC & - \\
\hline 58625 & LB 2080 Kalakaua Owners LLC & - \\
\hline 58626 & CES Aviation LLC & - \\
\hline 58627 & CES Aviation VLLC & - \\
\hline 58628 & East Dover Limited & - \\
\hline 58629 & Luxembourg Residential Properties Loan Finance S.a.r.I. & -. \\
\hline 58630 & BNC Mortgage LLC & - \\
\hline 58631 & Structured Asset Securities Corporation & - \\
\hline 58632 & Lehman Scottish Finance L.P. & - \\
\hline 58633 & Lehman Commercial Paper Inc. & - \\
\hline 58634 & Lehman Brothers Commercial Corporation & - \\
\hline 58635 & Lehman Brothers Financial Products Inc. & - \\
\hline 58636 & Lehman Brothers Derivative Products Inc. & - \\
\hline 58637 & Lehman Brothers OTC Derivatives Inc. & - \\
\hline 58638 & Lehman Brothers Special Financing Inc. & - \\
\hline 58639 & Lehman Brothers Commodity Services Inc. & - \\
\hline 58640 & PAMI Statler Arms LLC & - \\
\hline 58641 & LB 745 LLC & - \\
\hline 58642 & CES Aviation IX LLC & - \\
\hline 58643 & Lehman Brothers Special Financing Inc. & - \\
\hline 58644 & Lehman Brothers Holdings Inc. & - \\
\hline 58645 & Lehman Brothers Commercial Corporation & $37,349,198$ \\
\hline 58646 & Lehman Brothers Commodity Services Inc. & - \\
\hline 58647 & Lehman Brothers Special Financing Inc. & 445,419 \\
\hline
\end{tabular}

Solely for purposes of voting on the Amended Plan or any Alternative Plan (as provided for in Sections 3(a)(1) and 3(b)(2) of this Agreement), the Parties agree that LBT will not vote Claim Number 58613. 
EXECUTION VERSION

\section{$\underline{\text { Schedule B }}$}

\section{Surviving Contracts}

1. Confidentiality Agreement, dated May 21, 2010, between Lehman Brothers Holdings Inc. and Lehman Brothers Treasury Co. B.V. 


\section{AMENDMENT TO SETTLEMENT AGREEMENT}

This Amendment (the "Amendment"), dated as of January 27, 2012, to the Settlement Agreement (defined below) is made and entered into by and among the Debtors ${ }^{1}$ and Rutger J. Schimmelpenninck and Frédéric Verhoeven, in their capacity as bankruptcy trustees (curatoren) (the "LBT Trustees") for Lehman Brothers Treasury Co. B.V. (such estate and corporate entity, collectively, "LBT"). The Debtors and the LBT Trustees shall each be referred to individually as a "Party" and collectively as the "Parties."

\section{$\underline{\mathrm{W}} \underline{\mathrm{I}} \underline{\mathrm{N}} \underline{\mathrm{E}} \underline{\mathrm{S}} \underline{\mathrm{S}} \underline{\mathrm{E}} \underline{\mathrm{T}} \underline{\mathrm{H}}$}

WHEREAS, the Debtors and the LBT Trustees are parties to that certain Settlement Agreement dated as of August 30, 2011 (the "Settlement Agreement");

WHEREAS, Section 19 of the Settlement Agreement provides that the Settlement Agreement only may be modified or amended by a writing signed by a duly authorized representative of each party thereto; and

WHEREAS, the Parties desire that the Settlement Agreement be amended in the manner, and on the terms and conditions, provided for herein.

NOW, THEREFORE, in consideration of the promises set forth herein, the Settlement Agreement, and for other good and valuable consideration, the receipt, adequacy and sufficiency of which are hereby acknowledged, the Parties agree as follows:

1. Amendments to Settlement Agreement.

(a) Section 3.(a)(2) of the Settlement Agreement is hereby amended and restated in its entirety to read as follows:

"3.(a)(2) As may be requested by the LBT Trustees, in order to assist the LBT Trustees in the administration and resolution of the LBT Case, upon the request of the LBT Trustees, which request shall be made no later than ten days prior to the Effective Date, LBHI shall as soon as reasonably practicable after receipt of such request, but no later than one day prior to the Effective Date, cause the transfer of the shares of LBT in exchange for one euro $(€ 1)$ to an entity designated by the LBT Trustees to be incorporated under Dutch law (the "Entity"). The Entity shall not own any interest, directly or indirectly, in any Debtor or Lehman Tax Affiliate (other than LBT), nor shall any Debtor or Lehman Tax Affiliate be a direct or indirect

As used herein, the "Debtors" means Lehman Brothers Holdings Inc. ("LBHI"); Lehman Brothers Special Financing Inc. ("LBSF”); Lehman Commercial Paper Inc.; Lehman Brothers Commercial Corporation ("LBCC"); Lehman Brothers Financial Products Inc.; Lehman Brothers OTC Derivatives Inc.; Lehman Brothers Derivative Products Inc.; Lehman Brothers Commodity Services Inc. ("LBCS"); Lehman Scottish Finance L.P.; CES Aviation LLC; CES Aviation V LLC; CES Aviation IX LLC; East Dover Limited; Luxembourg Residential Properties Loan Finance S.a.r.1; BNC Mortgage LLC; Structured Asset Securities Corporation; LB Rose Ranch LLC; LB 2080 Kalakaua Owners LLC; Merit LLC; LB Somerset LLC; LB Preferred Somerset LLC; LB 745 LLC; PAMI Statler Arms LLC. 
beneficiary or owner of the Entity. The LBT Trustees shall cause the Entity to be formed prior to the date of the transfer of the LBT shares."

(b) Section 2.2.(b) of the Settlement Agreement is hereby amended and restated in its entirety to read as follows:

"2.2.(b) Other than the Allowed US Claims and any claims against, or rights to distributions from, LBT on account of LBT Notes currently held or owned by a Debtor or hereinafter held, owned, or acquired by a Debtor in any capacity whatsoever, all other claims or receivables asserted or held by the Debtors against LBT will be deemed fully and forever expunged, extinguished, disallowed and released."

(c) Section 10.1 of the Settlement Agreement is hereby amended and restated in its entirety to read as follows:

"10.1. Debtors' Releases. Upon the occurrence of the Effective Date, and except as to (i) the allowed claims set forth in Section 2 hereof and any claims against LBT on account of LBT Notes currently held or owned by a Debtor or hereinafter held, owned, or acquired by a Debtor in any capacity whatsoever, (ii) the Debtors' distribution entitlements in the LBT Case, (iii) the agreements, promises, settlements, representations and warranties set forth in this Agreement, (iv) the performance of the obligations set forth herein, and (v) the claims, if any, arising under the surviving contracts set forth on Schedule B, provided that the foregoing exception shall not apply to the personal liability of the LBT Trustees, and subject to the effectiveness of this Agreement in accordance with Section 11 below, and in consideration of the foregoing and the LBT Trustees' execution of this Agreement, each Debtor on behalf of itself, its estate, and its successors and assigns, will fully and forever release, discharge and acquit LBT, the LBT estate and the LBT Trustees (in their personal and professional capacities), and their respective successors, assigns, officers, directors, employees, agents, representatives, consultants, financial advisors, accountants and attorneys, from all manners of action, causes of action, judgments, executions, debts, demands, rights, damages, costs, expenses, and claims of every kind, nature, and character whatsoever existing as of the date hereof, whether at law or in equity, whether based on contract (including, without limitation, quasi-contract or estoppel), statute, regulation, tort (excluding intentional torts, fraud, recklessness, gross negligence or willful misconduct) or otherwise, accrued or unaccrued, known or unknown, matured or unmatured, liquidated or unliquidated, certain or contingent, including, without limitation, all US Avoidance Actions."

2. Effect of Amendment. Except as expressly amended hereby, the Settlement Agreement shall remain unmodified and in full force and effect. To the extent of any inconsistency between the terms of the Settlement Agreement and this Amendment, this Amendment shall govern and control. All other terms and conditions of the Settlement Agreement shall apply to this Amendment.

3. Counterparts. This Amendment may be executed in counterparts, each of which constitutes an original, and all of which, collectively, constitute only one agreement. The signatures of all of the Parties hereto need not appear on the same counterpart. 
4. Execution. Signatures to this Amendment may be exchanged by facsimile transmission and/or electronic mail and shall constitute originals for all purposes.

IN WITNESS WHEREOF, the parties hereto have executed this Amendment as of the date indicated above:

LEHMAN BROTHERS HOLDINGS INC., LEHMAN COMMERCIAL PAPER INC., LEHMAN BROTHERS COMMODITY SERVICES INC., LEHMAN BROTHERS SPECIAL FINANCING INC., LEHMAN BROTHERS OTC DERIVATIVES INC., LEHMAN BROTHERS COMMERCIAL CORPORATION, LB 745 LLC, PAMI

STATLER ARMS LLC, CES AVIATION LLC, CES AVIATION V LLC, CES AVIATION IX LLC, LEHMAN SCOTTISH FINANCE L.P., BNC MORTGAGE LLC, LB ROSE RANCH LLC, STRUCTURED ASSET SECURITIES CORPORATION, LB 2080 KALAKAUA OWNERS LLC, MERIT LLC, LB PREFERRED SOMERSET LLC, LB SOMERSET LLC, as Debtors and Debtors in Possession

By:

Name: John Suckow

Title: Authorized Signatory

LEHMAN BROTHERS DERIVATIVES PRODUCTS INC., LEHMAN BROTHERS FINANCIAL PRODUCTS INC., EAST DOVER LIMITED, LUXEMBOURG RESIDENTIAL PROPERTIES LOAN FINANCE S.A.R.L., as Debtors and Debtors in Possession

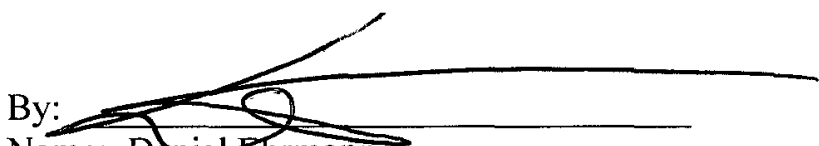

Name: D Ehrmann

Title: Authorized Signatory
Rutger J. Schimmelpenninck and Frédéric Verhoeven, in their capacity of bankruptcy trustees (curatoren) of LEHMAN BROTHERS TREASURY CO. B.V. 
4. Execution Signatures to this Amendment may be exchanged by facsimile transmission and/or electronic mail and shall constitute originals for all purposes

IN WITNESS WHEREOF, the parties hereto have executed this Amendment as of the date indicated above:

LEHMAN BROIHERS HOLDINGS INC., LEHMAN COMMERCIAL PAPER INC., LEHMAN BROTHERS COMMODITY SERVICES INC I $^{\text {LEHMAN BROTHERS }}$ SPECIAL FINANCING INC., LEHMAN BROTHERS OTC DERIVATIVES INC., LEHMAN BROTHERS COMMERCIAL CORPORAIION, LB 745 LLC, PAMI SIATLER ARMS LLC, CES AVIATION LLC, CES AVIATION V LLC, CES AVIATION IX LLC, LEHMAN SCOT TISH FINANCE L.P., BNC MORTGAGE LLC, LB ROSE RANCH LLC, STRUCTURED ASSEI SECURITIES CORPORATION, LB 2080 KALAKAUA OWNERS LLC, MERIT LLC, LB PREFERRED SOMERSET L.LC, LB SOMERSET L.LC, as Debtors and Debtors in Possession

By:

Name: John Suckow

Title: Authorized Signatory

LEHMAN BROIHERS DERIVATIVES PRODUCIS INC., LEHMAN BROTHERS FINANCIAL PRODUCTS INC., EAST DOVER LIMITED, LUXEMBOURG RESIDENTIAL PROPERTIES LOAN FINANCE S A.R.L., as

Debtors and Debtors in Possession

By:

Name: Daniel Ehrmann

Title: Authorized Signatory
Rutger J. Schimmelpenninck and Frédéric Verhoeven, in their capacity of bankruptcy trustees (curatoren) of LEHMAN BROTHERS TREASURY CO B.V.
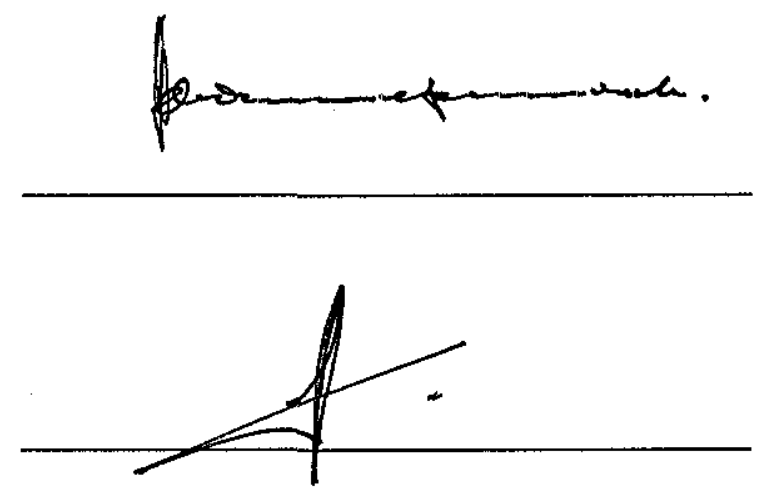


\section{SECOND AMENDMENT TO SETTLEMENT AGREEMENT}

This Second Amendment (the "Amendment"), dated as of December 5 , 2012, to the Settlement Agreement (defined below) is made and entered into by and among Lehman Brothers Holdings Inc., as Plan Administrator (the "Plan Administrator") under the Modified Third Amended Joint Chapter 11 Plan of Lehman Brothers Holdings Inc. and Its Affiliated Debtors for each of the Debtors, ${ }^{1}$ and Rutger J. Schimmelpenninck and Frédéric Verhoeven, in their capacity as bankruptcy trustees (curatoren) (the "LBT Trustees") for Lehman Brothers Treasury Co. B.V. (such estate and corporate entity, collectively, "LBT"). The Debtors and the LBT Trustees shall each be referred to individually as a "Party" and collectively as the "Parties."

\section{WII $\underline{\text { N }} \underline{\mathrm{S}} \underline{\mathrm{S}} \underline{\mathrm{E}} \underline{\mathrm{T}} \underline{\mathrm{H}}$}

WHEREAS, the Debtors and the LBT Trustees are parties to that certain Settlement Agreement dated as of August 30, 2011 (the "Settlement Agreement");

WHEREAS, Section 19 of the Settlement Agreement provides that the Settlement Agreement only may be modified or amended by a writing signed by a duly authorized representative of each party thereto; and

WHEREAS, the Parties desire that the Settlement Agreement be amended in the manner, and on the terms and conditions, provided for herein.

NOW, THEREFORE, in consideration of the promises set forth herein, the Settlement Agreement, and for other good and valuable consideration, the receipt, adequacy and sufficiency of which are hereby acknowledged, the Parties agree as follows:

\section{Amendments to Settlement Agreement.}

(a) Section 10.2 of the Settlement Agreement is hereby amended and restated in its entirety to read as follows:

"10.2 LBT's Releases. Upon the occurrence of the Effective Date, and except as to (i) the allowed claims set forth in Section 2 hereof, (ii) LBT's distribution entitlements in the Chapter 11 Cases, (iii) the agreements, promises, settlements, representations and warranties set forth in this Agreement, (iv) the performance of the obligations set forth herein, and (v) the claims, if any, arising under the surviving contracts set forth on Schedule B, and subject to the effectiveness of this Agreement in accordance with Section 11 below, and in consideration of the foregoing and each Debtor's execution of this Agreement, the LBT Trustees on behalf of the

As used herein, the "Debtors" means Lehman Brothers Holdings Inc.; Lehman Brothers Special Financing Inc.; Lehman Commercial Paper Inc.; Lehman Brothers Commercial Corporation; Lehman Brothers Financial Products Inc.; Lehman Brothers OTC Derivatives Inc.; Lehman Brothers Derivative Products Inc.; Lehman Brothers Commodity Services Inc.; Lehman Scottish Finance L.P.; CES Aviation LLC; CES Aviation V LLC; CES Aviation IX LLC; East Dover Limited; Luxembourg Residential Properties Loan Finance S.a.r.I; BNC Mortgage LLC; Structured Asset Securities Corporation; LB Rose Ranch LLC; LB 2080 Kalakaua Owners LLC; Merit LLC; LB Somerset LLC; LB Preferred Somerset LLC; LB 745 LLC; PAMI Statler Arms LLC. 
LBT estate, and its successors and assigns, will fully and forever release, discharge and acquit each Debtor and Alvarez and Marsal North America, LLC, and their respective successors, assigns, officers, directors, employees, agents, representatives, consultants, financial advisors, accountants and attorneys, from all manners of action, causes of action, judgments, executions, debts, demands, rights, damages, costs, expenses, and claims of every kind, nature, and character whatsoever existing as of the date LBT ceases to exist, whether at law or in equity, whether based on contract (including, without limitation, quasi-contract or estoppel), statute, regulation, tort (excluding intentional torts, fraud, recklessness, gross negligence or willful misconduct) or otherwise, accrued or unaccrued, known or unknown, matured or unmatured, liquidated or unliquidated, certain or contingent, including, without limitation, (i) any administrative expense claims arising under section 503 of the Bankruptcy Code, and (ii) LBT Avoidance Actions.

(b) The following is inserted into the Settlement Agreement as section 28:

"28. Conflicts with LBT Composition Plan. To the extent there is a conflict between the LBT Composition Plan and any matter expressly set forth in or goverend by the Settlement Agreement, the Settlement Agreement shall control as to that matter; provided, however, that the Parties agree that the releases contained in article 8 of the LBT Composition Plan shall be treated as supplemental to, and not in conflict with, the Debtors' releases set forth in section 10.1 of the Settlement Agreement."

2. Effectiveness of Amendment. This Amendment shall become effective on the date that the LBT Composition Plan becomes final, binding and effective in the LBT Case in accordance with its terms.

3. Effect of Amendment. Except as expressly amended hereby, the Settlement Agreement shall remain unmodified and in full force and effect. To the extent of any inconsistency between the terms of the Settlement Agreement and this Amendment, this Amendment shall govern and control. All other terms and conditions of the Settlement Agreement shall apply to this Amendment.

4. Counterparts. This Amendment may be executed in counterparts, each of which constitutes an original, and all of which, collectively, constitute only one agreement. The signatures of all of the Parties hereto need not appear on the same counterpart. 
5. Execution. Signatures to this Amendment may be exchanged by facsimile transmission and/or electronic mail and shall constitute originals for all purposes.

IN WITNESS WHEREOF, the parties hereto have executed this Amendment as of the date indicated above:

LEHMAN BROTHERS HOLDINGS INC., in its capacity as Plan Administrator for the Debtors

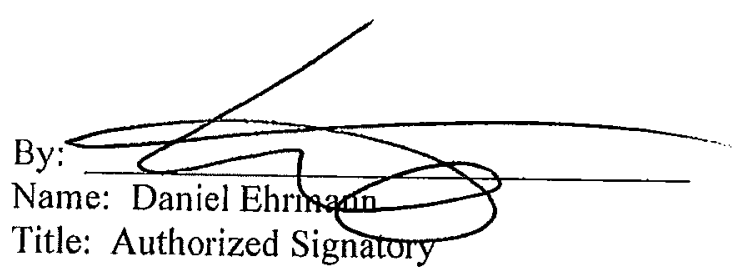

Rutger J. Schimmelpenninck and Frédéric Verhoeven, in their capacity of bankruptcy trustees (curatoren) of LEHMAN BROTHERS TREASURY CO. B.V.

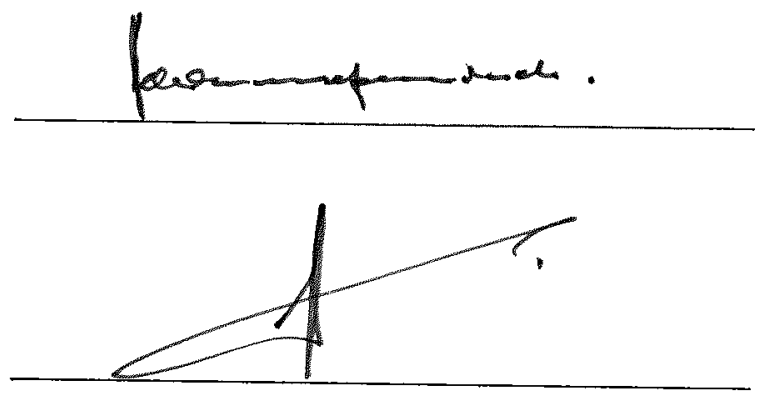


ANNEX II 


\title{
LEHMAN BROTHERS TREASURY CO. B.V. IN BANKRUPTCY CONSENT SOLICITATION MEMORANDUM
}

\author{
THIS CONSENT SOLICITATION MEMORANDUM IS APPROVED BY THE \\ SUPERVISORY JUDGE
}

This Consent Solicitation Memorandum describes the procedures and conditions pursuant to which LBT seeks consent from Noteholders (as defined in each of the attached Market Sections) for the Composition Plan offered by LBT to its Ordinary Creditors pursuant to Title I, Chapter 6 DBA. The Composition Plan is available on the LBT Website at www.lehmanbrotherstreasury.com, through db Link at www.tss.db.com/link, via the Clearing Systems and via related information providers where applicable. Copies are also available on request from the Principal Consent Agent.

Each Market Section contains procedures and conditions applicable to each particular Clearing System. In the event the procedures and conditions described in the general provisions of this memorandum conflict with those in a Market Section, the procedures and conditions in that Market Section shall prevail.

This Consent Solicitation Memorandum should be read in conjunction with and forms part of the Composition Plan. Capitalised terms and expressions contained in this Consent Solicitation Memorandum have the meanings set out in the definitions section on page 14, unless the context requires otherwise. In the event of a discrepancy or difference in interpretation between the Composition Plan and this Consent Solicitation Memorandum until the Effective Date the Consent Solicitation Memorandum shall prevail; as of the Effective Date the provisions of the Composition Plan shall prevail. 
This consent solicitation memorandum is primarily addressed to Direct Participants.

Direct Participants and other parties concerned (such as Clearing Systems, Intermediary Institutions and Noteholders other than Direct Participants) are urged to carefully read this Consent Solicitation Memorandum.

Only Direct Participants are entitled to submit "Filing and Voting Instructions" as defined in and provided for in this Consent Solicitation Memorandum. Filing and Voting Instructions can only be submitted to the Consent Agents in accordance with the procedures and conditions set forth in this Consent Solicitation Memorandum. Filing and Voting Instructions cannot be submitted to LBT or the Bankruptcy Trustees directly.

Noteholders other than Direct Participants are recommended to contact the Direct Participant or Intermediary Institution through which their Notes are held and to consult the "UBO information memorandum" available on the LBT Website. 


\section{TABLE OF CONTENTS}

PART I GENERAL INFORMATION

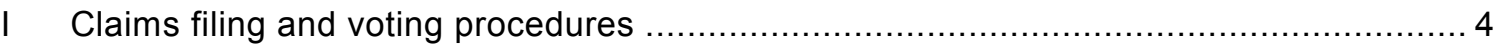

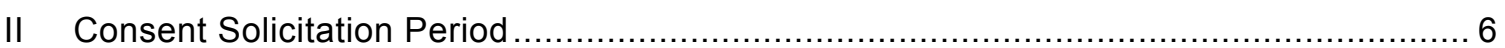

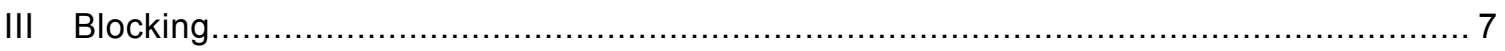

IV Filing of a Claim that differs from the corresponding LBT Note Valuation ..................... 7

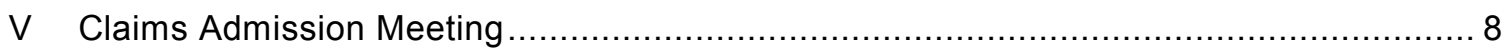

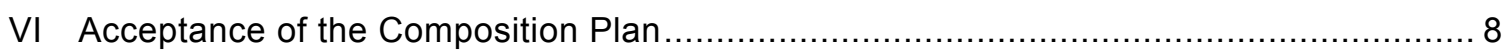

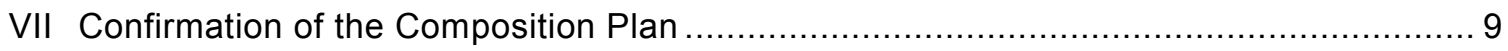

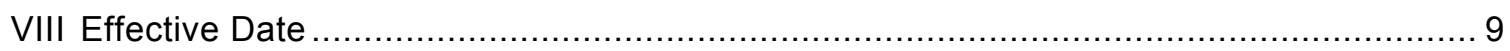

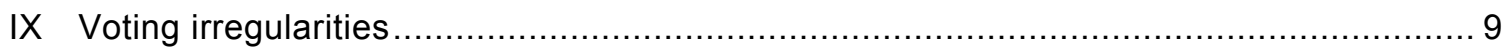

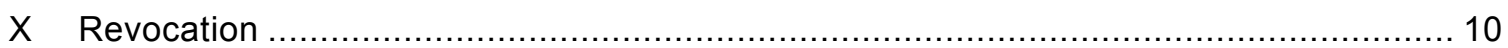

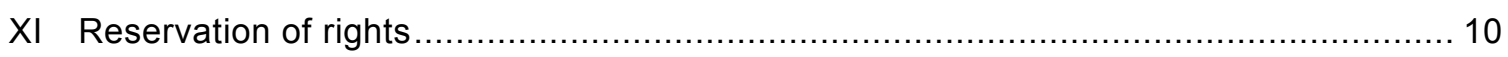

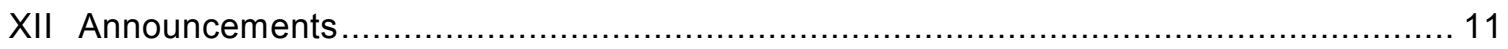

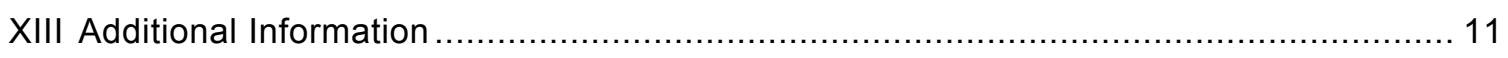

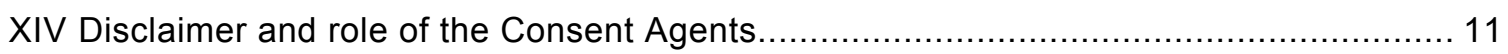

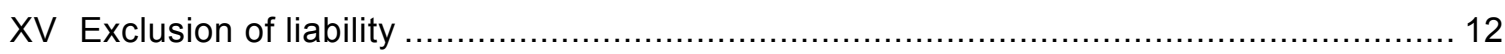

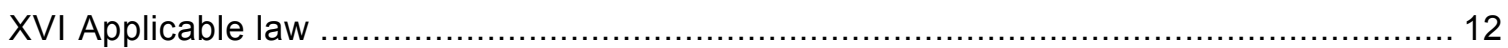

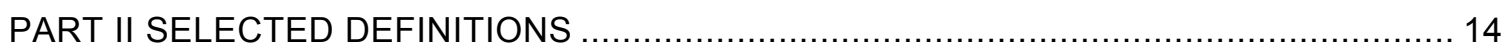

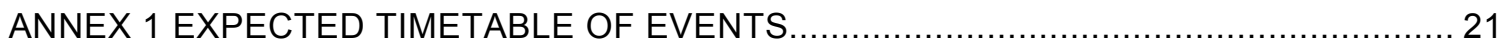

ANNEX 2 PROCEDURES FOR THE SUBMISSION OF FILING AND VOTING

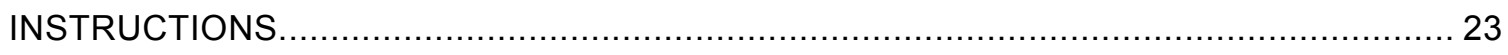

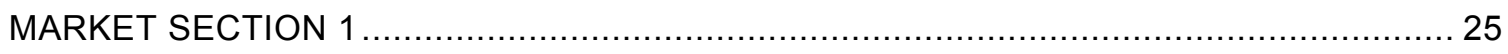

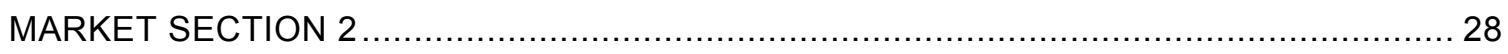

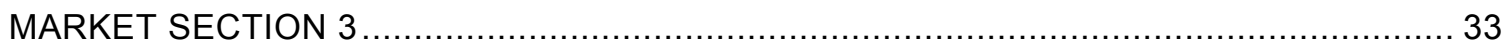

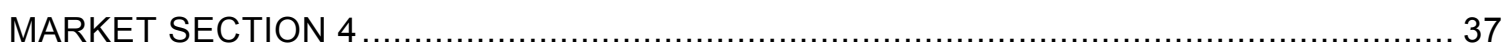

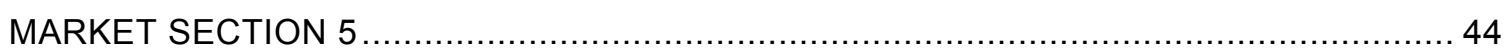

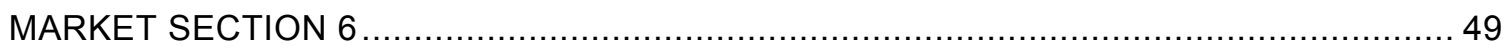

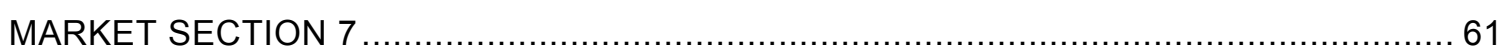

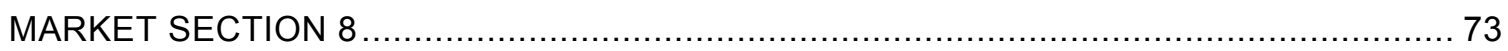

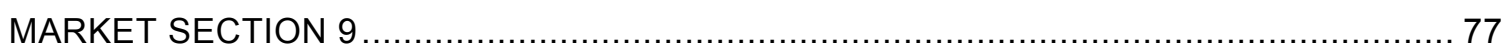

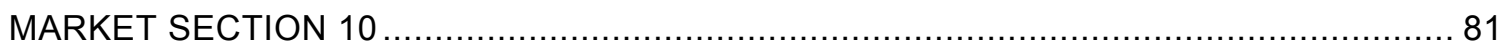

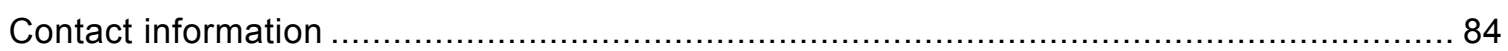




\section{PART I}

\section{GENERAL INFORMATION}

\section{Claims filing and voting procedures}

According to the DBA, Noteholders first need to file a Claim with the Bankruptcy Trustees to be allowed to vote on the Composition Plan.

Only Direct Participants are entitled to file Claims and, subsequently, cast votes according to the procedures and conditions set forth in this Consent Solicitation Memorandum. A Direct Participant can do so:

(i) for itself as a Noteholder; and/or

(ii) on behalf of other Noteholders.

Accordingly, a Noteholder that is not a Direct Participant must have its Claim filed on its behalf by the Direct Participant pertaining to the relevant Notes. Such Noteholder should contact and request such Direct Participant or the relevant Intermediary Institution through which it holds its Notes, as the case may be, to effect its instructions to file a Claim and cast a vote on its behalf prior to any deadlines imposed by such Direct Participant and/or Intermediary Institution.

The Bankruptcy Trustees have appointed Deutsche Bank AG, London Branch to act as Principal Consent Agent, Deutsche Bank Trust Company Americas to act as US Consent Agent and Deutsche Bank SpA to act as Italian Agent. Direct Participants can only submit Filing and Voting Instructions to the Consent Agents in accordance with the procedures and conditions set forth in this Consent Solicitation Memorandum. Filing and Voting Instructions cannot be submitted to LBT or the Bankruptcy Trustees directly.

Direct Participants, whether acting for themselves as Noteholder and/or acting on behalf of other Noteholders, are requested to file Claims and cast votes by submitting a Filing and Voting Instruction as described in further detail below. 
By submitting a Filing and Voting Instruction, the Direct Participant irrevocable appoints and instructs the Principal Consent Agent to act as proxy to:

(i) file a Claim with the Bankruptcy Trustees for each $I S I N^{1}$ that the Direct Participant holds or represents, for the proportionate share of the LBT Note Valuation applicable to that portion of the ISIN held or represented by such Direct Participant; and

(ii) vote at the Claims Admission Meeting either in favour or against the Composition Plan on the Direct Participant's behalf on the basis of such a Claim filed with the Bankruptcy Trustees.

If a Direct Participant intends to file Claims and cast votes pertaining to Notes issued under more than one ISIN, it must submit separate Filing and Voting Instructions for each separate ISIN.

A Direct Participant may submit Filing and Voting Instructions for portions of an ISIN in favour or against the Composition Plan in accordance with any instructions it receives from Noteholders it represents.

Claims are filed and votes are cast on the basis of the LBT Note Valuation applicable to the corresponding ISIN. However, for administrative reasons, the LBT Note Valuation of an ISIN will be applied on the Principal Consent Agent's receipt of a duly submitted Filing and Voting Instruction. The LBT Note Valuation of an ISIN will be applied by the Principal Consent Agent to the portion of the ISIN to which the Filing and Voting Filing and Voting Instruction relates. The LBT Note Valuation will be applied by the Principal Consent Agent by multiplying the nominal value of an ISIN contained in a Filing and Voting Instruction by the corresponding Admissible Amount Percentage attributed to that ISIN. The Admissible Amount Percentage for each ISIN can be found on the LBT Website and in Annex III to the Composition Plan. In order to aggregate Claims in different currencies, the exchange rate as of the date of the bankruptcy of LBT, as published on the LBT Website, will be applied to any non-EUR denominated Notes.

By submitting a Filing and Voting Instruction, each Direct Participant:

(i) accepts that it is bound by this Consent Solicitation Memorandum;

(ii) authorises the relevant Clearing System to disclose full details of its name, full legal entity name, Clearing System account number(s) and the nominal value of the Notes or quantity of Notes in respect of which it submitted Filing and Voting

\footnotetext{
${ }^{1}$ Or 'CUSIP' for Notes that are held through DTC.
} 


\section{THIS CONSENT SOLICITATION MEMORANDUM IS PRIMARILY ADDRESSED TO DIRECT PARTICIPANTS}

Instructions, on an ISIN by ISIN basis, to LBT, the Consent Agents, the Bankruptcy Trustees, and, to the extent necessary, the Supervisory Judge and the Dutch Courts;

(iii) represents and warrants that it is fully authorised to submit such Filing and Voting Instruction, on its own behalf as Noteholder and/or on behalf of other Noteholders; and

(iv) represents and warrants that all information submitted by it is, to the best of its knowledge, accurate and not misleading.

LBT will rely (a) on all Intermediary Institutions through which the Noteholders hold their Notes, if any, to make similar representations and warranties as those set out under (iii) and (iv) above when they forward the Noteholders' instructions to the Direct Participants or (if there are multiple layers of Intermediary Institutions) the next Intermediary Institution (as the case may be) and, consequently, (b) on each Direct Participant to actively seek such representations and warranties from the relevant Intermediary Institutions that hold an account with it.

Filing and Voting Instructions that are not submitted by a duly authorised Direct Participant shall not be taken into account.

\section{Consent Solicitation Period}

Direct Participants can only submit Filing and Voting Instructions during the Consent Solicitation Period. The Consent Solicitation Period commences on December 10, 2012 , and expires on January 25,2013 at 6 pm CET.

Only Filing and Voting Instructions actually received by the Principal Consent Agent, the US Consent Agent or the Italian Agent, as the case may be, on or before the Expiration Date shall be taken into account, unless LBT and/or the Bankruptcy Trustees agree otherwise.

LBT and/or the Bankruptcy Trustees expressly reserve the right to extend the Consent Solicitation Period. An extension of the Consent Solicitation Period will be followed as promptly as practicable by an announcement as described under paragraph XII (Announcements) below. If the Consent Solicitation Period is so extended, the period during which Filing and Voting Instructions will be accepted will end at 18:00 CET on the date to which the Consent Solicitation Period is extended. 


\section{THIS CONSENT SOLICITATION MEMORANDUM IS PRIMARILY ADDRESSED TO DIRECT PARTICIPANTS}

Once the Expiration Date has lapsed, each validly submitted Filing and Voting Instruction as well as the proxy granted by submitting such Filing and Voting Instruction will be deemed irrevocable, unless LBT and/or the Bankruptcy Trustees agree otherwise.

Direct Participants are requested to complete the Filing and Voting Instructions and arrange for the completed Filing and Voting Instructions to be submitted to the Principal Consent Agent in accordance with the procedures and conditions set forth in this Consent Solicitation Memorandum so that these are received by the Principal Consent Agent, the US Consent Agent or the Italian Agent, as the case may be, before the Expiration Date.

\section{Blocking}

Subject to the rules and procedures of the Clearing Systems as set forth in the Procedures for the Submission of Filing and Voting Instructions (see annex II), Notes in respect of which Filing and Voting Instructions have been submitted by a Direct Participant will be blocked by the relevant Clearing System and may not be traded as of the date of such submission until the earliest to occur of (or as soon as reasonably practicable thereafter):

(i) the date of a valid revocation of such Filing and Voting Instructions in accordance with the Procedures for the Submission of Filing and Voting Instructions. Such revocation must in each case be received by the Principal Consent Agent, the US Consent Agent or the Italian Agent, as the case may be, before the Expiration Date;

(ii) the date of the termination or withdrawal of the Consent Solicitation; or

(iii) the date that the Claims Admission Meeting is concluded.

\section{Filing of a Claim that differs from the corresponding LBT Note Valuation}

The Bankruptcy Trustees will dispute (betwisten) all Claims that are filed for an amount that differs from the corresponding LBT Note Valuation.

The filing of a Claim arising out of a Note for an amount that differs from the corresponding LBT Note Valuation applicable to that Note cannot be made via a Filing and Voting Instruction as provided for in this Consent Solicitation Memorandum.

Instead, a Noteholder who does not wish to file a Claim calculated in accordance with the relevant LBT Note Valuation, must file such Claim in accordance with article 110 DBA with the Bankruptcy Trustees on or before the Claims Filing Date in respect of 


\section{THIS CONSENT SOLICITATION MEMORANDUM IS PRIMARILY ADDRESSED TO DIRECT PARTICIPANTS}

which the following requirements apply (in addition to the requirements of article 110 DBA):

(i) the relevant Note should be blocked with the Clearing Systems;

(ii) evidence of such blocking should be provided to the Bankruptcy Trustees as a condition for acceptance of the Claim filed; and

(iii) the relevant Notes must remain blocked and may not be traded until the earliest to occur of:

a. the date of a valid revocation of such a Claims filing. Such revocation must in any case be delivered to the Bankruptcy Trustees before the Claims Filing Date; or

b. the date that the valuation of the Claims arising out of these Notes has been settled with the Bankruptcy Trustees or determined by a Final Order.

The Noteholder should also indicate whether a vote is cast in favour or against the Composition Plan with respect to such Claim filed.

The Bankruptcy Trustees will propose the Supervisory Judge to provisionally allow such Claim for voting purposes for an amount that equals the corresponding LBT Note Valuation.

\section{Claims Admission Meeting}

At the Claims Admission Meeting, Ordinary Creditors formally cast their vote. Noteholders can only cast votes pursuant to the Procedures for the Submission of Filing and Voting Instructions. Noteholders who submitted Filing and Voting Instructions are represented at the Claims Admission by a proxy granted to the Principal Consent Agent. The Principal Consent Agent will cast the votes by proxy on behalf of such Noteholders. The Principal Consent Agents will also present a report that includes a list of the Claims filed and the votes cast in the Consent Solicitation. Subsequently, the Supervisory Judge will assess the Claims filed and count the votes cast, in order to determine whether the conditions for acceptance of the Composition Plan as mentioned in article 145 DBA are met.

\section{Acceptance of the Composition Plan}

Article 145 DBA requires as a condition for acceptance of the Composition Plan that the Composition Plan is accepted by more than $50 \%$ of the Ordinary Creditors that hold admitted or provisionally admitted Claims represented at the Claims Admission Meeting, representing in total not less than $50 \%$ of the aggregate amount of the admitted and conditionally admitted Claims. 


\section{THIS CONSENT SOLICITATION MEMORANDUM IS PRIMARILY ADDRESSED TO DIRECT PARTICIPANTS}

\section{Confirmation of the Composition Plan}

If the Composition Plan is accepted by the required majority of Ordinary Creditors, at the conclusion of the Claims Admission Meeting, the Supervisory Judge will set a date for the confirmation hearing (homologatiezitting) to be held before the Amsterdam District Court.

If the Composition Plan is not accepted by the required majority, the Composition Plan may still be confirmed by the Supervisory Judge at the request of LBT and/or the Bankruptcy Trustees pursuant to Article 146 DBA.

The Amsterdam District Court will decide on the confirmation of the Composition Plan based on Article 153 DBA. The confirmation decision must be rendered as soon as possible after the confirmation hearing.

\section{Effective Date}

The Composition Plan becomes effective and binding on all Ordinary Creditors as soon as any decision from a Dutch Court confirming the Composition Plan is no longer subject to appeal.

As of the Effective Date, each Ordinary Creditor is bound by the Composition Plan, whether or not such Ordinary Creditor filed a Claim in the bankruptcy of LBT or voted in favour or against the Composition Plan.

The submission of Filing and Voting Instructions by Direct Participants is not a requirement in order for a Noteholder to be entitled to receive distributions as provided for in the Composition Plan. Nor is it necessary that such Noteholder (including the Direct Participant) physically appears at the Claims Admission Meeting.

\section{Voting irregularities}

None of LBT, the Bankruptcy Trustees, the Distribution Agents or the Consent Agents, or any of their respective affiliates, directors, employees or advisors or any other person related to them, are or will be under any duty to give notification of any defects or irregularities in any Filing and Voting Instruction or related information, nor will any of such entities or persons incur any liability in connection with such irregularities or for failure to give any such notification. 


\section{THIS CONSENT SOLICITATION MEMORANDUM IS PRIMARILY ADDRESSED TO DIRECT PARTICIPANTS}

Submissions of Filing and Voting Instructions or revocations thereof will not be deemed to have been made until any irregularities in such submissions or revocations have been cured.

None of LBT, the Bankruptcy Trustees, the Paying Agents or the Consent Agents, or any of their respective affiliates, directors, employees or advisors accepts any responsibility for any failure to submit or receive any Filing and Voting Instruction or any other notice or communication. Nor do they accept any responsibility for the failure of a Direct Participant to submit Filing and Voting Instructions in accordance with the instructions of the Noteholder(s) it represents. The Bankruptcy Trustees', LBT's or, as the case may be, the Supervisory Judges' determination in respect of any Filing and Voting Instruction or any other notice or communication shall be final and binding.

Failure to provide all required information as set out in Annex 2, 'Procedures For the Submission of Filing and Voting Instructions', may result in those votes not being taken into account by the Supervisory Judge.

\section{Revocation}

Filing and Voting Instructions may be revoked before the Expiration Date in the manner set forth in the Procedures for the Submission of Filing and Voting Instructions. A notice of revocation, to be effective, must:

(i) clearly indicate the relevant Filing and Voting Instruction to be revoked;

(ii) contain the aggregate nominal value or quantity of Notes to which such revocation relates; and

(iii) be received by the Principal Consent Agent, the US Consent Agent or the Italian Agent, as the case may be, before the Expiration Date.

Only the Direct Participant that submitted the original Filing and Voting Instruction is entitled to revoke such Filing and Voting Instruction previously submitted.

Filing and Voting Instructions that have been validly revoked may be resubmitted before the Expiration Date. Any such validly resubmitted Filing and Voting Instruction will be regarded as a new Filing and Voting Instruction.

\section{Reservation of rights}

Reference is made to article 5 of the Composition Plan. Before the Effective Date, LBT may amend, modify or waive any of the terms of the Composition Plan, or remedy any omission or inconsistency in the Composition Plan, in such a manner that may be 


\section{THIS CONSENT SOLICITATION MEMORANDUM IS PRIMARILY ADDRESSED TO DIRECT PARTICIPANTS}

considered necessary to carry out the purpose and intent of the Composition Plan, without being under any obligation to put such revised Composition Plan to a new vote or consent solicitation proceeding and regardless whether such amendment, modification, waiver or remedy is made before or after the Expiration Date, before or after the date of the Claims Admission Meeting and regardless of whether or not the Composition Plan is accepted or not, provided that any such amendment, modification, waiver or remedy does not materially change the Composition Plan.

LBT reserves the right, to amend, modify or waive any of the terms of the Consent Solicitation Memorandum, or remedy any omission or inconsistency in the Consent Solicitation Memorandum at any time, conditional upon the prior written approval of the Supervisory Judge of such amendment, modification, waiver or remedy.

LBT reserves the right, in its sole and absolute discretion to terminate the Consent Solicitation at any time.

Any amendment, modification, waiver, remedy or termination will be followed as promptly as practicable by an announcement as described under paragraph XII (Announcements) below.

\section{Announcements}

The Bankruptcy Trustees or LBT will communicate the results of the Claims Admission Meeting and any other announcements they deem relevant in connection with the Composition Plan and the Consent Solicitation via the LBT Website, through db Link, via the Clearing Systems and via relevant market information providers where applicable. Copies of such notices can also be obtained from the Consent Agents upon request.

\section{Additional Information}

Any questions or assistance required on how to submit a Filing and Voting Instructions or for requests for additional copies of this Consent Solicitation Memorandum may be directed to the Consent Agents listed on the back page of this document.

\section{Disclaimer and role of the Consent Agents}

In accordance with normal practice, none of the Consent Agents or the Paying Agents express any opinion as to the merits of the Composition Plan or this Consent Solicitation Memorandum. None of the Consent Agents or the Paying Agents have been involved in formulating the Composition Plan or makes any representation that all relevant 


\section{THIS CONSENT SOLICITATION MEMORANDUM IS PRIMARILY ADDRESSED TO DIRECT PARTICIPANTS}

information has been disclosed to Noteholders in or pursuant to this Consent Solicitation Memorandum or the Composition Plan. Accordingly, any party who is in doubt as to the impact or the effect of the Consent Solicitation or Composition Plan should seek their own legal and financial advice.

All authority conferred or agreed to be conferred on the Principal Consent Agent in its appointment by the Direct Participants (acting for themselves as Noteholder and/or acting on behalf of other Noteholders) to act as proxy to attend the Claims Admission Meeting, to represent the Direct Participant and indirectly other Noteholders (as the case may be) and to vote in respect of the Notes that are the subject of Filing and Voting Instructions shall, to the full extent permitted by law, be binding upon the successors, assigns, heirs, executors, administrators, liquidators, trustees in bankruptcy and legal representatives of the Direct Participant and/or other Noteholders and shall not be affected by, and shall survive, the incapacity of such Direct Participant and/or other Noteholders.

\section{Exclusion of liability}

Neither the Bankruptcy Trustees, nor LBT, nor de Stichting Lehman Brothers Treasury, nor the Consent Agents nor any of their agents, employees, advisors or subcontractors, nor Houthoff Buruma Coöperatief U.A., nor any of its direct or indirect subsidiaries, nor any of its or its (indirect) subsidiaries' shareholders, employees, subcontractors, advisors and agents shall be liable for any direct, indirect, special, incidental, consequential, punitive, exemplary or any other damages, including lost profits (even if the Bankruptcy Trustees, LBT and/or the Consent Agents or any of the above mentioned parties are advised by any (third) party of the possibility of such damages) arising in any way from or in connection with: (i) the use of, reliance on or inability to participate in this Consent Solicitation or to access this Consent Solicitation Memorandum or other documents or information provided in relation to the Consent Solicitation process and/or the Composition Plan, (ii) the interception, modification or misuse of the Consent Solicitation Memorandum, the Consent Solicitation and/or the Composition Plan, or (iii) claims of third parties in connection with the use of, reliance on or inability to participate in this Consent Solicitation or to access the Consent Solicitation Memorandum, the Consent Solicitation and/or the Composition Plan.

\section{Applicable law}

This Consent Solicitation Memorandum shall be governed by and construed in accordance with the laws of The Netherlands. All disputes arising out of or in connection with this Consent Solicitation Memorandum shall be submitted to the exclusive 
THIS CONSENT SOLICITATION MEMORANDUM IS PRIMARILY ADDRESSED TO

DIRECT PARTICIPANTS

jurisdiction of the District Court in Amsterdam, The Netherlands, notwithstanding the right of appeal.

In the event of a discrepancy or difference in interpretation between any various language versions of (part of) this Consent Solicitation Memorandum, the English language version shall prevail. 


\section{PART II}

\section{SELECTED DEFINITIONS}

In this Consent Solicitation Memorandum, the following words and expressions have, unless the context otherwise requires, the meanings set out opposite them below. All dates and times set forth in the definitions below are subject to amendment.

Admissible Amount Percentage

Annex

\section{Bankruptcy Date}

Bankruptcy Trustees

CBF

CET

Claim

Claims Admission Meeting the LBT Note Valuation of an ISIN expressed as a percentage of the corresponding outstanding nominal amount of that ISIN

an annex to this Consent Solicitation Memorandum

October 8, 2008

R.J. Schimmelpenninck and F. Verhoeven appointed by the Amsterdam District Court, solely acting in their capacity of bankruptcy trustees (curatoren) of LBT, without personal liability

Clearstream Banking AG, Frankfurt am Main

Central European Time

right to payment, whether or not such right is reduced to judgment, liquidated, unliquidated, fixed, contingent, matured, unmatured, disputed, undisputed, legal, equitable, secured, or unsecured

the meeting, chaired by the Supervisory Judge, in which each of the Claims of Ordinary Creditors that have been validly filed by or on behalf of Ordinary Creditors will either be admitted (erkend) or disputed (betwist), which meeting is scheduled for March 7, 2013 


\author{
Claims Filing Date
}

Clearing Systems

Clearstream

Composition Plan

Computershare

Consent Agents

Consent Solicitation the date at which Claims can ultimately be filed with the Bankruptcy Trustees as set by the Supervisory Judge in accordance with Article 108 DBA, being January 25, 2013

Euroclear Brussels, Clearstream, DTC, SIX SIS, CBF, Monte Titoli, VPS Norway, VP Denmark, and Euroclear Sweden as well as Euroclear Finland and any other entity or institution that takes on a similar role not being a Clearing System (such as Computershare ${ }^{2}$ )

Clearstream Banking, société anonyme, Luxembourg

the composition plan (faillissementsakkoord), including all annexes thereto offered by LBT to its Ordinary Creditors in accordance with the DBA

Computershare Investor Services Pty Limited, appointed as registrar for Notes issued in Australia

Deutsche Bank AG, London Branch as Principal Consent Agent, Deutsche Bank Trust Company Americas as US Consent Agent and Deutsche Bank S.p.A. as Italian Agent, together, the Consent Agents

the procedures related to the filing of Claims with the Bankruptcy Trustees and the casting of votes at the Claims Admission Meeting for the acceptance of the Composition Plan as set out in this Consent Solicitation Memorandum

\footnotetext{
${ }^{2}$ Computershare does not act and is not licensed to act as clearing system. Computershare is included in the definition of Clearing Systems solely for the purpose of this Consent Solicitation Memorandum because it provides certain investor services for LBT.
} 
Consent Solicitation Memorandum this consent solicitation memorandum, including the Annexes and the Market Sections, unless provided otherwise

Consent Solicitation Period

db Link

DBA

Definitive Valuation Principles

Direct Participant

Disputed Claim

Distribution Agent

DTC the period during which Direct Participants can submit Filing and Voting Instructions on their own behalf and/or on behalf of other Noteholders

www.tss.db.com/link

Dutch Bankruptcy Act

the valuation principles set out in paragraph six of the tenth public report of the Bankruptcy Trustees

each person or entity who is shown in the records of a Clearing System as a holder of a particular nominal amount of the Notes

any Noteholder claim whether submitted in accordance with the Consent Solicitation Memorandum or otherwise, as well as any claim submitted by an Other Ordinary Creditor, that either in whole or in part - is disputed (betwist) by the Bankruptcy Trustees at the Claims Admission Meeting and which at the Claims Admission Meeting is referred to the District Court for claim referral proceedings (renvooiprocedures); a list of provisionally disputed claims will be made available for inspection at the registry of the Amsterdam District Court at least for a period of 8 days before the Claims Admission Meeting

Deutsche Bank AG, London branch or any other party engaged by LBT to make distributions in accordance with article 3 of the Composition Plan

the Depository Trust Company 
Effective Date Electronic Filing and Voting
Instruction

EMTN Program

Euroclear Brussels

Euroclear Finland

Euroclear Sweden

Expiration Date

Filing and Voting Instruction the date on which the Composition Plan becomes final and binding as provided for in the Composition Plan

a Filing and Voting Instruction that is submitted electronically

the Euro Medium Term Note Program under which LBT issued Notes

Euroclear Bank S.A. / N.V.

Euroclear Finland Ltd

Euroclear Sweden AB

January 25, 2013 at 6 pm CET, the last date and time upon which Filing and Voting Instructions may be validly submitted to the Principal Consent Agent, the US Consent Agent or the Italian Agent, as the case may be, or such later date and time as may be determined in the sole discretion of LBT and/or the Bankruptcy Trustees

a filing and voting instruction submitted by a Direct Participant on its own behalf and/or on behalf of (other) Noteholders in accordance with the terms and procedures of this Consent Solicitation Memorandum

Filing and Voting Instruction Form a form which is used in certain Markets to submit Filing and Voting Instructions

Final Order

German Note Program a judgment of a court of competent jurisdiction that is no longer open to appeal or cassation

the German Note Issuance Program, under which LBT acted as issuer of Notes 
Intermediary Institution

ISIN

Issuance Programs

Italian Agent

Italian Program

LBT

LBT Note Valuation

LBT Website

Market any depositary bank, commercial bank, broker, dealer, custodian, trust company or other financial institution or intermediary institution who has indirect access to the Clearing Systems through its own account with a Direct Participant or (if there are multiple layers) through its own account with the next (final) Intermediary Institution, which holds an account with a Direct Participant

an outstanding Series of Notes as identified by its International Securities Identification Number. For the purposes of this Consent Solicitation Memorandum, "holding an ISIN" means holding an interest in a Series of Notes as identified by an ISIN

the programs related to the issuance of notes, certificates and/or other financial instruments under which LBT has acted, among other issuing entities, as issuer; these programs being the EMTN Program, the German Note Program, the Swiss Certificates Program and the Italian Program

Deutsche Bank S.p.A.

the Italian Inflation Linked Note Program

Lehman Brothers Treasury Co. B.V.

the value of an ISIN established in accordance with the Definitive Valuation Principles; all LBT Note Valuations are expressed in Euros using exchange rates as of the Bankruptcy Date of LBT

www.lehmanbrotherstreasury.com

a market or jurisdiction in which LBT has issued Notes 
Market Section

Monte Titoli

Noteholder

Notes

Ordinary Creditors

Other Ordinary Creditors

Paying Agents

Principal Consent Agent

Procedures for the Submission of Filing and Voting Instructions each of the market sections as attached to Annex 2 setting forth the Procedures for the Submission of Filing and Voting Instructions for such Market

Monte Titoli S.p.A.

has the meaning assigned thereto in each applicable Market Section

the financial instruments issued by LBT under the Issuance Programs as listed in the annex to the Composition Plan

all unsecured ordinary non-preferred creditors, being (i) Noteholders and (ii) Other Ordinary Creditors

unsecured non-preferred creditors holding a Claim against LBT other than a Claim arising out of Notes

Bank of New York Mellon London branch, New York and Frankfurt branch; BONY (Luxembourg S.A.) Italian branch; Citibank N.A. London branch and Zürich branch; DNB Bank ASA; Handelsbanken branch operations in Finland, Nordea Bank Finland PIc; The Royal Bank of Scotland plc, Edinburgh, Zürich Branch, Skandinaviska Enskilda Banken AB, Swedbank AB and any other entity appointed or to be appointed in such capacity

Deutsche Bank AG, London Branch

the procedures for the submission of filing and voting instructions in respect of each Market as set forth in the respective Market Sections 
THIS CONSENT SOLICITATION MEMORANDUM IS PRIMARILY ADDRESSED TO

DIRECT PARTICIPANTS

Series of Notes

SIX SIS

Supervisory Judge

Swiss Certificate Program

US Consent Agent

VP Denmark

VPS Norway the entirety of Notes of a single issuance of Notes, which may be comprised of one or more tranches issued on different issue dates

SIX SIS Ltd

Ms. W.A.H. Melissen

the Swiss Certificate Program under which LBT issued Notes

Deutsche Bank Trust Company Americas

VP Securities A/S

Verdipapirsentralen ASA 


\section{THIS CONSENT SOLICITATION MEMORANDUM IS PRIMARILY ADDRESSED TO DIRECT PARTICIPANTS}

\section{ANNEX 1 \\ EXPECTED TIMETABLE OF EVENTS}

The Bankruptcy Trustees and LBT reserve the right to extend the Expiration Date in their sole discretion. In such a case or if other dates and times are amended by the Bankruptcy Trustees or LBT, the actual timetable with respect to a or all Series of Notes may differ from the expected timetable set out below.

In submitting Filing and Voting Instructions, Direct Participants should take into account that the deadlines set by any Clearing System for the submission of their Filing and Voting Instructions will be earlier than the Expiration Date.

Noteholders who are not Direct Participants should take into account that the deadlines set by any Intermediary Institutions (and any Direct Participant) for the submission of their respective Filing and Voting Instructions will be earlier than the Expiration Date and the deadline set by any Clearing System for the submission of their Filing and Voting Instructions.

Noteholders who are not Direct Participants should contact the Direct Participants and/or the Intermediary Institution, (as the case may be) through which they hold their Notes to:

(i) inform themselves of any deadlines that may be imposed by those Direct Participants and/or Intermediary Institution (as the case may be), to timely submit the Filing and Voting Instructions on their behalf to the Principal Consent Agent, the US Consent Agent or the Italian Agent, as the case may be, before the Expiration Date; and

(ii) instruct those Direct Participants and/or Intermediary Institution (as the case may be) to process and submit Filing and Voting Instructions on their behalf in accordance with the Procedures for the Submission of Filing and Voting Instructions.

Any Direct Participant and/or Intermediary Institution, should enable those Noteholders to participate in the Consent Solicitation or (in the limited circumstances in which revocation is permitted) revoke their instruction, before the Expiration Date. 
Date or Time:

December 10, 2012

January 25, 2013 at 6 pm CET

January 25, 2013

March 7, 2013

\section{Action:}

offering of Composition Plan commencement of Consent Solicitation publication of this Consent Solicitation Memorandum

Expiration Date, or such later date and time as may be determined in the sole discretion of LBT and/or the Bankruptcy Trustees. Hereafter, each validly submitted Filing and Voting Instruction as well as the proxy granted by submitting such Filing and Voting Instruction will be deemed irrevocable, unless LBT and/or the Bankruptcy Trustees agree otherwise

Claims Filing Date

Claims Admission Meeting 


\section{ANNEX 2}

\section{PROCEDURES FOR THE SUBMISSION OF FILING AND VOTING INSTRUCTIONS}

The following section describes the Procedures for the Submission of Filing and Voting Instructions that Direct Participants must follow to validly submit Filing and Voting Instructions. The policies and procedures for submitting Filing and Voting Instructions may differ by Market. Direct Participants must therefore carefully read the Market Sections applicable to the Note(s) in respect of which it intends to submit (a) Filing and Voting Instruction(s). The Market Section applicable to Notes held, can easily be derived by reference to the ISIN prefix, unique to each Note issued in a particular Market.

Some Markets may require Filing and Voting Instructions to be submitted electronically (using Electronic Filing and Voting Instructions). Other Markets may require Filing and Voting Instructions to be submitted by completing paper instructions (using Filing and Voting Instruction Forms). In the latter case, a copy of the requisite Filing and Voting Instruction Form is included in the relevant Market Section.

Certain Markets may require Additional Noteholder Information (as defined in the applicable Market Section) to be submitted in order to comply with the applicable law and the different legal structures within which the Notes are being held.

\begin{tabular}{|c|c|c|c|}
\hline \multirow{2}{*}{ ISIN Prefix } & Clearing System & $\begin{array}{c}\text { Additional } \\
\text { Noteholder } \\
\text { Information }\end{array}$ & $\begin{array}{c}\text { Market } \\
\text { Section }\end{array}$ \\
\hline XS & Euroclear Brussels / Clearstream & No & 1 \\
\hline US & DTC & No & 2 \\
\hline CH & SIX SIS & Yes & 3 \\
\hline DE & CBF & Yes & 4 \\
\hline IT & Monte Titoli & Yes & 5 \\
\hline NO & VPS Norway & Yes & 6 \\
\hline DK & VP Denmark & Yes & 7 \\
\hline SE & Euroclear Sweden & Yes & 8 \\
\hline FI & Euroclear Finland & No & 10 \\
\hline AU & Computershare & & 9 \\
\hline
\end{tabular}


For the purposes of this Consent Solicitation, any Direct Participants with Euroclear Brussels and/or Clearstream that wish to submit Filing and Voting Instructions in respect of ISINs with a prefix other than "XS" that are held in Euroclear Brussels and/or Clearstream, should contact Euroclear Brussels and/or Clearstream to determine the relevant procedures for participating in the Consent Solicitation. Only Direct Participants at the relevant (domestic) Clearing Systems can submit instructions to the Consent Agents. 


\section{MARKET SECTION 1}

NOTEHOLDERS THAT HOLD NOTES THROUGH EUROCLEAR BRUSSELS AND/OR CLEARSTREAM (AS THE CASE MAY BE) WITH ISIN PREFIX "XS"

\section{(A) GENERAL}

For the purpose of this Market Section 1:

"Noteholder" means each Direct Participant at Euroclear Brussels and/or Clearstream.

\section{(B) PROCEDURES FOR THE SUBMISSION OF FILING AND VOTING INSTRUCTIONS}

Noteholders that wish to submit a Filing and Voting Instruction with the Principal Consent Agent must do so in accordance with the procedures of Euroclear Brussels and/or Clearstream (as the case may be). Noteholders should be aware that they must allow sufficient time for compliance with the standard operating procedures of Euroclear Brussels and/or Clearstream in order to ensure the submission of their Filing and Voting Instructions with the Principal Consent Agent in advance of the Expiration Date.

\section{Electronic Filing and Voting Instructions}

By submitting Electronic Filing and Voting Instructions on an ISIN by ISIN basis, each Noteholder irrevocable appoints and instructs the Principal Consent Agent to act as proxy to:

(i) file a Claim with the Bankruptcy Trustees for each ISIN that the Noteholder holds or represents, for the proportionate share of the LBT Note Valuation applicable to that portion of the ISIN held or represented by such Noteholder and to vote IN FAVOUR of the Composition Plan on the Noteholder's behalf on the basis of such a Claim filed with the Bankruptcy Trustees; or

(ii) file a Claim with the Bankruptcy Trustees for each ISIN that the Noteholder holds or represents, for the proportionate share of the LBT Note Valuation applicable to that portion of the ISIN held or represented by such Noteholder and to vote AGAINST the Composition Plan on the Noteholder's behalf on the basis of such a Claim filed with the Bankruptcy Trustees. 


\section{THIS CONSENT SOLICITATION MEMORANDUM IS PRIMARILY ADDRESSED TO DIRECT PARTICIPANTS}

\section{Procedures for submitting Electronic Filing and Voting Instructions}

To submit an Electronic Filing and Voting Instruction, a Noteholder should contact Euroclear Brussels and/or Clearstream for participation procedures and deadlines regarding the submission of an authenticated 'SWIFT' message and/or a 'Euclid' or 'Creation Online' instruction to authorise the submission of the Electronic Filing and Voting Instruction and the blocking of the Notes concerned in the relevant accounts in Euroclear Brussels and/or Clearstream.

The Noteholder must clearly state the aggregate nominal value or quantity of Notes with respect to which it wishes to submit the Electronic Filing and Voting Instruction(s).

The receipt of Electronic Filing and Voting Instructions from Noteholders by Euroclear Brussels and/or Clearstream may be acknowledged in accordance with the standard practices of Euroclear Brussels and/or Clearstream (as the case may be). For the avoidance of doubt, any such acknowledgement does not constitute an acceptance of the Electronic Filing and Voting Instruction by or on behalf of the Bankruptcy Trustees or LBT.

Failure to provide all required information may result in those votes not being taken into account by the Supervisory Judge.

\section{Blocking}

The Electronic Filing and Voting Instructions as referred to above will include an authorisation to Euroclear Brussels and/or Clearstream (as the case may be) to block the Notes for which Electronic Filing and Voting Instructions are submitted so that no transfers may be effected in relation to such Notes as of the date of such submission until the earliest to occur of (or as soon as reasonably practicable thereafter):

(i) the date of a valid revocation of such Electronic Filing and Voting Instructions in accordance with the procedures for revocation (see under 'Revocation' below). Such revocation must in each case be received by the Principal Consent Agent before the Expiration Date;

(ii) the date of the termination or withdrawal of the Consent Solicitation; or

(iii) the date that the Claims Admission Meeting is concluded

\section{Revocation}

Electronic Filing and Voting Instructions may be revoked before the Expiration Date by submitting an electronic revocation instruction to Euroclear Brussels and/or Clearstream in accordance with the applicable terms and conditions of Euroclear Brussels and/or 


\section{THIS CONSENT SOLICITATION MEMORANDUM IS PRIMARILY ADDRESSED TO DIRECT PARTICIPANTS}

Clearstream (as the case may be) and the terms and conditions set forth in this Consent Solicitation Memorandum. Such electronic revocation instruction, to be effective, must:

(i) clearly indicate the relevant Electronic Filing and Voting Instruction to be revoked;

(ii) contain the aggregate nominal value or quantity of Notes to which such revocation relates; and

(iii) be received by the Principal Consent Agent before the Expiration Date.

Only the Noteholder that submitted the Electronic Filing and Voting Instruction is entitled to revoke such Electronic Filing and Voting Instruction previously submitted.

Electronic Filing and Voting Instructions that have been validly revoked may be resubmitted before the Expiration Date. Any such validly resubmitted Electronic Filing and Voting Instruction will be regarded as a new Electronic Filing and Voting Instruction.

\section{Representations and Warranties}

By submitting Electronic Filing and Voting Instructions to the Principal Consent Agent pursuant to the procedures and conditions of this Consent Solicitation Memorandum, each Noteholder:

(i) accepts that it is bound by this Consent Solicitation Memorandum;

(ii) authorises Clearstream and/or Euroclear Brussels (as the case may be) to disclose full details of its name, full legal entity name, Euroclear Brussels and/or Clearstream account number(s) and the nominal value of the Notes or quantity of Notes in respect of which it submitted the Electronic Filing and Voting Instruction, on an ISIN by ISIN basis, to LBT, the Principal Consent Agent, the Bankruptcy Trustees, and, to the extent necessary, the Supervisory Judge and the Dutch Courts;

(iii) represents and warrants that it is fully authorised to submit such Electronic Filing and Voting Instruction; and

(iv) represents and warrants that all information submitted by it is, to the best of its knowledge, accurate and not misleading. 


\section{MARKET SECTION 2}

\section{NOTEHOLDERS THAT HOLD NOTES THROUGH DTC WITH A CUSIP OR ISIN PREFIX "US"}

\section{(A) GENERAL}

For the purpose of this Market Section 2:

"Agent's Message" has the meaning given thereto under the heading 'Blocking' in part (B) of this Market Section 2;

"ATOP" means the Automated Tender Offer Program;

"CUSIP Code" means Committee on Uniform Security Identification Procedures Code.

"Expiration Date" means January 24, 2013 at 5 pm NYCT.

"Noteholder" means each Direct Participant at DTC.

\section{(B) PROCEDURES FOR THE SUBMISSION OF FILING AND VOTING INSTRUCTIONS}

Noteholders that wish to submit an Electronic Filing and Voting Instruction must do so in accordance with DTC's ATOP procedures. Noteholders should note that they must allow sufficient time for compliance with the standard operating procedures of DTC in order to ensure the submission of their Filing and Voting Instructions to the US Consent Agent before the Expiration Date.

Noteholders must only submit Electronic Filing and Voting Instructions in authorised denominations pursuant to the indenture (or other governing documentation) for the Notes.

\section{Electronic Filing and Voting Instructions}

By submitting Electronic Filing and Voting Instructions on a CUSIP by CUSIP basis to the US Consent Agent (who will forward such instructions to the Principal Consent Agent) each Noteholder irrevocable appoints and instructs the Principal Consent Agent to act as proxy to:

(i) file a Claim with the Bankruptcy Trustees for each CUSIP that the Noteholder holds or represents, for the proportionate share of the LBT Note Valuation applicable to that portion of the CUSIP held or represented by such Noteholder 


\section{THIS CONSENT SOLICITATION MEMORANDUM IS PRIMARILY ADDRESSED TO DIRECT PARTICIPANTS}

and to vote IN FAVOUR of the Composition Plan on the Noteholder's behalf on the basis of such a Claim filed with the Bankruptcy Trustees; or

(ii) file a Claim with the Bankruptcy Trustees for each CUSIP that the Noteholder holds or represents, for the proportionate share of the LBT Note Valuation applicable to that portion of the CUSIP held or represented by such Noteholder and to vote AGAINST the Composition Plan on the Noteholder's behalf on the basis of such a Claim filed with the Bankruptcy Trustees.

\section{No letter of transmittal or consent form}

No letter of transmittal or consent form needs to be executed in relation to the Consent Solicitation or Electronic Filing and Voting Instructions delivered through DTC. The valid electronic delivery of Filing and Voting Instructions through the temporary transfer and surrender of existing Notes in accordance with DTC's ATOP procedures shall constitute a written Filing and Voting Instruction in connection with the Consent Solicitation authorising and instructing the Principal Consent Agent to act as a proxy to file a Claim with the Bankruptcy Trustees and vote in favour or against the Composition Plan according to the terms and conditions of this Consent Solicitation Memorandum.

\section{Procedures for submitting Electronic Filing and Voting Instructions}

To submit an Electronic Filing and Voting Instruction, a Noteholder should contact DTC for participation procedures and deadlines regarding the submission of Electronic Filing and Voting Instructions via DTC's ATOP procedures.

A Noteholder must submit an Electronic Filing and Voting Instruction (in authorised denomination and multiples thereof) by causing DTC to temporarily transfer and surrender the Notes concerned to the US Consent Agent in accordance with DTC's ATOP procedures, in each case indicating:

(i) the DTC participant number and full legal entity name of the Noteholder (i.e. the Direct Participant at DTC) and submitting the Electronic Filing and Voting Instruction by inserting this in the comments field of the instruction submitted through ATOP; and

(ii) the aggregate nominal value or quantity of Notes with respect to which it wishes to submit the Electronic Filing and Voting Instruction(s), and the respective portions of which the Noteholder wishes to vote in favour and/or against the Composition Plan.

Failure to provide all required information may result in those votes not being taken into account by the Supervisory Judge. 


\section{THIS CONSENT SOLICITATION MEMORANDUM IS PRIMARILY ADDRESSED TO DIRECT PARTICIPANTS}

In submitting Electronic Filing and Voting Instructions, Noteholders should take into account that they must allow sufficient time for completion of the ATOP procedures during the normal business hours of DTC to be able to timely submit the Electronic Filing and Voting Instructions to the US Consent Agent before the Expiration Date. Any Agent's Message received by the US Consent Agent after the Expiration Date will be disregarded and of no effect.

The receipt of Electronic Filing and Voting Instructions by DTC may be acknowledged in accordance with the standard practices of DTC. For the avoidance of doubt any such acknowledgement does not constitute an acceptance of the Electronic Filing and Voting Instruction by or on behalf of the Bankruptcy Trustees or LBT.

\section{Blocking}

Book-Entry Transfer

The Notes transferred to the US Consent Agent as part of the Consent Solicitation prior to the Expiration Date will be held under contra CUSIP Codes, which shall indicate whether the related Electronic Filing and Voting Instruction entails a vote in favour of, or against, the Composition Plan (each, the relevant "Contra CUSIP Code"). Such Contra CUSIP Codes will be established by DTC and made available to Noteholders at the launch of this Consent Solicitation.

DTC will verify each transfer and surrender of Notes and confirm the electronic delivery of an Electronic Filing and Voting Instruction by sending an Agent's Message to the US Consent Agent. The term "Agent's Message" in this context means a message transmitted by DTC, received by the US Consent Agent, and forming part of the bookentry confirmation, which states that DTC has received an express acknowledgement from the Noteholder submitting Electronic Filing and Voting Instructions which are the subject of such book-entry confirmation.

Any Notes transferred and surrendered will be held by the US Consent Agent and will not be available for transfer to third parties unless and until the US Consent Agent returns the Notes as provided for below.

The Notes concerned will be transferred back to the relevant Noteholders and will continue to be traded under their original CUSIP Codes upon the earliest to occur of (or as soon as reasonably practicable thereafter):

(i) the date of a valid revocation of an Electronic Filing and Voting Instruction in accordance with the procedures for revocation (see under 'Revocation' below). 


\section{THIS CONSENT SOLICITATION MEMORANDUM IS PRIMARILY ADDRESSED TO DIRECT PARTICIPANTS}

Such revocation must in each case be received by the US Consent Agent before the Expiration Date;

(ii) the date of the termination or withdrawal of the Consent Solicitation; or

(iii) five (5) business days after the date that the Claims Admission Meeting is concluded. The last day for the Notes to be transferred back to holders under the original CUSIP is March 14, 2013.

During the period that Notes are held under (a) Contra CUSIP Code(s), such Notes will not be freely transferable to third parties.

\section{Revocation}

Electronic Filing and Voting Instructions may be revoked before the Expiration Date by submitting a properly formatted and transmitted withdrawal request to the US Consent Agent before the Expiration Date. Such withdrawal request, to be effective, must:

(i) clearly indicate the relevant Electronic Filing and Voting Instruction to be revoked;

(ii) contain the aggregate nominal value or quantity of Notes to which such revocation relates; and

(iii) be received by the US Consent Agent before the Expiration Date.

Only the Noteholder that submitted the Electronic Filing and Voting Instruction is entitled to revoke such Electronic Filing and Voting Instruction previously submitted.

Electronic Filing and Voting Instructions that have been validly revoked may be resubmitted before the Expiration Date. Any such validly resubmitted Electronic Filing and Voting Instruction will be regarded as a new Electronic Filing and Voting Instruction.

\section{Representations and Warranties}

By submitting Electronic Filing and Voting Instructions to the US Consent Agent pursuant to the procedures and conditions of this Consent Solicitation Memorandum, each Noteholder:

(i) accepts that it is bound by this Consent Solicitation Memorandum;

(ii) authorises DTC to disclose full details of the Noteholder's name, full legal entity name as provided by the Noteholder in the Agent's Message, DTC participant number(s) and the nominal value of the Notes or quantity of Notes in respect of which it submitted the Electronic Filing and Voting Instruction (in authorised denomination and multiples thereof), on a CUSIP by CUSIP basis, to LBT, the Consent Agents, the Bankruptcy Trustees, and, to the extent necessary, the Supervisory Judge and the Dutch Courts; 
(iii) represents and warrants that it is fully authorised to submit such Electronic Filing and Voting Instruction; and

(iv) represents and warrants that all information submitted by it is, to the best of its knowledge, accurate and not misleading, including but not limited to, the Noteholder's full legal entity name that must be inserted in the comments field of the instruction submitted through ATOP.

\section{Miscellaneous}

Requests for assistance

Any requests for assistance in submitting an Electronic Filing and Voting Instruction should be directed to the US Consent Agent at:

DB Services Americas, Inc.

MS JCK01-0218

5022 Gate Parkway, Suite 200

Jacksonville, FL 32256

Email: db.reorg@db.com

Telephone Assistance: (800) 735-7777 (option \#1) 


\section{MARKET SECTION 3}

\section{NOTEHOLDERS THAT HOLD NOTES THROUGH SIX SIS WITH ISIN PREFIX "CH"}

\section{(A) GENERAL}

For the purpose of this Market Section 3:

"Noteholder" means:

(i) each Direct Participant at SIX SIS who holds Notes solely for its own account or

(ii) each beneficial owner of Notes holding such Notes, directly or indirectly, through accounts at SIX SIS in the name of a Direct Participant who acts, directly or indirectly, on such beneficial owner's behalf.

Only Direct Participants are allowed to submit Filing and Voting Instructions as provided for by this Consent Solicitation Memorandum. Noteholders who are not Direct Participants should contact the Direct Participants and/or the Intermediary Institutions (as the case may be) through which they hold their Notes to:

(i) inform themselves of any deadlines that may be imposed by those Direct Participants and/or Intermediary Institutions (as the case may be), to timely submit the Filing and Voting Instructions on their behalf before the Expiration Date; and

(ii) instruct them to process and submit Filing and Voting Instructions on their behalf in accordance with the Procedures for the Submission of Filing and Voting Instructions set forth under (B) below.

\section{(B) PROCEDURES FOR THE SUBMISSION OF FILING AND VOTING INSTRUCTIONS}

Direct Participants who wish to submit an Electronic Filing and Voting Instruction, whether acting for themselves and/or acting on behalf of other Noteholders must do so in accordance with the procedures of SIX SIS. Direct Participants should note that they must allow sufficient time for compliance with the standard operating procedures of SIX SIS to ensure submission of their Electronic Filing and Voting Instructions to the Principal Consent Agent before the Expiration Date. 


\section{THIS CONSENT SOLICITATION MEMORANDUM IS PRIMARILY ADDRESSED TO DIRECT PARTICIPANTS}

\section{Electronic Filing and Voting Instructions}

By submitting Electronic Filing and Voting Instructions on an ISIN by ISIN basis, each Direct Participant, whether acting for itself and/or acting on behalf of other Noteholders irrevocable appoints and instructs the Principal Consent Agent to act as proxy to:

(i) file a Claim with the Bankruptcy Trustees for each ISIN that the Direct Participant holds or represents, for the proportionate share of the LBT Note Valuation applicable to that portion of the ISIN held or represented by such Direct Participant and to vote IN FAVOUR of the Composition Plan on the Direct Participants behalf on the basis of such a Claim filed with the Bankruptcy Trustees; or

(ii) file a Claim with the Bankruptcy Trustees for each ISIN that the Direct Participant holds or represents, for the proportionate share of the LBT Note Valuation applicable to that portion of the ISIN held or represented by such Direct Participant and to vote AGAINST the Composition Plan on the Direct Participants behalf on the basis of such a Claim filed with the Bankruptcy Trustees.

\section{Procedures for submitting Filing and Voting Instructions}

Applicable procedures and other requirements

To submit an Electronic Filing and Voting Instruction, a Direct Participant should contact SIX SIS for the relevant participation procedures and deadlines and the blocking of the Notes in the relevant accounts in SIX SIS, in each case indicating:

(i) the Additional Noteholder Information (as defined below) on whose behalf the Direct Participant is submitting the Electronic Filing and Voting Instruction; and

(ii) the aggregate nominal value or quantity of Notes with respect to which it wishes to submit the Electronic Filing and Voting Instruction(s).

Failure to provide all required information may result in those votes not being taken into account by the Supervisory Judge.

Electronic Filing and Voting Instructions must comply and be transmitted in accordance with the usual procedure of SIX SIS, so as to be received by SIX SIS sufficiently in advance of the Expiration Date.

The receipt of such Electronic Filing and Voting Instructions by SIX SIS may be acknowledged in accordance with the standard practices of SIX SIS. For the avoidance of doubt, any such acknowledgement does not constitute an acceptance of the Electronic Filing and Voting Instruction by or on behalf of the Bankruptcy Trustees or LBT. 


\section{THIS CONSENT SOLICITATION MEMORANDUM IS PRIMARILY ADDRESSED TO DIRECT PARTICIPANTS}

\section{Additional Noteholder Information}

Direct Participants must also provide the full legal entity name of the Noteholder on whose behalf they are submitting such Electronic Filing and Voting Instructions in accordance with the applicable procedures of SIX SIS, (the "Additional Noteholder Information").

If a Direct Participant has entered Electronic Filing and Voting Instruction(s) via the systems of SIX SIS on behalf of an Intermediary Institution not being a Noteholder, then the Intermediary Institution must request the relevant Additional Noteholder Information from the counterparty(s) of such Intermediary Institution until the Noteholder level is reached.

Any Direct Participants who are also the Noteholder must still advise the Principal Consent Agent in this manner.

Any votes submitted via SIX SIS for which Additional Noteholder Information is not supplied may result in those votes not being taken into account by the Supervisory Judge.

\section{Blocking}

The Electronic Filing and Voting Instructions as referred to above will include an authorisation to SIX SIS to block the Notes for which Electronic Filing and Voting Instructions are submitted so that no transfers may be effected in relation to such Notes as of the date of such submission until the earliest to occur of (or as soon as reasonably practicable thereafter):

(i) the date of a valid revocation of such Electronic Filing and Voting Instructions in accordance with the procedures for revocation (see under 'Revocation' below). Such revocation must in each case be received by the Principal Consent Agent before the Expiration Date;

(ii) the date of the termination or withdrawal of the Consent Solicitation; or

(iii) the date that the Claims Admission Meeting is concluded.

The submission of Electronic Filing and Voting Instructions will not further restrict the transferability of the Notes.

\section{Revocation}

Electronic Filing and Voting Instructions may be revoked before the Expiration Date by submitting an electronic revocation instruction to SIX SIS in accordance with the applicable terms and conditions of SIX SIS and the terms and conditions set forth in this 


\section{THIS CONSENT SOLICITATION MEMORANDUM IS PRIMARILY ADDRESSED TO DIRECT PARTICIPANTS}

Consent Solicitation Memorandum. Such electronic revocation instruction, to be effective, must:

(i) clearly indicate the relevant Electronic Filing and Voting Instruction to be revoked;

(ii) contain the aggregate nominal value or quantity of Notes to which such revocation relates; and

(iii) be received by the Principal Consent Agent before the Expiration Date.

Only the Direct Participant that submitted the Electronic Filing and Voting Instruction is entitled to revoke such Electronic Filing and Voting Instruction previously submitted.

Electronic Filing and Voting Instructions that have been validly revoked may be resubmitted before the Expiration Date. Any such validly resubmitted Electronic Filing and Voting Instruction will be regarded as a new Electronic Filing and Voting Instruction.

\section{Representations and Warranties}

By submitting Electronic Filing and Voting Instructions to the Principal Consent Agent pursuant to the procedures and conditions of this Consent Solicitation Memorandum, each Direct Participant:

(i) accepts that it is bound by this Consent Solicitation Memorandum;

(ii) authorises SIX SIS to disclose full details of its name, full legal entity name, SIX SIS account number(s) and the nominal value of the Notes or quantity of Notes in respect of which it submitted the Electronic Filing and Voting Instruction, on an ISIN by ISIN basis, to LBT, the Principal Consent Agent, the Bankruptcy Trustees, and, to the extent necessary, the Supervisory Judge and the Dutch Courts;

(iii) represents and warrants that it is fully authorised to submit such Electronic Filing and Voting Instruction; and

(iv) represents and warrants that all information submitted by it is, to the best of its knowledge, accurate and not misleading.

LBT will rely (a) on all Intermediary Institutions through which the Noteholders hold their Notes, if any, to make similar representations and warranties as those set out under (iii) and (iv) above when they forward the Noteholders' instructions to the Direct Participants or (if there are multiple layers of Intermediary Institutions) the next Intermediary Institution (as the case may be) and, consequently, (b) on each Direct Participant to actively seek such representations and warranties from the relevant Intermediary Institutions that hold an account with it. 


\section{MARKET SECTION 4}

\section{NOTEHOLDERS THAT HOLD NOTES THROUGH CBF WITH ISIN PREFIX "DE"}

\section{(A) GENERAL}

For the purpose of this Market Section 4:

"Noteholder" means:

(i) each Direct Participant at CBF who holds Notes solely for its own account; and

(ii) each beneficial owner of Notes holding such Notes, directly or indirectly, through accounts at CBF in the name of a Direct Participant who acts, directly or indirectly, on such beneficial owner's behalf.

Only Direct Participants are allowed to submit Filing and Voting Instructions as provided for by this Consent Solicitation Memorandum. Noteholders who are not a Direct Participant should contact the Direct Participants and/or the Intermediary Institutions (as the case may be) through which they hold their Notes to:

(i) inform themselves of any deadlines that may be imposed by those Direct Participants and/or Intermediary Institutions (as the case may be), to timely submit the Filing and Voting Instructions on their behalf before the Expiration Date; and

(ii) instruct them to process and submit Filing and Voting Instructions on their behalf in accordance with the Procedures for the Submission of Filing and Voting Instructions set forth under (B) below.

\section{(B) PROCEDURES FOR THE SUBMISSION OF FILING AND VOTING INSTRUCTIONS}

Direct Participants who wish to submit an Electronic Filing and Voting Instruction whether acting for itself and/or acting on behalf of other Noteholders:

(i) must do so in accordance with the procedures of CBF; and

(ii) are, furthermore, required to submit the Additional Noteholder Information (as defined below) directly to the Principal Consent Agent as set forth below.

Direct Participants should note that they must allow sufficient time for compliance with the standard operating procedures of CBF to ensure submission of their Electronic Filing and Voting instructions to the Principal Consent Agent before the Expiration Date. 


\section{THIS CONSENT SOLICITATION MEMORANDUM IS PRIMARILY ADDRESSED TO DIRECT PARTICIPANTS}

\section{Electronic Filing and Voting Instructions}

By submitting Electronic Filing and Voting Instructions on an ISIN by ISIN basis, each Direct Participant, whether acting for itself and/or acting on behalf of other Noteholders, irrevocable appoints and instructs the Principal Consent Agent to act as proxy to:

(i) file a Claim with the Bankruptcy Trustees for each ISIN that the Direct Participant holds or represents, for the proportionate share of the LBT Note Valuation applicable to that portion of the ISIN held or represented by such Direct Participant and to vote IN FAVOUR of the Composition Plan on the Direct Participants behalf on the basis of such a Claim filed with the Bankruptcy Trustees; or

(ii) file a Claim with the Bankruptcy Trustees for each ISIN that the Direct Participant holds or represents, for the proportionate share of the LBT Note Valuation applicable to that portion of the ISIN held or represented by such Direct Participant and to vote AGAINST the Composition Plan on the Direct Participants behalf on the basis of such a Claim filed with the Bankruptcy Trustees.

\section{Procedures for submitting Electronic Filing and Voting Instructions}

Applicable procedures and other requirements

To submit an Electronic Filing and Voting Instruction, Direct Participants should follow CBF's participation procedures and deadlines regarding the submission of an Electronic Filing and Voting Instruction.

Direct Participants who wish to participate in the Consent Solicitation must submit their Electronic Filing and Voting Instruction by instructing CBF electronically through the 'CASCADE system' (a settlement platform of CBF, ("Cascade"). The normal procedures for Cascade need to be adhered to effect the transfer of the Notes concerned to one of the technical ISINs specified in Table 1 (CBF Technical ISIN List) under the heading 'Miscellaneous' below and must thereby confirm its and/or the relevant Noteholders' instructions to either vote "In Favour" or "Against".

The Direct Participant must clearly state the aggregate nominal value or number of Notes with respect to which it submits the Electronic Filing and Voting Instructions.

Electronic Filing and Voting Instructions must comply with and be transmitted in accordance with the usual procedure of CBF, so as to be received by CBF sufficiently in advance of the Expiration Date.

The receipt of such Electronic Filing and Voting Instructions by CBF may be acknowledged in accordance with the standard practices of CBF. For the avoidance of 


\section{THIS CONSENT SOLICITATION MEMORANDUM IS PRIMARILY ADDRESSED TO DIRECT PARTICIPANTS}

doubt any such acknowledgement does not constitute an acceptance of the Electronic Filing and Voting Instruction by or on behalf of the Bankruptcy Trustees or LBT.

\section{Additional Noteholder Information}

Together with the submission of Electronic Filing and Voting Instructions, Direct Participants must also provide certain additional information pertaining to the Noteholders on whose behalf such Electronic Filing and Voting Instructions have been submitted by completing a template spreadsheet (the "Template") detailing the additional required information (the "Additional Noteholder Information") and sending this Template directly to the Principal Consent Agent at:

\section{LBT-Consent@list.db.com}

If a Direct Participant has entered Electronic Filing and Voting Instruction(s) via Cascade on behalf of an Intermediary Institution who is not the Noteholder, then the Intermediary Institution must request the relevant Additional Noteholder Information from the counterparty(s) of such Intermediary Institution until the Noteholder level is reached.

Direct Participants must complete the Template with the breakdown of votes as advised by the relevant Noteholders. The total nominal value of votes represented on the Template must equal the votes cast via Cascade. Any Direct Participants who are also a Noteholder must still advise the Principal Consent Agent in this manner.

Any votes submitted via Cascade for which Additional Noteholder Information is not supplied may result in those votes not being taken into account by the Supervisory Judge.

The Template must be obtained directly from the Principal Consent Agent using the following contact information:

Email: $\quad$ LBT-Consent@list.db.com

Subject: $\quad$ LBT Consent Process (Additional Noteholder Information)

\section{Blocking}

The Electronic Filing and Voting Instructions as referred to above will include an authorisation to CBF to transfer the Notes for which Electronic Filing and Voting Instructions are submitted to a suspense account at CBF so that no transfers may be effected in relation to such Notes. 


\section{THIS CONSENT SOLICITATION MEMORANDUM IS PRIMARILY ADDRESSED TO DIRECT PARTICIPANTS}

Upon submission of an Electronic Filing and Voting Instruction, CBF will cause the amount of Notes to which such Electronic Filing and Voting Instruction relates to be debited from the relevant Direct Participant's account held with CBF and temporarily transferred to the applicable suspense account at CBF (see below).

Note(s) in respect of which any action is taken to file a Claim or to submit an instruction (including by submission of an Electronic Filing and Voting Instruction) will be temporarily transferred to a suspense account at CBF and such Notes may not be traded or transferred during the period beginning at the time at which the Direct Participant submits an Electronic Filing and Voting Instruction and ending on the earliest of (or as soon as reasonably practicable thereafter):

(i) the date of a valid revocation of such Electronic Voting Instruction. Such revocation must in each case be submitted to CBF before the Expiration Date; or

(ii) the date of the termination or withdrawal of the Consent Solicitation; or

(iii) the date that the Claims Admission Meeting is concluded.

The submission of Electronic Filing and Voting Instructions will not further restrict the transferability of the Notes.

\section{Revocation}

Electronic Filing and Voting Instructions may be revoked before the Expiration Date by submitting an electronic revocation instruction to CBF in accordance with the applicable terms and conditions of CBF and the terms and conditions set forth in this Consent Solicitation Memorandum. Such electronic revocation instruction, to be effective, must:

(i) clearly indicate the relevant Electronic Filing and Voting Instruction to be revoked;

(ii) contain the aggregate nominal value or quantity of Notes to which such revocation relates; and

(iii) be received by the Principal Consent Agent before the Expiration Date.

Only the Direct Participant that submitted the Electronic Filing and Voting Instruction is entitled to revoke such Electronic Filing and Voting Instruction previously submitted.

Electronic Filing and Voting Instructions that have been validly revoked may be resubmitted before the Expiration Date. Any such validly resubmitted Electronic Filing and Voting Instruction will be regarded as a new Electronic Filing and Voting Instruction.

\section{Representations and Warranties}

By submitting Electronic Filing and Voting Instructions to the Principal Consent Agent pursuant to the procedures and conditions of this Consent Solicitation Memorandum, each Direct Participant: 


\section{THIS CONSENT SOLICITATION MEMORANDUM IS PRIMARILY ADDRESSED TO DIRECT PARTICIPANTS}

(i) accepts that it is bound by this Consent Solicitation Memorandum;

(ii) authorises CBF to disclose full details of its name, full legal entity name, CBF account number(s) and the nominal value of the Notes or quantity of Notes in respect of which it submitted the Electronic Filing and Voting Instruction, on an ISIN by ISIN basis, to LBT, the Principal Consent Agent, the Bankruptcy Trustees, and, to the extent necessary, the Supervisory Judge and the Dutch Courts;

(iii) represents and warrants that it is fully authorised to submit such Electronic Filing and Voting Instruction;

(iv) represents and warrants that all information submitted by it is, to the best of its knowledge, accurate and not misleading; and

LBT will rely (a) on all Intermediary Institutions through which the Noteholders hold their Notes, if any, to make similar representations and warranties as those set out under (iii) and (iv) above when they forward the Noteholders' instructions to the Direct Participants or (if there are multiple layers of Intermediary Institutions) the next Intermediary Institution (as the case may be) and, consequently, (b) on each Direct Participant to actively seek such representations and warranties from the relevant Intermediary Institutions that hold an account with it.

\section{Miscellaneous}

CBF Technical ISIN List

Table 1: CBF Technical ISIN List

\begin{tabular}{|l|l|l|}
\hline Existing ISIN & 'In Favour' ISIN & 'Against' ISIN \\
\hline DE000A0G0Y08 & DE000A1G9M01 & DE000A1G9PL3 \\
\hline DE000A0NTKC6 & DE000A1G9M19 & DE000A1G9PM1 \\
\hline DE000A0NTS89 & DE000A1G9M27 & DE000A1G9PN9 \\
\hline DE000A0N1VM8 & DE000A1G9M35 & DE000A1G9PP4 \\
\hline DE000A0TLG93 & DE000A1G9M43 & DE000A1G9PQ2 \\
\hline DE000A0TLKY4 & DE000A1G9M50 & DE000A1G9PR0 \\
\hline DE000A0TLL96 & DE000A1G9M68 & DE000A1G9PS8 \\
\hline DE000A0TN6J5 & DE000A1G9M76 & DE000A1G9PT6 \\
\hline DE000A0TQG23 & DE000A1G9M84 & DE000A1G9PU4 \\
\hline DE000A0TR731 & DE000A1G9M92 & DE000A1G9PV2 \\
\hline DE000A0TR749 & DE000A1G9NA1 & DE000A1G9PW0 \\
\hline DE000A0TT7X8 & DE000A1G9NB9 & DE000A1G9PX8 \\
\hline DE000A0TVPR6 & DE000A1G9ND5 & DE000A1G9PZ3 \\
\hline DE000A0TV576 & DE000A1G9NE3 & DE000A1G9P08 \\
\hline & &
\end{tabular}


THIS CONSENT SOLICITATION MEMORANDUM IS PRIMARILY ADDRESSED TO DIRECT PARTICIPANTS

\begin{tabular}{|c|c|c|}
\hline Existing ISIN & 'In Favour' ISIN & 'Against' ISIN \\
\hline DE000A0TX6H7 & DE000A1G9NF0 & DE000A1G9P16 \\
\hline DE000A0TU1P4 & DE000A1G9NH6 & DE000A1G9P32 \\
\hline DE000AOWDDE2 & DE000A1G9NK0 & DE000A1G9P57 \\
\hline DE000A0LHNW7 & DE000A1G9NM6 & DE000A1G9P73 \\
\hline DE000AOLHVD0 & DE000A1G9NN4 & DE000A1G9P81 \\
\hline DE000A0LJV62 & DE000A1G9NP9 & DE000A1G9P99 \\
\hline DE000A0LU6X5 & DE000A1G9NQ7 & DE000A1G9QA4 \\
\hline DE000A0MGS69 & DE000A1G9NR5 & DE000A1G9QB2 \\
\hline DE000AOMHVVO & DE000A1G9NS3 & DE000A1G9QC0 \\
\hline DE000A0MHXQ6 & DE000A1G9NT1 & DE000A1G9QD8 \\
\hline DE000A0MJHE1 & DE000A1G9NU9 & DE000A1G9QE6 \\
\hline DE000A0NLYL5 & DE000A1G9NV7 & DE000A1G9QF3 \\
\hline DE000A0NLZG2 & DE000A1G9NW5 & DE000A1G9QG1 \\
\hline DE000A0NMGK2 & DE000A1G9NX3 & DE000A1G9QH9 \\
\hline DE000A0NMJ46 & DE000A1G9NY1 & DE000A1G9QJ5 \\
\hline DE000AONMXZ5 & DE000A1G9NZ8 & DE000A1G9QK3 \\
\hline DE000A0NPV47 & DE000A1G9N00 & DE000A1G9QL1 \\
\hline DE000A0NTV01 & DE000A1G9N18 & DE000A1G9QM9 \\
\hline DE000A0NXKZ9 & DE000A1G9N26 & DE000A1G9QN7 \\
\hline DE000A0NZAV4 & DE000A1G9N34 & DE000A1G9QP2 \\
\hline DE000A0N6GH8 & DE000A1G9N42 & DE000A1G9QQ0 \\
\hline DE000A0N7XQ2 & DE000A1G9N59 & DE000A1G9QR8 \\
\hline DE000A0N8MX9 & DE000A1G9N67 & DE000A1G9QS6 \\
\hline DE000A0SG1J6 & DE000A1G9N75 & DE000A1G9QT4 \\
\hline DE000A0SG1R9 & DE000A1G9N83 & DE000A1G9QU2 \\
\hline DE000A0SHLW6 & DE000A1G9N91 & DE000A1G9QV0 \\
\hline DE000A0SHPH8 & DE000A1G9PA6 & DE000A1G9QW8 \\
\hline DE000A0SUA81 & DE000A1G9PB4 & DE000A1G9QX6 \\
\hline DE000A0SUA99 & DE000A1G9PC2 & DE000A1G9QY4 \\
\hline DE000A0SUEV6 & DE000A1G9PD0 & DE000A1G9QZ1 \\
\hline DE000A0SUT07 & DE000A1G9PE8 & DE000A1G9Q07 \\
\hline DE000A0S1160 & DE000A1G9PF5 & DE000A1G9Q15 \\
\hline DE000A0S2A33 & DE000A1G9PG3 & DE000A1G9Q23 \\
\hline DE000A0S5NN9 & DE000A1G9PH1 & DE000A1G9Q31 \\
\hline DE000A0S7D50 & DE000A1G9PJ7 & DE000A1G9Q49 \\
\hline DE000A0V4E15 & DE000A1G9PK5 & DE000A1G9Q56 \\
\hline DE000A0TVK20 & DE000A1G9NC7 & DE000A1G9PY6 \\
\hline
\end{tabular}


THIS CONSENT SOLICITATION MEMORANDUM IS PRIMARILY ADDRESSED TO DIRECT PARTICIPANTS

\begin{tabular}{|l|l|l|}
\hline Existing ISIN & 'In Favour' ISIN & 'Against' ISIN \\
\hline DE000A1HBEY1 $\left({ }^{*}\right)$ & DE000A1HBFR2 & DE000A1HBFS0 \\
\hline DE000A0TVAJ5 & DE000A1G9NJ2 & DE000A1G9P40 \\
\hline DE000A1HBEZ8 $\left(^{*}\right)$ & DE000A1HBFT8 & DE000A1HBFU6 \\
\hline DE000A0TPVQ8 & DE000A1G9NG8 & DE000A1G9P24 \\
\hline DE000A1HBEX3 $\left(^{*}\right)$ & DE000A1HBFP6 & DE000A1HBFQ4 \\
\hline DE000A1HB472 $\left(^{*}\right)$ & DE000A1HB480 & DE000A1HB498 \\
\hline DE000A0G4LS9 & DE000A1G9NL8 & DE000A1G9P65 \\
\hline DE000A1HBEW5 $\left({ }^{*}\right)$ & DE000A1HBFM3 & DE000A1HBFN1 \\
\hline
\end{tabular}

(*) Technical ISINs applied to accelerated Notes 


\section{MARKET SECTION 5 \\ NOTEHOLDERS THAT HOLD NOTES THROUGH MONTE TITOLI WITH ISIN PREFIX “IT"}

\section{(A) GENERAL}

For the purpose of this Market Section 5:

"Noteholder" means:

(i) each Direct Participant at Monte Titoli who holds Notes solely for its own account; and

(ii) each beneficial owner of Notes holding such Notes, directly or indirectly, through accounts at Monte Titoli in the name of a Direct Participant who acts, directly or indirectly, on such beneficial owner's behalf.

Only Direct Participants are allowed to submit Filing and Voting Instructions as provided for by this Consent Solicitation Memorandum. Noteholders who are not a Direct Participant should contact the Direct Participants and/or the Intermediary Institutions (as the case may be) through which they hold their Notes to:

(i) inform themselves of any deadlines that may be imposed by those Direct Participants and/or Intermediary Institutions (as the case may be), to timely submit the Filing and Voting Instructions on their behalf before the Expiration Date; and

(ii) instruct them to process and submit Filing and Voting Instructions on their behalf in accordance with the Procedures for the Submission of Filing and Voting Instructions set forth under $(B)$ below.

\section{(B) PROCEDURES FOR THE SUBMISSION OF FILING AND VOTING INSTRUCTIONS}

Direct Participants who wish to submit an Electronic Filing and Voting Instruction whether acting for itself and/or acting on behalf of other Noteholders:

(i) must do so in accordance with the procedures of Monte Titoli; and

(ii) are required to submit the Additional Noteholder Information (as defined below) directly to the Italian Agent as set forth below.

Direct Participants should note that they must allow sufficient time for compliance with the standard operating procedures of Monte Titoli to ensure submission of their 


\section{THIS CONSENT SOLICITATION MEMORANDUM IS PRIMARILY ADDRESSED TO DIRECT PARTICIPANTS}

Electronic Filing and Voting Instructions to the Principal Consent Agent before the Expiration Date.

\section{Electronic Filing and Voting Instructions}

By submitting Electronic Filing and Voting Instructions to the Italian Agent (who will forward such instructions to the Principal Consent Agent) on an ISIN by ISIN basis, each Direct Participant whether acting for itself and/or acting on behalf of other Noteholders irrevocable appoints and instructs the Principal Consent Agent to act as proxy to:

(i) file a Claim with the Bankruptcy Trustees for each ISIN that the Direct Participant holds or represents, for the proportionate share of the LBT Note Valuation applicable to that portion of the ISIN held or represented by such Direct Participant and to vote IN FAVOUR of the Composition Plan on the Direct Participants behalf on the basis of such a Claim filed with the Bankruptcy Trustees; or

(ii) file a Claim with the Bankruptcy Trustees for each ISIN that the Direct Participant holds or represents, for the proportionate share of the LBT Note Valuation applicable to that portion of the ISIN held or represented by such Direct Participant and to vote AGAINST the Composition Plan on the Direct Participants behalf on the basis of such a Claim filed with the Bankruptcy Trustees.

\section{Procedures for submitting Electronic Filing and Voting Instructions}

Applicable procedures and other requirements

To submit an Electronic Filing and Voting Instruction, Direct Participants should contact Monte Titoli for participation procedures and deadlines regarding the submission of an Electronic Filing and Voting Instruction.

Direct Participants who wish to participate in the Consent Solicitation must submit their Electronic Filing and Voting Instruction by instructing Monte Titoli electronically through the 'MTX system' (a settlement platform of Monte Titoli, ("MTX"). The normal procedures for MTX need to be adhered to effect the transfer of the Notes concerned to one of the technical ISINs specified in Table 1 (Monte Titoli Technical ISIN List) under the heading 'Miscellaneous' below and must thereby confirm its and/or the relevant Noteholders' instructions to file a Claim and either vote "In Favour" or "Against".

The Direct Participant must clearly state the aggregate nominal value or number of Notes with respect to which it submits the Electronic Filing and Voting Instructions. Electronic Filing and Voting Instructions must comply with and be transmitted in accordance with the usual procedure of Monte Titoli, so as to be received by the Italian Agent sufficiently in advance of the Expiration Date. 


\section{THIS CONSENT SOLICITATION MEMORANDUM IS PRIMARILY ADDRESSED TO DIRECT PARTICIPANTS}

The receipt of such Electronic Filing and Voting Instructions by Monte Titoli may be acknowledged in accordance with the standard practices of Monte Titoli. For the avoidance of doubt any such acknowledgement does not constitute an acceptance of the Electronic Filing and Voting Instruction by or on behalf of the Bankruptcy Trustees or LBT.

\section{Additional Noteholder Information}

Together with the submission of Electronic Filing and Voting Instructions, Direct Participants must also provide certain additional information pertaining to the Noteholders on whose behalf such Electronic Filing and Voting Instructions have been submitted by completing a template spreadsheet (the "Template") detailing the additional required information (the "Additional Noteholder Information") and sending that directly to the Italian Agent at:

\section{Email: sfs.italy@list.db.com}

If a Direct Participant has entered Electronic Filing and Voting Instruction(s) via MTX on behalf of an Intermediary Institution who is not the Noteholder, then the Intermediary Institution must request the relevant Additional Noteholder Information from the counterparty(s) of such Intermediary Institution until the Noteholder level is reached.

Direct Participants must complete the Template with the breakdown of votes as advised by the relevant Noteholders. The total nominal value of votes represented on the Template must equal the votes cast via MTX. Any Direct Participants who are also the Noteholder must still advise the Principal Consent Agent in this manner.

Any votes submitted via MTX for which Additional Noteholder Information is not supplied may result in those votes not being taken into account by the Supervisory Judge.

The Template must be obtained directly from the Italian Agent using the following contact information:

Email: sfs.italy@list.db.com

Subject: LBT Consent Process (Additional Noteholder Information)

\section{Blocking}

The Electronic Filing and Voting Instructions referred to above will include an authorisation to Monte Titoli to transfer the Notes for which Electronic Filing and Voting 


\section{THIS CONSENT SOLICITATION MEMORANDUM IS PRIMARILY ADDRESSED TO DIRECT PARTICIPANTS}

Instructions are submitted to a suspense account at Monte Titoli so that no transfers may be effected in relation to such Notes.

Upon submission of an Electronic Filing and Voting Instruction, Monte Titoli will cause the amount of Notes to which such Electronic Filing and Voting Instruction relates to be debited from the relevant Direct Participant's account held with Monte Titoli and temporarily transferred to the applicable suspense account at Monte Titoli (see below).

Note(s) in respect of which any action is taken to file a Claim or to submit an instruction (including by submission of an Electronic Filing and Voting Instruction) will be temporarily transferred to a suspense account at Monte Titoli and such Notes may not be traded or transferred during the period beginning at the time at which the Direct Participant submits an Electronic Filing and Voting Instruction and ending on the earliest of (or as soon as reasonably practicable thereafter):

(i) the date of a valid revocation of such Electronic Voting Instruction. Such revocation must in each case be submitted to Monte Titoli before the Expiration Date; or

(ii) the date of the termination or withdrawal of the Consent Solicitation; or (iii) the date that the Claims Admission Meeting is concluded.

The submission of Electronic Filing and Voting Instructions will not further restrict the transferability of the Notes.

\section{Revocation}

Electronic Filing and Voting Instructions may be revoked before the Expiration Date by submitting an electronic revocation instruction to Monte Titoli in accordance with the applicable terms and conditions of Monte Titoli and the terms and conditions set forth in this Consent Solicitation Memorandum. Such electronic revocation instruction, to be effective, must:

(i) clearly indicate the relevant Electronic Filing and Voting Instruction to be revoked;

(ii) contain the aggregate nominal value or quantity of Notes to which such revocation relates; and

(iii) be received and authorised by the Italian Agent before the Expiration Date.

Only the Direct Participant that submitted the Electronic Filing and Voting Instruction is entitled to revoke such Electronic Filing and Voting Instruction previously submitted.

Electronic Filing and Voting Instructions that have been validly revoked may be resubmitted before the Expiration Date. Any such validly resubmitted Electronic Filing and Voting Instruction will be regarded as a new Electronic Filing and Voting Instruction. 


\section{Representations and Warranties}

By submitting Electronic Filing and Voting Instructions to the Italian Agent pursuant to the procedures and conditions of this Consent Solicitation Memorandum, each Direct Participant:

(i) accepts that it is bound by this Consent Solicitation Memorandum;

(ii) authorises Monte Titoli to disclose full details of its name, full legal entity name, Monte Titoli account number(s) and the nominal value of the Notes or quantity of Notes in respect of which it submitted the Electronic Filing and Voting Instruction, on an ISIN by ISIN basis, to LBT, the Principal Consent Agent, the Bankruptcy Trustees, and, to the extent necessary, the Supervisory Judge and the Dutch Courts;

(iii) represents and warrants that it is fully authorised to submit such Electronic Filing and Voting Instruction; and

(iv) represents and warrants that all information submitted by it is, to the best of its knowledge, accurate and not misleading.

LBT will rely (a) on all Intermediary Institutions through which the Noteholders hold their Notes, if any, to make similar representations and warranties as those set out under (iii) and (iv) above when they forward the Noteholders' instructions to the Direct Participants or (if there are multiple layers of Intermediary Institutions) the next Intermediary Institution (as the case may be) and, consequently, (b) on each Direct Participant to actively seek such representations and warranties from the relevant Intermediary Institutions that hold an account with it.

Miscellaneous

Monte Titoli Technical ISIN List

\begin{tabular}{|l|l|l|}
\hline Existing ISIN & 'In Favour' ISIN & 'Against' ISIN \\
\hline IT0006578600 & IT000657860098 & IT000657860099 \\
\hline
\end{tabular}




\section{MARKET SECTION 6}

\section{NOTEHOLDERS THAT HOLD NOTES THROUGH VPS NORWAY WITH ISIN PREFIX "NO"}

\section{(A) GENERAL}

For the purpose of this Market Section 6:

"Nominee" means: each Direct Participant at VPS Norway acting as a nominee on behalf of one or more Noteholders.

"Noteholder" means:

(i) each Direct Participant at VPS Norway who holds Notes for its own account; and

(ii) each beneficial owner of Notes holding such Notes in a VPS Norway registered account, directly or indirectly, via a Nominee acting on behalf of such beneficial owner.

Only Direct Participants (including Nominees) are allowed to submit Filing and Voting Instructions as provided for by this Consent Solicitation Memorandum. Noteholders who are not Direct Participants should contact the Nominee through which they hold their Notes to:

(i) inform themselves of any deadlines that may be imposed by the Nominee, with a view to the timely submission of Filing and Voting Instructions on their behalf before the Expiration Date;

(ii) instruct the Nominee to process and submit Filing and Voting Instructions on their behalf in accordance with the Procedure for the Submission of Filing and Voting Instructions set forth under $(\mathrm{C})$ below; and

(iii) supply the Nominee with their name, full legal entity name and any other information required to enable the Nominee to complete the relevant Filing and Voting Instruction Form (the "Additional Noteholder Information").

\section{(B) RECORD DATE}

Only Noteholders as at close of business on December 7, 2012 (the "Record Date") are eligible to submit instructions (directly or via their Nominee) to file Claims and vote on the Composition Plan. 


\section{THIS CONSENT SOLICITATION MEMORANDUM IS PRIMARILY ADDRESSED TO DIRECT PARTICIPANTS}

\section{(C) PROCEDURE FOR THE SUBMISSION OF FILING AND VOTING INSTRUCTIONS}

Direct Participants that wish to submit a Filing and Voting Instruction to the Principal Consent Agent whether acting for itself and/or acting on behalf of other Noteholders must do so in accordance with the procedure for the submission of Filing and Voting Instructions set forth in this Section C. Direct Participants must ensure delivery of the Filing and Voting Instruction to the Principal Consent Agent before the Expiration Date.

\section{Filing and Voting Instructions}

By submitting Filing and Voting Instructions, each Direct Participant, whether acting for itself and/or acting on behalf of other Noteholders irrevocable appoints and instructs the Principal Consent Agent to act as proxy to:

(i) file a Claim with the Bankruptcy Trustees for each ISIN that the Direct Participant holds or represents, for the proportionate share of the LBT Note Valuation applicable to that portion of the ISIN held or represented by such Direct Participant and to vote IN FAVOUR of the Composition Plan on the Direct Participant's behalf on the basis of such a Claim filed with the Bankruptcy Trustees; or

(ii) file a Claim with the Bankruptcy Trustees for each ISIN that the Direct Participant holds or represents, for the proportionate share of the LBT Note Valuation applicable to that portion of the ISIN held or represented by such Direct Participant and to vote AGAINST the Composition Plan on the Direct Participant's behalf on the basis of such a Claim filed with the Bankruptcy Trustees.

\section{Procedures for submitting Filing and Voting Instruction Forms}

a) Instructions for Direct Participants holding Notes for their own account

Direct Participants holding Notes for their own account who wish to submit a Filing and Voting Instruction must deliver a fully completed Filing and Voting Instruction Form found on page 54 of this Consent Solicitation Memorandum directly to the Principal Consent Agent in advance of the Expiration Date, including all of the following mandatory information:

(i) name of Direct Participant as shown on the register(s) of VPS Norway;

(ii) address of Direct Participant as shown on the register(s) of VPS Norway;

(iii) contact name, telephone number and email address of Direct Participant;

(iv) unique VPS Norway account number as shown on the register of VPS Norway; and

(v) the relevant voting action for each ISIN to be voted on. 
Failure to complete all required fields may result in those votes not being taken into account by the Supervisory Judge.

Completed Filing and Voting Instruction Forms must be delivered directly to the Principal Consent Agent as follows:

(i) A scanned PDF version of each completed and signed Filing and Voting Instruction Form should be returned by email before the Expiration Date to:

LBT-Consent@list.db.com

Subject: Debt \& Agency Services re: LBT Consent Process (Norway); and

(ii) the original copy should be sent as soon as possible following submission to the Principal Consent Agent at:

Deutsche Bank AG, London Branch

PO BOX 64399

Winchester House

1 Great Winchester Street

London EC2N 2DB

United Kingdom

Attention: Debt \& Agency Services

re: LBT Consent Process (Norway)

b) Instructions for Direct Participants acting as a Nominee

Direct Participants acting as Nominee who wish to submit a Filing and Voting Instruction on behalf of one or more Noteholders must deliver a fully completed Filing and Voting Instruction Form for Direct Participants acting as Nominee found on page 57 of this Consent Solicitation Memorandum directly to the Principal Consent Agent on or before the Expiration Date, including all of the following mandatory information:

(i) name of Nominee as shown on the register(s) of VPS Norway;

(ii) address of Nominee as shown on the register(s) of VPS Norway;

(iii) contact name, telephone number and email address of Nominee;

(iv) unique VPS Norway account number as detailed on the registers of VPS Norway;

(v) information relating to the relevant Noteholder which includes: full legal name, address and account number with the Nominee;

(vi) the relevant voting action for each ISIN to be voted on. 
Direct Participants acting as Nominee are required to complete one Filing and Voting Instruction Form for Direct Participants acting as Nominee for each Noteholder who wishes to participate in the Consent Solicitation.

Failure to complete all required fields may result in those votes not being taken into account by the Supervisory Judge.

Completed Filing and Voting Instruction Forms for Direct Participants acting as Nominee must be delivered directly to the Principal Consent Agent as follows:

(i) A scanned PDF version of each completed and signed Filing and Voting Instruction Form for Direct Participants acting as Nominee should be returned by email before the Expiration Date to:

\section{LBT-Consent@list.db.com}

Subject: Debt \& Agency Services re: LBT Consent Process (Norway); and

(ii) the original copy should be sent as soon as possible following submission to the Principal Consent Agent at:

Deutsche Bank AG, London Branch

PO BOX 64399

Winchester House

1 Great Winchester Street

London EC2N 2DB

United Kingdom

Attention: Debt \& Agency Services re: LBT Consent Process (Norway)

\section{Revocation}

Filing and Voting Instructions may be revoked before the Expiration Date by submitting a revocation form (the "Revocation Form"). Only Direct Participants (if applicable, on behalf of a Noteholder) that submitted the Filing and Voting Instruction Form are entitled to revoke such Filing and Voting Instruction previously submitted.

Revocation Forms are available from the Principal Consent Agent upon request by email to:

LBT-Consent@list.db.com

Subject: Debt \& Agency Services re: Revocation Request (Norway) 


\section{THIS CONSENT SOLICITATION MEMORANDUM IS PRIMARILY ADDRESSED TO DIRECT PARTICIPANTS}

Completed Revocation Forms should be delivered to the Principal Consent Agent before the Expiration Date by email to:

\section{LBT-Consent@list.db.com}

Subject: Debt \& Agency Services re: Revocation Submission (Norway)

\section{Resubmission of votes}

Filing and Voting Instructions that have been revoked may be resubmitted. Any such Filing and Voting Instruction will be regarded as a new Filing and Voting Instruction. Any revocation and resubmission instructions should be received by the Principal Consent Agent before the Expiration Date. The procedure for resubmitting a new Filing and Voting Instruction is the same as described in Procedures for Submitting Filing and Voting Instruction above.

\section{Representations and Warranties}

By submitting Filing and Voting Instructions to the Principal Consent Agent pursuant to the procedures and conditions of this Consent Solicitation Memorandum, each Direct Participant:

(i) accepts that it is bound by this Consent Solicitation Memorandum;

(ii) authorises VPS Norway to disclose full details of its name and legal identity, its VPS Norway account number and the nominal value of the Notes in respect of which it submitted the Filing and Voting Instruction Form, on an ISIN by ISIN basis, as the case may be, to LBT, the Principal Consent Agent, the Bankruptcy Trustees, and, to the extent necessary, the Supervisory Judge and the Dutch Courts; and

(iii) represents and warrants that it is fully authorised to submit such Filing and Voting Instruction; and

(iv) represents and warrants that all information submitted by it is, to the best of its knowledge, accurate and not misleading.

LBT will rely (a) on all Intermediary Institutions through which the Noteholders hold their Notes, if any, to make similar representations and warranties as those set out under (iii) and (iv) above when they forward the Noteholders' instructions to the Direct Participants or (if there are multiple layers of Intermediary Institutions) the next Intermediary Institution (as the case may be) and, consequently, (b) on each Direct Participant to actively seek such representations and warranties from the relevant Intermediary Institutions that hold an account with it. 


\section{FILING AND VOTING INSTRUCTION FORM FOR NOTES DEPOSITED AND HELD THROUGH VPS NORWAY}

\section{PLEASE COMPLETE THIS FORM ONLY IF YOU ARE A DIRECT PARTICIPANT HOLDING NOTES FOR YOUR OWN ACCOUNT}

\section{PLEASE PRINT CLEARLY}

Legal Name of Direct Participant as recorded on the register of VPS Norway:

Address of Direct Participant as recorded on the register of VPS Norway:

Contact Name of Direct Participant (if different from Legal Name):

Telephone Number of Direct Participant:

Email address of Direct Participant:

VPS Norway unique Account Number in which the Notes are held:

\begin{tabular}{|c|c|c|c|c|}
\hline \multicolumn{5}{|c|}{ NOTE DESCRIPTION AND FILING AND VOTING INSTRUCTION } \\
\hline \multirow[t]{2}{*}{ ISIN } & \multirow[t]{2}{*}{ Short Note Description } & \multirow[t]{2}{*}{$\begin{array}{l}\text { please insert } \\
\text { Nominal amount of } \\
\text { Notes being voted } \\
\text { upon per ISIN }\end{array}$} & \multicolumn{2}{|c|}{$\begin{array}{l}\text { please insert a } \checkmark \text { in the } \\
\text { relevant column(s) to } \\
\text { indicate your voting } \\
\text { action }\end{array}$} \\
\hline & & & IN FAVOUR & AGAINST \\
\hline NO0010395965 & Greater China Magnum Note Private Placement & & & \\
\hline NO0010402738 & Greater China Magnum Note 2 Private Placement & & & \\
\hline NO0010393507 & Global Podium Note Private Placement & & & \\
\hline NO0010392731 & Global Podium Note & & & \\
\hline NO0010387749 & 5 yr Basket Note Linked to Global Titans Podium & & & \\
\hline
\end{tabular}




\section{THIS CONSENT SOLICITATION MEMORANDUM IS PRIMARILY ADDRESSED TO DIRECT PARTICIPANTS}

By completing and submitting this Filing and Voting Instruction Form, we hereby request a Claim to be filed with the Bankruptcy Trustees for each ISIN we hold (as identified above), for the proportionate share of the LBT Note Valuations applicable to that ISIN and vote IN FAVOUR or AGAINST the Composition Plan.

BY COMPLETING AND SUBMITTING THIS FILING AND VOTING FORM WE HEREBY CERTIFY THAT WE HOLD THE ABOVE SECURITIES AS AT THE RECORD DATE.

By completing and submitting this Filing and Voting Instruction Form, we hereby certify to irrevocable appoint the Principal Consent Agent or any of their respective employees to act as proxy to file Claims with the Bankruptcy Trustees and to cast votes relating to the Notes in which we have an interest (as identified above) at the Claims Admission Meeting.

By submitting Filing and Voting Instructions to the Principal Consent Agent, we authorise VPS Norway to disclose full details related to our: legal identity, nominal holdings of Notes and VPS Norway account details to LBT, the Principal Consent Agent, the Bankruptcy Trustees and, to the extent necessary, the Supervisory Judge and the Dutch Court.

The delivery of a Filing and Voting Instruction by a Direct Participant will, on acceptance of the Filing and Voting Instruction by the Bankruptcy Trustees and LBT, constitute a binding acceptance of the Direct Participant to the terms and conditions of the Consent Solicitation Memorandum and the Filing and Voting Instruction.

\section{Revoking Votes}

Filing and Voting Instructions may be revoked any time during Consent Solicitation Period. Only the Direct Participant (if applicable on behalf of a Noteholder) that submitted the Filing and Voting Instruction is entitled to revoke such Filing and Voting Instruction previously submitted. Revocation Forms are available from the Consent Agent upon request by email to:

\section{LBT-Consent@list.db.com}

Subject: Debt \& Agency Services re: Revocation Request (Norway)

Completed Revocation Forms may be delivered at any time during the Consent Solicitation Period to the Principal Consent Agent by email to: 


\section{LBT-Consent@list.db.com}

Subject: Debt \& Agency Services re: Revocation of Previous Instruction (Norway)

\section{Resubmission of Votes}

Filing and Voting Instructions that have been revoked may be resubmitted before the Expiration Date. Any such Filing and Voting Instruction will be regarded as a new Filing and Voting Instruction. Any revocation and resubmission instructions should be received by the Principal Consent Agent before the Expiration Date.

Authorised signature(s)

Dated:

This form MUST be delivered to the Principal Consent Agent by email as a PDF attachment before the Expiration Date.

Deutsche Bank AG, London

Email: LBT-Consent@list.db.com

Subject: Debt \& Agency Services re: LBT Consent Process (Norway)

The original copy should be sent as soon as possible following submission to the Principal Consent Agent at:

Deutsche Bank AG, London Branch

PO BOX 64399

Winchester House

1 Great Winchester Street

London EC2N 2DB

United Kingdom

Attention: Debt \& Agency Services re: LBT Consent Process (Norway)

\section{** END OF FORM**}




\section{FILING AND VOTING INSTRUCTION FORM FOR DIRECT PARTICIPANTS ACTING} AS NOMINEE FOR NOTES DEPOSITED AND HELD THROUGH VPS NORWAY

\section{PLEASE COMPLETE THIS FORM IF YOU ARE A NOMINEE ONLY \\ PLEASE PRINT CLEARLY}

Legal Name of Nominee as recorded on the register of VPS Norway:

Address of Nominee as recorded on the register of VPS Norway:

Contact Name at Nominee:

Telephone number of Nominee:

Email address of Nominee:

VPS Norway unique Account Number in which the Notes are held:

Noteholder information (please return one form for each Noteholder):

Legal Name of Noteholder:

Address of Noteholder:

Account Number of Noteholder with Nominee: 


\begin{tabular}{|c|c|c|c|c|}
\hline \multicolumn{5}{|c|}{ NOTE DESCRIPTION AND FILING AND VOTING INSTRUCTION } \\
\hline \multirow[t]{2}{*}{ ISIN } & \multirow[t]{2}{*}{ Short Note Description } & \multirow{2}{*}{$\begin{array}{l}\text { please insert } \\
\text { Nominal amount } \\
\text { of Notes being } \\
\text { voted upon per } \\
\text { ISIN }\end{array}$} & \multicolumn{2}{|c|}{$\begin{array}{l}\text { please insert a } \checkmark \text { in the } \\
\text { relevant column(s) to } \\
\text { indicate your voting } \\
\text { action }\end{array}$} \\
\hline & & & $\begin{array}{c}\text { IN } \\
\text { FAVOUR }\end{array}$ & AGAINST \\
\hline NO0010395965 & $\begin{array}{l}\text { Greater China Magnum Note Private } \\
\text { Placement }\end{array}$ & & & \\
\hline NO0010402738 & $\begin{array}{l}\text { Greater China Magnum Note } 2 \text { Private } \\
\text { Placement }\end{array}$ & & & \\
\hline NO0010393507 & Global Podium Note Private Placement & & & \\
\hline NO0010392731 & Global Podium Note & & & \\
\hline NO0010387749 & $\begin{array}{l}5 \text { yr Basket Note Linked to Global Titans } \\
\text { Podium }\end{array}$ & & & \\
\hline
\end{tabular}

By completing and submitting this Filing and Voting Instruction Form for Direct Participants acting as Nominee, we hereby request a Claim to be filed with the Bankruptcy Trustees for each ISIN we hold or represent (as identified above), for the proportionate share of the LBT Note Valuations applicable to that ISIN and vote IN FAVOUR or AGAINST the Composition Plan.

BY COMPLETING AND SUBMITTING THIS FILING AND VOTING FORM WE HEREBY CERTIFY THAT WE HOLD THE ABOVE SECURITIES AS AT THE RECORD DATE.

By completing and submitting this Filing and Voting Instruction Form for Direct Participants acting as Nominee, we hereby certify to irrevocable appoint the Principal Consent Agent or any of their respective employees to act as proxy to file Claims with the Bankruptcy Trustees and to cast votes relating to the Notes in which we have an interest (as identified above) at the Claims Admission Meeting.

By submitting this Filing and Voting Instruction Form for Direct Participants acting as Nominee to the Principal Consent Agent, we authorise VPS Norway to disclose full details related to our: legal identity, nominal holdings of Notes and VPS Norway account details to LBT, the Principal Consent Agent, the Bankruptcy Trustees and, to the extent necessary, the Supervisory Judge and the Dutch Court. 


\section{THIS CONSENT SOLICITATION MEMORANDUM IS PRIMARILY ADDRESSED TO DIRECT PARTICIPANTS}

The delivery of a Filing and Voting Instruction Form for Direct Participants acting as Nominee by a Direct Participant will, on acceptance of the Filing and Voting Instruction by the Bankruptcy Trustees and LBT, constitute a binding acceptance of such Direct Participant to the terms and conditions of the Consent Solicitation Memorandum and the Filing and Voting Instruction.

\section{Revoking Votes}

Filing and Voting Instructions may be revoked any time during Consent Solicitation Period. Only the Direct Participant (if applicable, on behalf of a Noteholder) that submitted the Filing and Voting Instruction is entitled to revoke such Filing and Voting Instruction previously submitted. Revocation Forms are available from the Principal Consent Agent upon request by email to:

\section{LBT-Consent@list.db.com}

Subject: Debt \& Agency Services re: Revocation Request (Norway)

Completed Revocation Forms may be delivered at any time during the Consent Solicitation Period to the Principal Consent Agent by email to:

\section{LBT-Consent@list.db.com}

Subject: Debt \& Agency Services re: Revocation of Previous Instruction (Norway)

\section{Resubmission of votes}

Filing and Voting Instructions that have been revoked may be resubmitted before the Expiration Date. Any such Filing and Voting Instruction will be regarded as a new Filing and Voting Instruction. Any revocation and resubmission instructions should be received by the Principal Consent Agent before the Expiration Date.

Authorised signature(s)

Dated: 
This form MUST be delivered to the Principal Consent Agent by email as a PDF attachment before the Expiration Date.

Deutsche Bank AG, London

Email: LBT-Consent@list.db.com

Subject: Debt \& Agency Services re: LBT Consent Process (Norway)

The original copy should be sent as soon as possible following submission to the Principal Consent Agent at:

Deutsche Bank AG, London Branch

PO BOX 64399

Winchester House

1 Great Winchester Street

London EC2N 2DB

United Kingdom

Attention: Debt \& Agency Services re: LBT Consent Process (Norway) 


\section{MARKET SECTION 7}

\section{NOTEHOLDERS THAT HOLD NOTES THROUGH VP WITH ISIN PREFIX "DK"}

\section{(A) GENERAL}

For the purpose of this Market Section 7:

"Nominee" means: each Direct Participant at VP acting as a nominee on behalf of one or more Noteholders.

"Noteholder" means:

(i) each Direct Participant at VP who holds Notes for its own account; and

(ii) each beneficial owner of Notes holding such Notes in a VP registered account, directly or indirectly, via a Nominee acting on behalf of such beneficial owner.

Only Direct Participants (including Nominees) are allowed to submit Filing and Voting Instructions as provided for by this Consent Solicitation Memorandum. Noteholders who are not Direct Participants should contact the Nominee through which they hold their Notes to:

(i) inform themselves of any deadlines that may be imposed by the Nominee, with a view to the timely submission of Filing and Voting Instructions on their behalf before the Expiration Date;

(ii) instruct the Nominee to process and submit Filing and Voting Instructions on their behalf in accordance with the Procedure for the Submission of Filing and Voting Instructions set forth under $(\mathrm{C})$ below; and

(iii) supply the Nominee with their name, full legal entity name and any other information required to enable the Nominee to complete the relevant Filing and Voting Instruction (the "Additional Noteholder Information").

\section{(B) RECORD DATE}

Only Noteholders as at close of business on December 7, 2012 (the "Record Date") are eligible to submit instructions (directly or via their Nominee) to file Claims and vote on the Composition Plan. 


\section{THIS CONSENT SOLICITATION MEMORANDUM IS PRIMARILY ADDRESSED TO DIRECT PARTICIPANTS}

\section{(C) PROCEDURE FOR THE SUBMISSION OF FILING AND VOTING INSTRUCTIONS}

Direct Participants that wish to submit a Filing and Voting Instruction through the Principal Consent Agent, whether acting for itself and/or acting on behalf of other Noteholders must do so in accordance with the procedure for the submission of Filing and Voting Instructions set forth in this section C. Direct Participants must ensure delivery of the Filing and Voting Instruction to the Principal Consent Agent before the Expiration Date.

\section{Filing and Voting Instructions}

By submitting Filing and Voting Instructions, each Direct Participant, whether acting for itself and/or acting on behalf of other Noteholders irrevocable appoints and instructs the Principal Consent Agent to act as proxy to:

(i) file a Claim with the Bankruptcy Trustees for each ISIN that the Direct Participant holds or represents, for the proportionate share of the LBT Note Valuation applicable to that portion of the ISIN held or represented by such Direct Participant and to vote IN FAVOUR of the Composition Plan on the Direct Participant's behalf on the basis of such a Claim filed with the Bankruptcy Trustees; or

(ii) file a Claim with the Bankruptcy Trustees for each ISIN that the Direct Participant holds or represents, for the proportionate share of the LBT Note Valuation applicable to that portion of the ISIN held or represented by such Direct Participant and to vote AGAINST the Composition Plan on the Direct Participant's behalf on the basis of such a Claim filed with the Bankruptcy Trustees.

\section{Procedures for submitting Filing and Voting Instruction Forms}

a) Instructions for Direct Participants holding Notes for their own account

Direct Participants holding Notes for their own account who wish to submit a Filing and Voting Instruction must deliver a fully completed Filing and Voting Instruction Form found on page 66 of this Consent Solicitation Memorandum directly to the Principal Consent Agent before the Expiration Date, including all of the following mandatory information:

(i) proof of holdings, being either (a) the VP Cover Letter sent to you with a copy of the Consent Solicitation Memorandum, or (b) other proof of holdings as may be requested by the Principal Consent Agent to confirm your eligibility to file a Claim and vote;

(ii) name of Direct Participant as shown on the register(s) of VP;

(iii) address of Direct Participant as shown on the register(s) of VP;

(iv) contact name of Direct Participant; 


\section{THIS CONSENT SOLICITATION MEMORANDUM IS PRIMARILY ADDRESSED TO DIRECT PARTICIPANTS}

(v) unique VP account number as shown on the register of VP;

(vi) the relevant voting action for each ISIN to be voted on.

Failure to complete all required fields and supply proof of holdings may result in those votes not being taken into account by the Supervisory Judge.

Completed Filing and Voting Instruction Forms and proof of holdings must be delivered directly to the Principal Consent Agent as follows:

(i) A scanned PDF version of each completed and signed Filing and Voting Instruction Form and proof of holdings should be returned by email before the Expiration Date to:

\section{LBT-Consent@list.db.com}

Subject: Debt \& Agency Services re: LBT Consent Process (Denmark); and

(ii) the original copies should be sent as soon as possible following submission to the Principal Consent Agent at:

Deutsche Bank AG, London Branch

PO BOX 64399

Winchester House

1 Great Winchester Street

London EC2N 2DB

United Kingdom

Attention: Debt \& Agency Services

re: LBT Consent Process (Denmark)

b) Instructions for Direct Participants acting as a Nominee

Direct Participants acting as a Nominee who wish to submit a Filing and Voting Instruction on behalf of one or more Noteholders must deliver a fully completed Filing and Voting Instruction Form for Direct Participants acting as Nominee found on page 69 of this Consent Solicitation Memorandum directly to the Principal Consent Agent on or before the Expiration Date, including all of the following mandatory information:

(i) proof of holdings, being either (a) the VP Cover Letter sent to you with a copy of the Consent Solicitation Memorandum, or (b) other Proof of Holdings as may be requested by the Principal Consent Agent to confirm your eligibility to file a Claim and vote;

(ii) name of Nominee as shown on the register(s) of VP; 


\section{THIS CONSENT SOLICITATION MEMORANDUM IS PRIMARILY ADDRESSED TO DIRECT PARTICIPANTS}

(iii) address of Nominee as shown on the register(s) of VP;

(iv) contact name of Nominee;

(v) unique VP account number as detailed on the register of VP;

(vi) information relating to the relevant Noteholder which includes: name, address and account number with the Nominee; and

(vii) the relevant voting action for each ISIN to be voted on.

Direct Participants acting as a Nominee are required to complete one Filing and Voting Instruction Form for Direct Participants acting as Nominee for each Noteholder who wishes to participate in the Consent Solicitation. Nominees may choose to submit multiple Filing and Voting Instruction Forms represented by a single proof of holdings or otherwise submit single Filing and Voting Instruction Forms accompanied by a proof of holdings with each submission.

Failure to complete all required fields and supply proof of holdings may result in those votes not being taken into account by the Supervisory Judge.

Completed Filing and Voting Instruction Forms and proof of holdings for Direct Participants acting as Nominee must be delivered directly to the Principal Consent Agent as follows:

(i) A scanned PDF version of each completed and signed Filing and Voting Instruction Form for Direct Participants acting as Nominee should be returned by email before the Expiration Date to:

\section{LBT-Consent@list.db.com}

Subject: Debt \& Agency Services re: LBT Consent Process (Denmark); and

(ii) the original copies should be sent as soon as possible following submission to the Principal Consent Agent at:

Deutsche Bank AG, London Branch

PO BOX 64399

Winchester House

1 Great Winchester Street

London EC2N 2DB

United Kingdom

Attention: Debt \& Agency Services re: LBT Consent Process (Denmark) 


\section{THIS CONSENT SOLICITATION MEMORANDUM IS PRIMARILY ADDRESSED TO DIRECT PARTICIPANTS}

\section{Revocation}

Filing and Voting Instructions may be revoked before the Expiration Date by submitting a revocation form (the "Revocation Form"). Only Direct Participants (if applicable, on behalf of a Noteholder) that submitted the Filing and Voting Instruction Form are entitled to revoke such Filing and Voting Instruction previously submitted.

Revocation Forms are available from the Principal Consent Agent upon request by email to:

\section{LBT-Consent@list.db.com}

Subject: Debt \& Agency Services re: Revocation Request (Denmark)

Completed Revocation Forms should be delivered to the Principal Consent Agent on or before the Expiration Date by email to:

\section{LBT-Consent@list.db.com}

Subject: Debt \& Agency Services re: Revocation Submission (Denmark)

\section{Resubmission of votes}

Filing and Voting Instructions that have been revoked may be resubmitted. Any such Filing and Voting Instruction will be regarded as a new Filing and Voting Instruction. Any revocation and resubmission instructions should be received by the Principal Consent Agent before the Expiration Date. The procedure for submitting a new Filing and Voting Instruction is the same as described in Procedures for Submitting Filing and Voting Instruction above.

\section{Representations and Warranties}

By submitting Filing and Voting Instructions to the Principal Consent Agent pursuant to the procedures and conditions of this Consent Solicitation Memorandum, each Direct Participant:

(i) accepts that it is bound by this Consent Solicitation Memorandum;

(ii) will disclose full details of its name and legal identity, its VP account number and the nominal value of the Notes in respect of which it submitted the Filing and Voting Instruction Form, on an ISIN by ISIN basis, as the case may be, to LBT, the Principal Consent Agent, the Bankruptcy Trustees, and, to the extent necessary, the Supervisory Judge and the Dutch Courts; and

(iii) represents and warrants that it is fully authorised to submit such Filing and Voting Instruction; and

(iv) represents and warrants that all information submitted by it is, to the best of its knowledge, accurate and not misleading. 
LBT will rely (a) on all Intermediary Institutions through which the Noteholders hold their Notes, if any, to make similar representations and warranties as those set out under (iii) and (iv) above when they forward the Noteholders' instructions to the Direct Participants or (if there are multiple layers of Intermediary Institutions) the next Intermediary Institution (as the case may be) and, consequently, (b) on each Direct Participant to actively seek such representations and warranties from the relevant Intermediary Institutions that hold an account with it. 


\section{FILING AND VOTING INSTRUCTION FORM FOR NOTES DEPOSITED AND HELD THROUGH VP}

\section{PLEASE COMPLETE THIS FORM ONLY IF YOU ARE A DIRECT PARTICIPANT HOLDING NOTES FOR YOUR OWN ACCOUNT}

\section{PLEASE PRINT CLEARLY}

Legal Name of Direct Participant as recorded on the register of VP:

Address of Direct Participant as recorded on the register of VP:

Telephone Number of Direct Participant:

Email address of Direct Participant:

VP unique Account Number in which the Notes are held:

\begin{tabular}{|c|c|c|c|c|}
\hline \multicolumn{5}{|c|}{ NOTE DESCRIPTION AND FILING AND VOTING INSTRUCTION } \\
\hline \multirow[t]{2}{*}{ ISIN } & \multirow[t]{2}{*}{ Short Note Description } & \multirow[t]{2}{*}{$\begin{array}{l}\text { please insert } \\
\text { Nominal amount of } \\
\text { Notes being voted } \\
\text { upon per ISIN }\end{array}$} & \multicolumn{2}{|c|}{$\begin{array}{l}\text { please insert a } \checkmark \text { in the } \\
\text { relevant column(s) to } \\
\text { indicate your voting } \\
\text { action }\end{array}$} \\
\hline & & & IN FAVOUR & AGAINST \\
\hline DK0030106190 & USD DKK NOTE & & & \\
\hline DK0030072194 & $\begin{array}{l}2 Y \text { TWIN CLIQUET NOTE } 100 \% \text { CAPITAL } \\
\text { PROTECTED NOTE }\end{array}$ & & & \\
\hline DK0030068242 & FX LINKED NOTE USD DKK & & & \\
\hline DK0030096961 & FX LINKED NOTE USD DKK & & & \\
\hline
\end{tabular}




\section{THIS CONSENT SOLICITATION MEMORANDUM IS PRIMARILY ADDRESSED TO DIRECT PARTICIPANTS}

By completing and submitting this Filing and Voting Instruction Form (together with proof of holdings), we hereby request a Claim to be filed with the Bankruptcy Trustees for each ISIN we hold (as identified above), for the proportionate share of the LBT Note Valuations applicable to that ISIN and vote IN FAVOUR or AGAINST the Composition Plan.

\section{BY COMPLETING AND SUBMITTING THIS FILING AND VOTING FORM WE HEREBY CERTIFY THAT WE HOLD THE ABOVE SECURITIES AS AT THE RECORD DATE.}

By completing and submitting this Filing and Voting Instruction Form, (together with proof of holdings), we hereby certify to irrevocable appoint the Principal Consent Agent or any of their respective employees to act as proxy to file Claims with the Bankruptcy Trustees and to cast votes relating to the Notes in which we have an interest (as identified above) at the Claims Admission Meeting.

By submitting Filing and Voting Instructions to the Principal Consent Agent, we authorise disclosure of our full details related to our: legal identity, nominal holdings of Notes and VP account details to LBT, the Principal Consent Agent, the Bankruptcy Trustees and, to the extent necessary, the Supervisory Judge and the Dutch Court.

The delivery of a Filing and Voting Instruction (together with proof of holdings) by a Direct Participant will, on acceptance of the Filing and Voting Instruction by the Bankruptcy Trustees and LBT, constitute a binding acceptance of the Direct Participant to the terms and conditions of the Consent Solicitation Memorandum and the Filing and Voting Instruction.

\section{Revoking Votes}

Filing and Voting Instructions may be revoked any time during Consent Solicitation Period. Only the Direct Participant (if applicable on behalf of a Noteholder) that submitted the Filing and Voting Instruction is entitled to revoke such Filing and Voting Instruction previously submitted. Revocation Forms are available from the Principal Consent Agent upon request by email to:

\section{LBT-Consent@list.db.com}

Subject: Debt \& Agency Services re: Revocation Request (Denmark)

Completed Revocation Forms may be delivered at any time during the Consent Solicitation Period to the Principal Consent Agent by email to: 


\section{LBT-Consent@list.db.com}

Subject: Debt \& Agency Services re: Revocation of Previous Instruction (Denmark)

\section{Resubmission of Votes}

Filing and Voting Instructions that have been revoked may be resubmitted before the Expiration Date (together with proof of holdings). Any such Filing and Voting Instruction will be regarded as a new Filing and Voting Instruction. Any revocation and resubmission instructions should be received by the Principal Consent Agent before the Expiration Date.

Authorised signature(s)

Dated:

This form MUST be delivered to the Principal Consent Agent together with proof of holdings by email as a PDF attachment before the Expiration Date.

Deutsche Bank AG, London

Email: LBT-Consent@list.db.com

Subject: Debt \& Agency Services re: LBT Consent Process (Denmark)

The original copies should be sent as soon as possible following submission to the Principal Consent Agent at:

Deutsche Bank AG, London Branch

PO BOX 64399

Winchester House

1 Great Winchester Street

London EC2N 2DB

United Kingdom

Attention: Debt \& Agency Services re: LBT Consent Process (Denmark) 


\section{FILING AND VOTING INSTRUCTION FORM FOR DIRECT PARTICIPANTS ACTING AS NOMINEE FOR NOTES DEPOSITED AND HELD THROUGH VP}

\section{PLEASE COMPLETE THIS FORM IF YOU ARE A NOMINEE ONLY}

\section{PLEASE PRINT CLEARLY}

Legal Name of Nominee as recorded on the register of VP:

Address of Nominee as recorded on the register of VP :

Telephone number of Nominee:

Email address of Nominee:

VP unique Account Number

in which the Notes are held:

Noteholder information (please return one form for each Noteholder):

Legal Name of Noteholder:

Address of Noteholder:

Account Number of Noteholder with Nominee:

\begin{tabular}{|c|c|c|c|c|}
\hline \multicolumn{5}{|c|}{ NOTE DESCRIPTION AND FILING AND VOTING INSTRUCTION } \\
\hline \multirow[t]{2}{*}{ ISIN } & \multirow[t]{2}{*}{ Short Note Description } & \multirow[t]{2}{*}{$\begin{array}{l}\text { please insert } \\
\text { Nominal amount of } \\
\text { Notes being voted } \\
\text { upon per ISIN }\end{array}$} & \multicolumn{2}{|c|}{$\begin{array}{l}\text { please insert a } \checkmark \text { in the } \\
\text { relevant column(s) to } \\
\text { indicate your voting } \\
\text { action }\end{array}$} \\
\hline & & & IN FAVOUR & AGAINST \\
\hline DK0030106190 & USD DKK NOTE & & & \\
\hline DK0030072194 & $\begin{array}{l}2 Y \text { TWIN CLIQUET NOTE } 100 \% \text { CAPITAL } \\
\text { PROTECTED NOTE }\end{array}$ & & & \\
\hline DK0030068242 & FX LINKED NOTE USD DKK & & & \\
\hline DK0030096961 & FX LINKED NOTE USD DKK & & & \\
\hline
\end{tabular}


By completing and submitting this Filing and Voting Instruction Form for Direct Participants acting as Nominee, we hereby request a Claim to be filed with the Bankruptcy Trustees for each ISIN we hold or represent (as identified above), for the proportionate share of the LBT Note Valuations applicable to that ISIN and vote IN FAVOUR or AGAINST the Composition Plan.

BY COMPLETING AND SUBMITTING THIS FILING AND VOTING FORM WE HEREBY CERTIFY THAT WE HOLD THE ABOVE SECURITIES AS AT THE RECORD DATE.

By completing and submitting this Filing and Voting Instruction Form for Direct Participants acting as Nominee, we hereby certify to irrevocable appoint the Principal Consent Agent or any of their respective employees to act as proxy to file Claims with the Bankruptcy Trustees and to cast votes relating to the Notes in which we have an interest (as identified above) at the Claims Admission Meeting.

By submitting this Filing and Voting Instruction Form for Direct Participants acting as Nominee to the Principal Consent Agent, we authorise VP to disclose full details related to our: legal identity, nominal holdings of Notes and VP account details to LBT, the Principal Consent Agent, the Bankruptcy Trustees and, to the extent necessary, the Supervisory Judge and the Dutch Court.

The delivery of a Filing and Voting Instruction Form for Direct Participants acting as Nominee by a Direct Participant will, on acceptance of the Filing and Voting Instruction by the Bankruptcy Trustees and LBT, constitute a binding acceptance of such Direct Participant to the terms and conditions of the Consent Solicitation Memorandum and the Filing and Voting Instruction.

\section{Revoking Votes}

Filing and Voting Instructions may be revoked any time during Consent Solicitation Period. Only the Direct Participant (if applicable, on behalf of a Noteholder) that submitted the Filing and Voting Instruction is entitled to revoke such Filing and Voting Instruction previously submitted. Revocation Forms are available from the Principal Consent Agent upon request by email to:

LBT-Consent@list.db.com

Subject: Debt \& Agency Services re: Revocation Request (Denmark) 
Completed Revocation Forms may be delivered at any time during the Consent Solicitation Period to the Principal Consent Agent by email to:

\section{LBT-Consent@list.db.com}

Subject: Debt \& Agency Services re: Revocation of Previous Instruction (Denmark)

\section{Resubmission of votes}

Filing and Voting Instructions that have been revoked may be resubmitted before the Expiration Date. Any such Filing and Voting Instruction will be regarded as a new Filing and Voting Instruction. Any revocation and resubmission instructions should be received by the Principal Consent Agent before the Expiration Date.

Authorised signature(s)

Dated:

This form MUST be delivered to the Principal Consent Agent by email as a PDF attachment before the Expiration Date.

Deutsche Bank AG, London

Email: LBT-Consent@list.db.com

Subject: Debt \& Agency Services re: LBT Consent Process (Denmark)

The original copy should be sent as soon as possible following submission to the Principal Consent Agent at:

Deutsche Bank AG, London Branch

PO BOX 64399

Winchester House

1 Great Winchester Street

London EC2N 2DB

United Kingdom

Attention: Debt \& Agency Services re: LBT Consent Process (Denmark) 


\section{MARKET SECTION 8}

\section{NOTEHOLDERS THAT HOLD NOTES THROUGH EUROCLEAR SWEDEN WITH ISIN PREFIX "SE"}

\section{(A) GENERAL}

For the purpose of this Market Section 8:

"Nominee" means each Direct Participant at Euroclear Sweden acting as a nominee on behalf of one or more Noteholders.

"Noteholder" means:

(i) each Direct Participant at Euroclear Sweden who holds Notes for its own account; and

(ii) each beneficial owner of Notes holding such Notes in a Euroclear Sweden registered account, directly or indirectly, via a Nominee acting on behalf of such beneficial owner.

Only Direct Participants (including Nominees) are allowed to submit Filing and Voting Instructions as provided for by this Consent Solicitation Memorandum. Noteholders who are not Direct Participants should contact the Nominee through which they hold their Notes to:

(i) inform themselves of any deadlines that may be imposed by the Nominee, with a view to the timely submission of Filing and Voting Instructions on their behalf before the Expiration Date;

(ii) instruct the Nominee to process and submit Filing and Voting Instructions on their behalf in accordance with the Procedure for the Submission of Filing and Voting Instructions set forth under $(\mathrm{C})$ below; and

(iii) supply the Nominee with their name, full legal entity name and any other information required to enable the Nominee to complete the relevant Filing and Voting Instruction (the "Additional Noteholder Information").

\section{(B) RECORD DATE}

Only Noteholders as at close of business on December 7, 2012 (the "Record Date") are eligible to submit instructions (directly or via their Nominee) to file Claims and vote on the Composition Plan. 


\section{THIS CONSENT SOLICITATION MEMORANDUM IS PRIMARILY ADDRESSED TO DIRECT PARTICIPANTS}

\section{(C) PROCEDURE FOR THE SUBMISSION OF FILING AND VOTING INSTRUCTIONS}

Direct Participants that wish to submit a Filing and Voting Instruction with the Principal Consent Agent, whether acting for itself and/or acting on behalf of other Noteholders must do so in accordance with the procedures of Euroclear Sweden as set forth below.

Direct Participants should note that they must allow sufficient time for compliance with the standard operating procedures of Euroclear Sweden in order to ensure delivery of their Electronic Filing and Voting Instructions to the Principal Consent Agent in advance of the Expiration Date.

\section{Electronic Filing and Voting Instructions}

By submitting Electronic Filing and Voting Instructions on an ISIN by ISIN basis, each Direct Participant, whether acting for itself and/or acting on behalf of other Noteholders irrevocable appoints and instructs the Principal Consent Agent to act as proxy to:

(i) file a Claim with the Bankruptcy Trustees for each ISIN that the Direct Participant holds or represents, for the proportionate share of the LBT Note Valuation applicable to that portion of the ISIN held or represented by such Direct Participant and to vote IN FAVOUR of the Composition Plan on the Direct Participant's behalf on the basis of such a Claim filed with the Bankruptcy Trustees; or

(ii) file a Claim with the Bankruptcy Trustees for each ISIN that the Direct Participants holds or represents, for the proportionate share of the LBT Note Valuation applicable to that portion of the ISIN held or represented by such Direct Participant and to vote AGAINST the Composition Plan on the Direct Participants behalf on the basis of such a Claim filed with the Bankruptcy Trustees.

\section{Procedures for submitting Filing and Voting Instructions}

Direct Participants who wish to submit an Electronic Filing and Voting Instruction must do so by using the voting system offered by Euroclear Sweden in accordance with the applicable terms and conditions of Euroclear Sweden and the terms and conditions set forth in this Consent Solicitation Memorandum.

The receipt of an Electronic Filing and Voting Instruction by Euroclear Sweden may be acknowledged in accordance with the standard practices of Euroclear Sweden. For the avoidance of doubt any such acknowledgement does not constitute an acceptance of the Electronic Filing and Voting Instruction by or on behalf of the Bankruptcy Trustees or LBT. 


\section{THIS CONSENT SOLICITATION MEMORANDUM IS PRIMARILY ADDRESSED TO DIRECT PARTICIPANTS}

\section{Revocation and amendment}

An Electronic Filing and Voting Instruction may be revoked by submitting a revocation form to the Principal Consent Agent only on or up until two days after the Expiration Date. Such revocation form can be obtained from the Principal Consent Agent directly. Electronic Filing and Voting Instructions that have been validly revoked cannot be resubmitted.

An Electronic Filing and Voting Instruction may be amended at any time before the Expiration Date between the two voting options, 'in Favour' or 'Against' as previously outlined in this document and in accordance with the terms and conditions set forth in this Consent Solicitation Memorandum.

For any Electronic Filing and Voting Instructions that have been amended, the most recent validly resubmitted Electronic Filing and Voting Instruction will be regarded as a new Electronic Filing and Voting Instruction and the previous instruction will be considered cancelled.

Only the Direct Participant that submitted the Electronic Filing and Voting Instruction is entitled to revoke or amend an Electronic Filing and Voting Instruction previously submitted.

\section{Representations and Warranties}

By submitting Electronic Filing and Voting Instructions pursuant to the procedures and conditions of this Consent Solicitation Memorandum, each Direct Participant:

(i) accepts that it is bound by this Consent Solicitation Memorandum;

(ii) authorises Euroclear Sweden to disclose full details of its name, full legal entity name, Euroclear Sweden's account number and the nominal value of the Notes in respect of which it submitted the Electronic Filing and Voting Instruction, to LBT, the Principal Consent Agent, the Bankruptcy Trustees, and, to the extent necessary, the Supervisory Judge and the Dutch Courts;

(iii) represents and warrants that it is fully authorised to submit such Electronic Filing and Voting Instruction; and

(iv) represents and warrants that all information submitted by it is, to the best of its knowledge, accurate and not misleading.

LBT will rely (a) on all Intermediary Institutions through which the Noteholders hold their Notes, if any, to make similar representations and warranties as those set out under (iii) and (iv) above when they forward the Noteholders' instructions to the Direct Participants or (if there are multiple layers of Intermediary Institutions) the next Intermediary 
THIS CONSENT SOLICITATION MEMORANDUM IS PRIMARILY ADDRESSED TO DIRECT PARTICIPANTS

Institution (as the case may be) and, consequently, (b) on each Direct Participant to actively seek such representations and warranties from the relevant Intermediary Institutions that hold an account with it. 


\section{MARKET SECTION 9}

\section{NOTEHOLDERS THAT HOLD NOTES THROUGH EUROCLEAR FINLAND WITH ISIN PREFIX "FI"}

\section{(A) GENERAL}

For the purpose of this Market Section 9:

"Directly Registered Holder" means: each Direct Participant at Euroclear Finland who holds Notes for its own account.

"Nominee" means each Direct Participant at Euroclear Finland acting as a nominee on behalf of one or more Noteholders.

"Noteholder" means:

(i) each Directly Registered Holder; and

(ii) each beneficial owner of Notes holding such Notes in a Euroclear Finland registered account, directly or indirectly, via a Nominee acting on behalf of such beneficial owner.

Only Direct Participants (Directly Registered Holders and Nominees) are allowed to submit Filing and Voting Instructions as provided for by this Consent Solicitation Memorandum. Noteholders who are not Directly Registered Holders should contact the Nominee through which they hold their Notes to:

(i) inform themselves of any deadlines that may be imposed by the Nominee, with a view to the timely submission of Filing and Voting Instructions on their behalf before the Expiration Date;

(ii) instruct the Nominee to process and submit Filing and Voting Instructions on their behalf in accordance with the Procedure for the Submission of Filing and Voting Instructions set forth under (C) below; and

(iii) supply the Nominee with their name, full legal entity name and any other information required to enable the Nominee to complete the relevant Filing and Voting Instruction (the "Additional Noteholder Information").

\section{(B) RECORD DATE}

Only Noteholders as at close of business on December 7, 2012 (the "Record Date") are eligible to submit instructions (directly or via their Nominee) to file Claims and vote on the Composition Plan. 


\section{THIS CONSENT SOLICITATION MEMORANDUM IS PRIMARILY ADDRESSED TO DIRECT PARTICIPANTS}

\section{(C) PROCEDURE FOR THE SUBMISSION OF FILING AND VOTING INSTRUCTIONS}

Direct Participants that wish to submit a Filing and Voting Instruction to the Principal Consent Agent, whether acting for itself and/or acting on behalf of other Noteholders, must do so in accordance with the procedures of Euroclear Finland as set forth below.

Direct Participants should note that they must allow sufficient time for compliance with the standard operating procedures of Euroclear Finland in order to ensure delivery of their Electronic Filing and Voting Instructions to the Principal Consent Agent in advance of the Expiration Date.

\section{Filing and Voting Instructions}

By submitting Filing and Voting Instructions, each Direct Participant, whether acting for itself and/or acting on behalf of other Noteholders irrevocable appoints and instructs the Principal Consent Agent to act as proxy to:

(i) file a Claim with the Bankruptcy Trustees for each ISIN that the Direct Participant holds or represents, for the proportionate share of the LBT Note Valuation applicable to that portion of the ISIN held or represented by such Direct Participant and to vote IN FAVOUR of the Composition Plan on the Direct Participant's behalf on the basis of such a Claim filed with the Bankruptcy Trustees; or

(ii) file a Claim with the Bankruptcy Trustees for each ISIN that the Direct Participant holds or represents, for the proportionate share of the LBT Note Valuation applicable to that portion of the ISIN held or represented by such Direct Participant and to vote AGAINST the Composition Plan on the Direct Participants behalf on the basis of such a Claim filed with the Bankruptcy Trustees.

Any votes submitted with the option to ABSTAIN will not be taken into account.

\section{Procedures for submitting Filing and Voting Instructions}

The receipt of a Filing and Voting Instruction by Euroclear Finland may be acknowledged in accordance with the standard practices of Euroclear Finland. For the avoidance of doubt any such acknowledgement does not constitute an acceptance of the Filing and Voting Instruction by or on behalf of the Bankruptcy Trustees or LBT.

a) Instructions for Direct Participants holding Notes for their own account

Direct Participants holding Notes for their own account who wish to submit an Filing and Voting Instruction must do so by using the voting system offered by Euroclear Finland 


\section{THIS CONSENT SOLICITATION MEMORANDUM IS PRIMARILY ADDRESSED TO DIRECT PARTICIPANTS}

which can be accessed via a link on the LBT Website:

www.lehmanbrotherstreasury.com.

b) Instructions for Direct Participants acting as Nominee

Direct Participants acting as a Nominee that wish to submit Filing and Voting Instructions on behalf of one or more Noteholders must do so by submitting, or procure submission of, their voting instructions as well as information on the identity of such Noteholders directly to Euroclear Finland at the latest three business days prior to the Expiration Date.

Failure to provide all required information may result in those votes not being taken into account by the Supervisory Judge.

\section{Revocation}

Filing and Voting Instructions may be revoked before the Expiration Date by submitting an instruction to Euroclear Finland in accordance with the applicable terms and conditions of Euroclear Finland and the terms and conditions set forth in this Consent Solicitation Memorandum.

Only the Direct Participant that submitted the Filing and Voting Instruction is entitled to revoke such Filing and Voting Instruction previously submitted.

Filing and Voting Instructions that have been validly revoked may be resubmitted before the Expiration Date. Any such validly resubmitted Filing and Voting Instruction will be regarded as a new Filing and Voting Instruction.

\section{Representations and Warranties}

By submitting Filing and Voting Instructions to the Principal Consent Agent pursuant to the procedures and conditions of this Consent Solicitation Memorandum, each Direct Participant:

(i) accepts that it is bound by this Consent Solicitation Memorandum;

(ii) authorises Euroclear Finland to disclose full details of its name, full legal entity name, Euroclear Finland's account number and the nominal value of the Notes in respect of which it submitted the Electronic Filing and Voting Instruction, to LBT, the Principal Consent Agent, the Bankruptcy Trustees, and, to the extent necessary, the Supervisory Judge and the Dutch Courts;

(iii) represents and warrants that it is fully authorised to submit such Electronic Filing and Voting Instruction; and 
(iv) represents and warrants that all information submitted by it is, to the best of its knowledge, accurate and not misleading.

LBT will rely (a) on all Intermediary Institutions through which the Noteholders hold their Notes, if any, to make similar representations and warranties as those set out under (iii) and (iv) above when they forward the Noteholders' instructions to the Direct Participants or (if there are multiple layers of Intermediary Institutions) the next Intermediary Institution (as the case may be) and, consequently, (b) on each Direct Participant to actively seek such representations and warranties from the relevant Intermediary Institutions that hold an account with it. 


\section{MARKET SECTION 10}

\section{NOTEHOLDERS THAT HOLD NOTES THROUGH COMPUTERSHARE WITH ISIN PREFIX "AU"}

\section{(A) GENERAL}

For the purpose of this Market Section 10:

"Noteholder" means each Direct Registered Holder on the bond register with Computershare.

\section{(B) RECORD DATE}

Only Noteholders who hold Notes on the bond register with Computershare as at close of business on December 7, 2012 (the "Record Date") are eligible to submit Filing and Voting Instructions.

\section{(C) PROCEDURES FOR THE SUBMISSION OF FILING AND VOTING INSTRUCTIONS}

Noteholders who hold Notes on the bond register with Computershare on the Record Date who wish to participate in the Consent Solicitation process should submit, or procure submission of, their Filing and Voting instruction electronically using Computershare's voting system 'Investor Vote'.

Noteholders should note that they must allow sufficient time for compliance with the standard operating procedures of Computershare in order to ensure delivery of their voting instructions to the Principal Consent Agent before the Expiration Date.

\section{Electronic Filing and Voting Instructions}

By submitting Electronic Filing and Voting Instructions, each Noteholder irrevocable appoints and instructs the Principal Consent Agent to act as proxy to:

(i) file a Claim with the Bankruptcy Trustees for each ISIN that the Noteholder holds or represents, for the proportionate share of the LBT Note Valuation applicable to that portion of the ISIN held or represented by such Noteholder and to vote IN FAVOUR of the Composition Plan on the Noteholder's behalf on the basis of such a Claim filed with the Bankruptcy Trustees; or 


\section{THIS CONSENT SOLICITATION MEMORANDUM IS PRIMARILY ADDRESSED TO DIRECT PARTICIPANTS}

(ii) file a Claim with the Bankruptcy Trustees for each ISIN that the Noteholder holds or represents, for the proportionate share of the LBT Note Valuation applicable to that portion of the ISIN held or represented by such Noteholder and to vote AGAINST the Composition Plan on the Noteholder's behalf on the basis of such a Claim filed with the Bankruptcy Trustees.

\section{Procedures for submitting Electronic Filing and Voting Instructions}

Noteholders who wish to submit Electronic Filing and Voting Instructions must do so in accordance with the procedures of Computershare's online voting system 'Investor Vote'.

Noteholders should contact Computershare for participation procedures and deadlines regarding the submission of an Electronic Filing and Voting Instruction and the blocking of the Notes in the relevant accounts in Computershare, as the case may be. The Noteholder must clearly state the aggregate nominal value or number of Notes with respect to which it wishes to submit the Electronic Filing and Voting Instructions.

The receipt of such Electronic Filing and Voting Instructions by Computershare may be acknowledged in accordance with the standard practices of Computershare. For the avoidance of doubt any such acknowledgement does not constitute an acceptance of the Electronic Filing and Voting Instruction by or on behalf of the Bankruptcy Trustees or LBT.

Failure to provide all required information may result in those votes not being taken into account by the Supervisory Judge.

\section{Blocking}

No transfer of Notes may be effected at any time from and including close of business on the Record Date until the earlier of (or as soon as reasonably practicable thereafter):

(i) the date of the termination or withdrawal of the Consent Solicitation; or

(ii) the date the Claims Admission Meeting is concluded.

The submission of Electronic Filing and Voting Instructions will not further restrict the transferability of the Notes. 


\section{Revocation}

Noteholders may cast votes up to the Expiration Date. Noteholders may alter or withdraw the votes that they have cast via the Investor Vote system of Computershare up to the Expiration Date.

\section{Representations and Warranties}

By submitting Electronic Filing and Voting Instructions to the Principal Consent Agent pursuant to the procedures and conditions of this Consent Solicitation Memorandum, the Noteholder:

(i) accepts that it is bound by this Consent Solicitation Memorandum;

(ii) authorises Computershare to disclose full details of its name, full legal entity name, their Computershare investor ID number and the nominal value of the Notes in respect of which it submitted the Electronic Filing and Voting Instruction, on an ISIN by ISIN basis, as the case may be, to LBT, the Principal Consent Agent, the Bankruptcy Trustees, and, to the extent necessary, the Supervisory Judge and the Dutch Courts; and

(iii) represents and warrants that it is fully authorised to submit such Filing and Voting Instruction; and

(iv) that all information submitted by it is, to the best of its knowledge, accurate and not misleading.

\section{Miscellaneous}

Requests for assistance

Any requests for assistance in submitting an Electronic Filing and Voting Instruction should be directed to Computershare at:

Computershare

Yarra Falls, 452 Johnston Street

Abbotsford VIC 3067, Melbourne, Australia

\section{Registry@computershare.com.au}

Telephone: 1800550184 or 0394154133

Attn: Fixed Interest Team 


\section{CONTACT INFORMATION}

\section{LBT / BANKRUPTCY TRUSTEES}

Houthoff Buruma Coöperatief U.A.

P.O. Box 75505

1070 AM Amsterdam

The Netherlands

Telephone: +31(0)206056000

Attn. Curatoren Lehman Brothers Treasury Co. B.V.

Email: info.lbtreasurybv@houthoff.com

\section{PRINCIPAL CONSENT AGENT}

Deutsche Bank AG, London Branch

Winchester House

1 Great Winchester Street

London EC2N 2DB

United Kingdom

Telephone: +44 2075475000

Attn: Debt \& Agency Services

Email: LBT-Consent@list.db.com

\section{US CONSENT AGENT}

DB Services Americas, Inc.

MS JCK01-0218

5022 Gate Parkway, Suite 200

Jacksonville, FL 32256

Telephone: (800) 735-7777 (option \#1)

Email: db.reorg@db.com 
THIS CONSENT SOLICITATION MEMORANDUM IS PRIMARILY ADDRESSED TO

DIRECT PARTICIPANTS

\section{ITALIAN AGENT}

Deutsche Bank S.p.A.

Piazza del Calendario, 3

20126 Milano

Telephone : +390240242991/ 2155

Attn: GTB / SFS Team

Email: sfs.italy@list.db.com 
ANNEX III 


\section{ANNEX III - VSA signatories}

1. AG Super Fund International Partners, L.P.

2. Botticelli, L.L.C.

3. BSOF Master Fund, L.P.

4. Contrarian Capital Management, L.L.C.

5. Cyrus Capital Partners, L.P.

6. M.H. Davidson \& Co.

7. Davidson Kempner Distressed Opportunities Fund, L.P.

8. Davidson Kempner Distressed Opportunities International, L.P.

9. Davidson Kempner European Opportunities Fund, L.P.

10. Davidson Kempner International, Ltd.

11. Davidson Kempner Institutional Partners

12. Davidson Kempner Long-term Opportunities International Master Fund, L.P.

13. Davidson Kempner Long-term Opportunities Fund, L.P.

14. Davidson Kempner Partners

15. Elliott Management Corp.

16. Golden Tree Asset Management, L.P.

17. Goldman, Sachs \& Co.

18. King Street Capital Management, L.P.

19. Knighthead Master Fund L.P.

20. MAP 84 Segregated Portfolio (LMA SPC)

21. Mason Capital Management, L.L.C.

22. Mount Kellett Master Fund II, L.P.

23. Serengeti Asset Management, L.P.

24. Silver Point Capital Fund, L.P.

25. Silver Point Capital Offshore Master Fund, L.P.

26. Silver Point Capital Offshore Fund, Ltd.

27. The Värde Fund V-B, L.P.

28. The Värde Fund VI-A, L.P.

29. The Värde Fund VIII, L.P.

30. The Värde Fund IX, L.P.

31. The Värde Fund $X$ (Master), L.P.

32. The Värde Fund VII-B, L.P.

33. The Värde Fund IX-A, L.P.

34. Värde Investment Partners (Offshore) Master, L.P.

35. Värde Investment Partners, L.P.

36. York Capital Management Global Advisors, L.L.C. 
ANNEX IV 
Lehman Brothers Holdings Inc.

1271 Avenue of the Americas

New York, New York 10019

December 5, 2012

Rutger J. Schimmelpenninck and Frédéric Verhoeven, curatoren van Lehman Brothers Treasury Co. B.V.

Houthoff Buruma

PO Box 75505

NL-1070 AM Amsterdam

the Netherlands

Gentlemen:

Reference is made to that certain settlement agreement dated August 30, 2011, among the Debtors and the LBT Trustees (the "Settlement Agreement"). Capitalized terms used but not defined herein shall have the meanings ascribed to them in the Settlement Agreement. On December 5, 2012, LBT made available the Composition Plan for Lehman Brothers Treasury Co. B.V. (the "LBT Composition Plan"). In accordance with section 3(a)(3) of the Settlement Agreement, the Debtors support approval of the LBT Composition Plan.

Nothing herein should be deemed to be an admission or waiver of any rights, claims and defenses of the Debtors including those arising under the Settlement Agreement.

LEHMAN BROTHERS HOLDINGS INC., as Plan Administrator for the Debtors

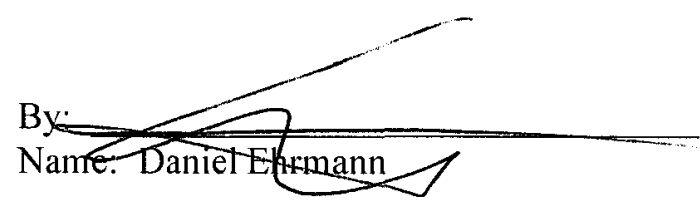


ANNEX V 


\section{Annex V}

Final List of LBT Note Valuations (5 December 2012)

\begin{tabular}{|c|c|c|c|c|}
\hline ISIN & Currency & $\begin{array}{l}\text { Maturity } \\
\text { date }\end{array}$ & $\begin{array}{c}\text { Admissible } \\
\text { Amount in EUR }\end{array}$ & $\begin{array}{c}\text { Admissible } \\
\text { Amount \% }\end{array}$ \\
\hline XS0320100323 & USD & 14-Sep-2008 & $1,100,352$ & $100.0000 \%$ \\
\hline XS0290596161 & EUR & 15-Sep-2008 & $2,904,948$ & $57.5010 \%$ \\
\hline XS0319739537 & SGD & 15-Sep-2008 & 736,226 & $77.2960 \%$ \\
\hline XS0319817788 & USD & 15-Sep-2008 & 427,558 & $31.5052 \%$ \\
\hline XS0320033466 & USD & 15-Sep-2008 & 548,372 & $41.5300 \%$ \\
\hline $\mathrm{CH} 0039308686$ & USD & 16-Sep-2008 & $9,371,319$ & $58.0681 \%$ \\
\hline XS0154706153 & EUR & 16-Sep-2008 & $11,133,350$ & $104.0500 \%$ \\
\hline XS0228314885 & JPY & 16-Sep-2008 & 114,898 & $11.2031 \%$ \\
\hline XS0260439210 & AUD & 16-Sep-2008 & $1,297,706$ & $48.7548 \%$ \\
\hline XS0291463221 & JPY & 16-Sep-2008 & 472,373 & $65.9008 \%$ \\
\hline XS0350116330 & HKD & 16-Sep-2008 & 855,710 & $47.6815 \%$ \\
\hline XS0350116843 & HKD & 16-Sep-2008 & 338,984 & $47.8515 \%$ \\
\hline XS0378248529 & HKD & 17-Sep-2008 & 472,273 & $100.0000 \%$ \\
\hline XS0320521429 & USD & 18-Sep-2008 & 565,939 & $70.1353 \%$ \\
\hline XS0369673073 & USD & 18-Sep-2008 & 383,656 & $104.6000 \%$ \\
\hline XS0383076493 & HKD & 18-Sep-2008 & 220,889 & $77.9523 \%$ \\
\hline XS0359370722 & JPY & 19-Sep-2008 & 747,920 & $103.7200 \%$ \\
\hline XS0371594762 & USD & 19-Sep-2008 & 483,148 & $102.7500 \%$ \\
\hline XS0378981806 & HKD & 19-Sep-2008 & 307,951 & $108.6770 \%$ \\
\hline XS0268077780 & USD & 22-Sep-2008 & 735,544 & $100.2694 \%$ \\
\hline XS0290556454 & JPY & 22-Sep-2008 & 839,226 & $55.7526 \%$ \\
\hline XS0311685209 & USD & 22-Sep-2008 & $5,960,974$ & $101.5750 \%$ \\
\hline XS0320033540 & USD & 23-Sep-2008 & 683,239 & $93.1392 \%$ \\
\hline XS0290770378 & JPY & 24-Sep-2008 & 226,629 & $52.6424 \%$ \\
\hline XS0290976157 & JPY & 24-Sep-2008 & 275,352 & $38.1141 \%$ \\
\hline XS0291657004 & JPY & 24-Sep-2008 & 185,257 & $51.6904 \%$ \\
\hline XS0291905858 & JPY & 24-Sep-2008 & 176,881 & $49.3532 \%$ \\
\hline XS0292220455 & JPY & 24-Sep-2008 & 179,223 & $50.0068 \%$ \\
\hline XS0321317603 & EUR & 24-Sep-2008 & 670,984 & $67.0984 \%$ \\
\hline XS0321795170 & $\mathrm{CHF}$ & 24-Sep-2008 & 847,684 & $41.1286 \%$ \\
\hline XS0360517105 & JPY & 24-Sep-2008 & 746,610 & $104.0556 \%$ \\
\hline XS0361311102 & JPY & 24-Sep-2008 & 611,435 & $84.8364 \%$ \\
\hline XS0380276971 & HKD & 24-Sep-2008 & 234,393 & $82.7182 \%$ \\
\hline XS0261613474 & AUD & 25-Sep-2008 & $1,429,248$ & $53.6969 \%$ \\
\hline XS0380268952 & HKD & 25-Sep-2008 & 283,364 & $100.0000 \%$ \\
\hline XS0380275908 & HKD & 25-Sep-2008 & 245,691 & $86.7052 \%$ \\
\hline XS0384984018 & $\mathrm{HKD}$ & 26-Sep-2008 & 377,818 & $100.0000 \%$ \\
\hline XS0384984281 & HKD & 26 -Sep-2008 & 377,818 & $100.0000 \%$ \\
\hline XS0322064840 & EUR & 27-Sep-2008 & $1,600,000$ & $100.0000 \%$ \\
\hline XS0322265157 & USD & 28-Sep-2008 & $1,169,562$ & $53.1449 \%$ \\
\hline XS0268033908 & EUR & 29-Sep-2008 & $3,535,000$ & $101.0000 \%$ \\
\hline XS0268789939 & GBP & 29-Sep-2008 & 962,045 & $59.8199 \%$ \\
\hline XS0322031591 & USD & 29-Sep-2008 & 499,309 & $45.3772 \%$ \\
\hline 52519VAD8 & USD & 30-Sep-2008 & $1,379,034$ & $121.2838 \%$ \\
\hline XS0323826221 & USD & 30-Sep-2008 & 810,741 & $7.1211 \%$ \\
\hline XS0381368280 & HKD & 30-Sep-2008 & 382,728 & $90.0441 \%$ \\
\hline XS0381368363 & HKD & 30-Sep-2008 & 283,364 & $100.0000 \%$ \\
\hline XS0381371664 & HKD & 30-Sep-2008 & 259,672 & $91.6391 \%$ \\
\hline XS0262585374 & AUD & 2-Oct-2008 & $1,451,867$ & $54.5467 \%$ \\
\hline XS0322469403 & SGD & 2-Oct-2008 & $3,433,744$ & $88.3824 \%$ \\
\hline XS0381364966 & HKD & 2-Oct-2008 & 595,530 & $90.0705 \%$ \\
\hline XS0381438919 & HKD & 2-Oct-2008 & 244,548 & $86.3017 \%$ \\
\hline XS0352986813 & HKD & 3-Oct-2008 & 914,818 & $80.0436 \%$ \\
\hline XS0381855781 & HKD & 3-Oct-2008 & 241,003 & $85.0507 \%$ \\
\hline XS0382187945 & HKD & 3-Oct-2008 & 367,968 & $77.9142 \%$ \\
\hline XS0382188083 & HKD & 3-Oct-2008 & 272,380 & $82.3918 \%$ \\
\hline XS0382188166 & HKD & 3-Oct-2008 & 447,961 & $79.0434 \%$ \\
\hline XS0270328858 & USD & 6-Oct-2008 & $3,250,257$ & $119.7500 \%$ \\
\hline XS0323619600 & $\mathrm{CHF}$ & 8-Oct-2008 & $7,818,756$ & $116.0000 \%$ \\
\hline XS0323619782 & $\mathrm{CHF}$ & 8-Oct-2008 & $1,615,355$ & $114.0000 \%$ \\
\hline XS0324723203 & USD & 8-Oct-2008 & 244,412 & $66.6364 \%$ \\
\hline XS0382588001 & HKD & 8-Oct-2008 & 179,606 & $63.3834 \%$ \\
\hline XS0382588340 & HKD & 8-Oct-2008 & 340,862 & $72.1748 \%$ \\
\hline XS0323643063 & USD & 9-Oct-2008 & $2,502,003$ & $51.5742 \%$ \\
\hline XS0323869205 & USD & 9-Oct-2008 & 94,992 & $8.2743 \%$ \\
\hline XS0375559753 & USD & 9-Oct-2008 & $73,375,690$ & $100.0257 \%$ \\
\hline XS0180383662 & USD & $10-$ Oct-2008 & $5,176,829$ & $100.8151 \%$ \\
\hline XS0374062528 & USD & $10-$ Oct-2008 & 382,372 & $104.2500 \%$ \\
\hline XS0374191251 & USD & 10-Oct-2008 & 380,905 & $103.8500 \%$ \\
\hline XS0383457453 & HKD & 10-Oct-2008 & 275,699 & $72.9714 \%$ \\
\hline XS0384213442 & HKD & $10-$ Oct-2008 & 373,919 & $98.9680 \%$ \\
\hline XS0385755979 & JPY & 10-Oct-2008 & 558,403 & $77.9028 \%$ \\
\hline XS0374326105 & USD & $13-O c t-2008$ & 381,089 & $103.9000 \%$ \\
\hline XS0295438369 & EUR & 14-Oct-2008 & $4,514,368$ & $103.1384 \%$ \\
\hline
\end{tabular}




\begin{tabular}{|c|c|c|c|c|}
\hline ISIN & Currency & $\begin{array}{l}\text { Maturity } \\
\text { date }\end{array}$ & $\begin{array}{c}\text { Admissible } \\
\text { Amount in EUR }\end{array}$ & $\begin{array}{c}\text { Admissible } \\
\text { Amount \% }\end{array}$ \\
\hline XS0383378071 & USD & 15-Oct-2008 & 399,270 & $49.2121 \%$ \\
\hline XS0383554655 & HKD & 15-Oct-2008 & 226,451 & $79.9153 \%$ \\
\hline XS0383554812 & HKD & 15-Oct-2008 & 271,151 & $95.6901 \%$ \\
\hline XS0177644621 & EUR & $16-$-Oct-2008 & 396,000 & $90.0000 \%$ \\
\hline XS0324583607 & USD & $16-$ Oct-2008 & $2,200,704$ & $100.0000 \%$ \\
\hline XS0386289929 & JPY & 16-Oct-2008 & 576,494 & $80.4267 \%$ \\
\hline XS0271187634 & USD & 17-Oct-2008 & $1,063,911$ & $120.8602 \%$ \\
\hline XS0294645535 & JPY & 17-Oct-2008 & 130,544 & $36.4244 \%$ \\
\hline XS0294646426 & JPY & $17-$ Oct-2008 & 137,209 & $38.2842 \%$ \\
\hline XS0325077864 & USD & 17-Oct-2008 & $2,566,812$ & $55.9852 \%$ \\
\hline XS0326402731 & USD & 17-Oct-2008 & $1,516,808$ & $51.6928 \%$ \\
\hline XS0377054381 & USD & 17-Oct-2008 & 319,313 & $21.7644 \%$ \\
\hline XS0231644260 & USD & 20-Oct-2008 & 714,183 & $101.4139 \%$ \\
\hline XS0264130369 & AUD & 20-Oct-2008 & $1,487,602$ & $55.8892 \%$ \\
\hline XS0271188285 & AUD & $20-$ Oct-2008 & $1,130,408$ & $30.3353 \%$ \\
\hline XS0325790276 & USD & $20-$ Oct-2008 & $28,692,229$ & $79.0726 \%$ \\
\hline XS0359724472 & USD & 22-Oct-2008 & 225,260 & $61.4149 \%$ \\
\hline XS0384368485 & USD & 22-Oct-2008 & 795,829 & $58.5469 \%$ \\
\hline US52519VAR78 & USD & 23-Oct-2008 & $7,685,465$ & $82.4947 \%$ \\
\hline XS0326172557 & USD & 23-Oct-2008 & $2,015,965$ & $62.4583 \%$ \\
\hline XS0326172631 & GBP & 23-Oct-2008 & $3,485,488$ & $33.8637 \%$ \\
\hline XS0356499052 & USD & 23-Oct-2008 & 696,217 & $63.2722 \%$ \\
\hline XS0232035534 & $\mathrm{CHF}$ & $24-$ Oct-2008 & $4,682,832$ & $104.9901 \%$ \\
\hline XS0232035880 & EUR & $24-O c t-2008$ & $4,631,460$ & $105.9831 \%$ \\
\hline XS0232037159 & USD & $24-$ Oct-2008 & $3,525,351$ & $107.4873 \%$ \\
\hline XS0271522442 & JPY & 24-Oct-2008 & 865,044 & $36.0246 \%$ \\
\hline XS0326264750 & EUR & 24-Oct-2008 & 587,652 & $64.7193 \%$ \\
\hline XS0326490843 & USD & 24-Oct-2008 & 946,374 & $43.0032 \%$ \\
\hline XS0328465306 & GBP & $25-$ Oct-2008 & $1,438,317$ & $48.6060 \%$ \\
\hline XS0137335468 & USD & 26 -Oct-2008 & $2,095,424$ & $100.2274 \%$ \\
\hline XS0324841153 & USD & 26-Oct-2008 & $9,186,972$ & $108.0000 \%$ \\
\hline XS0327847553 & HKD & $27-$ Oct-2008 & 556,307 & $29.3750 \%$ \\
\hline XS0328210496 & HKD & $29-$ Oct-2008 & 187,913 & $24.8681 \%$ \\
\hline XS0327234380 & USD & 30-Oct-2008 & 242,816 & $14.3916 \%$ \\
\hline XS0327235783 & AUD & 30-Oct-2008 & $1,784,566$ & $53.2112 \%$ \\
\hline XS0378451917 & USD & $30-$ Oct-2008 & 253,742 & $69.1804 \%$ \\
\hline XS0378452303 & USD & 30-Oct-2008 & 191,476 & $52.2039 \%$ \\
\hline XS0378480692 & USD & $30-$ Oct-2008 & 277,245 & $75.5879 \%$ \\
\hline XS0379577397 & USD & 30-Oct-2008 & 678,772 & $92.5302 \%$ \\
\hline XS0272349332 & USD & 31-Oct-2008 & $1,866,417$ & $38.8443 \%$ \\
\hline XS0272577809 & EUR & $31-O c t-2008$ & 289,481 & $38.5975 \%$ \\
\hline XS0386716269 & HKD & 31-Oct-2008 & 310,686 & $82.2316 \%$ \\
\hline XS0251155205 & USD & 2-Nov-2008 & 848,472 & $111.2151 \%$ \\
\hline XS0272915116 & USD & 3-Nov-2008 & $1,880,286$ & $88.3864 \%$ \\
\hline XS0273083096 & USD & 3-Nov-2008 & 700,924 & $79.6249 \%$ \\
\hline XS0304593857 & EUR & 3-Nov-2008 & 898,203 & $179.6407 \%$ \\
\hline XS0327847801 & USD & 3-Nov-2008 & 368,453 & $32.4048 \%$ \\
\hline XS0329337850 & HKD & 3-Nov-2008 & $1,373,996$ & $30.2740 \%$ \\
\hline XS0297488883 & HKD & 5-Nov-2008 & 414,611 & $48.7726 \%$ \\
\hline XS0273584382 & USD & 6-Nov-2008 & $3,889,094$ & $106.0323 \%$ \\
\hline XS0328586358 & USD & 6-Nov-2008 & 225,080 & $30.6829 \%$ \\
\hline XS0329714074 & HKD & 6-Nov-2008 & $1,530,416$ & $28.7027 \%$ \\
\hline XS0328209480 & JPY & 7-Nov-2008 & 360,244 & $25.0932 \%$ \\
\hline XS0382037975 & USD & 7-Nov-2008 & 252,613 & $51.0166 \%$ \\
\hline XS0363204602 & USD & 9-Nov-2008 & 100,220 & $27.3239 \%$ \\
\hline XS0273904044 & GBP & 10-Nov-2008 & 274,612 & $13.3401 \%$ \\
\hline XS0326046504 & USD & 10-Nov-2008 & $3,176,937$ & $108.0000 \%$ \\
\hline XS0330074344 & USD & 10-Nov-2008 & $2,722,752$ & $51.0544 \%$ \\
\hline XS0381626679 & USD & 12-Nov-2008 & 531,567 & $72.4632 \%$ \\
\hline XS0382626967 & USD & 12-Nov-2008 & 161,679 & $36.7335 \%$ \\
\hline XS0273921568 & HKD & 13-Nov-2008 & $1,089,189$ & $60.6913 \%$ \\
\hline XS0329628829 & USD & 13-Nov-2008 & $2,174,437$ & $52.9320 \%$ \\
\hline XS0330867846 & HKD & $13-N o v-2008$ & $1,481,819$ & $32.6837 \%$ \\
\hline XS0274497279 & GBP & 14-Nov-2008 & 196,960 & $11.3398 \%$ \\
\hline XS0329714231 & USD & 14-Nov-2008 & 247,284 & $28.0914 \%$ \\
\hline XS0329714314 & EUR & 14-Nov-2008 & 728,609 & $48.5739 \%$ \\
\hline XS0329804735 & USD & 14-Nov-2008 & $1,608,401$ & $62.6449 \%$ \\
\hline XS0274445120 & $\mathrm{CHF}$ & 17-Nov-2008 & $3,540,513$ & $100.0000 \%$ \\
\hline XS0330074930 & USD & 17-Nov-2008 & 313,080 & $42.6791 \%$ \\
\hline XS0330421834 & HKD & 17-Nov-2008 & 698,158 & $27.3758 \%$ \\
\hline XS0331039569 & USD & $17-$ Nov-2008 & $31,101,913$ & $59.3196 \%$ \\
\hline XS0331400456 & USD & 17-Nov-2008 & $4,139,729$ & $42.7197 \%$ \\
\hline XS0331661172 & HKD & 17-Nov-2008 & $2,714,429$ & $62.7466 \%$ \\
\hline XS0331195932 & USD & 19-Nov-2008 & $3,959,020$ & $71.9591 \%$ \\
\hline XS0235648747 & USD & 20-Nov-2008 & $5,444,467$ & $49.4793 \%$ \\
\hline XS0330867689 & USD & 21-Nov-2008 & 366,784 & $100.0000 \%$ \\
\hline $\mathrm{CH} 0039308660$ & $\mathrm{CHF}$ & 22-Nov-2008 & 326,453 & $50.6851 \%$ \\
\hline XS0234972981 & $\mathrm{CHF}$ & 24-Nov-2008 & $2,829,965$ & $25.9853 \%$ \\
\hline XS0271794363 & SEK & 24-Nov-2008 & $1,123,351$ & $100.0000 \%$ \\
\hline
\end{tabular}




\begin{tabular}{|c|c|c|c|c|}
\hline ISIN & Currency & $\begin{array}{l}\text { Maturity } \\
\text { date }\end{array}$ & $\begin{array}{c}\text { Admissible } \\
\text { Amount in EUR }\end{array}$ & $\begin{array}{c}\text { Admissible } \\
\text { Amount \% }\end{array}$ \\
\hline XS0271795840 & SEK & 24-Nov-2008 & 667,799 & $100.0000 \%$ \\
\hline XS0329609449 & USD & 24-Nov-2008 & $148,497,047$ & $101.2156 \%$ \\
\hline XS0330206789 & USD & 24-Nov-2008 & 573,186 & $55.8119 \%$ \\
\hline \begin{tabular}{|l|} 
XS0331399856 \\
\end{tabular} & EUR & 24-Nov-2008 & 760,910 & $58.5315 \%$ \\
\hline XS0331399930 & USD & 24-Nov-2008 & 685,768 & $60.3122 \%$ \\
\hline \begin{tabular}{|l} 
XS0332546448 \\
\end{tabular} & HKD & 24-Nov-2008 & 612,776 & $31.6465 \%$ \\
\hline \begin{tabular}{|l} 
XS0332547099 \\
\end{tabular} & USD & 24-Nov-2008 & $1,408,142$ & $34.9014 \%$ \\
\hline XS0364513787 & USD & 24-Nov-2008 & 456,147 & $65.4546 \%$ \\
\hline XS0332136380 & USD & 26-Nov-2008 & $9,009,942$ & $59.7885 \%$ \\
\hline \begin{tabular}{|l|} 
XS0332185676 \\
\end{tabular} & USD & 26-Nov-2008 & $16,010,193$ & $59.1407 \%$ \\
\hline XS0275536307 & USD & 28-Nov-2008 & 251,717 & $57.1900 \%$ \\
\hline XS0275725611 & USD & 28-Nov-2008 & $1,387,975$ & $62.0357 \%$ \\
\hline XS0275726007 & USD & 28-Nov-2008 & $1,429,345$ & $59.9533 \%$ \\
\hline \begin{tabular}{|l|} 
XS0276148508 \\
\end{tabular} & HKD & 28-Nov-2008 & $1,095,787$ & $61.0590 \%$ \\
\hline \begin{tabular}{|l|} 
XS0333308632 \\
\end{tabular} & USD & 28-Nov-2008 & 993,541 & $52.4959 \%$ \\
\hline \begin{tabular}{|l|} 
XS0332848372 \\
\end{tabular} & USD & 30-Nov-2008 & 190,728 & $20.0000 \%$ \\
\hline \begin{tabular}{|l|} 
XS0275924578 \\
\end{tabular} & USD & 1-Dec-2008 & $1,575,239$ & $61.3533 \%$ \\
\hline \begin{tabular}{|l|} 
XS0275925112 \\
\end{tabular} & USD & 1-Dec-2008 & 965,047 & $61.1885 \%$ \\
\hline XS0276121307 & EUR & 1-Dec-2008 & $9,500,000$ & $100.0000 \%$ \\
\hline \begin{tabular}{|l|} 
XS0276139341 \\
\end{tabular} & USD & 1-Dec-2008 & $3,720,032$ & $62.2227 \%$ \\
\hline $\begin{array}{l}\text { XS0276149738 } \\
\end{array}$ & USD & 1-Dec-2008 & $2,064,492$ & $61.8531 \%$ \\
\hline XS0276286993 & HKD & 1-Dec-2008 & $1,853,608$ & $61.3260 \%$ \\
\hline \begin{tabular}{|l|} 
XS0301886247 \\
\end{tabular} & USD & 1-Dec-2008 & 259,810 & $37.2814 \%$ \\
\hline \begin{tabular}{|l|} 
XS0301979331 \\
\end{tabular} & USD & 1-Dec-2008 & 480,656 & $107.4148 \%$ \\
\hline \begin{tabular}{|l|} 
XS0332134179 \\
\end{tabular} & USD & 1-Dec-2008 & 287,697 & $29.2678 \%$ \\
\hline \begin{tabular}{|l|} 
XS0332762904 \\
\end{tabular} & USD & 1-Dec-2008 & 526,424 & $59.8018 \%$ \\
\hline XS0334090106 & HKD & 1-Dec-2008 & 408,380 & $54.0445 \%$ \\
\hline \begin{tabular}{|l|} 
XS0334223699 \\
\end{tabular} & HKD & 1-Dec-2008 & 362,581 & $41.2761 \%$ \\
\hline XS0180580226 & USD & 3-Dec-2008 & $11,382,979$ & $102.0873 \%$ \\
\hline XS0180580572 & HKD & 3-Dec-2008 & $24,106,612$ & $102.0876 \%$ \\
\hline \begin{tabular}{|l}
$\mathrm{XS} 0332762227$ \\
\end{tabular} & $\mathrm{HKD}$ & 3-Dec-2008 & $1,053,379$ & $65.6014 \%$ \\
\hline \begin{tabular}{|l|} 
XS0334088118 \\
\end{tabular} & GBP & 3-Dec-2008 & 361,170 & $40.1028 \%$ \\
\hline \begin{tabular}{|l|} 
XS0334090288 \\
\end{tabular} & USD & 3-Dec-2008 & 326,516 & $44.5107 \%$ \\
\hline \begin{tabular}{|l|}
$X S 0276437521$ \\
\end{tabular} & USD & 4-Dec-2008 & $1,884,698$ & $58.3914 \%$ \\
\hline XS0276444147 & USD & 4-Dec-2008 & $1,797,300$ & $57.6489 \%$ \\
\hline \begin{tabular}{|l|} 
XS0276598538 \\
\end{tabular} & USD & 5-Dec-2008 & $1,283,976$ & $60.3557 \%$ \\
\hline \begin{tabular}{|l|}
$X S 0276599346$ \\
\end{tabular} & USD & 5-Dec-2008 & $1,686,259$ & $59.7067 \%$ \\
\hline XS0276600292 & USD & 5-Dec-2008 & $2,510,242$ & $60.0344 \%$ \\
\hline XS0276793311 & USD & 5-Dec-2008 & 443,268 & $35.5449 \%$ \\
\hline \begin{tabular}{|l|} 
XS0334702072 \\
\end{tabular} & USD & 5-Dec-2008 & 276,082 & $24.9242 \%$ \\
\hline \begin{tabular}{|l|} 
XS0158383454 \\
\end{tabular} & EUR & 6-Dec-2008 & $29,500,000$ & $118.0000 \%$ \\
\hline XS0277181243 & USD & 8-Dec-2008 & $1,400,817$ & $61.5998 \%$ \\
\hline \begin{tabular}{|l|} 
XS0304977910 \\
\end{tabular} & USD & 8-Dec-2008 & 733,568 & $100.0000 \%$ \\
\hline \begin{tabular}{|l} 
XS0334923322 \\
\end{tabular} & HKD & 8-Dec-2008 & $1,142,560$ & $52.4790 \%$ \\
\hline XS0368097951 & USD & 11-Dec-2008 & 709,216 & $84.0699 \%$ \\
\hline \begin{tabular}{|l|} 
XS0368098173 \\
\end{tabular} & USD & $11-$ Dec-2008 & 350,142 & $95.4626 \%$ \\
\hline XS0368098256 & HKD & 11-Dec-2008 & 230,262 & $81.2603 \%$ \\
\hline \begin{tabular}{|l|} 
XS0303176456 \\
\end{tabular} & JPY & 12-Dec-2008 & 68,139 & $19.0122 \%$ \\
\hline \begin{tabular}{|l} 
XS0335742663 \\
\end{tabular} & USD & 12-Dec-2008 & 882,931 & $48.5327 \%$ \\
\hline \begin{tabular}{|l}
$\mathrm{XS} 0334656617$ \\
\end{tabular} & USD & 13-Dec-2008 & 209,449 & $28.5521 \%$ \\
\hline \begin{tabular}{|l|} 
XS0336129589 \\
\end{tabular} & USD & 14-Dec-2008 & 11,626 & $1.5849 \%$ \\
\hline XS0336130835 & USD & 14-Dec-2008 & 10,441 & $0.0150 \%$ \\
\hline \begin{tabular}{|l|} 
XS0278216691 \\
\end{tabular} & EUR & 15-Dec-2008 & $1,000,000$ & $100.0000 \%$ \\
\hline XS0336250732 & HKD & 15-Dec-2008 & 959,239 & $48.8248 \%$ \\
\hline XS0335127089 & JPY & $18-$ Dec-2008 & 146,657 & $20.3888 \%$ \\
\hline XS0335346556 & EUR & 18-Dec-2008 & 855,525 & $68.4420 \%$ \\
\hline \begin{tabular}{|l|} 
XS0336644199 \\
\end{tabular} & USD & 18-Dec-2008 & $1,119,685$ & $55.7064 \%$ \\
\hline \begin{tabular}{|l|} 
XS0335623491 \\
\end{tabular} & USD & 19-Dec-2008 & $1,186,400$ & $58.8109 \%$ \\
\hline \begin{tabular}{|l|} 
XS0336928030 \\
\end{tabular} & HKD & 19-Dec-2008 & $1,496,242$ & $54.4360 \%$ \\
\hline XS0225522365 & USD & 20-Dec-2008 & $10,193,663$ & $102.9333 \%$ \\
\hline \begin{tabular}{|l} 
XS0226116746 \\
\end{tabular} & USD & 20-Dec-2008 & $4,951,555$ & $102.7391 \%$ \\
\hline XS0336336531 & USD & 20-Dec-2008 & $5,717,419$ & $82.0420 \%$ \\
\hline XS0336336960 & USD & 20-Dec-2008 & 40,040 & $3.6389 \%$ \\
\hline XS0121110455 & EUR & 22-Dec-2008 & $3,409,030$ & $70.8738 \%$ \\
\hline \begin{tabular}{|l|} 
XS0183025609 \\
\end{tabular} & USD & $22-$ Dec-2008 & $3,704,115$ & $100.9890 \%$ \\
\hline \begin{tabular}{|l|} 
XS0207884379 \\
\end{tabular} & USD & 22-Dec-2008 & $1,346,023$ & $54.1268 \%$ \\
\hline XS0336249643 & USD & 22-Dec-2008 & 412,345 & $31.2283 \%$ \\
\hline XS0337406036 & USD & 22-Dec-2008 & 803,640 & $54.7761 \%$ \\
\hline \begin{tabular}{|l|} 
XS0368700109 \\
\end{tabular} & HKD & 22-Dec-2008 & $3,739,662$ & $64.9585 \%$ \\
\hline \begin{tabular}{|l|} 
XS0336416309 \\
\end{tabular} & USD & 24-Dec-2008 & 229,867 & $31.3355 \%$ \\
\hline XS0336573406 & USD & 24-Dec-2008 & 535,771 & $31.0793 \%$ \\
\hline XS0308085330 & USD & $26-$ Dec-2008 & $1,542,979$ & $105.1694 \%$ \\
\hline \begin{tabular}{|l}
$\mathrm{XS} 0372823673$ \\
\end{tabular} & USD & $26-$ Dec-2008 & 374,333 & $72.8986 \%$ \\
\hline \begin{tabular}{|l|} 
XS0337617327 \\
\end{tabular} & USD & 28-Dec-2008 & 341,759 & $26.6221 \%$ \\
\hline \begin{tabular}{|l|}
$X S 0121503774$ \\
\end{tabular} & EUR & 29-Dec-2008 & $6,152,036$ & $69.7510 \%$ \\
\hline \begin{tabular}{|l|}
$X S 0122516296$ \\
\end{tabular} & EUR & 29-Dec-2008 & $4,491,207$ & $69.4159 \%$ \\
\hline \begin{tabular}{|l|} 
XS0122516379 \\
\end{tabular} & USD & 29-Dec-2008 & $3,000,314$ & $70.2754 \%$ \\
\hline XS0280241851 & USD & 29-Dec-2008 & $1,833,920$ & $100.0000 \%$ \\
\hline XS0307390608 & USD & 29-Dec-2008 & 570,235 & $62.1876 \%$ \\
\hline
\end{tabular}




\begin{tabular}{|c|c|c|c|c|}
\hline ISIN & Currency & $\begin{array}{l}\text { Maturity } \\
\text { date }\end{array}$ & $\begin{array}{c}\text { Admissible } \\
\text { Amount in EUR }\end{array}$ & $\begin{array}{c}\text { Admissible } \\
\text { Amount \% } \\
\end{array}$ \\
\hline XS0336927818 & USD & 29-Dec-2008 & 596,377 & $54.1987 \%$ \\
\hline XS0337553258 & USD & 29-Dec-2008 & 274,030 & $37.3557 \%$ \\
\hline \begin{tabular}{|l|l}
$X S 0373182566$ \\
\end{tabular} & JPY & 29-Dec-2008 & $3,583,972$ & $100.0000 \%$ \\
\hline XS0208110055 & EUR & 30-Dec-2008 & 7,058 & $14.1157 \%$ \\
\hline \begin{tabular}{|l|} 
XS0230752882 \\
\end{tabular} & EUR & 30-Dec-2008 & $10,168,003$ & $101.6800 \%$ \\
\hline XS0238679079 & $\mathrm{CHF}$ & 30-Dec-2008 & $6,640,763$ & $114.5645 \%$ \\
\hline XS0238681307 & $\mathrm{CHF}$ & 30-Dec-2008 & $4,485,847$ & $77.3862 \%$ \\
\hline \begin{tabular}{|l|} 
XS0165668459 \\
\end{tabular} & USD & 31-Dec-2008 & $43,756,621$ & $105.5735 \%$ \\
\hline \begin{tabular}{|l} 
XS0337553761 \\
\end{tabular} & USD & 31-Dec-2008 & 520,028 & $59.0752 \%$ \\
\hline \begin{tabular}{|l|} 
XS0338330672 \\
\end{tabular} & HKD & 31-Dec-2008 & 748,035 & $43.2761 \%$ \\
\hline \begin{tabular}{|l|} 
XS0281184498 \\
\end{tabular} & HKD & 5-Jan-2009 & $1,005,985$ & $106.5047 \%$ \\
\hline \begin{tabular}{|l|l} 
XS0293784525 \\
\end{tabular} & EUR & 5-Jan-2009 & $5,861,873$ & $15.0304 \%$ \\
\hline \begin{tabular}{|l|} 
XS0335143102 \\
\end{tabular} & NZD & 5-Jan-2009 & 599,012 & $71.3390 \%$ \\
\hline \begin{tabular}{|l|} 
XS0338329740 \\
\end{tabular} & USD & 5-Jan-2009 & 641,823 & $76.0812 \%$ \\
\hline \begin{tabular}{|l} 
XS0338524795 \\
\end{tabular} & USD & 5-Jan-2009 & 713,060 & $63.1400 \%$ \\
\hline \begin{tabular}{|l|} 
XS0338676629 \\
\end{tabular} & USD & 5-Jan-2009 & 438,652 & $74.7462 \%$ \\
\hline XS0238861115 & JPY & 6-Jan-2009 & 786,369 & $60.5376 \%$ \\
\hline \begin{tabular}{|l|} 
XS0306849158 \\
\end{tabular} & JPY & 6-Jan-2009 & 346,326 & $48.3160 \%$ \\
\hline \begin{tabular}{|l|} 
XS0338525099 \\
\end{tabular} & USD & 7-Jan-2009 & 266,296 & $33.0014 \%$ \\
\hline \begin{tabular}{|l|l} 
XS0352110554 \\
\end{tabular} & USD & 7-Jan-2009 & $6,025,386$ & $106.6728 \%$ \\
\hline \begin{tabular}{|l|} 
XS0373609378 \\
\end{tabular} & ILS & 8-Jan-2009 & 339,805 & $46.1951 \%$ \\
\hline XS0280904714 & EUR & 9-Jan-2009 & 482,774 & $29.2590 \%$ \\
\hline \begin{tabular}{|l} 
XS0293784871 \\
\end{tabular} & EUR & 9-Jan-2009 & $1,798,644$ & $179.8644 \%$ \\
\hline XS0308982650 & SGD & 9-Jan-2009 & $2,671,409$ & $80.7413 \%$ \\
\hline \begin{tabular}{|l|} 
XS0240010248 \\
\end{tabular} & EUR & 11-Jan-2009 & $2,019,844$ & $116.0830 \%$ \\
\hline \begin{tabular}{|l|} 
XS0281423235 \\
\end{tabular} & USD & 12-Jan-2009 & 805,798 & $57.8139 \%$ \\
\hline \begin{tabular}{|l|} 
XS0309364262 \\
\end{tabular} & USD & 12-Jan-2009 & 156,760 & $15.2639 \%$ \\
\hline XS0310309785 & USD & 12-Jan-2009 & $14,671,362$ & $100.0000 \%$ \\
\hline \begin{tabular}{|l|} 
XS0324461838 \\
\end{tabular} & USD & 12-Jan-2009 & 441,311 & $31.6629 \%$ \\
\hline XS0338765133 & HKD & 12-Jan-2009 & $3,159,987$ & $64.9614 \%$ \\
\hline \begin{tabular}{|l|} 
XS0338801623 \\
\end{tabular} & USD & 12-Jan-2009 & 950,791 & $81.0074 \%$ \\
\hline XS0339221912 & HKD & 12-Jan-2009 & 768,443 & $30.6425 \%$ \\
\hline \begin{tabular}{|l|} 
XS0367651782 \\
\end{tabular} & $\mathrm{CHF}$ & 12-Jan-2009 & $8,384,001$ & $100.0000 \%$ \\
\hline XS0280903740 & JPY & 13-Jan-2009 & 361,296 & $36.0032 \%$ \\
\hline XS0304635286 & $\mathrm{CZK}$ & 13-Jan-2009 & $1,856,618$ & $100.0000 \%$ \\
\hline XS0308527612 & AUD & 13-Jan-2009 & 106,971 & $33.4908 \%$ \\
\hline \begin{tabular}{|l|} 
XS0338685299 \\
\end{tabular} & EUR & 14-Jan-2009 & $1,300,000$ & $100.0000 \%$ \\
\hline XS0339762162 & USD & 14-Jan-2009 & 778,785 & $43.8694 \%$ \\
\hline \begin{tabular}{|l} 
XS0281959311 \\
\end{tabular} & EUR & 16-Jan-2009 & $1,117,135$ & $39.1977 \%$ \\
\hline XS0338846057 & USD & 16-Jan-2009 & 344,932 & $42.7465 \%$ \\
\hline \begin{tabular}{|l|} 
XS0338846131 \\
\end{tabular} & USD & 16-Jan-2009 & 713,801 & $64.8702 \%$ \\
\hline XS0339760117 & USD & 16-Jan-2009 & $10,441,208$ & $38.6792 \%$ \\
\hline \begin{tabular}{|l|} 
XS0281953207 \\
\end{tabular} & HKD & 19-Jan-2009 & $1,479,995$ & $49.2731 \%$ \\
\hline \begin{tabular}{|l} 
XS0281969112 \\
\end{tabular} & HKD & 19-Jan-2009 & 823,614 & $49.8268 \%$ \\
\hline \begin{tabular}{|l|} 
XS0281980432 \\
\end{tabular} & EUR & 19-Jan-2009 & 49,682 & $3.9745 \%$ \\
\hline XS0282034460 & EUR & 19-Jan-2009 & 928,551 & $13.0782 \%$ \\
\hline \begin{tabular}{|l|} 
XS0281979269 \\
\end{tabular} & USD & 20-Jan-2009 & 368,602 & $28.7130 \%$ \\
\hline \begin{tabular}{|l|} 
XS0271893694 \\
\end{tabular} & EUR & 22-Jan-2009 & $46,505,307$ & $107.3604 \%$ \\
\hline \begin{tabular}{|l|} 
XS0282579290 \\
\end{tabular} & JPY & 22-Jan-2009 & 169,308 & $23.6201 \%$ \\
\hline \begin{tabular}{|l|} 
XS0339560889 \\
\end{tabular} & USD & 22-Jan-2009 & 852,182 & $50.5085 \%$ \\
\hline XS0340114353 & USD & 22-Jan-2009 & $1,071,304$ & $60.8500 \%$ \\
\hline XS0341733110 & HKD & 22-Jan-2009 & $1,034,783$ & $28.3084 \%$ \\
\hline XS0340113629 & USD & 23-Jan-2009 & 291,275 & $24.8167 \%$ \\
\hline XS0340648145 & USD & 23-Jan-2009 & 625,646 & $29.9256 \%$ \\
\hline XS0340348852 & USD & 25-Jan-2009 & 163,509 & $11.1448 \%$ \\
\hline \begin{tabular}{|l|} 
XS0340349074 \\
\end{tabular} & USD & 25-Jan-2009 & 301,151 & $20.5264 \%$ \\
\hline \begin{tabular}{|l|} 
XS0342144416 \\
\end{tabular} & USD & 25-Jan-2009 & 139,697 & $11.2021 \%$ \\
\hline \begin{tabular}{|l|} 
XS0282763035 \\
\end{tabular} & USD & 26-Jan-2009 & 715,927 & $27.4916 \%$ \\
\hline \begin{tabular}{|l|} 
XS0282764199 \\
\end{tabular} & USD & 26-Jan-2009 & 643,190 & $8.6384 \%$ \\
\hline XS0283189016 & USD & 26-Jan-2009 & 255,075 & $8.1816 \%$ \\
\hline \begin{tabular}{|l|} 
XS0283189875 \\
\end{tabular} & USD & 26-Jan-2009 & 180,053 & $8.1816 \%$ \\
\hline XS0311755697 & JPY & 26-Jan-2009 & 107,112 & $29.3348 \%$ \\
\hline XS0340649036 & USD & 26-Jan-2009 & 377,755 & $39.6120 \%$ \\
\hline XS0341175866 & USD & 26-Jan-2009 & 570,297 & $14.8082 \%$ \\
\hline \begin{tabular}{|l|} 
XS0341731338 \\
\end{tabular} & USD & 28-Jan-2009 & $1,001,320$ & $105.0000 \%$ \\
\hline \begin{tabular}{|l|} 
XS0342399754 \\
\end{tabular} & USD & 29-Jan-2009 & 979,946 & $44.0879 \%$ \\
\hline \begin{tabular}{|l} 
XS0342989554 \\
\end{tabular} & USD & 29-Jan-2009 & 297,194 & $40.5135 \%$ \\
\hline XS0283944899 & EUR & 30-Jan-2009 & 298,090 & $18.0661 \%$ \\
\hline XS0284490629 & USD & 30-Jan-2009 & 168,119 & $32.7020 \%$ \\
\hline XS0342399598 & USD & 30-Jan-2009 & 315,447 & $33.0783 \%$ \\
\hline XS0284084802 & USD & 2-Feb-2009 & 897,873 & $61.1990 \%$ \\
\hline XS0341731767 & USD & 2-Feb-2009 & $1,258,512$ & $28.5934 \%$ \\
\hline \begin{tabular}{|l|} 
XS0343799044 \\
\end{tabular} & USD & 2-Feb-2009 & 349,463 & $50.1461 \%$ \\
\hline \begin{tabular}{|l|} 
XS0284731840 \\
\end{tabular} & GBP & 5-Feb-2009 & 361,208 & $16.0428 \%$ \\
\hline \begin{tabular}{|l|} 
XS0344102164 \\
\end{tabular} & HKD & 6-Feb-2009 & 470,298 & $50.8070 \%$ \\
\hline XS0313893215 & EUR & 7-Feb-2009 & $15,563,785$ & $146.3312 \%$ \\
\hline XS0123410838 & EUR & 9-Feb-2009 & $4,306,370$ & $68.3551 \%$ \\
\hline \begin{tabular}{|l|} 
XS0185349916 \\
\end{tabular} & EUR & 9-Feb-2009 & $2,957,800$ & $115.0000 \%$ \\
\hline \begin{tabular}{|l|} 
XS0285457114 \\
\end{tabular} & USD & 9-Feb-2009 & 785,786 & $28.1891 \%$ \\
\hline
\end{tabular}




\begin{tabular}{|c|c|c|c|c|}
\hline ISIN & Currency & $\begin{array}{l}\text { Maturity } \\
\text { date }\end{array}$ & $\begin{array}{c}\text { Admissible } \\
\text { Amount in EUR }\end{array}$ & $\begin{array}{c}\text { Admissible } \\
\text { Amount \% } \\
\end{array}$ \\
\hline XS0285460845 & HKD & 9-Feb-2009 & 143,207 & $13.4172 \%$ \\
\hline XS0339537804 & USD & 9-Feb-2009 & $7,279,196$ & $100.0000 \%$ \\
\hline \begin{tabular}{|l|l|}
$X S 0161241681$ \\
\end{tabular} & EUR & 10-Feb-2009 & $7,990,710$ & $102.4450 \%$ \\
\hline XS0243990446 & JPY & 10-Feb-2009 & 337,911 & $46.8375 \%$ \\
\hline XS0314479337 & USD & 10-Feb-2009 & $5,624,277$ & $127.7836 \%$ \\
\hline XS0315548700 & JPY & 10-Feb-2009 & 270,095 & $30.7099 \%$ \\
\hline \begin{tabular}{|l|} 
XS0315559061 \\
\end{tabular} & USD & 10-Feb-2009 & $4,169,828$ & $29.9699 \%$ \\
\hline \begin{tabular}{|l|} 
XS0345814874 \\
\end{tabular} & HKD & 11-Feb-2009 & $1,612,806$ & $53.5264 \%$ \\
\hline \begin{tabular}{|l|} 
XS0381855518 \\
\end{tabular} & USD & 11-Feb-2009 & $3,667,840$ & $100.0000 \%$ \\
\hline \begin{tabular}{|l|} 
XS0285759121 \\
\end{tabular} & EUR & 12-Feb-2009 & 225,016 & $16.0726 \%$ \\
\hline \begin{tabular}{|l|} 
XS0345278062 \\
\end{tabular} & USD & 12-Feb-2009 & 770,246 & $105.0000 \%$ \\
\hline \begin{tabular}{|l|} 
XS0369868590 \\
\end{tabular} & HKD & 12-Feb-2009 & $3,670,391$ & $51.2311 \%$ \\
\hline \begin{tabular}{|l|} 
XS0343590831 \\
\end{tabular} & USD & 13-Feb-2009 & $1,272,720$ & $62.6344 \%$ \\
\hline \begin{tabular}{|l} 
XS0343590914 \\
\end{tabular} & HKD & 13-Feb-2009 & $3,132,094$ & $62.6247 \%$ \\
\hline \begin{tabular}{|l} 
XS0285837455 \\
\end{tabular} & USD & 14-Feb-2009 & 118,471 & $95.0000 \%$ \\
\hline $\mathrm{CH} 0036891106$ & $\mathrm{CHF}$ & 16-Feb-2009 & 396,384 & $61.5426 \%$ \\
\hline $\mathrm{CH} 0036891114$ & $\mathrm{CHF}$ & 16-Feb-2009 & 468,522 & $72.7428 \%$ \\
\hline $\mathrm{CH} 0036891122$ & $\mathrm{CHF}$ & 16-Feb-2009 & $1,209,349$ & $60.5689 \%$ \\
\hline XS0242973906 & JPY & 16-Feb-2009 & 162,657 & $18.6731 \%$ \\
\hline XS0284882114 & EUR & 16-Feb-2009 & $1,000,000$ & $100.0000 \%$ \\
\hline \begin{tabular}{|l|} 
XS0345791999 \\
\end{tabular} & USD & 16-Feb-2009 & 123,073 & $16.7773 \%$ \\
\hline XS0160491584 & EUR & 17-Feb-2009 & $46,994,591$ & $100.9768 \%$ \\
\hline \begin{tabular}{|l|} 
XS0243988978 \\
\end{tabular} & JPY & 17-Feb-2009 & 491,054 & $45.3508 \%$ \\
\hline XS0286242390 & USD & 17-Feb-2009 & 47,217 & $6.4366 \%$ \\
\hline \begin{tabular}{|l|} 
XS0316388445 \\
\end{tabular} & USD & 17-Feb-2009 & $4,244,450$ & $42.6573 \%$ \\
\hline \begin{tabular}{|l|} 
XS0316405637 \\
\end{tabular} & USD & 17-Feb-2009 & $9,436,908$ & $42.9615 \%$ \\
\hline \begin{tabular}{|l|l} 
XS0347451618 \\
\end{tabular} & USD & 17-Feb-2009 & 58,148 & $56.6200 \%$ \\
\hline US52519VAW63 & USD & 19-Feb-2009 & $6,685,681$ & $86.3879 \%$ \\
\hline XS0286778476 & EUR & 19-Feb-2009 & $1,634,929$ & $30.5594 \%$ \\
\hline XS0344101356 & USD & 19-Feb-2009 & $1,710,048$ & $59.7728 \%$ \\
\hline XS0344101513 & HKD & 19-Feb-2009 & $4,100,578$ & $59.7978 \%$ \\
\hline XS0186852728 & USD & 20-Feb-2009 & $6,270,575$ & $101.7625 \%$ \\
\hline \begin{tabular}{|l|l|} 
XS0198737735 \\
\end{tabular} & USD & 20-Feb-2009 & $6,069,726$ & $115.0000 \%$ \\
\hline XS0161241418 & EUR & 21-Feb-2009 & $97,520,170$ & $100.9761 \%$ \\
\hline XS0162196140 & EUR & 21-Feb-2009 & $161,458,222$ & $100.9761 \%$ \\
\hline XS0286994099 & USD & 23-Feb-2009 & $1,364,175$ & $27.9646 \%$ \\
\hline \begin{tabular}{|l|}
$X S 0287237761$ \\
\end{tabular} & USD & 23-Feb-2009 & $1,222,525$ & $28.0092 \%$ \\
\hline XS0287869050 & USD & 23-Feb-2009 & 689,624 & $28.4877 \%$ \\
\hline \begin{tabular}{|l} 
XS0315799709 \\
\end{tabular} & USD & 23-Feb-2009 & $2,743,545$ & $100.0000 \%$ \\
\hline \begin{tabular}{|l} 
XS0348324988 \\
\end{tabular} & $\mathrm{HKD}$ & 23-Feb-2009 & $3,137,374$ & $60.0103 \%$ \\
\hline \begin{tabular}{|l|} 
XS0348406876 \\
\end{tabular} & USD & 23-Feb-2009 & 438,760 & $58.6389 \%$ \\
\hline XS0244568035 & JPY & 24-Feb-2009 & 13,718 & $1.9138 \%$ \\
\hline \begin{tabular}{|l} 
XS0347383274 \\
\end{tabular} & USD & 25-Feb-2009 & 279,274 & $38.0706 \%$ \\
\hline XS0348919746 & AUD & 25-Feb-2009 & $1,437,317$ & $100.0000 \%$ \\
\hline \begin{tabular}{|l|} 
XS0384213871 \\
\end{tabular} & HKD & 25-Feb-2009 & $1,433,549$ & $37.9428 \%$ \\
\hline XS0346438145 & HKD & 26-Feb-2009 & $4,196,660$ & $46.3300 \%$ \\
\hline XS0346438228 & USD & 26-Feb-2009 & $1,442,844$ & $46.3342 \%$ \\
\hline \begin{tabular}{|l|} 
XS0349154152 \\
\end{tabular} & USD & 26-Feb-2009 & $1,158,492$ & $44.7382 \%$ \\
\hline \begin{tabular}{|l|} 
XS0288138729 \\
\end{tabular} & $\mathrm{CHF}$ & 27-Feb-2009 & 71,017 & $4.5005 \%$ \\
\hline XS0161760441 & EUR & 28-Feb-2009 & $4,650,000$ & $100.0000 \%$ \\
\hline XS0163036071 & EUR & 28-Feb-2009 & $4,152,591$ & $100.9749 \%$ \\
\hline XS0288569972 & USD & 2-Mar-2009 & 144,997 & $15.2046 \%$ \\
\hline \begin{tabular}{|l|} 
XS0288760761 \\
\end{tabular} & EUR & 2-Mar-2009 & 417,006 & $32.0774 \%$ \\
\hline XS0288802605 & USD & 2-Mar-2009 & 285,475 & $24.3225 \%$ \\
\hline XS0348407411 & HKD & 2-Mar-2009 & $1,343,007$ & $51.2935 \%$ \\
\hline \begin{tabular}{|l|} 
XS0245046544 \\
\end{tabular} & EUR & 3-Mar-2009 & $106,950,000$ & $100.0000 \%$ \\
\hline \begin{tabular}{|l|} 
XS0289701962 \\
\end{tabular} & USD & 3-Mar-2009 & $4,373,889$ & $89.8371 \%$ \\
\hline XS0349856343 & USD & 4-Mar-2009 & 54,736 & $7.4616 \%$ \\
\hline \begin{tabular}{|l} 
XS0349511872 \\
\end{tabular} & USD & 5-Mar-2009 & $1,695,335$ & $53.9972 \%$ \\
\hline XS0349512094 & HKD & 5-Mar-2009 & 937,036 & $48.3926 \%$ \\
\hline XS0349512250 & HKD & 5-Mar-2009 & $1,009,936$ & $53.9742 \%$ \\
\hline XS0351201651 & HKD & 6-Mar-2009 & $1,740,890$ & $45.0085 \%$ \\
\hline XS0213629487 & EUR & 9-Mar-2009 & $1,120,000$ & $100.0000 \%$ \\
\hline XS0245637748 & JPY & 9-Mar-2009 & 612,602 & $42.6894 \%$ \\
\hline \begin{tabular}{|l|} 
XS0289723263 \\
\end{tabular} & EUR & 9-Mar-2009 & 596,745 & $30.6023 \%$ \\
\hline \begin{tabular}{|l|} 
XS0289748682 \\
\end{tabular} & GBP & 9-Mar-2009 & 129,599 & $4.0292 \%$ \\
\hline \begin{tabular}{|l} 
XS0350571377 \\
\end{tabular} & USD & 11-Mar-2009 & 382,167 & $54.2677 \%$ \\
\hline XS0351506257 & SGD & 11-Mar-2009 & 875,276 & $90.0000 \%$ \\
\hline \begin{tabular}{|l|}
$X S 0124186981$ \\
\end{tabular} & EUR & 12-Mar-2009 & $4,243,235$ & $66.4043 \%$ \\
\hline XS0124187104 & USD & 12-Mar-2009 & $5,179,422$ & $67.2437 \%$ \\
\hline \begin{tabular}{|l|} 
XS0188371024 \\
\end{tabular} & USD & 12-Mar-2009 & $5,758,509$ & $100.0000 \%$ \\
\hline XS0349550771 & USD & 12-Mar-2009 & $8,680,762$ & $49.7106 \%$ \\
\hline \begin{tabular}{|l|} 
XS0350119359 \\
\end{tabular} & HKD & 12-Mar-2009 & $15,715,146$ & $49.6873 \%$ \\
\hline \begin{tabular}{|l|} 
XS0352912371 \\
\end{tabular} & USD & 12-Mar-2009 & $5,706,278$ & $105.4038 \%$ \\
\hline \begin{tabular}{|l} 
XS0162150071 \\
\end{tabular} & EUR & 13-Mar-2009 & $17,250,000$ & $100.0000 \%$ \\
\hline XS0290363497 & JPY & 13-Mar-2009 & 791,018 & $21.2221 \%$ \\
\hline XS0352088875 & $\mathrm{CHF}$ & 13-Mar-2009 & 272,933 & $33.9005 \%$ \\
\hline \begin{tabular}{|l|} 
XS0312058752 \\
\end{tabular} & USD & 14-Mar-2009 & $3,760,385$ & $102.5231 \%$ \\
\hline \begin{tabular}{|l} 
XS0354225954 \\
\end{tabular} & USD & 14-Mar-2009 & $2,310,345$ & $104.9821 \%$ \\
\hline
\end{tabular}




\begin{tabular}{|c|c|c|c|c|}
\hline ISIN & Currency & $\begin{array}{l}\text { Maturity } \\
\text { date }\end{array}$ & $\begin{array}{c}\text { Admissible } \\
\text { Amount in EUR }\end{array}$ & $\begin{array}{c}\text { Admissible } \\
\text { Amount \% } \\
\end{array}$ \\
\hline XS0286128771 & USD & 15-Mar-2009 & 367,518 & $100.0000 \%$ \\
\hline XS0286129159 & EUR & 15-Mar-2009 & $1,434,000$ & $100.0000 \%$ \\
\hline \begin{tabular}{|l|l}
$X S 0246674138$ \\
\end{tabular} & JPY & 16-Mar-2009 & 476,856 & $43.6266 \%$ \\
\hline \begin{tabular}{|l|} 
XS0290557692 \\
\end{tabular} & USD & 16-Mar-2009 & 509,574 & $23.1550 \%$ \\
\hline \begin{tabular}{|l|l|} 
XS0290694925 \\
\end{tabular} & USD & 16-Mar-2009 & 81,784 & $4.7442 \%$ \\
\hline XS0352089410 & USD & 18-Mar-2009 & 201,035 & $24.9138 \%$ \\
\hline \begin{tabular}{|l|} 
XS0246862998 \\
\end{tabular} & JPY & 19-Mar-2009 & 660,456 & $33.4569 \%$ \\
\hline \begin{tabular}{|l|} 
XS0247650087 \\
\end{tabular} & JPY & 19-Mar-2009 & 380,999 & $27.6710 \%$ \\
\hline \begin{tabular}{|l|} 
XS0291396959 \\
\end{tabular} & EUR & 19-Mar-2009 & $3,090,000$ & $103.0000 \%$ \\
\hline \begin{tabular}{|l|} 
XS0242396249 \\
\end{tabular} & USD & 20-Mar-2009 & $11,810,265$ & $107.3317 \%$ \\
\hline \begin{tabular}{|l|l|}
$X S 0237611495$ \\
\end{tabular} & JPY & 23-Mar-2009 & $7,239,876$ & $101.0035 \%$ \\
\hline \begin{tabular}{|l|} 
XS0247651721 \\
\end{tabular} & JPY & 23-Mar-2009 & 329,569 & $45.9781 \%$ \\
\hline \begin{tabular}{|l|} 
XS0291251808 \\
\end{tabular} & JPY & 23-Mar-2009 & 351,140 & $34.9911 \%$ \\
\hline \begin{tabular}{|l|} 
XS0291974664 \\
\end{tabular} & USD & 23-Mar-2009 & $1,355,568$ & $80.3439 \%$ \\
\hline \begin{tabular}{|l|} 
XS0292198420 \\
\end{tabular} & EUR & 23-Mar-2009 & 179,390 & $11.9593 \%$ \\
\hline \begin{tabular}{|l|} 
XS0351359368 \\
\end{tabular} & HKD & 23-Mar-2009 & $5,386,614$ & $55.3407 \%$ \\
\hline \begin{tabular}{|l|} 
XS0351359442 \\
\end{tabular} & USD & 23-Mar-2009 & $2,708,463$ & $55.3550 \%$ \\
\hline \begin{tabular}{|l|l|} 
XS0175976983 \\
\end{tabular} & USD & 24-Mar-2009 & $3,759,712$ & $107.8998 \%$ \\
\hline \begin{tabular}{|l|} 
XS0214408840 \\
\end{tabular} & EUR & 24-Mar-2009 & 715,000 & $100.0000 \%$ \\
\hline \begin{tabular}{|l|l} 
XS0248497595 \\
\end{tabular} & AUD & 24-Mar-2009 & 242,175 & $20.3092 \%$ \\
\hline \begin{tabular}{|l|} 
XS0353258832 \\
\end{tabular} & USD & 24-Mar-2009 & 278,609 & $37.9800 \%$ \\
\hline XS0143892023 & USD & 25-Mar-2009 & $1,580,798$ & $101.6483 \%$ \\
\hline \begin{tabular}{|l|} 
XS0353507212 \\
\end{tabular} & USD & 25-Mar-2009 & 255,670 & $34.8529 \%$ \\
\hline \begin{tabular}{|l|} 
XS0125538974 \\
\end{tabular} & USD & 26-Mar-2009 & $15,575,039$ & $106.1595 \%$ \\
\hline \begin{tabular}{|l|} 
XS0125559111 \\
\end{tabular} & EUR & 26-Mar-2009 & $26,358,450$ & $105.4338 \%$ \\
\hline XS0144646386 & USD & 26-Mar-2009 & 696,488 & $103.2013 \%$ \\
\hline \begin{tabular}{|l|} 
XS0247757049 \\
\end{tabular} & JPY & 26-Mar-2009 & 227,614 & $31.7545 \%$ \\
\hline \begin{tabular}{|l|} 
XS0292337309 \\
\end{tabular} & USD & 26-Mar-2009 & 75,454 & $6.0505 \%$ \\
\hline \begin{tabular}{|l|} 
XS0353875528 \\
\end{tabular} & USD & 26-Mar-2009 & $1,054,859$ & $99.1713 \%$ \\
\hline \begin{tabular}{|l|} 
XS0353875791 \\
\end{tabular} & USD & 26-Mar-2009 & 831,858 & $83.9992 \%$ \\
\hline XS0246082043 & EUR & 27-Mar-2009 & $4,951,242$ & $102.4254 \%$ \\
\hline \begin{tabular}{|l|} 
XS0163560690 \\
\end{tabular} & EUR & 28-Mar-2009 & $29,271,195$ & $100.9700 \%$ \\
\hline \begin{tabular}{|l|} 
XS0354643016 \\
\end{tabular} & USD & 28-Mar-2009 & $1,493,247$ & $101.7797 \%$ \\
\hline XS0354645227 & USD & 28-Mar-2009 & 3,367 & $0.9180 \%$ \\
\hline XS0249400044 & USD & 30-Mar-2009 & $3,058,979$ & $100.0000 \%$ \\
\hline \begin{tabular}{|l|l} 
XS0293664461 \\
\end{tabular} & USD & 30-Mar-2009 & $3,762,096$ & $102.5698 \%$ \\
\hline XS0354310046 & USD & 30-Mar-2009 & 348,445 & $95.0000 \%$ \\
\hline \begin{tabular}{|l} 
XS0125559467 \\
\end{tabular} & EUR & 4-Apr-2009 & $27,732,232$ & $101.6019 \%$ \\
\hline XS0248302845 & USD & 6-Apr-2009 & 235,124 & $24.6554 \%$ \\
\hline \begin{tabular}{|l|} 
XS0248499617 \\
\end{tabular} & JPY & 6-Apr-2009 & 517,637 & $72.1578 \%$ \\
\hline \begin{tabular}{|l|} 
XS0249034603 \\
\end{tabular} & JPY & 6-Apr-2009 & 421,102 & $58.7479 \%$ \\
\hline XS0249435776 & JPY & 7-Apr-2009 & 218,448 & $30.4267 \%$ \\
\hline \begin{tabular}{|l|l}
$X S 0249774711$ \\
\end{tabular} & CZK & 7-Apr-2009 & $2,377,574$ & $100.0000 \%$ \\
\hline \begin{tabular}{|l|} 
XS0270249807 \\
\end{tabular} & GBP & 13-Apr-2009 & $1,286,587$ & $100.0000 \%$ \\
\hline XS0248142894 & EUR & 14-Apr-2009 & $3,358,116$ & $57.6897 \%$ \\
\hline \begin{tabular}{|l|} 
XS0294244032 \\
\end{tabular} & AUD & 14-Apr-2009 & $1,337,647$ & $35.8967 \%$ \\
\hline XS0294545156 & GBP & 14-Apr-2009 & 183,232 & $6.4735 \%$ \\
\hline \begin{tabular}{|l|} 
XS0322153270 \\
\end{tabular} & $\mathrm{CHF}$ & 15-Apr-2009 & $9,661,213$ & $100.0000 \%$ \\
\hline \begin{tabular}{|l|l} 
XS0295277684 \\
\end{tabular} & USD & 16-Apr-2009 & $1,386,329$ & $85.9020 \%$ \\
\hline \begin{tabular}{|l|} 
XS0295278146 \\
\end{tabular} & HKD & 16-Apr-2009 & $2,191,777$ & $85.9428 \%$ \\
\hline \begin{tabular}{|l|} 
XS0324983450 \\
\end{tabular} & SGD & 16-Apr-2009 & 499,485 & $46.3429 \%$ \\
\hline XS0295258627 & $\mathrm{CHF}$ & 17-Apr-2009 & $5,101,181$ & $79.2009 \%$ \\
\hline \begin{tabular}{|l|} 
XS0126892172 \\
\end{tabular} & EUR & 20-Apr-2009 & $16,182,222$ & $161.8222 \%$ \\
\hline XS0251375233 & USD & 20-Apr-2009 & 450,084 & $50.2913 \%$ \\
\hline \begin{tabular}{|l|} 
XS0281973148 \\
\end{tabular} & USD & 20-Apr-2009 & 399,266 & $25.9181 \%$ \\
\hline \begin{tabular}{|l|} 
XS0326026068 \\
\end{tabular} & SGD & 23-Apr-2009 & 798,711 & $54.0091 \%$ \\
\hline \begin{tabular}{|l|} 
XS0358410164 \\
\end{tabular} & USD & 23-Apr-2009 & 338,084 & $38.4064 \%$ \\
\hline \begin{tabular}{|l|} 
XS0250113841 \\
\end{tabular} & $\mathrm{CHF}$ & 24-Apr-2009 & 889,630 & $64.4978 \%$ \\
\hline \begin{tabular}{|l|} 
XS0358446275 \\
\end{tabular} & USD & 24-Apr-2009 & $2,303,565$ & $104.6740 \%$ \\
\hline XS0146656417 & USD & 26-Apr-2009 & $1,061,972$ & $101.9493 \%$ \\
\hline \begin{tabular}{|l|l|}
$X S 0251658885$ \\
\end{tabular} & EUR & 27-Apr-2009 & $2,850,000$ & $95.0000 \%$ \\
\hline XS0296545576 & GBP & 27-Apr-2009 & 186,100 & $7.4178 \%$ \\
\hline \begin{tabular}{|l|}
$X S 0296792582$ \\
\end{tabular} & USD & 27-Apr-2009 & $1,826,585$ & $100.0000 \%$ \\
\hline XS0296830267 & USD & 27-Apr-2009 & 151,094 & $7.4899 \%$ \\
\hline \begin{tabular}{|l|} 
XS0297918301 \\
\end{tabular} & GBP & 27-Apr-2009 & 337,603 & $21.8668 \%$ \\
\hline \begin{tabular}{|l|} 
XS0326538120 \\
\end{tabular} & SGD & 27-Apr-2009 & $1,264,426$ & $68.1697 \%$ \\
\hline XS0326608519 & SGD & 27-Apr-2009 & 726,042 & $43.2331 \%$ \\
\hline XS0246449440 & USD & 28-Apr-2009 & $4,488,903$ & $123.3724 \%$ \\
\hline \begin{tabular}{|l|} 
XS0251995709 \\
\end{tabular} & JPY & 28-Apr-2009 & 498,378 & $36.2282 \%$ \\
\hline XS0361039067 & USD & 29-Apr-2009 & 832,455 & $51.5351 \%$ \\
\hline \begin{tabular}{|l} 
XS0283951597 \\
\end{tabular} & USD & 30-Apr-2009 & 168,487 & $20.8801 \%$ \\
\hline XS0297127861 & AUD & 30-Apr-2009 & $1,162,422$ & $31.1944 \%$ \\
\hline \begin{tabular}{|l|} 
XS0325550472 \\
\end{tabular} & $\mathrm{CHF}$ & 30-Apr-2009 & $14,835,759$ & $100.0000 \%$ \\
\hline \begin{tabular}{|l|} 
XS0327261946 \\
\end{tabular} & USD & 30-Apr-2009 & $2,200,704$ & $100.0000 \%$ \\
\hline XS0327465190 & USD & 30-Apr-2009 & 781,715 & $49.5644 \%$ \\
\hline XS0361471997 & USD & 30-Apr-2009 & 465,117 & $50.1619 \%$ \\
\hline \begin{tabular}{|l|} 
XS0297515446 \\
\end{tabular} & USD & 1-May-2009 & 163,496 & $6.3679 \%$ \\
\hline \begin{tabular}{|l|} 
XS0166737659 \\
\end{tabular} & EUR & 2-May-2009 & $7,680,729$ & $102.4097 \%$ \\
\hline XS0126892255 & EUR & 4-May-2009 & $33,209,368$ & $101.5422 \%$ \\
\hline
\end{tabular}




\begin{tabular}{|c|c|c|c|c|}
\hline ISIN & Currency & $\begin{array}{l}\text { Maturity } \\
\text { date }\end{array}$ & $\begin{array}{c}\text { Admissible } \\
\text { Amount in EUR }\end{array}$ & $\begin{array}{c}\text { Admissible } \\
\text { Amount \% } \\
\end{array}$ \\
\hline XS0297908849 & AUD & 4-May-2009 & $1,992,663$ & $53.4745 \%$ \\
\hline XS0297915117 & AUD & 4-May-2009 & 965,788 & $25.9176 \%$ \\
\hline \begin{tabular}{|l|l|}
$X S 0251416367$ \\
\end{tabular} & USD & 5-May-2009 & $3,667,840$ & $100.0000 \%$ \\
\hline \begin{tabular}{|l|l}
$X S 0252767792$ \\
\end{tabular} & USD & 5-May-2009 & $3,667,840$ & $100.0000 \%$ \\
\hline \begin{tabular}{|l} 
XS0297490277 \\
\end{tabular} & EUR & 5-May-2009 & 129,023 & $9.9248 \%$ \\
\hline XS0297906801 & GBP & 5-May-2009 & $1,258,356$ & $23.8550 \%$ \\
\hline \begin{tabular}{|l|} 
XS0297907791 \\
\end{tabular} & EUR & 5-May-2009 & 359,175 & $10.5640 \%$ \\
\hline \begin{tabular}{|l|} 
XS0298317347 \\
\end{tabular} & EUR & 5-May-2009 & 395,421 & $28.2443 \%$ \\
\hline \begin{tabular}{|l|} 
XS0298318667 \\
\end{tabular} & USD & 5-May-2009 & 921,034 & $50.2222 \%$ \\
\hline \begin{tabular}{|l|} 
XS0298437244 \\
\end{tabular} & GBP & 5-May-2009 & 234,755 & $10.4265 \%$ \\
\hline \begin{tabular}{|l|} 
XS0298442160 \\
\end{tabular} & USD & 5-May-2009 & 90,381 & $7.7005 \%$ \\
\hline XS0362181934 & USD & 5-May-2009 & $4,972,358$ & $84.4124 \%$ \\
\hline \begin{tabular}{|l|} 
XS0328587679 \\
\end{tabular} & USD & 6-May-2009 & 860,628 & $78.2139 \%$ \\
\hline \begin{tabular}{|l|} 
XS0362361593 \\
\end{tabular} & HKD & 6-May-2009 & $1,885,598$ & $71.9388 \%$ \\
\hline \begin{tabular}{|l|} 
XS0298614552 \\
\end{tabular} & EUR & 7-May-2009 & $3,196,760$ & $98.0000 \%$ \\
\hline \begin{tabular}{|l|} 
XS0298886556 \\
\end{tabular} & USD & 8-May-2009 & 482,362 & $9.3937 \%$ \\
\hline XS0298931956 & GBP & 8-May-2009 & $1,131,509$ & $54.9666 \%$ \\
\hline \begin{tabular}{|l} 
XS0362182155 \\
\end{tabular} & USD & 8-May-2009 & 445,755 & $60.7654 \%$ \\
\hline \begin{tabular}{|l|} 
XS0250879763 \\
\end{tabular} & USD & 10-May-2009 & $3,667,840$ & $100.0000 \%$ \\
\hline \begin{tabular}{|l|} 
XS0299411222 \\
\end{tabular} & EUR & 10-May-2009 & 95,977 & $9.5977 \%$ \\
\hline \begin{tabular}{|l|}
$X S 0298612697$ \\
\end{tabular} & AUD & 11-May-2009 & $1,578,684$ & $42.3651 \%$ \\
\hline XS0299369511 & AUD & 11-May-2009 & $1,555,922$ & $41.7543 \%$ \\
\hline \begin{tabular}{|l|} 
XS0299665249 \\
\end{tabular} & USD & 11-May-2009 & $1,070,720$ & $42.3074 \%$ \\
\hline XS0300476214 & HKD & 11-May-2009 & 927,590 & $85.7685 \%$ \\
\hline \begin{tabular}{|l|} 
XS0300516969 \\
\end{tabular} & USD & 11-May-2009 & $1,145,226$ & $80.1530 \%$ \\
\hline XS0300878799 & USD & 11-May-2009 & 592,562 & $89.7534 \%$ \\
\hline \begin{tabular}{|l|} 
XS0251909478 \\
\end{tabular} & $\mathrm{CHF}$ & 12-May-2009 & $6,582,524$ & $119.0950 \%$ \\
\hline XS0251909635 & $\mathrm{CHF}$ & 12-May-2009 & $5,280,843$ & $109.3209 \%$ \\
\hline \begin{tabular}{|l|} 
XS0285864939 \\
\end{tabular} & USD & 12-May-2009 & 132,521 & $8.4025 \%$ \\
\hline XS0274127009 & EUR & 13-May-2009 & $3,280,000$ & $100.0000 \%$ \\
\hline XS0329430044 & USD & 13-May-2009 & 62,816 & $8.5631 \%$ \\
\hline XS0329714157 & SGD & 13-May-2009 & 398,049 & $58.8169 \%$ \\
\hline \begin{tabular}{|l|} 
DE000A0TU1P4 \\
\end{tabular} & USD & 14-May-2009 & $8,379,229$ & $68.3168 \%$ \\
\hline XS0297730847 & $\mathrm{CHF}$ & 14-May-2009 & $2,118,382$ & $100.0000 \%$ \\
\hline \begin{tabular}{|l|} 
XS0299661099 \\
\end{tabular} & AUD & 14-May-2009 & $1,646,186$ & $44.1766 \%$ \\
\hline XS0329713423 & AUD & 14-May-2009 & 446,846 & $69.9500 \%$ \\
\hline \begin{tabular}{|l|} 
XS0364226299 \\
\end{tabular} & HKD & 15-May-2009 & 819,773 & $73.5510 \%$ \\
\hline XS0362747353 & USD & 16-May-2009 & $2,466,468$ & $62.2646 \%$ \\
\hline XS0364549112 & USD & 16-May-2009 & 108,709 & $14.8192 \%$ \\
\hline XS0253214646 & JPY & 18-May-2009 & 436,927 & $49.2978 \%$ \\
\hline \begin{tabular}{|l|} 
XS0253612534 \\
\end{tabular} & JPY & 18-May-2009 & 264,457 & $36.8196 \%$ \\
\hline XS0299172725 & USD & 18-May-2009 & $1,702,711$ & $61.0825 \%$ \\
\hline XS0300152070 & EUR & 18-May-2009 & 110,423 & $9.2019 \%$ \\
\hline XS0300153714 & EUR & 18-May-2009 & $1,312,210$ & $77.1888 \%$ \\
\hline XS0300154365 & USD & 18-May-2009 & $2,937,498$ & $78.5176 \%$ \\
\hline XS0300155099 & EUR & 18-May-2009 & 223,167 & $7.9703 \%$ \\
\hline XS0300339578 & EUR & 18-May-2009 & $1,501,546$ & $62.5644 \%$ \\
\hline \begin{tabular}{|l|} 
XS0300349296 \\
\end{tabular} & AUD & 18-May-2009 & $2,200,610$ & $51.6731 \%$ \\
\hline \begin{tabular}{|l|} 
XS0300349452 \\
\end{tabular} & GBP & 18-May-2009 & 208,488 & $20.2559 \%$ \\
\hline XS0300349882 & USD & 18-May-2009 & $2,130,597$ & $38.7257 \%$ \\
\hline XS0300350203 & SGD & 18-May-2009 & 304,595 & $39.2004 \%$ \\
\hline XS0300350625 & USD & 18-May-2009 & 875,821 & $34.6063 \%$ \\
\hline XS0300351193 & AUD & 18-May-2009 & $1,951,422$ & $52.3678 \%$ \\
\hline XS0300663167 & USD & 18-May-2009 & $3,626,614$ & $77.2469 \%$ \\
\hline XS0300691457 & AUD & 18-May-2009 & $1,796,646$ & $100.0000 \%$ \\
\hline XS0361915621 & HKD & 18-May-2009 & $2,639,213$ & $61.4777 \%$ \\
\hline \begin{tabular}{|l|} 
XS0361915894 \\
\end{tabular} & USD & 18-May-2009 & $1,877,721$ & $61.4576 \%$ \\
\hline XS0192355302 & USD & 19-May-2009 & $2,701,731$ & $100.0000 \%$ \\
\hline \begin{tabular}{|l|} 
XS0216280932 \\
\end{tabular} & EUR & 20-May-2009 & 504,804 & $100.9608 \%$ \\
\hline XS0363707265 & USD & 20-May-2009 & 616,777 & $64.6762 \%$ \\
\hline \begin{tabular}{|l|} 
XS0363707349 \\
\end{tabular} & USD & 20-May-2009 & 458,939 & $62.5626 \%$ \\
\hline XS0300661542 & JPY & 21-May-2009 & $1,238,179$ & $42.1313 \%$ \\
\hline XS0300662607 & EUR & 21-May-2009 & $1,620,270$ & $27.2314 \%$ \\
\hline XS0362745498 & USD & 21-May-2009 & $2,012,268$ & $69.7109 \%$ \\
\hline \begin{tabular}{|l|} 
XS0362745571 \\
\end{tabular} & HKD & 21-May-2009 & $4,746,044$ & $69.7388 \%$ \\
\hline XS0365348936 & MXN & 21-May-2009 & $95,003,853$ & $105.4699 \%$ \\
\hline \begin{tabular}{|l|} 
XS0254466153 \\
\end{tabular} & USD & 22-May-2009 & $1,995,946$ & $54.4175 \%$ \\
\hline XS0363956722 & USD & 22-May-2009 & 536,475 & $56.9123 \%$ \\
\hline XS0363956995 & USD & 22-May-2009 & 897,121 & $54.9643 \%$ \\
\hline XS0331533256 & USD & 23-May-2009 & 936,033 & $100.0000 \%$ \\
\hline XS0365855526 & USD & 23-May-2009 & 633,873 & $43.2048 \%$ \\
\hline XS0254853947 & EUR & 24-May-2009 & $1,125,000$ & $90.0000 \%$ \\
\hline \begin{tabular}{|l|} 
XS0364742469 \\
\end{tabular} & USD & 25-May-2009 & $19,586,268$ & $100.0000 \%$ \\
\hline \begin{tabular}{|l|} 
XS0253717986 \\
\end{tabular} & USD & 26-May-2009 & $2,284,332$ & $103.8001 \%$ \\
\hline XS0254532046 & USD & 26-May-2009 & $2,264,621$ & $102.9044 \%$ \\
\hline XS0300152666 & EUR & 26-May-2009 & $1,944,539$ & $64.8180 \%$ \\
\hline XS0301128061 & USD & 26-May-2009 & $3,434,241$ & $56.4043 \%$ \\
\hline XS0301129036 & USD & 26-May-2009 & $4,859,850$ & $56.6235 \%$ \\
\hline \begin{tabular}{|l|} 
XS0301129549 \\
\end{tabular} & EUR & 26-May-2009 & 804,640 & $28.7371 \%$ \\
\hline
\end{tabular}




\begin{tabular}{|c|c|c|c|c|}
\hline ISIN & Currency & $\begin{array}{l}\text { Maturity } \\
\text { date }\end{array}$ & $\begin{array}{c}\text { Admissible } \\
\text { Amount in EUR }\end{array}$ & $\begin{array}{c}\text { Admissible } \\
\text { Amount \% } \\
\end{array}$ \\
\hline XS0301130554 & EUR & 26-May-2009 & $1,182,902$ & $45.4962 \%$ \\
\hline XS0301337225 & USD & 26-May-2009 & $1,393,146$ & $52.7538 \%$ \\
\hline \begin{tabular}{|l|} 
XS0301340872 \\
\end{tabular} & EUR & 26-May-2009 & $1,107,388$ & $19.7748 \%$ \\
\hline XS0301567227 & USD & 26-May-2009 & $1,361,910$ & $53.0445 \%$ \\
\hline \begin{tabular}{|l|} 
XS0301568977 \\
\end{tabular} & USD & 26-May-2009 & 917,838 & $78.1998 \%$ \\
\hline XS0331399773 & USD & 26-May-2009 & 558,844 & $69.2560 \%$ \\
\hline XS0363206722 & HKD & 26-May-2009 & 519,085 & $68.6950 \%$ \\
\hline XS0363206995 & USD & 26-May-2009 & 498,921 & $68.6999 \%$ \\
\hline XS0301130711 & USD & 27-May-2009 & 598,348 & $77.6827 \%$ \\
\hline XS0301336417 & HKD & 27-May-2009 & 488,625 & $47.8993 \%$ \\
\hline \begin{tabular}{|l|} 
XS0328873681 \\
\end{tabular} & $\mathrm{CHF}$ & 27-May-2009 & $10,310,447$ & $100.0000 \%$ \\
\hline XS0364868058 & USD & 27-May-2009 & 117,850 & $16.0654 \%$ \\
\hline \begin{tabular}{|l|} 
XS0365916252 \\
\end{tabular} & USD & 27-May-2009 & 518,319 & $70.6573 \%$ \\
\hline XS0193227260 & JPY & 28-May-2009 & $21,667,989$ & $100.7634 \%$ \\
\hline XS0301956396 & AUD & 28-May-2009 & 721,992 & $75.3478 \%$ \\
\hline XS0366314226 & USD & 28-May-2009 & 106,176 & $26.3161 \%$ \\
\hline XS0366401031 & USD & 28-May-2009 & $8,550,237$ & $101.3538 \%$ \\
\hline XS0169124509 & EUR & 29-May-2009 & 171,671 & $104.0431 \%$ \\
\hline \begin{tabular}{|l} 
XS0203544027 \\
\end{tabular} & EUR & 29-May-2009 & $1,830,313$ & $100.9550 \%$ \\
\hline XS0301958178 & USD & 29-May-2009 & 159,296 & $9.4414 \%$ \\
\hline \begin{tabular}{|l|} 
XS0302043012 \\
\end{tabular} & EUR & 29-May-2009 & $1,288,998$ & $17.7793 \%$ \\
\hline XS0302115372 & USD & 29-May-2009 & 99,891 & $8.2528 \%$ \\
\hline \begin{tabular}{|l|} 
XS0302117311 \\
\end{tabular} & USD & 29-May-2009 & 115,784 & $8.7687 \%$ \\
\hline \begin{tabular}{|l|} 
XS0302280499 \\
\end{tabular} & USD & 29-May-2009 & $2,170,486$ & $54.7927 \%$ \\
\hline XS0302285290 & USD & 29-May-2009 & 756,085 & $54.2471 \%$ \\
\hline XS0332612505 & USD & 29-May-2009 & 382,923 & $100.0000 \%$ \\
\hline \begin{tabular}{|l|} 
XS0366475076 \\
\end{tabular} & $\mathrm{HKD}$ & 29-May-2009 & $6,679,637$ & $89.6299 \%$ \\
\hline XS0366668464 & USD & 29-May-2009 & 235,133 & $45.7904 \%$ \\
\hline \begin{tabular}{|l|} 
XS0366668548 \\
\end{tabular} & USD & 29-May-2009 & 214,325 & $58.4336 \%$ \\
\hline \begin{tabular}{|l|} 
XS0366859485 \\
\end{tabular} & USD & 29-May-2009 & $1,190,506$ & $69.3546 \%$ \\
\hline \begin{tabular}{|l|} 
XS0366879913 \\
\end{tabular} & USD & 30-May-2009 & 107,784 & $13.0028 \%$ \\
\hline XS0366880176 & USD & 30-May-2009 & 95,590 & $13.0309 \%$ \\
\hline XS0128700274 & EUR & 31-May-2009 & $64,503,424$ & $101.7083 \%$ \\
\hline XS0251195847 & GBP & 1-Jun-2009 & $310,156,602$ & $102.9023 \%$ \\
\hline XS0253634850 & EUR & 1-Jun-2009 & $3,896,609$ & $105.8861 \%$ \\
\hline \begin{tabular}{|l} 
XS0253635154 \\
\end{tabular} & USD & 1-Jun-2009 & $4,073,644$ & $108.8861 \%$ \\
\hline XS0276154738 & USD & 1-Jun-2009 & $1,440,811$ & $56.9308 \%$ \\
\hline \begin{tabular}{|l|} 
XS0302370308 \\
\end{tabular} & USD & 1-Jun-2009 & 188,621 & $10.0835 \%$ \\
\hline \begin{tabular}{|l|} 
XS0302370720 \\
\end{tabular} & USD & 1-Jun-2009 & 100,366 & $8.0482 \%$ \\
\hline XS0302371538 & USD & 1-Jun-2009 & 743,339 & $33.7773 \%$ \\
\hline \begin{tabular}{|l|} 
XS0302504948 \\
\end{tabular} & EUR & 1-Jun-2009 & 313,549 & $27.2652 \%$ \\
\hline XS0302669196 & EUR & 1-Jun-2009 & 112,076 & $22.4153 \%$ \\
\hline XS0302669519 & EUR & 1-Jun-2009 & 569,688 & $52.9942 \%$ \\
\hline \begin{tabular}{|l|} 
XS0365870756 \\
\end{tabular} & USD & 1-Jun-2009 & 702,673 & $79.8236 \%$ \\
\hline \begin{tabular}{|l|} 
XS0365915791 \\
\end{tabular} & USD & 2-Jun-2009 & $1,526,261$ & $83.2240 \%$ \\
\hline \begin{tabular}{|l|} 
XS0366065687 \\
\end{tabular} & USD & 2-Jun-2009 & 604,156 & $28.3995 \%$ \\
\hline XS0366074242 & USD & 2-Jun-2009 & 473,113 & $64.4948 \%$ \\
\hline XS0364513514 & HKD & 3-Jun-2009 & $3,209,776$ & $65.2250 \%$ \\
\hline \begin{tabular}{|l|} 
XS0364513860 \\
\end{tabular} & USD & 3-Jun-2009 & $1,442,473$ & $65.2199 \%$ \\
\hline XS0366125507 & USD & 3-Jun-2009 & 699,116 & $79.4196 \%$ \\
\hline \begin{tabular}{|l|} 
XS0366300357 \\
\end{tabular} & USD & 3-Jun-2009 & 735,352 & $100.2432 \%$ \\
\hline XS0367878997 & HKD & 3-Jun-2009 & $1,015,473$ & $70.4978 \%$ \\
\hline $\mathrm{CH} 0039308652$ & $\mathrm{CHF}$ & 4-Jun-2009 & $2,750,615$ & $50.2424 \%$ \\
\hline \begin{tabular}{|l|} 
XS0302821755 \\
\end{tabular} & AUD & 4-Jun-2009 & $2,619,304$ & $70.2909 \%$ \\
\hline \begin{tabular}{|l|} 
XS0302906077 \\
\end{tabular} & USD & 4-Jun-2009 & $1,130,900$ & $70.0747 \%$ \\
\hline XS0366918240 & USD & 4-Jun-2009 & 195,579 & $26.6614 \%$ \\
\hline \begin{tabular}{|l|} 
XS0366986593 \\
\end{tabular} & USD & 4-Jun-2009 & $1,313,082$ & $89.4997 \%$ \\
\hline XS0252899512 & EUR & 5-Jun-2009 & 205,748 & $102.8740 \%$ \\
\hline XS0255671967 & JPY & 5-Jun-2009 & 284,562 & $39.6993 \%$ \\
\hline \begin{tabular}{|l} 
XS0303172117 \\
\end{tabular} & USD & 5-Jun-2009 & 478,558 & $40.7731 \%$ \\
\hline \begin{tabular}{|l} 
XS0303178825 \\
\end{tabular} & AUD & 5-Jun-2009 & $2,576,952$ & $69.1543 \%$ \\
\hline \begin{tabular}{|l|} 
XS0365038586 \\
\end{tabular} & USD & 5-Jun-2009 & 689,368 & $66.6486 \%$ \\
\hline \begin{tabular}{|l|} 
XS0365048387 \\
\end{tabular} & HKD & 5-Jun-2009 & $2,536,917$ & $66.6466 \%$ \\
\hline XS0366859055 & ILS & 5-Jun-2009 & 690,937 & $82.1889 \%$ \\
\hline XS0366859642 & USD & 5-Jun-2009 & 483,025 & $65.8459 \%$ \\
\hline XS0302668545 & EUR & 8-Jun-2009 & $1,643,646$ & $51.3639 \%$ \\
\hline XS0303759632 & USD & 8-Jun-2009 & 231,235 & $16.5905 \%$ \\
\hline \begin{tabular}{|l|} 
XS0367878567 \\
\end{tabular} & USD & 8-Jun-2009 & 217,642 & $29.6690 \%$ \\
\hline \begin{tabular}{|l|} 
XS0368588777 \\
\end{tabular} & HKD & 8-Jun-2009 & $2,593,305$ & $61.0124 \%$ \\
\hline \begin{tabular}{|l|} 
XS0368988522 \\
\end{tabular} & USD & 8-Jun-2009 & $1,577,171$ & $100.0000 \%$ \\
\hline \begin{tabular}{|l|} 
XS0254780611 \\
\end{tabular} & USD & 10-Jun-2009 & $2,332,746$ & $106.0000 \%$ \\
\hline XS0367878641 & USD & 10-Jun-2009 & 722,753 & $57.9563 \%$ \\
\hline XS0303865074 & USD & 11-Jun-2009 & $3,780,415$ & $76.9173 \%$ \\
\hline XS0366385085 & JPY & 11-Jun-2009 & 291,113 & $79.9157 \%$ \\
\hline XS0369514947 & USD & 11-Jun-2009 & $1,218,159$ & $89.7619 \%$ \\
\hline $\mathrm{CH} 0039308694$ & USD & 12-Jun-2009 & $1,326,044$ & $40.1703 \%$ \\
\hline $\mathrm{CH} 0039308710$ & USD & 12-Jun-2009 & $1,299,955$ & $50.6314 \%$ \\
\hline XS0303864184 & AUD & 12-Jun-2009 & $2,666,665$ & $71.5619 \%$ \\
\hline XS0304471070 & USD & 12-Jun-2009 & 376,122 & $73.2470 \%$ \\
\hline
\end{tabular}




\begin{tabular}{|c|c|c|c|c|}
\hline ISIN & Currency & $\begin{array}{l}\text { Maturity } \\
\text { date }\end{array}$ & $\begin{array}{c}\text { Admissible } \\
\text { Amount in EUR }\end{array}$ & $\begin{array}{c}\text { Admissible } \\
\text { Amount \% } \\
\end{array}$ \\
\hline \begin{tabular}{|l|} 
XS0256313239 \\
\end{tabular} & JPY & 15-Jun-2009 & 397,804 & $55.3852 \%$ \\
\hline XS0278222236 & EUR & 15-Jun-2009 & 100,000 & $100.0000 \%$ \\
\hline \begin{tabular}{|l|l} 
XS0304472474 \\
\end{tabular} & GBP & 15-Jun-2009 & 130,248 & $8.8031 \%$ \\
\hline XS0304473019 & AUD & 15-Jun-2009 & $2,821,119$ & $75.7067 \%$ \\
\hline \begin{tabular}{|l|} 
XS0304565723 \\
\end{tabular} & USD & 15-Jun-2009 & $1,335,676$ & $55.1755 \%$ \\
\hline XS0305158031 & AUD & 15-Jun-2009 & $6,595,688$ & $100.0000 \%$ \\
\hline \begin{tabular}{|l|} 
XS0334693818 \\
\end{tabular} & USD & 15-Jun-2009 & $3,594,484$ & $98.0000 \%$ \\
\hline \begin{tabular}{|l|} 
XS0366986163 \\
\end{tabular} & HKD & 15-Jun-2009 & 833,222 & $67.5970 \%$ \\
\hline \begin{tabular}{|l|} 
XS0366986676 \\
\end{tabular} & HKD & 15-Jun-2009 & $2,655,801$ & $88.4190 \%$ \\
\hline XS0366986833 & USD & 15-Jun-2009 & 859,623 & $88.4406 \%$ \\
\hline \begin{tabular}{|l|} 
XS0368588421 \\
\end{tabular} & HKD & 15-Jun-2009 & $3,971,272$ & $72.1171 \%$ \\
\hline XS0194346135 & JPY & 16-Jun-2009 & 926,918 & $85.0193 \%$ \\
\hline \begin{tabular}{|l|}
$X S 0256934000$ \\
\end{tabular} & EUR & 16-Jun-2009 & $3,200,000$ & $100.0000 \%$ \\
\hline \begin{tabular}{|l|} 
XS0257807288 \\
\end{tabular} & EUR & 16-Jun-2009 & $6,000,000$ & $100.0000 \%$ \\
\hline \begin{tabular}{|l|}
$X S 0257807874$ \\
\end{tabular} & USD & 16-Jun-2009 & $3,051,643$ & $104.0000 \%$ \\
\hline \begin{tabular}{|l|} 
XS0368366018 \\
\end{tabular} & JPY & 16-Jun-2009 & 219,961 & $61.3734 \%$ \\
\hline XS0368366109 & JPY & 16-Jun-2009 & 216,762 & $60.4810 \%$ \\
\hline \begin{tabular}{|l|} 
XS0368366281 \\
\end{tabular} & JPY & 16-Jun-2009 & 216,236 & $60.3342 \%$ \\
\hline XS0368574637 & JPY & 16-Jun-2009 & 217,272 & $60.6232 \%$ \\
\hline \begin{tabular}{|l|} 
XS0368587969 \\
\end{tabular} & JPY & 16-Jun-2009 & 216,762 & $60.4810 \%$ \\
\hline XS0368574710 & JPY & 17-Jun-2009 & 197,864 & $55.2079 \%$ \\
\hline XS0368575527 & JPY & 17-Jun-2009 & $1,093,240$ & $50.8393 \%$ \\
\hline \begin{tabular}{|l} 
XS0368586482 \\
\end{tabular} & JPY & 17-Jun-2009 & 214,119 & $59.7435 \%$ \\
\hline XS0368586722 & JPY & 17-Jun-2009 & 213,629 & $59.6069 \%$ \\
\hline \begin{tabular}{|l|} 
XS0368587456 \\
\end{tabular} & JPY & 17-Jun-2009 & 213,629 & $59.6069 \%$ \\
\hline \begin{tabular}{|l|} 
XS0368587613 \\
\end{tabular} & JPY & 17-Jun-2009 & 195,780 & $54.6264 \%$ \\
\hline \begin{tabular}{|l|} 
XS0368588181 \\
\end{tabular} & JPY & 17-Jun-2009 & 660,264 & $61.4089 \%$ \\
\hline \begin{tabular}{|l|l|} 
XS0369337711 \\
\end{tabular} & USD & 17-Jun-2009 & $1,569,347$ & $109.7094 \%$ \\
\hline \begin{tabular}{|l|} 
XS0305084591 \\
\end{tabular} & USD & 18-Jun-2009 & $2,082,923$ & $53.5744 \%$ \\
\hline XS0305098971 & USD & 18-Jun-2009 & 739,034 & $53.0238 \%$ \\
\hline \begin{tabular}{|l|} 
XS0305099359 \\
\end{tabular} & GBP & 18-Jun-2009 & $2,191,266$ & $81.1029 \%$ \\
\hline XS0305099789 & EUR & 18-Jun-2009 & $2,347,974$ & $48.9161 \%$ \\
\hline \begin{tabular}{|l|} 
XS0305100389 \\
\end{tabular} & EUR & 18-Jun-2009 & 510,726 & $25.5363 \%$ \\
\hline XS0305100892 & EUR & 18-Jun-2009 & 647,368 & $19.0402 \%$ \\
\hline XS0368800669 & JPY & 18-Jun-2009 & 201,759 & $56.2949 \%$ \\
\hline XS0368995907 & JPY & 18-Jun-2009 & 230,243 & $64.2424 \%$ \\
\hline \begin{tabular}{|l|} 
XS0369674550 \\
\end{tabular} & USD & 18-Jun-2009 & 162,876 & $42.5350 \%$ \\
\hline DE000A0SG1R9 & EUR & 19-Jun-2009 & $26,786,708$ & $108.3780 \%$ \\
\hline XS0305438151 & EUR & 19-Jun-2009 & 216,897 & $25.5172 \%$ \\
\hline XS0305438821 & USD & 19-Jun-2009 & 502,458 & $62.2682 \%$ \\
\hline \begin{tabular}{|l|} 
XS0368995220 \\
\end{tabular} & JPY & 19-Jun-2009 & 234,276 & $65.3676 \%$ \\
\hline XS0368995493 & JPY & 19-Jun-2009 & 191,039 & $53.3037 \%$ \\
\hline \begin{tabular}{|l} 
XS0368995659 \\
\end{tabular} & JPY & 19-Jun-2009 & 232,941 & $64.9952 \%$ \\
\hline XS0368996038 & JPY & 19-Jun-2009 & 204,315 & $57.0079 \%$ \\
\hline \begin{tabular}{|l|} 
XS0368996111 \\
\end{tabular} & JPY & 19-Jun-2009 & 201,217 & $56.1437 \%$ \\
\hline XS0257593037 & JPY & 20-Jun-2009 & 623,009 & $8.6916 \%$ \\
\hline XS0279202682 & EUR & 20-Jun-2009 & $2,750,000$ & $100.0000 \%$ \\
\hline \begin{tabular}{|l|} 
DE000A0S7D50 \\
\end{tabular} & EUR & 22-Jun-2009 & $5,956,938$ & $54.1540 \%$ \\
\hline \begin{tabular}{|l} 
XS0305627043 \\
\end{tabular} & USD & 22-Jun-2009 & $3,020,217$ & $54.1731 \%$ \\
\hline \begin{tabular}{|l|} 
XS0305886227 \\
\end{tabular} & $\mathrm{HKD}$ & 22-Jun-2009 & 708,642 & $53.5890 \%$ \\
\hline XS0306153015 & USD & 22-Jun-2009 & $1,420,654$ & $54.5531 \%$ \\
\hline XS0306693127 & USD & 22-Jun-2009 & 160,583 & $6.7356 \%$ \\
\hline \begin{tabular}{|l} 
XS0323353499 \\
\end{tabular} & EUR & 22-Jun-2009 & $1,700,977$ & $54.1540 \%$ \\
\hline XS0368700281 & HKD & 22-Jun-2009 & $2,815,003$ & $86.3847 \%$ \\
\hline XS0368751433 & USD & 22-Jun-2009 & $7,360,316$ & $86.3847 \%$ \\
\hline \begin{tabular}{|l|} 
XS0370358151 \\
\end{tabular} & USD & 22-Jun-2009 & 972,711 & $102.0000 \%$ \\
\hline \begin{tabular}{|l|} 
XS0168797032 \\
\end{tabular} & EUR & 23-Jun-2009 & $23,477,779$ & $108.7690 \%$ \\
\hline XS0369744353 & JPY & 23-Jun-2009 & 194,733 & $54.3344 \%$ \\
\hline \begin{tabular}{|l} 
XS0369744601 \\
\end{tabular} & JPY & 23-Jun-2009 & 195,334 & $54.5022 \%$ \\
\hline XS0369744783 & JPY & 23-Jun-2009 & 196,738 & $54.8937 \%$ \\
\hline \begin{tabular}{|l|} 
XS0369744866 \\
\end{tabular} & JPY & 23-Jun-2009 & 192,778 & $53.7889 \%$ \\
\hline XS0182881093 & USD & 24-Jun-2009 & 105,263 & $102.4958 \%$ \\
\hline XS0336414940 & SGD & 24-Jun-2009 & 793,755 & $77.2382 \%$ \\
\hline XS0336415327 & SGD & 24-Jun-2009 & 324,737 & $47.9841 \%$ \\
\hline \begin{tabular}{|l|} 
XS0369192991 \\
\end{tabular} & USD & 24-Jun-2009 & 718,268 & $76.4955 \%$ \\
\hline \begin{tabular}{|l|} 
XS0369744510 \\
\end{tabular} & JPY & 24-Jun-2009 & 184,478 & $51.4730 \%$ \\
\hline \begin{tabular}{|l} 
DE000AOWDDE2 \\
\end{tabular} & USD & 25-Jun-2009 & $6,840,012$ & $84.7664 \%$ \\
\hline XS0369515084 & HKD & 25-Jun-2009 & $2,474,300$ & $64.3628 \%$ \\
\hline XS0369545313 & USD & 25-Jun-2009 & $1,185,091$ & $64.3632 \%$ \\
\hline DE000A0S2A33 & EUR & 26-Jun-2009 & $8,632,401$ & $140.2958 \%$ \\
\hline XS0304156986 & USD & 26-Jun-2009 & $6,602,113$ & $100.0000 \%$ \\
\hline XS0336616577 & USD & 26-Jun-2009 & 862,885 & $71.2900 \%$ \\
\hline \begin{tabular}{|l|} 
XS0129914874 \\
\end{tabular} & EUR & 28-Jun-2009 & $40,760,476$ & $101.7867 \%$ \\
\hline \begin{tabular}{|l|} 
XS0257988484 \\
\end{tabular} & EUR & 28-Jun-2009 & $4,500,000$ & $100.0000 \%$ \\
\hline \begin{tabular}{|l} 
XS0337407943 \\
\end{tabular} & USD & 28-Jun-2009 & 576,906 & $112.3484 \%$ \\
\hline US52521XAB47 & USD & 29-Jun-2009 & $21,332,198$ & $84.7815 \%$ \\
\hline XS0258782720 & EUR & 29-Jun-2009 & 782,462 & $13.0410 \%$ \\
\hline \begin{tabular}{|l|}
$X S 0259010022$ \\
\end{tabular} & USD & 29-Jun-2009 & $4,841,549$ & $100.0000 \%$ \\
\hline \begin{tabular}{|l} 
XS0305949595 \\
\end{tabular} & USD & 29-Jun-2009 & 48,481 & $6.6089 \%$ \\
\hline
\end{tabular}




\begin{tabular}{|c|c|c|c|c|}
\hline ISIN & Currency & $\begin{array}{c}\text { Maturity } \\
\text { date }\end{array}$ & $\begin{array}{c}\text { Admissible } \\
\text { Amount in EUR }\end{array}$ & $\begin{array}{c}\text { Admissible } \\
\text { Amount \% }\end{array}$ \\
\hline XS0307093491 & AUD & 29-Jun-2009 & $1,319,489$ & $35.4094 \%$ \\
\hline XS0307264050 & USD & 29-Jun-2009 & 589,671 & $39.2117 \%$ \\
\hline XS0307616937 & USD & 29-Jun-2009 & 483,564 & $7.4485 \%$ \\
\hline XS0308389807 & USD & 29-Jun-2009 & $1,373,973$ & $100.0000 \%$ \\
\hline XS0337408248 & USD & 29-Jun-2009 & 733,568 & $100.0000 \%$ \\
\hline XS0370386442 & USD & 29-Jun-2009 & 209,195 & $81.4784 \%$ \\
\hline XS0370386954 & HKD & 29-Jun-2009 & 469,478 & $81.4821 \%$ \\
\hline XS0258047165 & USD & 30-Jun-2009 & 255,393 & $105.1816 \%$ \\
\hline XS0307616424 & EUR & 2-Jul-2009 & $1,079,583$ & $56.8202 \%$ \\
\hline XS0256368308 & USD & 3-Jul-2009 & $2,332,746$ & $106.0000 \%$ \\
\hline XS0257595834 & JPY & 3-Jul-2009 & 216,597 & $24.6150 \%$ \\
\hline XS0307153493 & USD & 6-Jul-2009 & 89,698 & $6.1138 \%$ \\
\hline XS0308098663 & USD & 6-Jul-2009 & $1,569,057$ & $28.1439 \%$ \\
\hline XS0308099125 & USD & 6-Jul-2009 & 280,608 & $6.2709 \%$ \\
\hline XS0308100402 & USD & 6-Jul-2009 & $2,232,271$ & $60.8606 \%$ \\
\hline XS0308102283 & AUD & 6-Jul-2009 & $2,965,634$ & $79.5849 \%$ \\
\hline XS0308274140 & USD & 6-Jul-2009 & 510,518 & $22.4496 \%$ \\
\hline XS0308390052 & USD & 6-Jul-2009 & 308,448 & $26.2798 \%$ \\
\hline XS0308390722 & USD & 6-Jul-2009 & $1,789,272$ & $60.9784 \%$ \\
\hline XS0308588838 & USD & 6-Jul-2009 & 55,312 & $6.2834 \%$ \\
\hline XS0338526576 & USD & 7-Jul-2009 & $5,452,077$ & $58.0532 \%$ \\
\hline XS0338676033 & USD & 7-Jul-2009 & 380,734 & $39.9243 \%$ \\
\hline XS0372820737 & JPY & 7-Jul-2009 & 377,530 & $52.6692 \%$ \\
\hline XS0372820810 & JPY & 7-Jul-2009 & 186,658 & $52.0813 \%$ \\
\hline XS0287032790 & EUR & 9-Jul-2009 & $1,896,000$ & $100.0000 \%$ \\
\hline XS0308734242 & EUR & 9-Jul-2009 & 573,637 & $22.9455 \%$ \\
\hline XS0308734911 & USD & 9-Jul-2009 & 544,102 & $7.8906 \%$ \\
\hline XS0373590685 & JPY & 9-Jul-2009 & 381,929 & $53.2829 \%$ \\
\hline XS0257101856 & EUR & 10-Jul-2009 & $5,230,607$ & $117.8861 \%$ \\
\hline XS0259811114 & EUR & 10-Jul-2009 & $1,000,000$ & $100.0000 \%$ \\
\hline XS0308937514 & JPY & 10-Jul-2009 & $1,411,411$ & $49.2265 \%$ \\
\hline XS0308970994 & USD & 10-Jul-2009 & 185,009 & $7.8814 \%$ \\
\hline XS0308971539 & EUR & 10-Jul-2009 & 802,386 & $57.3133 \%$ \\
\hline XS0308973311 & USD & 10-Jul-2009 & 45,559 & $6.2106 \%$ \\
\hline XS0374132677 & HKD & 10-Jul-2009 & 333,320 & $88.2223 \%$ \\
\hline XS0374132750 & HKD & 10-Jul-2009 & 337,466 & $89.3196 \%$ \\
\hline XS0309436862 & EUR & 13-Jul-2009 & 535,341 & $23.7929 \%$ \\
\hline XS0309813839 & USD & 13-Jul-2009 & $1,612,449$ & $88.3122 \%$ \\
\hline XS0310083950 & AUD & 13-Jul-2009 & $2,531,490$ & $67.9343 \%$ \\
\hline XS0258947745 & EUR & 14-Jul-2009 & $5,031,165$ & $63.6051 \%$ \\
\hline XS0259664653 & JPY & 14-Jul-2009 & 422,832 & $58.9139 \%$ \\
\hline XS0259959962 & USD & 14-Jul-2009 & $2,063,160$ & $125.0000 \%$ \\
\hline XS0260769434 & USD & 14-Jul-2009 & $2,670,188$ & $104.0000 \%$ \\
\hline XS0260770010 & EUR & 14-Jul-2009 & $3,500,000$ & $100.0000 \%$ \\
\hline XS0373776433 & JPY & 14-Jul-2009 & 261,273 & $72.9005 \%$ \\
\hline XS0373826808 & JPY & 14-Jul-2009 & 228,928 & $63.8754 \%$ \\
\hline XS0374643509 & JPY & 14-Jul-2009 & 188,344 & $52.5517 \%$ \\
\hline XS0151487054 & EUR & 15-Jul-2009 & $5,208,575$ & $104.1715 \%$ \\
\hline XS0374643764 & JPY & 15-Jul-2009 & 378,696 & $52.8319 \%$ \\
\hline XS0303539273 & USD & 16-Jul-2009 & $6,232,394$ & $100.0000 \%$ \\
\hline XS0306096628 & GBP & 16-Jul-2009 & $3,197,170$ & $100.0000 \%$ \\
\hline XS0310084339 & EUR & 17-Jul-2009 & $1,307,093$ & $26.9504 \%$ \\
\hline XS0310085575 & EUR & 17-Jul-2009 & 765,310 & $26.8530 \%$ \\
\hline XS0310085815 & USD & 17-Jul-2009 & 488,536 & $27.1826 \%$ \\
\hline XS0339222308 & USD & 17-Jul-2009 & 826,354 & $93.8738 \%$ \\
\hline XS0339532755 & AUD & 18-Jul-2009 & 79,851 & $100.0000 \%$ \\
\hline XS0308269819 & EUR & 20-Jul-2009 & 750,000 & $100.0000 \%$ \\
\hline XS0310476766 & SGD & 20-Jul-2009 & $2,252,683$ & $86.4164 \%$ \\
\hline XS0310486641 & USD & 20-Jul-2009 & 842,033 & $76.5239 \%$ \\
\hline XS0310793905 & USD & 20-Jul-2009 & 949,955 & $76.1752 \%$ \\
\hline XS0310414908 & JPY & 21-Jul-2009 & $1,109,466$ & $49.9295 \%$ \\
\hline XS0310487292 & JPY & 21-Jul-2009 & $2,926,709$ & $46.3983 \%$ \\
\hline XS0331566181 & USD & 21-Jul-2009 & 462,148 & $90.0000 \%$ \\
\hline XS0223590612 & $\mathrm{CHF}$ & 22-Jul-2009 & $5,133,325$ & $100.0000 \%$ \\
\hline XS0375919718 & JPY & 22-Jul-2009 & 214,092 & $59.7360 \%$ \\
\hline XS0172402421 & USD & 23-Jul-2009 & $1,505,623$ & $100.0227 \%$ \\
\hline XS0311179252 & USD & 23-Jul-2009 & $1,659,665$ & $59.5383 \%$ \\
\hline XS0311484561 & USD & 23-Jul-2009 & 88,177 & $6.6779 \%$ \\
\hline XS0376340344 & JPY & 23-Jul-2009 & 224,758 & $62.7121 \%$ \\
\hline XS0376340690 & JPY & 23-Jul-2009 & 211,853 & $59.1111 \%$ \\
\hline XS0376340930 & JPY & 23-Jul-2009 & 234,486 & $65.4262 \%$ \\
\hline XS0376779657 & JPY & 23-Jul-2009 & 223,944 & $62.4848 \%$ \\
\hline XS0376779814 & JPY & 23-Jul-2009 & 176,552 & $49.2616 \%$ \\
\hline XS0376779905 & JPY & 23-Jul-2009 & 201,571 & $56.2423 \%$ \\
\hline XS0311479488 & JPY & 24-Jul-2009 & 944,885 & $65.9104 \%$ \\
\hline XS0311482193 & EUR & 24-Jul-2009 & 517,629 & $30.4488 \%$ \\
\hline XS0311486269 & USD & 24-Jul-2009 & 580,572 & $27.2909 \%$ \\
\hline XS0131585845 & EUR & 26-Jul-2009 & $40,038,989$ & $101.8091 \%$ \\
\hline XS0260445530 & $\mathrm{CHF}$ & 26-Jul-2009 & $2,383,645$ & $74.0169 \%$ \\
\hline
\end{tabular}




\begin{tabular}{|c|c|c|c|c|}
\hline ISIN & Currency & $\begin{array}{l}\text { Maturity } \\
\text { date }\end{array}$ & $\begin{array}{c}\text { Admissible } \\
\text { Amount in EUR }\end{array}$ & $\begin{array}{c}\text { Admissible } \\
\text { Amount \% } \\
\end{array}$ \\
\hline \begin{tabular}{|l|} 
XS0310125546 \\
\end{tabular} & EUR & 26-Jul-2009 & $1,500,000$ & $100.0000 \%$ \\
\hline XS0311740582 & AUD & 27-Jul-2009 & $3,726,377$ & $100.0000 \%$ \\
\hline \begin{tabular}{|l|l|}
$X S 0311853195$ \\
\end{tabular} & USD & 27-Jul-2009 & 453,380 & $28.0931 \%$ \\
\hline \begin{tabular}{|l|} 
XS0312172298 \\
\end{tabular} & USD & 27-Jul-2009 & 45,969 & $6.2665 \%$ \\
\hline XS0312194854 & USD & 27-Jul-2009 & $1,942,628$ & $65.3874 \%$ \\
\hline XS0312428609 & AUD & 27-Jul-2009 & $3,726,377$ & $100.0000 \%$ \\
\hline \begin{tabular}{|l|} 
XS0312435729 \\
\end{tabular} & USD & 27-Jul-2009 & 76,723 & $6.1523 \%$ \\
\hline \begin{tabular}{|l|} 
XS0340756898 \\
\end{tabular} & USD & 28-Jul-2009 & $2,677,523$ & $100.0000 \%$ \\
\hline \begin{tabular}{|l|} 
XS0336151088 \\
\end{tabular} & EUR & 29-Jul-2009 & $10,000,000$ & $100.0000 \%$ \\
\hline XS0312427460 & USD & 30-Jul-2009 & 150,437 & $10.5167 \%$ \\
\hline \begin{tabular}{|l|} 
XS0312461642 \\
\end{tabular} & USD & 30-Jul-2009 & $1,401,431$ & $63.6810 \%$ \\
\hline \begin{tabular}{|l|} 
XS0312723272 \\
\end{tabular} & AUD & 30-Jul-2009 & $2,283,551$ & $61.2807 \%$ \\
\hline \begin{tabular}{|l|} 
XS0342399325 \\
\end{tabular} & USD & 30-Jul-2009 & $1,642,159$ & $66.8236 \%$ \\
\hline \begin{tabular}{|l} 
XS0241762748 \\
\end{tabular} & USD & 31-Jul-2009 & $2,200,704$ & $100.0000 \%$ \\
\hline \begin{tabular}{|l|} 
XS0261032238 \\
\end{tabular} & $\mathrm{CHF}$ & 31-Jul-2009 & $10,007,358$ & $77.6871 \%$ \\
\hline \begin{tabular}{|l|} 
XS0284114567 \\
\end{tabular} & EUR & 31-Jul-2009 & 950,000 & $95.0000 \%$ \\
\hline XS0312723603 & USD & 31-Jul-2009 & 922,413 & $41.9145 \%$ \\
\hline \begin{tabular}{|l} 
XS0344835078 \\
\end{tabular} & USD & 5-Aug-2009 & 157,927 & $8.9703 \%$ \\
\hline \begin{tabular}{|l|} 
XS0344884019 \\
\end{tabular} & USD & 5-Aug-2009 & 261,669 & $59.0854 \%$ \\
\hline \begin{tabular}{|l|l|}
$X S 0380728112$ \\
\end{tabular} & AUD & 5-Aug-2009 & $1,338,781$ & $101.0000 \%$ \\
\hline \begin{tabular}{|l|}
$X S 0262696874$ \\
\end{tabular} & GBP & 7-Aug-2009 & 284,025 & $110.3794 \%$ \\
\hline \begin{tabular}{|l} 
XS0313789074 \\
\end{tabular} & USD & 7-Aug-2009 & 238,002 & $21.6296 \%$ \\
\hline \begin{tabular}{|l} 
XS0313791567 \\
\end{tabular} & USD & 7-Aug-2009 & $1,091,343$ & $57.2200 \%$ \\
\hline XS0263098674 & JPY & 10-Aug-2009 & $1,134,952$ & $52.7790 \%$ \\
\hline \begin{tabular}{|l|} 
XS0273587302 \\
\end{tabular} & USD & 10-Aug-2009 & $1,062,097$ & $68.9452 \%$ \\
\hline \begin{tabular}{|l} 
XS0314157644 \\
\end{tabular} & USD & 10-Aug-2009 & $1,053,177$ & $79.7606 \%$ \\
\hline \begin{tabular}{|l|} 
XS0314391672 \\
\end{tabular} & USD & 10-Aug-2009 & 838,675 & $81.6630 \%$ \\
\hline XS0314392647 & JPY & 10-Aug-2009 & $1,498,337$ & $60.4526 \%$ \\
\hline \begin{tabular}{|l|} 
XS0314578310 \\
\end{tabular} & AUD & 10-Aug-2009 & $4,480,677$ & $120.2422 \%$ \\
\hline XS0262163206 & USD & 14-Aug-2009 & $3,388,168$ & $125.0000 \%$ \\
\hline \begin{tabular}{|l|} 
XS0309306651 \\
\end{tabular} & USD & 14-Aug-2009 & $1,138,498$ & $100.0000 \%$ \\
\hline XS0309307113 & GBP & 14-Aug-2009 & $2,076,552$ & $100.0000 \%$ \\
\hline \begin{tabular}{|l|} 
XS0265524438 \\
\end{tabular} & USD & 15-Aug-2009 & $41,100,445$ & $101.8693 \%$ \\
\hline XS0315549690 & JPY & 17-Aug-2009 & $2,322,296$ & $57.3422 \%$ \\
\hline \begin{tabular}{|l} 
XS0264209387 \\
\end{tabular} & $\mathrm{CHF}$ & 18-Aug-2009 & $2,254,283$ & $100.0000 \%$ \\
\hline \begin{tabular}{|l|} 
XS0264242321 \\
\end{tabular} & EUR & 18-Aug-2009 & 610,180 & $61.0180 \%$ \\
\hline \begin{tabular}{|l|} 
XS0383779906 \\
\end{tabular} & HKD & 19-Aug-2009 & $1,215,508$ & $85.7914 \%$ \\
\hline XS0383013066 & USD & 21-Aug-2009 & 871,155 & $58.5004 \%$ \\
\hline XS0262353831 & EUR & 22-Aug-2009 & $7,037,313$ & $101.4168 \%$ \\
\hline XS0317359478 & USD & 23-Aug-2009 & $2,200,704$ & $100.0000 \%$ \\
\hline \begin{tabular}{|l|} 
XS0275453438 \\
\end{tabular} & GBP & 24-Aug-2009 & $2,271,116$ & $84.0583 \%$ \\
\hline XS0315257484 & GBP & 24-Aug-2009 & $1,672,564$ & $100.0000 \%$ \\
\hline XS0316455061 & USD & 24-Aug-2009 & 670,282 & $63.0157 \%$ \\
\hline XS0316826733 & AUD & 24-Aug-2009 & $3,726,377$ & $100.0000 \%$ \\
\hline \begin{tabular}{|l} 
XS0316829166 \\
\end{tabular} & JPY & 24-Aug-2009 & 882,677 & $72.9654 \%$ \\
\hline XS0316992154 & USD & 24-Aug-2009 & 128,747 & $13.5006 \%$ \\
\hline XS0384213954 & USD & 25-Aug-2009 & 163,388 & $18.5609 \%$ \\
\hline \begin{tabular}{|l|} 
XS0382589074 \\
\end{tabular} & USD & 26-Aug-2009 & 637,189 & $86.8617 \%$ \\
\hline \begin{tabular}{|l|} 
XS0316992824 \\
\end{tabular} & USD & 27-Aug-2009 & $3,004,418$ & $68.8340 \%$ \\
\hline XS0317181716 & EUR & 27-Aug-2009 & $5,000,000$ & $100.0000 \%$ \\
\hline \begin{tabular}{|l} 
XS0263871674 \\
\end{tabular} & EUR & 28-Aug-2009 & $37,200,000$ & $100.0000 \%$ \\
\hline XS0278450027 & EUR & 28-Aug-2009 & $7,195,000$ & $100.0000 \%$ \\
\hline \begin{tabular}{|l} 
XS0317366689 \\
\end{tabular} & GBP & 28-Aug-2009 & $2,889,949$ & $89.8485 \%$ \\
\hline XS0317417003 & USD & 28-Aug-2009 & 189,704 & $17.2403 \%$ \\
\hline \begin{tabular}{|l} 
XS0348936914 \\
\end{tabular} & EUR & 28-Aug-2009 & $1,500,000$ & $100.0000 \%$ \\
\hline XS0226380334 & $\mathrm{CHF}$ & 30-Aug-2009 & $7,585,341$ & $100.0000 \%$ \\
\hline \begin{tabular}{|l|} 
XS0264994459 \\
\end{tabular} & EUR & 31-Aug-2009 & $3,200,000$ & $100.0000 \%$ \\
\hline XS0317742335 & JPY & 1-Sep-2009 & 602,041 & $44.2056 \%$ \\
\hline XS0317744380 & USD & 1-Sep-2009 & $2,790,196$ & $96.2936 \%$ \\
\hline XS0264195222 & USD & 4-Sep-2009 & 339,275 & $125.0000 \%$ \\
\hline \begin{tabular}{|l|} 
XS0314889154 \\
\end{tabular} & USD & 4-Sep-2009 & $1,467,136$ & $100.0000 \%$ \\
\hline XS0265627751 & $\mathrm{CHF}$ & 7-Sep-2009 & $2,208,940$ & $31.1274 \%$ \\
\hline XS0302510911 & GBP & 7-Sep-2009 & 675,217 & $43.7344 \%$ \\
\hline XS0266551299 & JPY & 8-Sep-2009 & 120,433 & $33.6032 \%$ \\
\hline \begin{tabular}{|l|} 
XS0288704264 \\
\end{tabular} & USD & 9-Sep-2009 & $1,577,171$ & $100.0000 \%$ \\
\hline \begin{tabular}{|l|} 
XS0384062211 \\
\end{tabular} & JPY & 10-Sep-2009 & 272,440 & $76.0162 \%$ \\
\hline \begin{tabular}{|l|} 
XS0200454188 \\
\end{tabular} & USD & 11-Sep-2009 & 416,300 & $113.5000 \%$ \\
\hline XS0319000260 & JPY & 11-Sep-2009 & 178,403 & $36.5348 \%$ \\
\hline XS0319632575 & AUD & 12-Sep-2009 & $3,726,377$ & $100.0000 \%$ \\
\hline XS0319632732 & AUD & 12-Sep-2009 & $3,726,377$ & $100.0000 \%$ \\
\hline XS0346438061 & USD & 12-Sep-2009 & $3,741,087$ & $58.1843 \%$ \\
\hline XS0260341911 & GBP & 14-Sep-2009 & $2,395,626$ & $100.0000 \%$ \\
\hline \begin{tabular}{|l|} 
XS0266686897 \\
\end{tabular} & JPY & 14-Sep-2009 & 206,233 & $47.9526 \%$ \\
\hline \begin{tabular}{|l|} 
XS0266698801 \\
\end{tabular} & JPY & 14-Sep-2009 & 153,286 & $21.3849 \%$ \\
\hline XS0266901700 & JPY & 14-Sep-2009 & 487,267 & $39.9874 \%$ \\
\hline XS0319612114 & USD & 14-Sep-2009 & $1,189,673$ & $50.6801 \%$ \\
\hline XS0319740626 & USD & 14-Sep-2009 & $1,428,991$ & $100.0000 \%$ \\
\hline XS0320033110 & USD & 14-Sep-2009 & 529,382 & $72.1654 \%$ \\
\hline \begin{tabular}{|l} 
XS0320102295 \\
\end{tabular} & AUD & 14-Sep-2009 & $4,156,841$ & $111.5518 \%$ \\
\hline
\end{tabular}




\begin{tabular}{|c|c|c|c|c|}
\hline ISIN & Currency & $\begin{array}{c}\text { Maturity } \\
\text { date }\end{array}$ & $\begin{array}{c}\text { Admissible } \\
\text { Amount in EUR }\end{array}$ & $\begin{array}{c}\text { Admissible } \\
\text { Amount \% }\end{array}$ \\
\hline XS0267045705 & JPY & 15-Sep-2009 & 316,052 & $41.0620 \%$ \\
\hline \begin{tabular}{|l|} 
XS0289550658 \\
\end{tabular} & SGD & 16-Sep-2009 & 576,499 & $100.0000 \%$ \\
\hline \begin{tabular}{|l} 
XS0320520884 \\
\end{tabular} & USD & 18-Sep-2009 & $3,583,453$ & $76.9285 \%$ \\
\hline XS0320521007 & USD & 18-Sep-2009 & 192,948 & $14.2177 \%$ \\
\hline XS0197481897 & USD & 20-Sep-2009 & $7,602,134$ & $103.6323 \%$ \\
\hline XS0200049590 & USD & 20-Sep-2009 & $16,181,618$ & $102.5990 \%$ \\
\hline \begin{tabular}{|l} 
XS0201733945 \\
\end{tabular} & USD & 20-Sep-2009 & $7,417,004$ & $101.1086 \%$ \\
\hline \begin{tabular}{|l} 
XS0320744724 \\
\end{tabular} & USD & 21-Sep-2009 & 120,529 & $13.6921 \%$ \\
\hline $\begin{array}{l}\text { XS0320745028 } \\
\end{array}$ & AUD & 21-Sep-2009 & $3,726,377$ & $100.0000 \%$ \\
\hline XS0321101007 & USD & 21-Sep-2009 & $2,954,746$ & $76.7221 \%$ \\
\hline \begin{tabular}{|l|} 
XS0321712738 \\
\end{tabular} & HKD & 21-Sep-2009 & $4,866,677$ & $104.1731 \%$ \\
\hline XS0321795840 & AUD & 21-Sep-2009 & $8,081,265$ & $216.8665 \%$ \\
\hline XS0349857317 & USD & 22-Sep-2009 & $4,665,493$ & $106.0000 \%$ \\
\hline XS0176801537 & EUR & 25-Sep-2009 & $2,475,876$ & $101.6787 \%$ \\
\hline XS0189451346 & USD & 25-Sep-2009 & $50,082,325$ & $101.3994 \%$ \\
\hline \begin{tabular}{|l} 
XS0267329307 \\
\end{tabular} & $\mathrm{CHF}$ & 25-Sep-2009 & $5,040,795$ & $82.3825 \%$ \\
\hline \begin{tabular}{|l} 
XS0321495532 \\
\end{tabular} & USD & 25-Sep-2009 & $2,200,704$ & $100.0000 \%$ \\
\hline XS0353823130 & USD & 25-Sep-2009 & 297,648 & $101.4383 \%$ \\
\hline \begin{tabular}{|l|} 
XS0320876120 \\
\end{tabular} & USD & 28-Sep-2009 & $1,237,144$ & $88.7618 \%$ \\
\hline \begin{tabular}{|l|} 
XS0321794280 \\
\end{tabular} & AUD & 28-Sep-2009 & $3,726,377$ & $100.0000 \%$ \\
\hline XS0321980582 & USD & 28-Sep-2009 & 598,599 & $54.4007 \%$ \\
\hline \begin{tabular}{|l} 
XS0322030437 \\
\end{tabular} & USD & 28-Sep-2009 & $1,067,513$ & $103.9452 \%$ \\
\hline XS0322030940 & AUD & 28-Sep-2009 & $2,560,610$ & $68.7158 \%$ \\
\hline \begin{tabular}{|l|} 
XS0322467886 \\
\end{tabular} & USD & 28-Sep-2009 & 543,233 & $24.6845 \%$ \\
\hline \begin{tabular}{|l|}
$X S 0322467969$ \\
\end{tabular} & AUD & 28-Sep-2009 & $3,726,377$ & $100.0000 \%$ \\
\hline \begin{tabular}{|l} 
XS0322468777 \\
\end{tabular} & AUD & 28-Sep-2009 & $2,932,933$ & $78.7074 \%$ \\
\hline XS0322498923 & HKD & 28-Sep-2009 & $3,860,031$ & $71.6957 \%$ \\
\hline XS0267059755 & EUR & 29-Sep-2009 & $2,206,850$ & $95.0000 \%$ \\
\hline XS0200265709 & $\mathrm{CHF}$ & 30-Sep-2009 & $35,768,965$ & $100.9780 \%$ \\
\hline XS0270184244 & USD & 30-Sep-2009 & $8,147,182$ & $111.0624 \%$ \\
\hline XS0293138813 & EUR & 30-Sep-2009 & 800,000 & $100.0000 \%$ \\
\hline XS0322470088 & USD & 1-Oct-2009 & 752,137 & $102.5313 \%$ \\
\hline XS0322468850 & USD & 2-Oct-2009 & 610,205 & $59.4165 \%$ \\
\hline XS0136264214 & EUR & 5-Oct-2009 & $11,897,711$ & $110.8310 \%$ \\
\hline XS0266486025 & USD & 5-Oct-2009 & $3,667,840$ & $100.0000 \%$ \\
\hline \begin{tabular}{|l|} 
XS0266544831 \\
\end{tabular} & EUR & 5-Oct-2009 & $1,800,000$ & $90.0000 \%$ \\
\hline XS0268238622 & JPY & 5-Oct-2009 & 331,617 & $18.5055 \%$ \\
\hline XS0268244356 & JPY & 5-Oct-2009 & 230,980 & $32.2240 \%$ \\
\hline \begin{tabular}{|l|} 
XS0269787858 \\
\end{tabular} & USD & 5-Oct-2009 & $3,921,100$ & $106.9049 \%$ \\
\hline \begin{tabular}{|l|} 
XS0294545669 \\
\end{tabular} & USD & $5-$ - ct-2009 & $1,159,038$ & $100.0000 \%$ \\
\hline \begin{tabular}{|l|} 
XS0319273404 \\
\end{tabular} & USD & 5-Oct-2009 & 733,568 & $100.0000 \%$ \\
\hline \begin{tabular}{|l} 
XS0320337685 \\
\end{tabular} & GBP & 5-Oct-2009 & $3,150,852$ & $100.0000 \%$ \\
\hline \begin{tabular}{|l|} 
XS0323081801 \\
\end{tabular} & USD & 5-Oct-2009 & 735,172 & $77.0913 \%$ \\
\hline XS0269092366 & GBP & 6-Oct-2009 & $1,309,613$ & $107.1471 \%$ \\
\hline \begin{tabular}{|l} 
XS0323634823 \\
\end{tabular} & AUD & 6-Oct-2009 & $5,605,027$ & $75.2075 \%$ \\
\hline XS0323635473 & AUD & 6-Oct-2009 & $1,759,895$ & $47.2280 \%$ \\
\hline XS0323635713 & AUD & 6-Oct-2009 & $3,726,377$ & $100.0000 \%$ \\
\hline \begin{tabular}{|l|} 
XS0324187839 \\
\end{tabular} & AUD & 6-Oct-2009 & $5,605,027$ & $75.2075 \%$ \\
\hline \begin{tabular}{|l} 
XS0306772426 \\
\end{tabular} & USD & 8-Oct-2009 & 769,434 & $104.8892 \%$ \\
\hline XS0323881671 & USD & 9-Oct-2009 & 505,081 & $34.4263 \%$ \\
\hline \begin{tabular}{|l|} 
XS0323881754 \\
\end{tabular} & AUD & 9-Oct-2009 & 747,663 & $54.0187 \%$ \\
\hline XS0323882216 & SGD & 9-Oct-2009 & 620,481 & $70.7277 \%$ \\
\hline XS0352062565 & CZK & 9-Oct-2009 & 390,081 & $99.9915 \%$ \\
\hline XS0325385259 & USD & $11-$ Oct-2009 & 429,141 & $19.5002 \%$ \\
\hline XS0325385333 & USD & $11-$ Oct-2009 & $1,630,361$ & $44.4502 \%$ \\
\hline XS0324356376 & EUR & $12-$ Oct-2009 & $1,123,307$ & $72.4714 \%$ \\
\hline XS0324461911 & AUD & $12-$ Oct-2009 & $2,961,748$ & $79.4806 \%$ \\
\hline \begin{tabular}{|l}
$\mathrm{XS} 0324462133$ \\
\end{tabular} & AUD & $12-$ Oct-2009 & $2,630,712$ & $70.5970 \%$ \\
\hline XS0323634666 & USD & $13-$ Oct-2009 & $6,300,276$ & $100.3334 \%$ \\
\hline XS0324461671 & USD & $13-$ Oct-2009 & $1,855,056$ & $87.2004 \%$ \\
\hline XS0324464345 & USD & $13-$ Oct-2009 & $4,500,641$ & $80.1997 \%$ \\
\hline XS0324476943 & USD & 13-Oct-2009 & 589,419 & $80.3496 \%$ \\
\hline XS0356443852 & AUD & $14-$ Oct-2009 & $1,120,316$ & $99.8820 \%$ \\
\hline XS0324983963 & AUD & $15-$ Oct-2009 & $2,911,787$ & $78.1399 \%$ \\
\hline XS0324984185 & AUD & $15-$ Oct-2009 & $3,721,180$ & $99.8605 \%$ \\
\hline \begin{tabular}{|l} 
XS0324844256 \\
\end{tabular} & USD & $16-$ Oct-2009 & 553,805 & $75.4946 \%$ \\
\hline XS0325080900 & USD & $16-$ Oct-2009 & $2,932,053$ & $39.9697 \%$ \\
\hline \begin{tabular}{|l} 
XS0325081460 \\
\end{tabular} & USD & $16-$ Oct-2009 & $3,506,049$ & $47.7945 \%$ \\
\hline XS0269866306 & JPY & $19-$ Oct-2009 & $1,011,227$ & $28.2153 \%$ \\
\hline \begin{tabular}{|l|} 
XS0270233397 \\
\end{tabular} & JPY & 19-Oct-2009 & 195,171 & $27.2283 \%$ \\
\hline XS0270986499 & GBP & 19-Oct-2009 & $33,500,532$ & $104.1532 \%$ \\
\hline XS0323535418 & USD & $19-$ Oct-2009 & $5,495,927$ & $99.8673 \%$ \\
\hline \begin{tabular}{|l|} 
XS0325197845 \\
\end{tabular} & USD & 19-Oct-2009 & 982,673 & $83.7237 \%$ \\
\hline \begin{tabular}{|l} 
XS0325476215 \\
\end{tabular} & EUR & 19-Oct-2009 & $5,290,626$ & $99.8231 \%$ \\
\hline XS0325557212 & USD & $19-$ Oct-2009 & 19,023 & $103.7287 \%$ \\
\hline \begin{tabular}{|l} 
XS0325784204 \\
\end{tabular} & USD & $19-$ Oct-2009 & $3,478,581$ & $47.4200 \%$ \\
\hline XS0325784626 & GBP & 19-Oct-2009 & 279,992 & $25.6028 \%$ \\
\hline XS0325786167 & USD & 19-Oct-2009 & 8,678 & $11.8299 \%$ \\
\hline \begin{tabular}{|l} 
XS0325786084 \\
\end{tabular} & $\mathrm{HKD}$ & 22-Oct-2009 & $1,447,566$ & $56.0144 \%$ \\
\hline
\end{tabular}




\begin{tabular}{|c|c|c|c|c|}
\hline ISIN & Currency & $\begin{array}{l}\text { Maturity } \\
\text { date }\end{array}$ & $\begin{array}{c}\text { Admissible } \\
\text { Amount in EUR }\end{array}$ & $\begin{array}{c}\text { Admissible } \\
\text { Amount \% }\end{array}$ \\
\hline XS0325786324 & USD & 22-Oct-2009 & 746,715 & $36.3544 \%$ \\
\hline XS0325841368 & USD & 22-Oct-2009 & $1,009,985$ & $57.8492 \%$ \\
\hline XS0325886389 & USD & 23-Oct-2009 & 771,169 & $75.0899 \%$ \\
\hline XS0325886462 & USD & 23-Oct-2009 & 901,959 & $45.5389 \%$ \\
\hline XS0325886546 & USD & 23-Oct-2009 & 732,225 & $99.8169 \%$ \\
\hline XS0326025847 & USD & 23-Oct-2009 & $5,540,730$ & $83.9236 \%$ \\
\hline \begin{tabular}{|l|} 
XS0326025920 \\
\end{tabular} & USD & 23-Oct-2009 & $8,970,233$ & $78.3860 \%$ \\
\hline XS0326026225 & USD & 23-Oct-2009 & 835,417 & $96.5120 \%$ \\
\hline XS0326026498 & HKD & 23-Oct-2009 & $1,457,929$ & $72.9799 \%$ \\
\hline XS0326486734 & AUD & 23-Oct-2009 & $2,691,862$ & $72.2380 \%$ \\
\hline \begin{tabular}{|l|} 
XS0326482402 \\
\end{tabular} & USD & 24-Oct-2009 & $2,357,465$ & $99.8042 \%$ \\
\hline XS0326540290 & USD & 24-Oct-2009 & 188,599 & $12.8549 \%$ \\
\hline \begin{tabular}{|l|}
$X S 0271820978$ \\
\end{tabular} & EUR & 26-Oct-2009 & $1,346,023$ & $89.7349 \%$ \\
\hline \begin{tabular}{|l|} 
XS0325447893 \\
\end{tabular} & EUR & 26-Oct-2009 & $12,251,911$ & $122.5191 \%$ \\
\hline \begin{tabular}{|l} 
XS0326404430 \\
\end{tabular} & USD & 26-Oct-2009 & 659,409 & $64.2076 \%$ \\
\hline XS0326865325 & EUR & 26-Oct-2009 & $1,449,681$ & $80.5378 \%$ \\
\hline XS0326865754 & USD & 26-Oct-2009 & $1,304,678$ & $52.3099 \%$ \\
\hline XS0326866133 & USD & 26-Oct-2009 & 173,535 & $13.9154 \%$ \\
\hline XS0327055702 & USD & 26-Oct-2009 & $3,368,018$ & $45.9128 \%$ \\
\hline \begin{tabular}{|l|l} 
XS0327277199 \\
\end{tabular} & USD & 26-Oct-2009 & 496,193 & $52.0315 \%$ \\
\hline \begin{tabular}{|l|}
$X S 0327277272$ \\
\end{tabular} & HKD & 26-Oct-2009 & 764,686 & $89.9534 \%$ \\
\hline \begin{tabular}{|l|} 
XS0326277810 \\
\end{tabular} & USD & 27-Oct-2009 & 412,137 & $37.4550 \%$ \\
\hline \begin{tabular}{|l|} 
XS0326278032 \\
\end{tabular} & USD & 27-Oct-2009 & $1,317,384$ & $44.8965 \%$ \\
\hline \begin{tabular}{|l|} 
XS0326403200 \\
\end{tabular} & USD & 27-Oct-2009 & 873,679 & $74.4374 \%$ \\
\hline XS0326403895 & HKD & 27-Oct-2009 & 543,263 & $71.8947 \%$ \\
\hline XS0326404190 & USD & 27-Oct-2009 & 578,906 & $71.7422 \%$ \\
\hline XS0326486221 & USD & 27-Oct-2009 & 402,195 & $54.8272 \%$ \\
\hline \begin{tabular}{|l|} 
XS0326490504 \\
\end{tabular} & USD & 27-Oct-2009 & $1,679,558$ & $76.3191 \%$ \\
\hline XS0326539102 & USD & 27-Oct-2009 & $3,873,508$ & $78.8114 \%$ \\
\hline \begin{tabular}{|l|} 
XS0326539367 \\
\end{tabular} & USD & 27-Oct-2009 & 274,652 & $41.6006 \%$ \\
\hline \begin{tabular}{|l|} 
XS0326608279 \\
\end{tabular} & USD & 27-Oct-2009 & $1,402,408$ & $49.6562 \%$ \\
\hline XS0326608352 & HKD & 27-Oct-2009 & $1,491,244$ & $49.6633 \%$ \\
\hline XS0326608436 & USD & 27-Oct-2009 & 564,606 & $49.6562 \%$ \\
\hline XS0326708491 & USD & 27-Oct-2009 & 732,571 & $55.1735 \%$ \\
\hline \begin{tabular}{|l|} 
XS0326862819 \\
\end{tabular} & HKD & 27-Oct-2009 & $1,016,581$ & $71.7510 \%$ \\
\hline \begin{tabular}{|l|} 
XS0326866307 \\
\end{tabular} & $\mathrm{HKD}$ & 27-Oct-2009 & $1,183,528$ & $69.8446 \%$ \\
\hline XS0203784094 & EUR & 28-Oct-2009 & $5,289,677$ & $105.7935 \%$ \\
\hline XS0326865671 & USD & 29-Oct-2009 & 429,665 & $48.0098 \%$ \\
\hline \begin{tabular}{|l|} 
XS0327055371 \\
\end{tabular} & USD & 29-Oct-2009 & $5,714,771$ & $108.1997 \%$ \\
\hline XS0327275144 & SGD & 29-Oct-2009 & 980,038 & $78.1992 \%$ \\
\hline \begin{tabular}{|l|} 
XS0327275573 \\
\end{tabular} & USD & 29-Oct-2009 & 338,340 & $15.3742 \%$ \\
\hline XS0327940176 & USD & 29-Oct-2009 & $1,654,964$ & $37.6008 \%$ \\
\hline XS0347064924 & EUR & 29-Oct-2009 & 58,577 & $0.1025 \%$ \\
\hline XS0269149497 & EUR & 30-Oct-2009 & $2,079,186$ & $77.0069 \%$ \\
\hline \begin{tabular}{|l|} 
XS0285986534 \\
\end{tabular} & EUR & 30-Oct-2009 & 755,956 & $89.6745 \%$ \\
\hline \begin{tabular}{|l|} 
XS0325785276 \\
\end{tabular} & USD & 30-Oct-2009 & $2,040,027$ & $106.9602 \%$ \\
\hline XS0327236088 & GBP & 30-Oct-2009 & 714,801 & $25.8409 \%$ \\
\hline XS0327275656 & AUD & 30-Oct-2009 & $2,596,680$ & $69.6838 \%$ \\
\hline \begin{tabular}{|l|} 
XS0327291349 \\
\end{tabular} & AUD & 30-Oct-2009 & $3,709,207$ & $99.5392 \%$ \\
\hline XS0328585970 & USD & 30-Oct-2009 & $2,196,785$ & $37.4332 \%$ \\
\hline \begin{tabular}{|l|} 
XS0381884617 \\
\end{tabular} & USD & 31-Oct-2009 & 912,686 & $62.2087 \%$ \\
\hline XS0268858502 & EUR & 2-Nov-2009 & $6,087,474$ & $101.4579 \%$ \\
\hline XS0270482424 & EUR & 2-Nov-2009 & $1,432,375$ & $94.6087 \%$ \\
\hline \begin{tabular}{|l|} 
XS0327464979 \\
\end{tabular} & USD & 2-Nov-2009 & 893,072 & $71.6139 \%$ \\
\hline \begin{tabular}{|l|} 
XS0327465430 \\
\end{tabular} & USD & 2-Nov-2009 & 409,965 & $59.4536 \%$ \\
\hline XS0327465604 & USD & 2-Nov-2009 & 81,053 & $11.0492 \%$ \\
\hline XS0327784376 & USD & 2-Nov-2009 & 755,590 & $96.2635 \%$ \\
\hline XS0327848015 & USD & 2-Nov-2009 & $2,435,385$ & $77.2074 \%$ \\
\hline \begin{tabular}{|l|} 
XS0327859301 \\
\end{tabular} & HKD & 2-Nov-2009 & 488,597 & $63.7832 \%$ \\
\hline \begin{tabular}{|l|} 
XS0329192511 \\
\end{tabular} & USD & 2-Nov-2009 & 130,751 & $9.9854 \%$ \\
\hline XS0329424153 & HKD & 2-Nov-2009 & $1,261,763$ & $102.5205 \%$ \\
\hline \begin{tabular}{|l|}
$X S 0272545434$ \\
\end{tabular} & GBP & 3-Nov-2009 & $1,325,515$ & $103.0257 \%$ \\
\hline \begin{tabular}{|l|} 
XS0234626058 \\
\end{tabular} & USD & 4-Nov-2009 & $3,688,380$ & $100.0000 \%$ \\
\hline XS0234626306 & HKD & 4-Nov-2009 & $3,625,166$ & $100.0000 \%$ \\
\hline XS0326865911 & AUD & 5-Nov-2009 & 770,072 & $72.3290 \%$ \\
\hline \begin{tabular}{|l|} 
XS0327940929 \\
\end{tabular} & AUD & 5-Nov-2009 & 663,755 & $53.9768 \%$ \\
\hline XS0328585467 & USD & 6-Nov-2009 & $2,735,866$ & $76.1129 \%$ \\
\hline \begin{tabular}{|l} 
XS0328586515 \\
\end{tabular} & USD & 6-Nov-2009 & 792,109 & $64.6589 \%$ \\
\hline \begin{tabular}{|l|} 
XS0328586606 \\
\end{tabular} & USD & 6-Nov-2009 & $1,032,707$ & $70.3893 \%$ \\
\hline XS0329665946 & USD & 6-Nov-2009 & 223,763 & $8.0272 \%$ \\
\hline \begin{tabular}{|l|} 
XS0329666167 \\
\end{tabular} & USD & 6-Nov-2009 & 111,881 & $8.0272 \%$ \\
\hline XS0328596316 & USD & 7-Nov-2009 & $1,754,002$ & $99.6273 \%$ \\
\hline XS0272576827 & JPY & 9-Nov-2009 & 120,533 & $33.6310 \%$ \\
\hline \begin{tabular}{|l|} 
XS0272915389 \\
\end{tabular} & JPY & 9-Nov-2009 & 114,309 & $31.8946 \%$ \\
\hline XS0297454471 & GBP & 9-Nov-2009 & 993,032 & $38.5917 \%$ \\
\hline \begin{tabular}{|l|} 
XS0328672430 \\
\end{tabular} & USD & 9-Nov-2009 & 776,309 & $75.5903 \%$ \\
\hline \begin{tabular}{|l|} 
XS0328672943 \\
\end{tabular} & USD & 9-Nov-2009 & 335,063 & $41.5234 \%$ \\
\hline \begin{tabular}{|l|} 
XS0328864698 \\
\end{tabular} & HKD & 9-Nov-2009 & $4,256,929$ & $78.3801 \%$ \\
\hline XS0328864771 & USD & 9-Nov-2009 & 111,474 & $15.1962 \%$ \\
\hline
\end{tabular}




\begin{tabular}{|c|c|c|c|c|}
\hline ISIN & Currency & $\begin{array}{c}\text { Maturity } \\
\text { date }\end{array}$ & $\begin{array}{c}\text { Admissible } \\
\text { Amount in EUR }\end{array}$ & $\begin{array}{c}\text { Admissible } \\
\text { Amount \% }\end{array}$ \\
\hline XS0328865588 & USD & 9-Nov-2009 & $1,039,774$ & $78.7455 \%$ \\
\hline XS0328865661 & AUD & 9-Nov-2009 & $2,501,214$ & $67.1219 \%$ \\
\hline XS0329336704 & USD & 9-Nov-2009 & 967,563 & $73.2768 \%$ \\
\hline XS0329337264 & AUD & 9-Nov-2009 & $2,526,760$ & $67.8074 \%$ \\
\hline XS0329337348 & HKD & 9-Nov-2009 & 963,335 & $46.2117 \%$ \\
\hline XS0329338072 & USD & 9-Nov-2009 & 985,607 & $72.6259 \%$ \\
\hline XS0362554551 & USD & $10-N o v-2009$ & $2,934,272$ & $100.0000 \%$ \\
\hline XS0329336969 & USD & 13-Nov-2009 & 486,581 & $33.1653 \%$ \\
\hline XS0329428907 & USD & 13-Nov-2009 & $1,188,398$ & $81.0012 \%$ \\
\hline XS0329429202 & USD & 13-Nov-2009 & 451,699 & $68.4174 \%$ \\
\hline XS0329430556 & USD & 13-Nov-2009 & 397,427 & $54.1773 \%$ \\
\hline XS0329713852 & USD & 13-Nov-2009 & 252,742 & $34.4538 \%$ \\
\hline XS0329715394 & USD & 13-Nov-2009 & 467,377 & $99.5514 \%$ \\
\hline XS0329715550 & USD & 13-Nov-2009 & $7,302,771$ & $99.5514 \%$ \\
\hline XS0329804909 & USD & 13-Nov-2009 & 984,995 & $61.0339 \%$ \\
\hline XS0331288513 & USD & 15-Nov-2009 & 200,722 & $9.8073 \%$ \\
\hline XS0253837370 & EUR & 16-Nov-2009 & $1,216,101$ & $101.3417 \%$ \\
\hline XS0275062916 & USD & 16-Nov-2009 & $1,533,132$ & $104.4983 \%$ \\
\hline XS0329804651 & USD & 16-Nov-2009 & 793,568 & $108.1792 \%$ \\
\hline XS0329804818 & USD & 16-Nov-2009 & 273,053 & $24.8150 \%$ \\
\hline XS0330074427 & USD & $16-N o v-2009$ & 476,150 & $32.4544 \%$ \\
\hline XS0330074690 & USD & $16-N o v-2009$ & 769,129 & $104.8477 \%$ \\
\hline XS0330075077 & USD & 16-Nov-2009 & 357,681 & $48.7590 \%$ \\
\hline XS0330075234 & USD & 16-Nov-2009 & 748,185 & $72.8518 \%$ \\
\hline XS0330075317 & USD & 16-Nov-2009 & 760,307 & $32.3891 \%$ \\
\hline XS0330201988 & USD & 16-Nov-2009 & $2,153,052$ & $77.2379 \%$ \\
\hline XS0330420943 & USD & 16-Nov-2009 & $1,085,166$ & $77.8578 \%$ \\
\hline XS0330867762 & AUD & 16-Nov-2009 & $2,290,681$ & $61.4720 \%$ \\
\hline XS0362891631 & EUR & 16-Nov-2009 & $1,991,471$ & $99.5735 \%$ \\
\hline XS0363637546 & $\mathrm{CHF}$ & 16-Nov-2009 & $1,281,934$ & $99.5166 \%$ \\
\hline XS0233810521 & EUR & 17-Nov-2009 & $8,971,594$ & $97.5173 \%$ \\
\hline XS0328864854 & USD & 17-Nov-2009 & $1,954,278$ & $47.3613 \%$ \\
\hline XS0328864938 & HKD & 17-Nov-2009 & $2,374,087$ & $47.3793 \%$ \\
\hline XS0330421164 & HKD & 19-Nov-2009 & $1,757,692$ & $109.4639 \%$ \\
\hline XS0330421321 & USD & 19-Nov-2009 & $2,328,730$ & $72.9776 \%$ \\
\hline XS0330422055 & HKD & 19-Nov-2009 & $1,173,415$ & $73.0768 \%$ \\
\hline XS0330730200 & USD & 20-Nov-2009 & 610,679 & $83.2478 \%$ \\
\hline XS0330730382 & USD & 20-Nov-2009 & $5,635,695$ & $80.8693 \%$ \\
\hline XS0330730465 & USD & $20-N o v-2009$ & 703,159 & $73.7343 \%$ \\
\hline XS0330730895 & HKD & $20-N o v-2009$ & $1,973,053$ & $109.9416 \%$ \\
\hline XS0330730978 & USD & 20-Nov-2009 & $4,144,736$ & $79.5789 \%$ \\
\hline XS0330731273 & USD & 20-Nov-2009 & 377,114 & $46.7347 \%$ \\
\hline XS0330889493 & USD & 20-Nov-2009 & $1,495,734$ & $99.4627 \%$ \\
\hline XS0204335409 & USD & 21-Nov-2009 & $3,933,039$ & $107.2304 \%$ \\
\hline XS0331533330 & EUR & 21-Nov-2009 & $2,379,089$ & $107.4081 \%$ \\
\hline XS0264737726 & MXN & 22-Nov-2009 & $67,856,193$ & $109.9840 \%$ \\
\hline XS0330205898 & HKD & 23-Nov-2009 & 787,963 & $66.7380 \%$ \\
\hline XS0330207837 & USD & 23-Nov-2009 & 997,442 & $69.7289 \%$ \\
\hline XS0331034172 & USD & 23-Nov-2009 & 819,321 & $85.9153 \%$ \\
\hline XS0331034768 & USD & 23-Nov-2009 & $5,539,269$ & $100.0150 \%$ \\
\hline XS0331044726 & AUD & 23-Nov-2009 & 782,780 & $49.0151 \%$ \\
\hline XS0331044999 & AUD & 23-Nov-2009 & $3,298,493$ & $72.8967 \%$ \\
\hline XS0331045020 & AUD & 23-Nov-2009 & $2,721,135$ & $60.1371 \%$ \\
\hline XS0331048040 & AUD & 23-Nov-2009 & $3,297,751$ & $72.8803 \%$ \\
\hline XS0331048123 & AUD & 23-Nov-2009 & $2,635,855$ & $99.0291 \%$ \\
\hline XS0331400027 & USD & 23-Nov-2009 & $1,383,415$ & $67.3526 \%$ \\
\hline XS0331400530 & USD & 23-Nov-2009 & $1,200,607$ & $67.3526 \%$ \\
\hline XS0331504745 & USD & 23-Nov-2009 & 745,426 & $72.0684 \%$ \\
\hline XS0331505395 & USD & 23-Nov-2009 & $1,069,580$ & $85.7677 \%$ \\
\hline XS0331505478 & USD & 23-Nov-2009 & $1,594,037$ & $83.5766 \%$ \\
\hline XS0331769454 & USD & 23-Nov-2009 & $3,153,300$ & $74.3699 \%$ \\
\hline XS0331769538 & USD & 23-Nov-2009 & $2,470,391$ & $78.1354 \%$ \\
\hline XS0332526929 & USD & 23-Nov-2009 & 671,000 & $99.4247 \%$ \\
\hline XS0275071230 & $\mathrm{CHF}$ & 24-Nov-2009 & $8,004,023$ & $99.4164 \%$ \\
\hline XS0275826484 & GBP & $24-N o v-2009$ & $1,163,330$ & $94.1874 \%$ \\
\hline XS0301889779 & HKD & 25-Nov-2009 & $3,630,904$ & $100.1844 \%$ \\
\hline XS0180153826 & USD & 26-Nov-2009 & $2,187,205$ & $99.3866 \%$ \\
\hline XS0180154550 & EUR & 26-Nov-2009 & 988,913 & $99.1889 \%$ \\
\hline XS0331880566 & AUD & 26-Nov-2009 & $3,687,834$ & $98.9656 \%$ \\
\hline XS0331881374 & USD & 27-Nov-2009 & 447,568 & $43.5804 \%$ \\
\hline XS0331881457 & USD & 27-Nov-2009 & 446,330 & $46.8028 \%$ \\
\hline XS0366131497 & USD & 27-Nov-2009 & $1,603,746$ & $99.3739 \%$ \\
\hline XS0367881603 & USD & 27-Nov-2009 & $7,405,930$ & $50.4788 \%$ \\
\hline XS0234632700 & $\mathrm{CHF}$ & 28-Nov-2009 & $4,414,498$ & $91.3860 \%$ \\
\hline XS0275908456 & USD & 28-Nov-2009 & 105,870 & $7.2161 \%$ \\
\hline XS0204933997 & USD & 29-Nov-2009 & $26,584,880$ & $107.7592 \%$ \\
\hline XS0275721628 & USD & 30-Nov-2009 & $1,861,837$ & $70.5015 \%$ \\
\hline XS0276147104 & USD & 30-Nov-2009 & $2,819,842$ & $71.8506 \%$ \\
\hline XS0276282737 & USD & 30-Nov-2009 & 480,225 & $32.7321 \%$ \\
\hline
\end{tabular}




\begin{tabular}{|c|c|c|c|c|}
\hline ISIN & Currency & $\begin{array}{c}\text { Maturity } \\
\text { date }\end{array}$ & $\begin{array}{c}\text { Admissible } \\
\text { Amount in EUR }\end{array}$ & $\begin{array}{c}\text { Admissible } \\
\text { Amount \% }\end{array}$ \\
\hline XS0332136620 & HKD & 30-Nov-2009 & 777,972 & $77.7025 \%$ \\
\hline \begin{tabular}{|l|} 
XS0332136976 \\
\end{tabular} & USD & 30-Nov-2009 & $1,203,740$ & $60.7755 \%$ \\
\hline \begin{tabular}{|l} 
XS0332137271 \\
\end{tabular} & USD & 30-Nov-2009 & $2,289,507$ & $82.1331 \%$ \\
\hline XS0332153807 & HKD & 30-Nov-2009 & 802,158 & $75.7585 \%$ \\
\hline XS0332547339 & USD & 30-Nov-2009 & $1,815,941$ & $61.8873 \%$ \\
\hline XS0332547503 & USD & 30-Nov-2009 & $4,240,279$ & $65.6858 \%$ \\
\hline \begin{tabular}{|l} 
XS0332547685 \\
\end{tabular} & USD & 30-Nov-2009 & 310,076 & $42.2695 \%$ \\
\hline XS0332763035 & USD & 30-Nov-2009 & 737,580 & $77.3438 \%$ \\
\hline XS0332763118 & HKD & 30-Nov-2009 & 675,831 & $67.5009 \%$ \\
\hline $\begin{array}{l}\text { XS0365325306 } \\
\end{array}$ & USD & 30-Nov-2009 & 819,168 & $101.5172 \%$ \\
\hline \begin{tabular}{|l} 
XS0270987547 \\
\end{tabular} & EUR & 1-Dec-2009 & $20,812,332$ & $99.1063 \%$ \\
\hline XS0276439493 & EUR & 1-Dec-2009 & $1,982,127$ & $99.1063 \%$ \\
\hline XS0333301546 & HKD & 3-Dec-2009 & $6,273,195$ & $107.1209 \%$ \\
\hline \begin{tabular}{|l} 
XS0333301629 \\
\end{tabular} & USD & 3-Dec-2009 & $3,469,452$ & $85.9919 \%$ \\
\hline XS0366802964 & USD & 3-Dec-2009 & $3,190,987$ & $118.5273 \%$ \\
\hline \begin{tabular}{|l} 
XS0181618850 \\
\end{tabular} & EUR & 4-Dec-2009 & $1,013,932$ & $98.6316 \%$ \\
\hline \begin{tabular}{|l|} 
XS0181619072 \\
\end{tabular} & EUR & 4-Dec-2009 & $1,635,552$ & $108.6746 \%$ \\
\hline \begin{tabular}{|l|} 
XS0331880640 \\
\end{tabular} & USD & 4-Dec-2009 & $1,099,079$ & $80.9872 \%$ \\
\hline \begin{tabular}{|l|}
$\mathrm{XS} 0333117611$ \\
\end{tabular} & USD & 4-Dec-2009 & 728,323 & $99.2851 \%$ \\
\hline \begin{tabular}{|l} 
XS0333301975 \\
\end{tabular} & $\mathrm{HKD}$ & 4-Dec-2009 & $1,148,879$ & $86.8807 \%$ \\
\hline XS0333302437 & HKD & 4-Dec-2009 & 359,833 & $47.6198 \%$ \\
\hline XS0333302601 & USD & 4-Dec-2009 & 695,334 & $63.1920 \%$ \\
\hline XS0333449295 & USD & 4-Dec-2009 & $1,169,673$ & $102.8709 \%$ \\
\hline \begin{tabular}{|l|} 
XS0275905270 \\
\end{tabular} & JPY & 7-Dec-2009 & 166,780 & $23.2675 \%$ \\
\hline \begin{tabular}{|l|}
$X S 0277121264$ \\
\end{tabular} & USD & 7-Dec-2009 & 747,810 & $72.8153 \%$ \\
\hline XS0333301462 & USD & 7-Dec-2009 & $2,398,631$ & $80.7361 \%$ \\
\hline XS0333302783 & USD & 7-Dec-2009 & $1,320,054$ & $87.7804 \%$ \\
\hline XS0333307584 & USD & 7-Dec-2009 & $1,150,668$ & $72.9577 \%$ \\
\hline \begin{tabular}{|l} 
XS0333496619 \\
\end{tabular} & USD & 7-Dec-2009 & $1,187,695$ & $53.9688 \%$ \\
\hline XS0333830700 & USD & 7-Dec-2009 & $1,371,218$ & $81.2715 \%$ \\
\hline XS0333830882 & USD & 7-Dec-2009 & 333,104 & $45.4087 \%$ \\
\hline XS0333830965 & HKD & 7-Dec-2009 & 302,696 & $45.7811 \%$ \\
\hline XS0333831187 & AUD & 7-Dec-2009 & $2,827,790$ & $75.8858 \%$ \\
\hline XS0334090445 & AUD & 7-Dec-2009 & $2,827,790$ & $75.8858 \%$ \\
\hline XS0334450672 & USD & 7-Dec-2009 & 387,627 & $48.0376 \%$ \\
\hline XS0334088548 & HKD & 10-Dec-2009 & $1,087,109$ & $42.6271 \%$ \\
\hline \begin{tabular}{|l|} 
XS0334088977 \\
\end{tabular} & USD & 10-Dec-2009 & 337,848 & $46.0554 \%$ \\
\hline XS0351779490 & USD & 10-Dec-2009 & 247,440 & $99.2088 \%$ \\
\hline \begin{tabular}{|l|} 
XS0150708971 \\
\end{tabular} & EUR & $11-$ Dec-2009 & $10,110,362$ & $102.6224 \%$ \\
\hline \begin{tabular}{|l} 
XS0334213112 \\
\end{tabular} & USD & $11-$ Dec-2009 & 628,463 & $50.3953 \%$ \\
\hline \begin{tabular}{|l|} 
XS0334225470 \\
\end{tabular} & USD & 11-Dec-2009 & 465,583 & $52.8903 \%$ \\
\hline XS0368739578 & ZAR & 11-Dec-2009 & $11,900,408$ & $109.9062 \%$ \\
\hline \begin{tabular}{|l} 
XS0325772456 \\
\end{tabular} & HUF & 13-Dec-2009 & 471,445 & $98.1212 \%$ \\
\hline XS0235227302 & EUR & 14-Dec-2009 & $2,564,125$ & $87.8125 \%$ \\
\hline XS0276842894 & JPY & 14-Dec-2009 & 164,978 & $23.0160 \%$ \\
\hline XS0334450755 & USD & 14-Dec-2009 & $2,438,625$ & $103.8854 \%$ \\
\hline XS0334701694 & USD & 14-Dec-2009 & $1,058,212$ & $48.0852 \%$ \\
\hline \begin{tabular}{|l|} 
XS0334921896 \\
\end{tabular} & USD & 14-Dec-2009 & 629,147 & $85.7653 \%$ \\
\hline \begin{tabular}{|l} 
XS0334922860 \\
\end{tabular} & $\mathrm{HKD}$ & 14-Dec-2009 & 979,671 & $47.4468 \%$ \\
\hline XS0335080346 & USD & 14-Dec-2009 & $1,622,430$ & $41.3401 \%$ \\
\hline \begin{tabular}{|l}
$\mathrm{XS} 0335156773$ \\
\end{tabular} & USD & 14-Dec-2009 & $1,015,079$ & $43.9287 \%$ \\
\hline XS0336249726 & USD & 14-Dec-2009 & 98,947 & $13.4885 \%$ \\
\hline XS0334450326 & AUD & 15-Dec-2009 & $2,770,564$ & $74.3501 \%$ \\
\hline XS0334225710 & AUD & 16-Dec-2009 & $3,066,025$ & $82.2790 \%$ \\
\hline \begin{tabular}{|l} 
DK0030072194 \\
\end{tabular} & DKK & 17-Dec-2009 & $15,484,632$ & $106.4691 \%$ \\
\hline XS0334450912 & AUD & 17-Dec-2009 & $2,881,052$ & $77.3151 \%$ \\
\hline \begin{tabular}{|l} 
XS0334704524 \\
\end{tabular} & AUD & 17-Dec-2009 & $2,881,052$ & $77.3151 \%$ \\
\hline XS0335143284 & AUD & 17-Dec-2009 & $3,254,014$ & $87.3238 \%$ \\
\hline $\begin{array}{l}\text { XS0335143441 } \\
\end{array}$ & AUD & 17-Dec-2009 & $2,790,022$ & $74.8722 \%$ \\
\hline XS0335387584 & HKD & 17-Dec-2009 & $1,616,936$ & $63.4025 \%$ \\
\hline XS0336415913 & USD & 17-Dec-2009 & 837,356 & $55.4118 \%$ \\
\hline XS0278449441 & USD & 18-Dec-2009 & 417,986 & $28.4899 \%$ \\
\hline XS0278671382 & USD & 19-Dec-2009 & $1,847,073$ & $83.9310 \%$ \\
\hline XS0335576475 & EUR & 21-Dec-2009 & $24,232,974$ & $103.3389 \%$ \\
\hline XS0335623061 & USD & 21-Dec-2009 & $2,208,313$ & $83.6214 \%$ \\
\hline \begin{tabular}{|l} 
XS0335743398 \\
\end{tabular} & HKD & 21-Dec-2009 & 724,124 & $38.2172 \%$ \\
\hline \begin{tabular}{|l} 
XS0335758586 \\
\end{tabular} & EUR & 21-Dec-2009 & 933,454 & $98.7782 \%$ \\
\hline \begin{tabular}{|l} 
XS0335971858 \\
\end{tabular} & USD & 21-Dec-2009 & 507,425 & $39.5269 \%$ \\
\hline XS0336050215 & EUR & 21-Dec-2009 & $1,852,091$ & $98.7782 \%$ \\
\hline XS0336250146 & USD & 21-Dec-2009 & 123,565 & $16.8444 \%$ \\
\hline XS0336250229 & USD & 21-Dec-2009 & 929,647 & $37.4939 \%$ \\
\hline XS0337385875 & USD & 21-Dec-2009 & 83,208 & $11.9399 \%$ \\
\hline XS0208333194 & SEK & 22-Dec-2009 & $2,434,714$ & $102.2432 \%$ \\
\hline \begin{tabular}{|l} 
XS0279295595 \\
\end{tabular} & USD & 22-Dec-2009 & 596,379 & $40.6492 \%$ \\
\hline XS0335143524 & AUD & 22-Dec-2009 & $1,477,712$ & $39.6554 \%$ \\
\hline \begin{tabular}{|l} 
XS0326516407 \\
\end{tabular} & USD & 24-Dec-2009 & $1,517,019$ & $100.0000 \%$ \\
\hline XS0335623731 & AUD & 24-Dec-2009 & $2,387,116$ & $64.0600 \%$ \\
\hline XS0336414437 & USD & 24-Dec-2009 & $1,302,595$ & $84.5570 \%$ \\
\hline \begin{tabular}{|l} 
XS0336414601 \\
\end{tabular} & $\mathrm{HKD}$ & 24-Dec-2009 & 998,028 & $84.5297 \%$ \\
\hline
\end{tabular}




\begin{tabular}{|c|c|c|c|c|}
\hline ISIN & Currency & $\begin{array}{c}\text { Maturity } \\
\text { date }\end{array}$ & $\begin{array}{c}\text { Admissible } \\
\text { Amount in EUR }\end{array}$ & $\begin{array}{c}\text { Admissible } \\
\text { Amount \% }\end{array}$ \\
\hline XS0336416051 & USD & 24-Dec-2009 & 925,659 & $84.1239 \%$ \\
\hline XS0336416564 & USD & 24-Dec-2009 & 421,876 & $44.2386 \%$ \\
\hline XS0336416721 & USD & 24-Dec-2009 & $7,503,621$ & $51.1447 \%$ \\
\hline XS0336616494 & NZD & 24-Dec-2009 & 857,704 & $91.9330 \%$ \\
\hline XS0336738769 & EUR & 27-Dec-2009 & 811,079 & $81.1079 \%$ \\
\hline XS0338072019 & USD & 27-Dec-2009 & $1,318,011$ & $98.9924 \%$ \\
\hline XS0338078131 & USD & 27-Dec-2009 & $2,772,543$ & $98.9924 \%$ \\
\hline XS0139285257 & EUR & 28-Dec-2009 & $12,367,542$ & $113.4637 \%$ \\
\hline XS0270495160 & EUR & 28-Dec-2009 & $10,419,509$ & $104.1951 \%$ \\
\hline XS0279424310 & $\mathrm{CHF}$ & 28-Dec-2009 & $1,081,757$ & $24.9532 \%$ \\
\hline XS0336019996 & EUR & 28-Dec-2009 & $1,146,418$ & $81.0190 \%$ \\
\hline XS0336020143 & EUR & 28-Dec-2009 & 567,133 & $81.0190 \%$ \\
\hline XS0336927149 & ISK & 28-Dec-2009 & 463,120 & $63.0816 \%$ \\
\hline XS0279730435 & USD & 29-Dec-2009 & $2,273,522$ & $103.3089 \%$ \\
\hline XS0280371989 & USD & 29-Dec-2009 & 268,418 & $18.2954 \%$ \\
\hline XS0280372367 & USD & 29-Dec-2009 & 288,863 & $19.6889 \%$ \\
\hline XS0336643035 & USD & 29-Dec-2009 & 520,091 & $64.4534 \%$ \\
\hline XS0336645089 & USD & 29-Dec-2009 & 808,153 & $40.0609 \%$ \\
\hline XS0336927735 & HKD & 29-Dec-2009 & 518,371 & $54.8805 \%$ \\
\hline XS0336927909 & USD & 29-Dec-2009 & $2,080,011$ & $88.8862 \%$ \\
\hline XS0337137623 & USD & 29-Dec-2009 & $3,638,004$ & $87.0057 \%$ \\
\hline XS0337553092 & USD & 29-Dec-2009 & 796,282 & $108.5491 \%$ \\
\hline XS0337553175 & USD & 29-Dec-2009 & 389,633 & $48.2862 \%$ \\
\hline XS0381884963 & USD & 29-Dec-2009 & 939,506 & $64.0368 \%$ \\
\hline XS0325886116 & NZD & 30-Dec-2009 & $1,538,606$ & $47.1187 \%$ \\
\hline XS0327275227 & AUD & 30-Dec-2009 & $1,521,434$ & $40.8288 \%$ \\
\hline XS0335742747 & HKD & 30-Dec-2009 & $2,244,861$ & $40.8360 \%$ \\
\hline XS0335743042 & USD & 30-Dec-2009 & $1,305,354$ & $40.8133 \%$ \\
\hline XS0335743125 & HKD & 30-Dec-2009 & 745,514 & $65.2300 \%$ \\
\hline XS0326539797 & NZD & 31-Dec-2009 & $1,411,232$ & $43.2180 \%$ \\
\hline XS0337553688 & USD & 31-Dec-2009 & 671,257 & $43.3676 \%$ \\
\hline XS0345801970 & SEK & 31-Dec-2009 & $2,093,562$ & $101.1044 \%$ \\
\hline XS0280981035 & USD & 4-Jan-2010 & 109,195 & $7.4427 \%$ \\
\hline XS0327465356 & AUD & 4-Jan-2010 & $1,543,730$ & $41.4271 \%$ \\
\hline XS0327847470 & AUD & 4-Jan-2010 & $2,453,385$ & $65.8383 \%$ \\
\hline XS0337553415 & USD & 4-Jan-2010 & $2,241,846$ & $100.1995 \%$ \\
\hline XS0338076515 & HKD & 4-Jan-2010 & $1,247,741$ & $105.6797 \%$ \\
\hline XS0338076606 & HKD & 4-Jan-2010 & 800,247 & $105.9037 \%$ \\
\hline XS0338330755 & USD & 4-Jan-2010 & $1,805,012$ & $100.4323 \%$ \\
\hline XS0338525172 & USD & 4-Jan-2010 & 181,498 & $42.6583 \%$ \\
\hline XS0338684482 & USD & 4-Jan-2010 & 539,747 & $36.4249 \%$ \\
\hline XS0338684565 & USD & 4-Jan-2010 & 83,192 & $11.3407 \%$ \\
\hline XS0338765307 & HKD & 4-Jan-2010 & 410,640 & $42.6224 \%$ \\
\hline XS0361670762 & USD & 4-Jan-2010 & $1,237,457$ & $56.2301 \%$ \\
\hline XS0374786365 & ZAR & 4-Jan-2010 & $2,724,462$ & $111.5840 \%$ \\
\hline XS0328210652 & AUD & 5-Jan-2010 & $1,566,024$ & $42.0254 \%$ \\
\hline XS0307481159 & USD & 6-Jan-2010 & 396,856 & $54.0994 \%$ \\
\hline XS0328587166 & AUD & 7-Jan-2010 & $1,691,719$ & $45.3985 \%$ \\
\hline XS0331878404 & EUR & 8-Jan-2010 & $25,599,178$ & $102.1923 \%$ \\
\hline XS0281219385 & USD & 9-Jan-2010 & 950,004 & $64.7523 \%$ \\
\hline XS0280507715 & USD & 11-Jan-2010 & $2,313,059$ & $105.1054 \%$ \\
\hline XS0329337421 & AUD & 11-Jan-2010 & $1,736,287$ & $46.5945 \%$ \\
\hline XS0337488091 & USD & 11-Jan-2010 & $12,088,908$ & $98.7986 \%$ \\
\hline XS0338675654 & USD & 11-Jan-2010 & $4,078,596$ & $55.5994 \%$ \\
\hline XS0338676207 & USD & $11-J a n-2010$ & $2,277,938$ & $107.0788 \%$ \\
\hline XS0338676389 & USD & 11-Jan-2010 & $1,061,289$ & $87.6818 \%$ \\
\hline XS0338676546 & USD & $11-J a n-2010$ & $5,009,893$ & $68.2949 \%$ \\
\hline XS0338764912 & USD & $11-J a n-2010$ & 836,011 & $81.4036 \%$ \\
\hline XS0338765059 & HKD & $11-J a n-2010$ & $2,863,118$ & $110.2259 \%$ \\
\hline XS0338765562 & HKD & 11-Jan-2010 & 489,860 & $47.1472 \%$ \\
\hline XS0338801383 & USD & 11-Jan-2010 & $4,078,254$ & $55.5948 \%$ \\
\hline XS0338802191 & USD & 11-Jan-2010 & $5,222,404$ & $71.1918 \%$ \\
\hline XS0240397496 & HKD & 12-Jan-2010 & $1,448,933$ & $100.0000 \%$ \\
\hline XS0240399435 & USD & 12-Jan-2010 & $3,859,302$ & $100.0000 \%$ \\
\hline XS0280723502 & JPY & $12-J a n-2010$ & 178,998 & $24.9720 \%$ \\
\hline XS0280903583 & JPY & 12-Jan-2010 & 178,241 & $24.8663 \%$ \\
\hline XS0281520352 & EUR & 12-Jan-2010 & $2,377,878$ & $79.2626 \%$ \\
\hline XS0329429541 & AUD & 12-Jan-2010 & $2,538,382$ & $68.1193 \%$ \\
\hline XS0309335080 & USD & 13-Jan-2010 & $1,444,250$ & $98.4401 \%$ \\
\hline XS0328865232 & NZD & 13-Jan-2010 & $1,471,008$ & $45.0486 \%$ \\
\hline XS0375612586 & USD & 15-Jan-2010 & 362,190 & $98.7474 \%$ \\
\hline XS0330204149 & AUD & 18-Jan-2010 & $1,556,044$ & $41.7575 \%$ \\
\hline XS0338845752 & USD & 18-Jan-2010 & $7,403,909$ & $105.1355 \%$ \\
\hline XS0338845919 & HKD & 18-Jan-2010 & $1,320,205$ & $107.5165 \%$ \\
\hline XS0338846214 & HKD & 18-Jan-2010 & $1,221,672$ & $69.9133 \%$ \\
\hline XS0339532672 & USD & 18-Jan-2010 & $1,013,738$ & $98.7091 \%$ \\
\hline XS0339560293 & USD & 18-Jan-2010 & 778,041 & $38.5682 \%$ \\
\hline XS0339560376 & HKD & 18-Jan-2010 & 449,480 & $38.6257 \%$ \\
\hline XS0209820801 & EUR & 19-Jan-2010 & $2,949,132$ & $98.3044 \%$ \\
\hline
\end{tabular}




\begin{tabular}{|c|c|c|c|c|}
\hline ISIN & Currency & $\begin{array}{l}\text { Maturity } \\
\text { date }\end{array}$ & $\begin{array}{c}\text { Admissible } \\
\text { Amount in EUR }\end{array}$ & $\begin{array}{c}\text { Admissible } \\
\text { Amount \% }\end{array}$ \\
\hline XS0281385046 & JPY & 19-Jan-2010 & 187,087 & $26.1005 \%$ \\
\hline XS0329714405 & NZD & 19-Jan-2010 & $2,306,983$ & $64.2270 \%$ \\
\hline XS0339413311 & USD & 19-Jan-2010 & 261,503 & $11.8827 \%$ \\
\hline XS0209198927 & USD & 20-Jan-2010 & $1,946,471$ & $102.6471 \%$ \\
\hline \begin{tabular}{|l|} 
XS0209637437 \\
\end{tabular} & USD & 21-Jan-2010 & $3,619,084$ & $98.6707 \%$ \\
\hline XS0331037605 & AUD & 21-Jan-2010 & $2,570,777$ & $68.9886 \%$ \\
\hline \begin{tabular}{|l|} 
XS0331504828 \\
\end{tabular} & NZD & 22-Jan-2010 & $2,379,088$ & $72.8579 \%$ \\
\hline XS0331505122 & NZD & 22-Jan-2010 & $2,306,327$ & $70.6296 \%$ \\
\hline XS0362646597 & USD & 22-Jan-2010 & 730,203 & $49.7706 \%$ \\
\hline XS0342097317 & AUD & 23-Jan-2010 & $15,011,978$ & $100.0000 \%$ \\
\hline \begin{tabular}{|l|} 
XS0282871358 \\
\end{tabular} & USD & 24-Jan-2010 & 117,611 & $8.0164 \%$ \\
\hline XS0281421965 & JPY & 25-Jan-2010 & 184,375 & $25.7222 \%$ \\
\hline XS0282574655 & JPY & 25-Jan-2010 & 171,347 & $47.8091 \%$ \\
\hline \begin{tabular}{|l|} 
XS0332527497 \\
\end{tabular} & EUR & 25-Jan-2010 & $1,200,000$ & $100.0000 \%$ \\
\hline \begin{tabular}{|l} 
XS0339237678 \\
\end{tabular} & HKD & 25-Jan-2010 & $2,074,174$ & $70.1581 \%$ \\
\hline XS0339238569 & HKD & 25-Jan-2010 & $1,272,265$ & $65.7053 \%$ \\
\hline XS0339559873 & USD & 25-Jan-2010 & $1,102,214$ & $42.0879 \%$ \\
\hline XS0339560020 & HKD & 25-Jan-2010 & $3,114,443$ & $42.1649 \%$ \\
\hline \begin{tabular}{|l|} 
XS0341031432 \\
\end{tabular} & AUD & 25-Jan-2010 & $2,780,780$ & $107.9276 \%$ \\
\hline XS0341160082 & USD & 25-Jan-2010 & 574,564 & $38.3944 \%$ \\
\hline \begin{tabular}{|l|} 
XS0341162708 \\
\end{tabular} & USD & 25-Jan-2010 & 682,645 & $46.5291 \%$ \\
\hline XS0331032044 & NZD & 26-Jan-2010 & $2,209,193$ & $67.6550 \%$ \\
\hline \begin{tabular}{|l|} 
XS0348407767 \\
\end{tabular} & GBP & 26-Jan-2010 & 630,421 & $97.9989 \%$ \\
\hline \begin{tabular}{|l|} 
XS0332108413 \\
\end{tabular} & AUD & 28-Jan-2010 & $1,614,542$ & $43.3274 \%$ \\
\hline XS0339763640 & HKD & 28-Jan-2010 & 484,310 & $45.9860 \%$ \\
\hline XS0339763996 & HKD & 28-Jan-2010 & 973,024 & $39.4694 \%$ \\
\hline XS0341223427 & AUD & 28-Jan-2010 & $4,158,473$ & $97.6461 \%$ \\
\hline \begin{tabular}{|l} 
XS0184751625 \\
\end{tabular} & EUR & 29-Jan-2010 & $1,272,497$ & $102.6207 \%$ \\
\hline XS0340647840 & AUD & 29-Jan-2010 & $3,637,895$ & $97.6255 \%$ \\
\hline \begin{tabular}{|l|} 
XS0341159589 \\
\end{tabular} & AUD & 29-Jan-2010 & $2,855,722$ & $67.0559 \%$ \\
\hline \begin{tabular}{|l|} 
XS0341732658 \\
\end{tabular} & USD & 29-Jan-2010 & $1,756,363$ & $106.4122 \%$ \\
\hline XS0342945184 & USD & 29-Jan-2010 & $3,362,254$ & $98.5683 \%$ \\
\hline XS0343610530 & USD & 29-Jan-2010 & 961,677 & $98.5683 \%$ \\
\hline \begin{tabular}{|l|} 
XS0283818671 \\
\end{tabular} & USD & 30-Jan-2010 & 259,224 & $17.6687 \%$ \\
\hline XS0283819562 & USD & 30-Jan-2010 & 952,386 & $64.9146 \%$ \\
\hline \begin{tabular}{|l|} 
XS0342300729 \\
\end{tabular} & EUR & 30-Jan-2010 & $1,570,045$ & $98.1278 \%$ \\
\hline XS0342303582 & EUR & 30-Jan-2010 & $1,766,301$ & $98.1278 \%$ \\
\hline \begin{tabular}{|l|} 
XS0362181421 \\
\end{tabular} & USD & 30-Jan-2010 & 559,741 & $38.1519 \%$ \\
\hline \begin{tabular}{|l|}
$X S 0272486753$ \\
\end{tabular} & EUR & 31-Jan-2010 & 482,940 & $72.9517 \%$ \\
\hline XS0284314571 & EUR & 1-Feb-2010 & $2,109,060$ & $98.0958 \%$ \\
\hline \begin{tabular}{|l|} 
XS0332763209 \\
\end{tabular} & AUD & 1-Feb-2010 & 727,119 & $68.2946 \%$ \\
\hline XS0342303400 & USD & 1-Feb-2010 & $2,854,995$ & $98.5298 \%$ \\
\hline $\mathrm{CH} 0027120648$ & EUR & 2-Feb-2010 & $15,806,324$ & $100.0400 \%$ \\
\hline $\mathrm{CH} 0027120655$ & $\mathrm{CHF}$ & 2-Feb-2010 & $11,410,336$ & $99.5263 \%$ \\
\hline XS0332136463 & AUD & 2-Feb-2010 & $1,944,806$ & $52.1903 \%$ \\
\hline \begin{tabular}{|l|} 
XS0341163342 \\
\end{tabular} & HKD & 2-Feb-2010 & $2,476,501$ & $42.4255 \%$ \\
\hline \begin{tabular}{|l|} 
XS0341166105 \\
\end{tabular} & USD & 2-Feb-2010 & $1,505,970$ & $42.4161 \%$ \\
\hline XS0332764785 & AUD & 3-Feb-2010 & $2,803,995$ & $75.2472 \%$ \\
\hline XS0334096483 & EUR & 3-Feb-2010 & $5,000,000$ & $100.0000 \%$ \\
\hline XS0335226659 & EUR & 4-Feb-2010 & $38,084,773$ & $100.9135 \%$ \\
\hline \begin{tabular}{|l|} 
XS0342782702 \\
\end{tabular} & USD & 5-Feb-2010 & $2,138,734$ & $97.1841 \%$ \\
\hline \begin{tabular}{|l|} 
XS0378810823 \\
\end{tabular} & USD & 5-Feb-2010 & - & $0.0000 \%$ \\
\hline XS0285045943 & EUR & 7-Feb-2010 & $96,356,052$ & $101.4274 \%$ \\
\hline \begin{tabular}{|l|} 
XS0284726683 \\
\end{tabular} & JPY & 8-Feb-2010 & 257,482 & $44.9016 \%$ \\
\hline \begin{tabular}{|l|} 
XS0282208718 \\
\end{tabular} & EUR & 9-Feb-2010 & $12,638,639$ & $99.9260 \%$ \\
\hline XS0284517413 & JPY & 9-Feb-2010 & 388,196 & $54.1573 \%$ \\
\hline XS0285459243 & JPY & 9-Feb-2010 & 146,823 & $40.9666 \%$ \\
\hline XS0285639141 & USD & 9-Feb-2010 & $1,116,896$ & $76.1276 \%$ \\
\hline XS0346650798 & $\mathrm{CHF}$ & $10-F e b-2010$ & $4,007,154$ & $98.4416 \%$ \\
\hline \begin{tabular}{|l} 
XS0334224077 \\
\end{tabular} & AUD & $11-F e b-2010$ & 735,236 & $55.2456 \%$ \\
\hline XS0334450839 & AUD & 11-Feb-2010 & 283,449 & $33.2787 \%$ \\
\hline \begin{tabular}{|l|} 
XS0341730363 \\
\end{tabular} & USD & $14-F e b-2010$ & 721,560 & $98.3631 \%$ \\
\hline \begin{tabular}{|l|} 
XS0346508962 \\
\end{tabular} & AUD & $14-F e b-2010$ & $2,545,855$ & $108.1988 \%$ \\
\hline $\mathrm{CH} 0036891080$ & $\mathrm{CHF}$ & 15-Feb-2010 & $1,253,118$ & $84.5909 \%$ \\
\hline XS0284513347 & JPY & 15-Feb-2010 & 214,456 & $37.3984 \%$ \\
\hline XS0284513933 & JPY & 15-Feb-2010 & 135,735 & $37.8728 \%$ \\
\hline XS0285620802 & JPY & $15-F e b-2010$ & 210,314 & $57.5268 \%$ \\
\hline \begin{tabular}{|l|} 
XS0285799002 \\
\end{tabular} & JPY & $15-F e b-2010$ & 168,897 & $39.2714 \%$ \\
\hline \begin{tabular}{|l|} 
XS0286406177 \\
\end{tabular} & USD & $15-F e b-2010$ & $1,042,246$ & $71.0395 \%$ \\
\hline XS0334224317 & AUD & 15-Feb-2010 & $1,706,388$ & $45.7921 \%$ \\
\hline \begin{tabular}{|l|} 
XS0334450599 \\
\end{tabular} & AUD & 15-Feb-2010 & $2,541,544$ & $68.2041 \%$ \\
\hline XS0345792294 & GBP & $15-F e b-2010$ & 967,297 & $97.6404 \%$ \\
\hline XS0346123150 & USD & 15-Feb-2010 & $4,435,608$ & $60.4662 \%$ \\
\hline \begin{tabular}{|l|} 
XS0285051750 \\
\end{tabular} & JPY & $16-F e b-2010$ & 278,146 & $25.8694 \%$ \\
\hline XS0285052998 & JPY & $16-F e b-2010$ & 344,578 & $48.0721 \%$ \\
\hline \begin{tabular}{|l|} 
XS0285201660 \\
\end{tabular} & JPY & $16-F e b-2010$ & 347,155 & $48.4316 \%$ \\
\hline \begin{tabular}{|l|}
$\mathrm{XS} 0285385026$ \\
\end{tabular} & JPY & $16-F e b-2010$ & 154,249 & $43.0387 \%$ \\
\hline \begin{tabular}{|l|} 
XS0287119480 \\
\end{tabular} & USD & 16-Feb-2010 & $2,885,488$ & $98.3374 \%$ \\
\hline XS0340433373 & USD & $16-F e b-2010$ & $1,174,394$ & $98.3374 \%$ \\
\hline
\end{tabular}




\begin{tabular}{|c|c|c|c|c|}
\hline ISIN & Currency & $\begin{array}{c}\text { Maturity } \\
\text { date }\end{array}$ & $\begin{array}{c}\text { Admissible } \\
\text { Amount in EUR }\end{array}$ & $\begin{array}{c}\text { Admissible } \\
\text { Amount \% }\end{array}$ \\
\hline XS0308939130 & USD & 17-Feb-2010 & $1,907,020$ & $51.9930 \%$ \\
\hline XS0346073207 & GBP & 18-Feb-2010 & $1,874,480$ & $107.9215 \%$ \\
\hline $\mathrm{CH} 0027120770$ & EUR & 19-Feb-2010 & $9,465,877$ & $70.5453 \%$ \\
\hline $\mathrm{CH} 0043088662$ & $\mathrm{CHF}$ & 19-Feb-2010 & 640,383 & $99.4259 \%$ \\
\hline XS0287096688 & EUR & $19-F e b-2010$ & 47,071 & $134.4877 \%$ \\
\hline XS0344142467 & AUD & 20-Feb-2010 & $10,457,358$ & $109.7009 \%$ \\
\hline XS0346879868 & USD & $20-F e b-2010$ & $1,009,393$ & $98.2860 \%$ \\
\hline $\mathrm{CH} 0027120663$ & $\mathrm{CHF}$ & 22-Feb-2010 & $14,117,791$ & $98.2927 \%$ \\
\hline $\mathrm{CH} 0027120689$ & EUR & 22-Feb-2010 & $14,664,262$ & $97.7617 \%$ \\
\hline $\mathrm{CH} 0027120705$ & USD & 22-Feb-2010 & $2,162,419$ & $98.2603 \%$ \\
\hline $\mathrm{CH} 0027120721$ & EUR & $22-F e b-2010$ & $2,932,852$ & $97.7617 \%$ \\
\hline $\mathrm{CH} 0027120747$ & EUR & 22-Feb-2010 & $4,888,087$ & $97.7617 \%$ \\
\hline XS0107875642 & JPY & 22-Feb-2010 & $4,410,477$ & $102.5509 \%$ \\
\hline XS0285799770 & JPY & 22-Feb-2010 & 173,558 & $40.3550 \%$ \\
\hline XS0286031850 & JPY & $22-F e b-2010$ & 408,042 & $40.4430 \%$ \\
\hline XS0286634125 & JPY & 22-Feb-2010 & 162,520 & $45.3462 \%$ \\
\hline XS0335143797 & AUD & 22-Feb-2010 & $2,433,763$ & $65.3118 \%$ \\
\hline $\mathrm{CH} 0027120622$ & USD & 23-Feb-2010 & $4,324,273$ & $98.2475 \%$ \\
\hline XS0285617683 & JPY & 23-Feb-2010 & 309,651 & $39.2056 \%$ \\
\hline XS0287478456 & JPY & 23-Feb-2010 & 135,102 & $36.8918 \%$ \\
\hline XS0335344932 & AUD & 23-Feb-2010 & $2,655,260$ & $71.2558 \%$ \\
\hline XS0335345665 & AUD & 23-Feb-2010 & $2,413,319$ & $64.7632 \%$ \\
\hline XS0352912611 & USD & 23-Feb-2010 & $22,740,610$ & $100.0000 \%$ \\
\hline XS0335624036 & AUD & 24-Feb-2010 & $2,338,314$ & $62.7503 \%$ \\
\hline XS0301341417 & USD & $25-F e b-2010$ & $2,311,108$ & $68.4892 \%$ \\
\hline XS0335972070 & AUD & 25-Feb-2010 & $2,302,542$ & $61.7904 \%$ \\
\hline XS0336249569 & AUD & 25-Feb-2010 & $2,273,210$ & $61.0032 \%$ \\
\hline XS0373045227 & USD & 25-Feb-2010 & 842,044 & $113.6509 \%$ \\
\hline XS0287900152 & USD & 26-Feb-2010 & $1,439,967$ & $78.5185 \%$ \\
\hline XS0288040834 & EUR & $26-F e b-2010$ & 830,437 & $97.6985 \%$ \\
\hline XS0347229352 & CAD & 26-Feb-2010 & 653,789 & $98.0096 \%$ \\
\hline XS0347694787 & USD & 26-Feb-2010 & $7,276,336$ & $99.1910 \%$ \\
\hline XS0347790403 & USD & $26-F e b-2010$ & 720,429 & $98.2089 \%$ \\
\hline XS0349166164 & AUD & 26-Feb-2010 & $8,759,951$ & $102.6292 \%$ \\
\hline XS0162289663 & EUR & 28 -Feb-2010 & $28,110,101$ & $104.7477 \%$ \\
\hline XS0191247112 & EUR & $28-F e b-2010$ & $26,368,260$ & $105.4730 \%$ \\
\hline XS0288356123 & EUR & 28-Feb-2010 & $2,217,040$ & $97.6669 \%$ \\
\hline XS0366668381 & USD & 28 -Feb-2010 & $1,402,606$ & $76.4813 \%$ \\
\hline XS0187189104 & EUR & 1-Mar-2010 & $5,380,089$ & $99.4471 \%$ \\
\hline XS0244566336 & USD & 1-Mar-2010 & 446,149 & $81.0921 \%$ \\
\hline XS0302452619 & USD & 1-Mar-2010 & $1,724,883$ & $69.1577 \%$ \\
\hline XS0302453005 & USD & 1-Mar-2010 & $2,616,294$ & $69.2530 \%$ \\
\hline XS0336414866 & AUD & 1-Mar-2010 & $2,400,849$ & $64.4285 \%$ \\
\hline XS0349852433 & EUR & 1-Mar-2010 & $5,422,055$ & $77.4579 \%$ \\
\hline XS0277538681 & SEK & 2-Mar-2010 & $37,144,242$ & $102.2987 \%$ \\
\hline XS0288428484 & JPY & 4-Mar-2010 & 424,212 & $59.0225 \%$ \\
\hline XS0336617203 & AUD & 4-Mar-2010 & $2,370,542$ & $63.6152 \%$ \\
\hline XS0336928113 & AUD & 4-Mar-2010 & 289,755 & $3.6287 \%$ \\
\hline XS0336930440 & AUD & 4-Mar-2010 & 289,755 & $3.6287 \%$ \\
\hline XS0349154400 & USD & 4-Mar-2010 & $1,889,832$ & $117.1008 \%$ \\
\hline XS0350105135 & EUR & 4-Mar-2010 & 780,831 & $97.6039 \%$ \\
\hline XS0351194005 & NZD & 4-Mar-2010 & $3,291,969$ & $107.7403 \%$ \\
\hline XS0288741464 & USD & 5-Mar-2010 & $1,369,864$ & $127.5545 \%$ \\
\hline XS0289067497 & USD & 5-Mar-2010 & $1,439,537$ & $98.1189 \%$ \\
\hline XS0337413917 & AUD & 5-Mar-2010 & $2,626,965$ & $70.4965 \%$ \\
\hline XS0338676116 & NZD & 5-Mar-2010 & $6,318,480$ & $96.7495 \%$ \\
\hline XS0340417251 & EUR & 5-Mar-2010 & $23,403,841$ & $101.7160 \%$ \\
\hline XS0186243118 & $\mathrm{CHF}$ & 8-Mar-2010 & $34,955,142$ & $99.1004 \%$ \\
\hline XS0186883798 & USD & 8-Mar-2010 & $44,457,446$ & $105.4411 \%$ \\
\hline XS0287541089 & USD & 8-Mar-2010 & 75,735 & $20.6484 \%$ \\
\hline XS0288589228 & JPY & 8-Mar-2010 & 361,846 & $50.4812 \%$ \\
\hline XS0289154030 & JPY & 8-Mar-2010 & 307,840 & $85.8935 \%$ \\
\hline XS0303764129 & USD & 8-Mar-2010 & $2,031,966$ & $65.9518 \%$ \\
\hline XS0289324641 & JPY & 9-Mar-2010 & 699,375 & $78.8328 \%$ \\
\hline XS0289511320 & EUR & 9-Mar-2010 & $48,762,642$ & $97.5253 \%$ \\
\hline XS0337877582 & AUD & 9-Mar-2010 & $2,716,022$ & $72.8864 \%$ \\
\hline XS0338084378 & AUD & 11-Mar-2010 & $2,655,285$ & $71.2565 \%$ \\
\hline XS0338675811 & AUD & 11-Mar-2010 & $1,318,816$ & $17.6957 \%$ \\
\hline XS0338675902 & AUD & 11-Mar-2010 & 536,752 & $14.4041 \%$ \\
\hline XS0349154582 & HKD & 11-Mar-2010 & $1,730,147$ & $77.6154 \%$ \\
\hline XS0350899182 & EUR & 13-Mar-2010 & $3,324,846$ & $71.5021 \%$ \\
\hline XS0350902580 & USD & 13-Mar-2010 & $1,186,862$ & $71.9080 \%$ \\
\hline XS0286894380 & GBP & 14-Mar-2010 & $5,437,691$ & $97.1597 \%$ \\
\hline XS0290440667 & USD & 14-Mar-2010 & 366,740 & $24.9970 \%$ \\
\hline XS0318943791 & EUR & 14-Mar-2010 & $2,472,866$ & $123.6433 \%$ \\
\hline XS0347683400 & USD & 14-Mar-2010 & $2,153,879$ & $98.0029 \%$ \\
\hline XS0348299180 & USD & 14-Mar-2010 & 381,746 & $98.0029 \%$ \\
\hline XS0289004490 & JPY & 15-Mar-2010 & 115,532 & $32.1540 \%$ \\
\hline XS0289748252 & JPY & 15-Mar-2010 & 140,369 & $39.1657 \%$ \\
\hline
\end{tabular}




\begin{tabular}{|c|c|c|c|c|}
\hline ISIN & Currency & $\begin{array}{l}\text { Maturity } \\
\text { date }\end{array}$ & $\begin{array}{c}\text { Admissible } \\
\text { Amount in EUR }\end{array}$ & $\begin{array}{c}\text { Admissible } \\
\text { Amount \% }\end{array}$ \\
\hline XS0290111417 & JPY & 15-Mar-2010 & 142,037 & $39.6312 \%$ \\
\hline XS0290555480 & JPY & 15-Mar-2010 & 222,709 & $34.5224 \%$ \\
\hline XS0290989309 & JPY & 15-Mar-2010 & 792,048 & $88.3989 \%$ \\
\hline XS0291660644 & JPY & 15-Mar-2010 & 231,683 & $32.2190 \%$ \\
\hline XS0349908839 & EUR & 15-Mar-2010 & $11,854,144$ & $101.0583 \%$ \\
\hline XS0351629687 & USD & 15-Mar-2010 & $1,097,911$ & $106.9052 \%$ \\
\hline XS0351630347 & USD & 15-Mar-2010 & 926,366 & $114.8021 \%$ \\
\hline $\mathrm{CH} 0027120945$ & $\mathrm{CHF}$ & 16-Mar-2010 & $2,695,048$ & $119.5523 \%$ \\
\hline \begin{tabular}{|l|} 
XS0289746470 \\
\end{tabular} & JPY & 16-Mar-2010 & 216,386 & $30.1881 \%$ \\
\hline XS0338801110 & AUD & 16-Mar-2010 & 629,539 & $16.8941 \%$ \\
\hline XS0340461150 & NZD & 16-Mar-2010 & $6,303,283$ & $96.5168 \%$ \\
\hline XS0339239294 & NZD & 17-Mar-2010 & $3,150,953$ & $96.4957 \%$ \\
\hline XS0213519464 & EUR & 18-Mar-2010 & 387,316 & $115.6169 \%$ \\
\hline XS0339559527 & NZD & 18-Mar-2010 & $3,150,264$ & $96.4746 \%$ \\
\hline XS0339559790 & NZD & 18-Mar-2010 & $3,150,264$ & $96.4746 \%$ \\
\hline XS0346859084 & USD & 18-Mar-2010 & $1,322,114$ & $97.9514 \%$ \\
\hline XS0352117641 & USD & 18-Mar-2010 & 640,525 & $20.7896 \%$ \\
\hline $\mathrm{CH} 0036891221$ & EUR & 19-Mar-2010 & $3,407,902$ & $97.3686 \%$ \\
\hline XS0247452799 & USD & 19-Mar-2010 & $1,054,678$ & $97.9385 \%$ \\
\hline XS0291145364 & USD & 19-Mar-2010 & $2,324,820$ & $105.6398 \%$ \\
\hline XS0338845596 & AUD & 19-Mar-2010 & $2,921,008$ & $78.3873 \%$ \\
\hline XS0339222050 & AUD & 19-Mar-2010 & $1,305,498$ & $35.0340 \%$ \\
\hline XS0352986904 & USD & 19-Mar-2010 & $5,755,662$ & $78.4612 \%$ \\
\hline \begin{tabular}{|l} 
XS0212467947 \\
\end{tabular} & USD & 20-Mar-2010 & $2,393,304$ & $108.7517 \%$ \\
\hline XS0345700198 & EUR & 20-Mar-2010 & $6,192,303$ & $103.2050 \%$ \\
\hline XS0290837383 & $\mathrm{CHF}$ & 21-Mar-2010 & $2,208,264$ & $97.9586 \%$ \\
\hline XS0187966949 & USD & 22-Mar-2010 & $20,965,817$ & $102.8005 \%$ \\
\hline XS0187967160 & $\mathrm{CHF}$ & 22-Mar-2010 & $22,057,257$ & $98.9257 \%$ \\
\hline XS0211225056 & USD & 22-Mar-2010 & $29,184,057$ & $99.4593 \%$ \\
\hline XS0214930231 & EUR & 22-Mar-2010 & 102,188 & $97.3218 \%$ \\
\hline XS0305443409 & GBP & 22-Mar-2010 & $1,647,254$ & $91.4520 \%$ \\
\hline \begin{tabular}{|l} 
XS0352987894 \\
\end{tabular} & USD & 22-Mar-2010 & $5,841,493$ & $79.6312 \%$ \\
\hline $\mathrm{CH} 0027120903$ & EUR & 23-Mar-2010 & $19,461,240$ & $97.3062 \%$ \\
\hline XS0247274599 & $\mathrm{CHF}$ & 23-Mar-2010 & $1,350,357$ & $97.9339 \%$ \\
\hline XS0291463734 & JPY & 23-Mar-2010 & 212,171 & $37.0000 \%$ \\
\hline XS0291464385 & JPY & 23-Mar-2010 & 287,192 & $40.0662 \%$ \\
\hline XS0339561002 & AUD & 23-Mar-2010 & 165,162 & $4.1368 \%$ \\
\hline XS0214633967 & EUR & 24-Mar-2010 & $4,674,814$ & $97.2906 \%$ \\
\hline XS0291656022 & JPY & 25-Mar-2010 & 417,688 & $64.7463 \%$ \\
\hline XS0306341958 & USD & 25-Mar-2010 & $1,790,629$ & $62.5894 \%$ \\
\hline XS0339559360 & AUD & 25-Mar-2010 & $2,952,770$ & $79.2397 \%$ \\
\hline XS0341160249 & AUD & 25-Mar-2010 & $2,989,863$ & $80.2351 \%$ \\
\hline XS0353289712 & USD & 25-Mar-2010 & 936,418 & $116.0477 \%$ \\
\hline XS0353507485 & USD & 25-Mar-2010 & 430,727 & $97.8611 \%$ \\
\hline XS0353557233 & USD & 25-Mar-2010 & $9,332,409$ & $97.8611 \%$ \\
\hline XS0292459327 & USD & 26-Mar-2010 & $1,008,485$ & $97.8482 \%$ \\
\hline XS0354065061 & USD & 26-Mar-2010 & $5,687,830$ & $77.5365 \%$ \\
\hline XS0354064841 & USD & 27-Mar-2010 & $5,699,584$ & $77.6967 \%$ \\
\hline XS0340649200 & AUD & 29-Mar-2010 & $2,230,703$ & $59.8625 \%$ \\
\hline XS0342120820 & AUD & 29-Mar-2010 & $2,978,589$ & $69.9410 \%$ \\
\hline XS0353676082 & $\mathrm{CHF}$ & 29-Mar-2010 & $3,343,092$ & $99.8170 \%$ \\
\hline XS0354298241 & USD & 29-Mar-2010 & $5,756,773$ & $78.4763 \%$ \\
\hline XS0292529129 & $\mathrm{CHF}$ & 30-Mar-2010 & $15,125,204$ & $97.8475 \%$ \\
\hline XS0293166517 & EUR & 30-Mar-2010 & $3,046,558$ & $101.5519 \%$ \\
\hline XS0341168069 & AUD & 30-Mar-2010 & $2,225,309$ & $59.7178 \%$ \\
\hline XS0352061757 & AUD & 31-Mar-2010 & $5,824,383$ & $104.2010 \%$ \\
\hline XS0355321455 & AUD & 31-Mar-2010 & $6,661,985$ & $104.2010 \%$ \\
\hline \begin{tabular}{|l} 
XS0290588572 \\
\end{tabular} & EUR & 2-Apr-2010 & $3,886,027$ & $97.1507 \%$ \\
\hline XS0356065994 & USD & 4-Apr-2010 & $22,007,042$ & $100.0000 \%$ \\
\hline XS0293964002 & USD & 5-Apr-2010 & $3,641,524$ & $97.7190 \%$ \\
\hline XS0109171586 & JPY & 6-Apr-2010 & $3,635,079$ & $101.4260 \%$ \\
\hline XS0286302988 & EUR & 6-Apr-2010 & $1,861,659$ & $114.9172 \%$ \\
\hline XS0292217311 & JPY & 6-Apr-2010 & 393,733 & $54.9297 \%$ \\
\hline XS0294837447 & USD & 6-Apr-2010 & $1,530,969$ & $99.1457 \%$ \\
\hline XS0342989398 & NZD & 6-Apr-2010 & $1,633,696$ & $50.0308 \%$ \\
\hline XS0343642905 & NZD & 6-Apr-2010 & $3,037,558$ & $93.0231 \%$ \\
\hline XS0355567453 & USD & 6-Apr-2010 & $5,166,607$ & $70.4312 \%$ \\
\hline XS0355694646 & AUD & 6-Apr-2010 & $8,183,781$ & $107.8067 \%$ \\
\hline XS0355694992 & NZD & 6-Apr-2010 & $5,966,559$ & $109.5078 \%$ \\
\hline XS0356421379 & AUD & 6-Apr-2010 & $1,134,094$ & $106.5198 \%$ \\
\hline XS0356421882 & NZD & 6-Apr-2010 & $1,000,351$ & $107.2226 \%$ \\
\hline XS0356422344 & AUD & 6-Apr-2010 & $1,119,427$ & $105.1422 \%$ \\
\hline XS0341528965 & EUR & 7-Apr-2010 & $5,668,540$ & $101.4413 \%$ \\
\hline \begin{tabular}{|l} 
XS0342989711 \\
\end{tabular} & AUD & 8-Apr-2010 & $2,858,099$ & $76.6991 \%$ \\
\hline XS0355694729 & USD & 8-Apr-2010 & $5,093,537$ & $69.4351 \%$ \\
\hline XS0292471454 & JPY & 9-Apr-2010 & 106,869 & $29.1995 \%$ \\
\hline XS0294024004 & $\mathrm{CHF}$ & 9-Apr-2010 & $3,120,247$ & $99.6810 \%$ \\
\hline XS0355937482 & USD & 9-Apr-2010 & 632,605 & $95.8186 \%$ \\
\hline XS0282145969 & SEK & 12-Apr-2010 & $59,474,052$ & $104.5227 \%$ \\
\hline
\end{tabular}




\begin{tabular}{|c|c|c|c|c|}
\hline ISIN & Currency & $\begin{array}{c}\text { Maturity } \\
\text { date }\end{array}$ & $\begin{array}{c}\text { Admissible } \\
\text { Amount in EUR }\end{array}$ & $\begin{array}{c}\text { Admissible } \\
\text { Amount \% }\end{array}$ \\
\hline XS0294059059 & JPY & 12-Apr-2010 & $1,615,701$ & $56.2661 \%$ \\
\hline XS0295198625 & USD & 12-Apr-2010 & 358,086 & $97.6285 \%$ \\
\hline \begin{tabular}{|l|} 
XS0344101943 \\
\end{tabular} & NZD & 12-Apr-2010 & $1,522,260$ & $46.6181 \%$ \\
\hline XS0356202811 & USD & 12-Apr-2010 & 447,288 & $6.0974 \%$ \\
\hline XS0357740843 & USD & 14-Apr-2010 & $5,857,445$ & $98.5786 \%$ \\
\hline XS0343798400 & AUD & 15-Apr-2010 & $3,241,481$ & $86.9875 \%$ \\
\hline \begin{tabular}{|l} 
XS0344101273 \\
\end{tabular} & AUD & 15-Apr-2010 & $3,143,408$ & $84.3556 \%$ \\
\hline XS0344549141 & AUD & 15-Apr-2010 & $6,874,341$ & $184.4779 \%$ \\
\hline XS0215902155 & EUR & 16-Apr-2010 & 610,686 & $96.9342 \%$ \\
\hline \begin{tabular}{|l|} 
XS0294123830 \\
\end{tabular} & SEK & 16-Apr-2010 & $1,001,407$ & $96.7219 \%$ \\
\hline XS0357385177 & USD & 16-Apr-2010 & $4,932,690$ & $67.2424 \%$ \\
\hline \begin{tabular}{|l} 
XS0293965660 \\
\end{tabular} & JPY & 19-Apr-2010 & 224,343 & $62.5961 \%$ \\
\hline \begin{tabular}{|l} 
XS0294898662 \\
\end{tabular} & JPY & 19-Apr-2010 & 384,335 & $53.3519 \%$ \\
\hline XS0295003981 & JPY & 19-Apr-2010 & 298,662 & $41.6663 \%$ \\
\hline \begin{tabular}{|l|} 
XS0345814791 \\
\end{tabular} & AUD & 19-Apr-2010 & $3,278,400$ & $87.9782 \%$ \\
\hline \begin{tabular}{|l} 
XS0345815178 \\
\end{tabular} & AUD & 19-Apr-2010 & $3,019,062$ & $81.0187 \%$ \\
\hline \begin{tabular}{|l} 
XS0346123408 \\
\end{tabular} & AUD & 19-Apr-2010 & $3,234,363$ & $86.7964 \%$ \\
\hline XS0216591692 & USD & 20-Apr-2010 & 593,447 & $100.4953 \%$ \\
\hline \begin{tabular}{|l} 
XS0294649529 \\
\end{tabular} & JPY & 20-Apr-2010 & 947,599 & $52.8798 \%$ \\
\hline XS0295276017 & JPY & 20-Apr-2010 & 264,806 & $52.7758 \%$ \\
\hline XS0346124638 & AUD & 22-Apr-2010 & $2,819,445$ & $75.6618 \%$ \\
\hline \begin{tabular}{|l} 
XS0346124984 \\
\end{tabular} & AUD & 22-Apr-2010 & $2,988,191$ & $80.1902 \%$ \\
\hline XS0358125473 & USD & 22-Apr-2010 & $5,225,803$ & $71.2381 \%$ \\
\hline \begin{tabular}{|l|} 
XS0358125713 \\
\end{tabular} & USD & 22-Apr-2010 & 310,165 & $42.2817 \%$ \\
\hline XS0358444734 & USD & 22-Apr-2010 & 437,177 & $5.9596 \%$ \\
\hline \begin{tabular}{|l} 
XS0358787421 \\
\end{tabular} & USD & 23-Apr-2010 & $5,272,646$ & $71.8767 \%$ \\
\hline \begin{tabular}{|l|} 
XS0358787694 \\
\end{tabular} & USD & 23-Apr-2010 & $5,272,646$ & $71.8767 \%$ \\
\hline XS0251644232 & EUR & 26-Apr-2010 & $3,784,559$ & $105.1267 \%$ \\
\hline XS0295860554 & JPY & 26-Apr-2010 & 352,811 & $49.2206 \%$ \\
\hline \begin{tabular}{|l} 
XS0296548596 \\
\end{tabular} & JPY & 26-Apr-2010 & 438,314 & $61.1004 \%$ \\
\hline \begin{tabular}{|l} 
XS0359607750 \\
\end{tabular} & USD & 26-Apr-2010 & 711,241 & $84.3099 \%$ \\
\hline \begin{tabular}{|l|} 
XS0295859622 \\
\end{tabular} & JPY & 27-Apr-2010 & 442,295 & $61.7046 \%$ \\
\hline XS0295860125 & JPY & 27-Apr-2010 & 308,993 & $43.1076 \%$ \\
\hline XS0295861289 & JPY & 27-Apr-2010 & 210,766 & $58.8079 \%$ \\
\hline \begin{tabular}{|l} 
XS0297021361 \\
\end{tabular} & JPY & 27-Apr-2010 & 161,859 & $44.7237 \%$ \\
\hline \begin{tabular}{|l|} 
XS0359352159 \\
\end{tabular} & USD & 28-Apr-2010 & 588,794 & $80.2643 \%$ \\
\hline XS0359608139 & USD & 28-Apr-2010 & 951,778 & $76.3214 \%$ \\
\hline \begin{tabular}{|l} 
XS0359722773 \\
\end{tabular} & USD & 28-Apr-2010 & $6,042,236$ & $82.3678 \%$ \\
\hline XS0359722856 & USD & 28-Apr-2010 & $6,875,722$ & $93.7298 \%$ \\
\hline \begin{tabular}{|l|} 
XS0359814976 \\
\end{tabular} & NZD & 28-Apr-2010 & $2,040,346$ & $109.3472 \%$ \\
\hline \begin{tabular}{|l} 
XS0359858593 \\
\end{tabular} & USD & 29-Apr-2010 & 747,489 & $78.3828 \%$ \\
\hline \begin{tabular}{|l} 
XS0359858676 \\
\end{tabular} & USD & 29-Apr-2010 & 710,267 & $80.6863 \%$ \\
\hline XS0297246950 & USD & 30-Apr-2010 & 601,533 & $82.0010 \%$ \\
\hline XS0360038714 & USD & 30-Apr-2010 & $1,428,922$ & $97.3953 \%$ \\
\hline \begin{tabular}{|l} 
XS0359279998 \\
\end{tabular} & AUD & 3-May-2010 & $3,567,016$ & $95.7234 \%$ \\
\hline XS0297522228 & EUR & 4-May-2010 & $4,829,881$ & $96.5976 \%$ \\
\hline XS0299852946 & SGD & 4-May-2010 & 543,940 & $97.7525 \%$ \\
\hline \begin{tabular}{|l|} 
XS0360700487 \\
\end{tabular} & USD & 4-May-2010 & $5,809,560$ & $79.1959 \%$ \\
\hline XS0360700560 & USD & 4-May-2010 & $5,810,770$ & $79.2124 \%$ \\
\hline XS0360700644 & USD & 4-May-2010 & $5,453,257$ & $74.3388 \%$ \\
\hline XS0360599665 & EUR & 5-May-2010 & $1,937,761$ & $96.8881 \%$ \\
\hline XS0361107757 & USD & 5-May-2010 & 755,276 & $73.5423 \%$ \\
\hline XS0361107831 & USD & 5-May-2010 & 323,231 & $73.4381 \%$ \\
\hline XS0350117064 & NZD & 6-May-2010 & $2,327,016$ & $71.2632 \%$ \\
\hline \begin{tabular}{|l} 
XS0360377765 \\
\end{tabular} & AUD & 6-May-2010 & $3,564,797$ & $95.6639 \%$ \\
\hline XS0349153931 & AUD & 7-May-2010 & $2,438,840$ & $65.4480 \%$ \\
\hline \begin{tabular}{|l} 
XS0361723553 \\
\end{tabular} & USD & 7-May-2010 & $4,927,040$ & $67.1654 \%$ \\
\hline XS0361723637 & USD & 7-May-2010 & $5,291,283$ & $72.1308 \%$ \\
\hline XS0195333447 & EUR & 8-May-2010 & $5,943,627$ & $131.9926 \%$ \\
\hline XS0195333520 & USD & 8-May-2010 & $6,023,263$ & $108.4378 \%$ \\
\hline XS0195333793 & EUR & 8-May-2010 & $6,443,643$ & $96.4329 \%$ \\
\hline XS0195333876 & USD & 8-May-2010 & $9,014,436$ & $118.3861 \%$ \\
\hline \begin{tabular}{|l} 
XS0298899450 \\
\end{tabular} & EUR & 9-May-2010 & $5,874,864$ & $97.9144 \%$ \\
\hline XS0299103084 & USD & 9-May-2010 & $4,842,398$ & $63.0182 \%$ \\
\hline \begin{tabular}{|l|} 
XS0297123019 \\
\end{tabular} & JPY & 10-May-2010 & 491,915 & $68.5393 \%$ \\
\hline \begin{tabular}{|l} 
XS0297123522 \\
\end{tabular} & JPY & 10-May-2010 & 431,539 & $60.1378 \%$ \\
\hline \begin{tabular}{|l} 
XS0300241923 \\
\end{tabular} & GBP & 10-May-2010 & $53,324,660$ & $103.6165 \%$ \\
\hline XS0361644098 & EUR & 10-May-2010 & $1,800,000$ & $100.0000 \%$ \\
\hline \begin{tabular}{|l} 
XS0361965212 \\
\end{tabular} & USD & 10-May-2010 & $5,424,238$ & $73.9432 \%$ \\
\hline XS0298201988 & JPY & 11-May-2010 & $1,111,415$ & $31.0107 \%$ \\
\hline XS0298320218 & JPY & 11-May-2010 & $1,431,465$ & $39.9407 \%$ \\
\hline XS0299701655 & USD & 11-May-2010 & 998,780 & $97.2526 \%$ \\
\hline \begin{tabular}{|l|} 
XS0360870488 \\
\end{tabular} & AUD & 11-May-2010 & $3,561,104$ & $95.5648 \%$ \\
\hline \begin{tabular}{|l} 
XS0350116926 \\
\end{tabular} & AUD & 12-May-2010 & $2,507,122$ & $67.2804 \%$ \\
\hline XS0360870306 & AUD & 12-May-2010 & $2,367,868$ & $63.5434 \%$ \\
\hline DE000A0MJHE1 & EUR & 13-May-2010 & $138,472,976$ & $59.7005 \%$ \\
\hline XS0192518024 & USD & 13-May-2010 & $1,351,076$ & $107.8961 \%$ \\
\hline XS0192518370 & USD & 13-May-2010 & $1,924,704$ & $121.5828 \%$ \\
\hline XS0362447806 & USD & 13-May-2010 & $5,902,309$ & $80.4603 \%$ \\
\hline
\end{tabular}




\begin{tabular}{|c|c|c|c|c|}
\hline ISIN & Currency & $\begin{array}{l}\text { Maturity } \\
\text { date }\end{array}$ & $\begin{array}{c}\text { Admissible } \\
\text { Amount in EUR }\end{array}$ & $\begin{array}{c}\text { Admissible } \\
\text { Amount \% } \\
\end{array}$ \\
\hline XS0363444406 & AUD & 13-May-2010 & $1,627,727$ & $105.4374 \%$ \\
\hline \begin{tabular}{|l|} 
XS0289028085 \\
\end{tabular} & SEK & 14-May-2010 & $19,479,502$ & $100.9360 \%$ \\
\hline XS0300113841 & EUR & 14-May-2010 & $2,895,180$ & $96.5060 \%$ \\
\hline \begin{tabular}{|l|} 
XS0362829599 \\
\end{tabular} & USD & 14-May-2010 & $5,629,720$ & $76.7443 \%$ \\
\hline \begin{tabular}{|l|} 
XS0188926421 \\
\end{tabular} & EUR & 17-May-2010 & $32,152,201$ & $100.3189 \%$ \\
\hline XS0299857234 & HKD & 17-May-2010 & $2,996,299$ & $58.2057 \%$ \\
\hline XS0350893904 & AUD & 17-May-2010 & $2,242,301$ & $60.1737 \%$ \\
\hline \begin{tabular}{|l|} 
XS0351627806 \\
\end{tabular} & NZD & 17-May-2010 & $4,147,035$ & $127.0000 \%$ \\
\hline \begin{tabular}{|l|} 
XS0363488361 \\
\end{tabular} & USD & 17-May-2010 & $5,434,666$ & $74.0854 \%$ \\
\hline \begin{tabular}{|l|} 
XS0300477709 \\
\end{tabular} & EUR & 18-May-2010 & $4,822,265$ & $96.4453 \%$ \\
\hline XS0300854261 & SEK & 18-May-2010 & 497,939 & $96.1879 \%$ \\
\hline \begin{tabular}{|l|} 
XS0298900647 \\
\end{tabular} & EUR & 19-May-2010 & $2,314,324$ & $96.4302 \%$ \\
\hline XS0351359103 & AUD & 19-May-2010 & $1,809,505$ & $48.5594 \%$ \\
\hline \begin{tabular}{|l|} 
XS0362223363 \\
\end{tabular} & GBP & 19-May-2010 & $3,859,762$ & $100.0000 \%$ \\
\hline XS0363488106 & USD & 19-May-2010 & 605,627 & $63.5070 \%$ \\
\hline \begin{tabular}{|l|} 
XS0299386101 \\
\end{tabular} & $\mathrm{CHF}$ & 21-May-2010 & $4,861,816$ & $92.3471 \%$ \\
\hline XS0351859094 & AUD & 21-May-2010 & $2,434,709$ & $65.3372 \%$ \\
\hline \begin{tabular}{|l|} 
XS0300880183 \\
\end{tabular} & USD & 22-May-2010 & 428,685 & $57.9171 \%$ \\
\hline XS0364512979 & USD & 23-May-2010 & $1,811,353$ & $121.6373 \%$ \\
\hline XS0366104338 & NZD & 23-May-2010 & $4,499,664$ & $110.0380 \%$ \\
\hline XS0148360042 & EUR & 24-May-2010 & $6,033,927$ & $100.5655 \%$ \\
\hline XS0301365945 & EUR & 24-May-2010 & $1,235,747$ & $91.5368 \%$ \\
\hline XS0362745654 & USD & 24-May-2010 & $3,353,563$ & $100.0345 \%$ \\
\hline XS0362745811 & HKD & 24-May-2010 & $2,052,713$ & $100.1487 \%$ \\
\hline \begin{tabular}{|l|} 
XS0364018779 \\
\end{tabular} & HKD & 24-May-2010 & $1,354,572$ & $66.7023 \%$ \\
\hline \begin{tabular}{|l|} 
XS0364777689 \\
\end{tabular} & EUR & 24-May-2010 & $13,836,375$ & $109.9172 \%$ \\
\hline \begin{tabular}{|l|} 
XS0218961109 \\
\end{tabular} & EUR & 25-May-2010 & $3,369,462$ & $127.7279 \%$ \\
\hline \begin{tabular}{|l|} 
XS0301339510 \\
\end{tabular} & USD & 25-May-2010 & $2,562,798$ & $55.4541 \%$ \\
\hline XS0301520184 & USD & 25-May-2010 & $2,285,845$ & $59.9243 \%$ \\
\hline XS0301568118 & HKD & 25-May-2010 & 926,807 & $56.0697 \%$ \\
\hline \begin{tabular}{|l|} 
XS0193532735 \\
\end{tabular} & USD & 26-May-2010 & 667,738 & $105.5987 \%$ \\
\hline XS0364742972 & USD & 27-May-2010 & 514,363 & $66.7790 \%$ \\
\hline \begin{tabular}{|l|} 
XS0364962661 \\
\end{tabular} & USD & 27-May-2010 & $4,556,062$ & $62.1082 \%$ \\
\hline XS0363582460 & USD & 28-May-2010 & $2,841,843$ & $100.0000 \%$ \\
\hline XS0366576774 & USD & 29-May-2010 & 424,646 & $41.3484 \%$ \\
\hline XS0366668621 & USD & 29-May-2010 & 379,219 & $51.6951 \%$ \\
\hline XS0365300069 & AUD & 30-May-2010 & $1,389,266$ & $107.8403 \%$ \\
\hline XS0367268066 & USD & 30-May-2010 & 196,066 & $26.7277 \%$ \\
\hline XS0367954335 & NZD & 30-May-2010 & $3,383,781$ & $108.5900 \%$ \\
\hline \begin{tabular}{|l|} 
XS0255599598 \\
\end{tabular} & EUR & 31-May-2010 & $2,405,753$ & $67.9591 \%$ \\
\hline \begin{tabular}{|l|} 
XS0299555739 \\
\end{tabular} & USD & 31-May-2010 & $1,258,583$ & $92.1429 \%$ \\
\hline XS0168796570 & EUR & 1-Jun-2010 & $23,587,901$ & $100.0760 \%$ \\
\hline \begin{tabular}{|l} 
XS0168796653 \\
\end{tabular} & EUR & 1-Jun-2010 & $56,373,817$ & $96.2339 \%$ \\
\hline XS0302282602 & USD & 1-Jun-2010 & $2,129,089$ & $56.3568 \%$ \\
\hline \begin{tabular}{|l|} 
XS0302861033 \\
\end{tabular} & EUR & 1-Jun-2010 & $3,175,719$ & $96.2339 \%$ \\
\hline XS0365338200 & USD & 1-Jun-2010 & 554,700 & $65.7537 \%$ \\
\hline \begin{tabular}{|l} 
XS0366090792 \\
\end{tabular} & USD & 1-Jun-2010 & $4,870,232$ & $66.3910 \%$ \\
\hline \begin{tabular}{|l|} 
XS0358366325 \\
\end{tabular} & EUR & 3-Jun-2010 & $13,619,489$ & $100.9749 \%$ \\
\hline \begin{tabular}{|l|}
$\mathrm{XS} 0366126737$ \\
\end{tabular} & HKD & 3-Jun-2010 & 411,053 & $66.9516 \%$ \\
\hline XS0366300191 & USD & 3-Jun-2010 & 846,160 & $67.8521 \%$ \\
\hline \begin{tabular}{|l} 
XS0302815609 \\
\end{tabular} & JPY & 4-Jun-2010 & 569,037 & $78.9913 \%$ \\
\hline XS0303800022 & USD & 4-Jun-2010 & $1,008,374$ & $96.9404 \%$ \\
\hline \begin{tabular}{|l|} 
XS0363629014 \\
\end{tabular} & USD & 4-Jun-2010 & $4,181,989$ & $102.3499 \%$ \\
\hline DE000A0TT7X8 & EUR & 7-Jun-2010 & $1,466,904$ & $104.7789 \%$ \\
\hline XS0220791585 & EUR & 7-Jun-2010 & $5,595,567$ & $96.1438 \%$ \\
\hline XS0301565957 & JPY & 7-Jun-2010 & 136,317 & $31.2306 \%$ \\
\hline \begin{tabular}{|l|}
$\mathrm{XS} 0302371702$ \\
\end{tabular} & JPY & 7-Jun-2010 & 292,138 & $33.9635 \%$ \\
\hline XS0302511216 & JPY & 7-Jun-2010 & 239,156 & $55.6077 \%$ \\
\hline XS0303315161 & USD & 7-Jun-2010 & $1,240,124$ & $55.4274 \%$ \\
\hline XS0333496700 & USD & 7-Jun-2010 & $1,290,706$ & $70.3796 \%$ \\
\hline \begin{tabular}{|l|} 
XS0355896944 \\
\end{tabular} & EUR & 7-Jun-2010 & $2,972,810$ & $100.9443 \%$ \\
\hline \begin{tabular}{|l|} 
XS0365383339 \\
\end{tabular} & EUR & 7-Jun-2010 & $2,442,108$ & $113.5864 \%$ \\
\hline XS0296735193 & EUR & 8-Jun-2010 & $10,000,000$ & $100.0000 \%$ \\
\hline XS0302350888 & EUR & 8-Jun-2010 & $19,311,214$ & $100.3701 \%$ \\
\hline \begin{tabular}{|l|}
$\mathrm{XS} 0302351266$ \\
\end{tabular} & $\mathrm{CHF}$ & 8-Jun-2010 & $4,130,796$ & $98.4417 \%$ \\
\hline \begin{tabular}{|l|} 
XS0303475957 \\
\end{tabular} & EUR & 8-Jun-2010 & $1,941,763$ & $97.0881 \%$ \\
\hline \begin{tabular}{|l|} 
XS0303476849 \\
\end{tabular} & EUR & 8-Jun-2010 & $1,941,763$ & $97.0881 \%$ \\
\hline XS0366126224 & AUD & 8-Jun-2010 & $2,202,058$ & $59.0938 \%$ \\
\hline XS0296067142 & EUR & 10-Jun-2010 & 332,039 & $9.9532 \%$ \\
\hline XS0365839835 & EUR & 10-Jun-2010 & 149,298 & $9.9532 \%$ \\
\hline XS0367880548 & USD & 10-Jun-2010 & $4,640,885$ & $126.5291 \%$ \\
\hline XS0368205869 & USD & 10-Jun-2010 & $4,326,922$ & $58.9846 \%$ \\
\hline XS0368574041 & SGD & 10-Jun-2010 & $1,262,888$ & $102.8248 \%$ \\
\hline \begin{tabular}{|l|} 
XS0292822771 \\
\end{tabular} & SEK & 11-Jun-2010 & $24,056,316$ & $95.7909 \%$ \\
\hline \begin{tabular}{|l|} 
XS0304276297 \\
\end{tabular} & JPY & 11-Jun-2010 & 406,886 & $56.4991 \%$ \\
\hline XS0368533369 & USD & 11-Jun-2010 & $4,290,224$ & $58.4843 \%$ \\
\hline XS0298860916 & USD & 14-Jun-2010 & $1,242,794$ & $96.8101 \%$ \\
\hline XS0302019731 & GBP & 14-Jun-2010 & $2,747,507$ & $95.5481 \%$ \\
\hline \begin{tabular}{|l|} 
XS0371015750 \\
\end{tabular} & USD & 14-Jun-2010 & 355,084 & $96.8101 \%$ \\
\hline
\end{tabular}




\begin{tabular}{|c|c|c|c|c|}
\hline ISIN & Currency & $\begin{array}{c}\text { Maturity } \\
\text { date }\end{array}$ & $\begin{array}{c}\text { Admissible } \\
\text { Amount in EUR }\end{array}$ & $\begin{array}{c}\text { Admissible } \\
\text { Amount \% }\end{array}$ \\
\hline XS0278370696 & USD & 15-Jun-2010 & 524,235 & $59.5531 \%$ \\
\hline XS0299083468 & USD & 15-Jun-2010 & $7,393,272$ & $96.7970 \%$ \\
\hline \begin{tabular}{|l|} 
XS0299085323 \\
\end{tabular} & EUR & 15-Jun-2010 & $7,221,005$ & $96.0240 \%$ \\
\hline XS0303671548 & EUR & 15-Jun-2010 & $4,801,200$ & $96.0240 \%$ \\
\hline \begin{tabular}{|l|} 
XS0303866981 \\
\end{tabular} & JPY & 15-Jun-2010 & 266,133 & $37.1283 \%$ \\
\hline XS0159948784 & USD & 16-Jun-2010 & 373,562 & $101.8480 \%$ \\
\hline \begin{tabular}{|l} 
XS0221834947 \\
\end{tabular} & $\mathrm{CHF}$ & 16-Jun-2010 & $6,240,434$ & $96.8890 \%$ \\
\hline \begin{tabular}{|l|} 
XS0368988951 \\
\end{tabular} & ILS & 16-Jun-2010 & 778,724 & $92.6314 \%$ \\
\hline XS0369584486 & $\mathrm{CHF}$ & 16-Jun-2010 & $3,494,636$ & $108.5154 \%$ \\
\hline \begin{tabular}{|l|} 
XS0221419459 \\
\end{tabular} & USD & 17-Jun-2010 & $4,252,186$ & $96.7710 \%$ \\
\hline \begin{tabular}{|l} 
XS0222198631 \\
\end{tabular} & USD & 17-Jun-2010 & $1,277,785$ & $96.7710 \%$ \\
\hline \begin{tabular}{|l|} 
XS0369418040 \\
\end{tabular} & USD & 17-Jun-2010 & 596,593 & $81.3275 \%$ \\
\hline XS0371134924 & USD & 17-Jun-2010 & 953,090 & $118.1138 \%$ \\
\hline XS0305085218 & USD & 18-Jun-2010 & 849,802 & $59.4077 \%$ \\
\hline XS0305155441 & JPY & 18-Jun-2010 & 169,701 & $46.8330 \%$ \\
\hline \begin{tabular}{|l|} 
XS0369673156 \\
\end{tabular} & USD & 18-Jun-2010 & 229,689 & $31.3112 \%$ \\
\hline \begin{tabular}{|l} 
XS0369673313 \\
\end{tabular} & USD & 18-Jun-2010 & 229,689 & $31.3112 \%$ \\
\hline XS0369673586 & USD & 18-Jun-2010 & 398,743 & $54.3566 \%$ \\
\hline \begin{tabular}{|l|} 
XS0370072422 \\
\end{tabular} & ZAR & 18-Jun-2010 & 770,659 & $115.6403 \%$ \\
\hline XS0220100183 & USD & 20-Jun-2010 & 87,138 & $118.7863 \%$ \\
\hline XS0295182546 & USD & 20-Jun-2010 & $7,702,594$ & $105.0018 \%$ \\
\hline $\begin{array}{l}\mathrm{XS} 0303572217 \\
\end{array}$ & JPY & 21-Jun-2010 & $7,216,415$ & $100.6762 \%$ \\
\hline XS0303746571 & EUR & 21-Jun-2010 & $9,593,451$ & $95.9345 \%$ \\
\hline \begin{tabular}{|l|} 
XS0304471666 \\
\end{tabular} & JPY & 21-Jun-2010 & 140,277 & $39.0925 \%$ \\
\hline \begin{tabular}{|l} 
XS0305154717 \\
\end{tabular} & JPY & 21-Jun-2010 & 791,738 & $36.8185 \%$ \\
\hline XS0305155011 & JPY & 21-Jun-2010 & 265,238 & $37.0033 \%$ \\
\hline XS0305631151 & USD & 21-Jun-2010 & 668,478 & $60.7513 \%$ \\
\hline XS0278638258 & USD & 22-Jun-2010 & $177,187,366$ & $105.0182 \%$ \\
\hline XS0305440991 & JPY & 22-Jun-2010 & 362,831 & $35.8088 \%$ \\
\hline XS0306144022 & JPY & 22-Jun-2010 & $1,192,130$ & $35.9718 \%$ \\
\hline \begin{tabular}{|l|} 
XS0306927723 \\
\end{tabular} & JPY & 22-Jun-2010 & $1,615,418$ & $74.5261 \%$ \\
\hline XS0357874451 & AUD & 24-Jun-2010 & $6,849,236$ & $183.8041 \%$ \\
\hline XS0170856115 & EUR & 25-Jun-2010 & $14,899,247$ & $99.3283 \%$ \\
\hline XS0253852254 & EUR & 28-Jun-2010 & $5,710,604$ & $80.4310 \%$ \\
\hline XS0370964073 & AUD & 28-Jun-2010 & $2,375,892$ & $106.1382 \%$ \\
\hline $\mathrm{CH} 0027120978$ & EUR & 29-Jun-2010 & $9,899,861$ & $91.0248 \%$ \\
\hline XS0303537574 & USD & 29-Jun-2010 & $2,450,024$ & $105.7926 \%$ \\
\hline XS0303538200 & EUR & 29-Jun-2010 & $1,389,039$ & $104.4390 \%$ \\
\hline \begin{tabular}{|l|} 
XS0307323161 \\
\end{tabular} & SEK & 29-Jun-2010 & 365,821 & $95.4951 \%$ \\
\hline \begin{tabular}{|l} 
XS0307325455 \\
\end{tabular} & SEK & 29-Jun-2010 & $1,639,273$ & $95.4951 \%$ \\
\hline \begin{tabular}{|l} 
XS0307326180 \\
\end{tabular} & SEK & 29-Jun-2010 & 680,229 & $95.4951 \%$ \\
\hline XS0223700658 & EUR & 30-Jun-2010 & $7,036,497$ & $88.8110 \%$ \\
\hline \begin{tabular}{|l|} 
XS0245728547 \\
\end{tabular} & EUR & 30-Jun-2010 & $1,770,296$ & $88.5148 \%$ \\
\hline XS0258901759 & EUR & 30-Jun-2010 & $3,680,180$ & $106.9820 \%$ \\
\hline \begin{tabular}{|l|} 
XS0306226696 \\
\end{tabular} & EUR & 30-Jun-2010 & $2,682,422$ & $95.8008 \%$ \\
\hline XS0170825664 & USD & 2-Jul-2010 & $8,087,853$ & $104.0128 \%$ \\
\hline \begin{tabular}{|l} 
XS0307617315 \\
\end{tabular} & USD & 2-Jul-2010 & 804,480 & $57.7193 \%$ \\
\hline \begin{tabular}{|l|} 
XS0359351938 \\
\end{tabular} & AUD & 2-Jul-2010 & $4,805,577$ & $180.5455 \%$ \\
\hline \begin{tabular}{|l} 
XS0235429437 \\
\end{tabular} & EUR & 5-Jul-2010 & $2,765,501$ & $145.5527 \%$ \\
\hline XS0306179168 & $\mathrm{CHF}$ & 5-Jul-2010 & $6,199,667$ & $108.5572 \%$ \\
\hline XS0336633150 & $\mathrm{CHF}$ & 5-Jul-2010 & $1,444,084$ & $33.5591 \%$ \\
\hline XS0359858759 & NZD & 8-Jul-2010 & $1,904,123$ & $58.3124 \%$ \\
\hline XS0304080558 & EUR & 9-Jul-2010 & $7,552,007$ & $95.6677 \%$ \\
\hline XS0304080715 & USD & 9-Jul-2010 & $6,801,691$ & $96.4835 \%$ \\
\hline XS0309103546 & EUR & 11-Jul-2010 & $11,270,960$ & $95.6382 \%$ \\
\hline XS0195874523 & USD & $12-J u l-2010$ & $1,528,372$ & $104.1738 \%$ \\
\hline \begin{tabular}{|l} 
XS0307256544 \\
\end{tabular} & JPY & 12-Jul-2010 & 493,692 & $35.1259 \%$ \\
\hline \begin{tabular}{|l} 
XS0308972347 \\
\end{tabular} & EUR & 12-Jul-2010 & $1,688,320$ & $25.9742 \%$ \\
\hline $\begin{array}{l}\text { XS0309366986 } \\
\end{array}$ & EUR & $13-J u l-2010$ & $5,960,000$ & $100.0000 \%$ \\
\hline XS0310847503 & USD & 13-Jul-2010 & $2,487,208$ & $113.0187 \%$ \\
\hline \begin{tabular}{|l} 
XS0358125630 \\
\end{tabular} & NZD & 14-Jul-2010 & $1,896,297$ & $58.0727 \%$ \\
\hline XS0361107674 & NZD & 14-Jul-2010 & $1,855,523$ & $56.8241 \%$ \\
\hline XS0276047494 & USD & 15-Jul-2010 & $206,440,620$ & $88.3189 \%$ \\
\hline XS0264429829 & USD & $16-J u l-2010$ & $5,986,154$ & $98.0219 \%$ \\
\hline XS0224250133 & $\mathrm{CHF}$ & 19-Jul-2010 & $3,845,811$ & $99.5168 \%$ \\
\hline \begin{tabular}{|l} 
XS0260979751 \\
\end{tabular} & SEK & 20-Jul-2010 & $1,358,841$ & $100.9577 \%$ \\
\hline \begin{tabular}{|l} 
XS0308460368 \\
\end{tabular} & USD & 20-Jul-2010 & $3,589,267$ & $97.8578 \%$ \\
\hline XS0222698283 & EUR & 21-Jul-2010 & $4,903,583$ & $97.0430 \%$ \\
\hline XS0376686308 & EUR & 22-Jul-2010 & $10,128,250$ & $101.2825 \%$ \\
\hline XS0309835139 & $\mathrm{CHF}$ & 23-Jul-2010 & $4,502,913$ & $108.5678 \%$ \\
\hline XS0313100678 & EUR & 23-Jul-2010 & $3,818,474$ & $95.4618 \%$ \\
\hline XS0363707695 & AUD & 23-Jul-2010 & $2,274,790$ & $61.0456 \%$ \\
\hline XS0309822319 & USD & 26-Jul-2010 & 143,288 & $39.0661 \%$ \\
\hline \begin{tabular}{|l|} 
XS0311621733 \\
\end{tabular} & JPY & 26-Jul-2010 & $1,440,541$ & $45.2880 \%$ \\
\hline XS0311744576 & JPY & 26-Jul-2010 & $1,106,304$ & $45.4208 \%$ \\
\hline XS0311765654 & USD & 26-Jul-2010 & $1,412,278$ & $96.2609 \%$ \\
\hline XS0313198201 & EUR & 26-Jul-2010 & $2,576,284$ & $95.4179 \%$ \\
\hline XS0364018340 & AUD & 26-Jul-2010 & $2,376,477$ & $63.7745 \%$ \\
\hline \begin{tabular}{|l} 
XS0364263227 \\
\end{tabular} & AUD & 27-Jul-2010 & 65,179 & $1.7491 \%$ \\
\hline
\end{tabular}




\begin{tabular}{|c|c|c|c|c|}
\hline ISIN & Currency & $\begin{array}{l}\text { Maturity } \\
\text { date }\end{array}$ & $\begin{array}{c}\text { Admissible } \\
\text { Amount in EUR }\end{array}$ & $\begin{array}{c}\text { Admissible } \\
\text { Amount \% } \\
\end{array}$ \\
\hline XS0224249630 & EUR & 29-Jul-2010 & 889,840 & $95.3741 \%$ \\
\hline \begin{tabular}{|l|} 
XS0309871019 \\
\end{tabular} & EUR & 30-Jul-2010 & $4,162,442$ & $92.4987 \%$ \\
\hline \begin{tabular}{|l|l} 
XS0310069538 \\
\end{tabular} & $\mathrm{CHF}$ & 30-Jul-2010 & $2,509,647$ & $73.7411 \%$ \\
\hline XS0313188400 & USD & 30-Jul-2010 & 705,754 & $96.2084 \%$ \\
\hline XS0364895614 & AUD & 30-Jul-2010 & $2,468,308$ & $66.2388 \%$ \\
\hline XS0364895887 & AUD & 30-Jul-2010 & $2,468,301$ & $66.2386 \%$ \\
\hline XS0310507743 & EUR & 1-Aug-2010 & $4,932,579$ & $98.6516 \%$ \\
\hline \begin{tabular}{|l|} 
XS0225771079 \\
\end{tabular} & EUR & 2-Aug-2010 & $6,821,531$ & $113.6922 \%$ \\
\hline \begin{tabular}{|l|} 
XS0309101508 \\
\end{tabular} & USD & 2-Aug-2010 & $2,056,017$ & $92.7146 \%$ \\
\hline \begin{tabular}{|l|} 
XS0380855659 \\
\end{tabular} & USD & 2-Aug-2010 & $5,301,615$ & $103.2452 \%$ \\
\hline XS0312176109 & JPY & 3-Aug-2010 & 521,947 & $33.8951 \%$ \\
\hline \begin{tabular}{|l|l} 
XS0312177255 \\
\end{tabular} & JPY & 3-Aug-2010 & 499,284 & $34.7026 \%$ \\
\hline XS0312721730 & JPY & 3-Aug-2010 & $1,425,453$ & $51.5951 \%$ \\
\hline \begin{tabular}{|l|} 
XS0313327370 \\
\end{tabular} & EUR & 3-Aug-2010 & $1,710,656$ & $95.3012 \%$ \\
\hline XS0313948050 & JPY & 3-Aug-2010 & 954,199 & $46.3382 \%$ \\
\hline \begin{tabular}{|l|} 
XS0365872968 \\
\end{tabular} & AUD & 3-Aug-2010 & 937,419 & $25.1563 \%$ \\
\hline XS0365915874 & AUD & 3-Aug-2010 & $3,234,012$ & $75.9386 \%$ \\
\hline \begin{tabular}{|l|} 
XS0365916096 \\
\end{tabular} & NZD & 4-Aug-2010 & $1,813,529$ & $55.5380 \%$ \\
\hline XS0225841898 & EUR & 5-Aug-2010 & $2,152,196$ & $95.2720 \%$ \\
\hline \begin{tabular}{|l|} 
XS0365916179 \\
\end{tabular} & AUD & 5-Aug-2010 & $2,523,664$ & $67.7243 \%$ \\
\hline XS0366125929 & AUD & 5-Aug-2010 & 814,168 & $21.8488 \%$ \\
\hline \begin{tabular}{|l|} 
XS0365870830 \\
\end{tabular} & NZD & 6-Aug-2010 & $1,855,151$ & $56.8127 \%$ \\
\hline \begin{tabular}{|l|} 
XS0379318024 \\
\end{tabular} & USD & 8-Aug-2010 & $2,449,921$ & $99.6340 \%$ \\
\hline \begin{tabular}{|l|} 
XS0367648721 \\
\end{tabular} & NZD & 10-Aug-2010 & $1,702,761$ & $52.1458 \%$ \\
\hline \begin{tabular}{|l|} 
XS0380276385 \\
\end{tabular} & HKD & 11-Aug-2010 & 955,449 & $105.4790 \%$ \\
\hline \begin{tabular}{|l|} 
XS0381306173 \\
\end{tabular} & USD & 11-Aug-2010 & $3,047,457$ & $103.8573 \%$ \\
\hline \begin{tabular}{|l|} 
XS0367648648 \\
\end{tabular} & NZD & 12-Aug-2010 & $2,045,611$ & $62.6454 \%$ \\
\hline \begin{tabular}{|l|} 
XS0383013579 \\
\end{tabular} & USD & 12-Aug-2010 & $1,094,163$ & $96.2298 \%$ \\
\hline XS0306901330 & USD & 13-Aug-2010 & $2,231,558$ & $96.0246 \%$ \\
\hline XS0306921957 & HUF & 13-Aug-2010 & $1,466,698$ & $91.4410 \%$ \\
\hline XS0116235499 & EUR & 14-Aug-2010 & $4,152,319$ & $103.8080 \%$ \\
\hline XS0315264001 & USD & 15-Aug-2010 & $1,056,320$ & $95.9983 \%$ \\
\hline \begin{tabular}{|l|} 
XS0263788779 \\
\end{tabular} & EUR & 16-Aug-2010 & $1,894,833$ & $94.7417 \%$ \\
\hline XS0286637656 & USD & 16-Aug-2010 & $1,227,070$ & $66.9096 \%$ \\
\hline XS0305574500 & EUR & 16-Aug-2010 & $9,189,764$ & $95.1124 \%$ \\
\hline \begin{tabular}{|l|} 
XS0305574849 \\
\end{tabular} & USD & $16-$ Aug-2010 & $5,310,448$ & $95.9852 \%$ \\
\hline XS0367930582 & NZD & 18-Aug-2010 & $1,517,190$ & $46.4629 \%$ \\
\hline XS0368098090 & NZD & 18-Aug-2010 & $1,745,625$ & $53.4585 \%$ \\
\hline $\mathrm{CH} 0027121000$ & EUR & 20-Aug-2010 & $1,844,060$ & $92.2030 \%$ \\
\hline \begin{tabular}{|l} 
XS0314857466 \\
\end{tabular} & JPY & 20-Aug-2010 & 347,523 & $48.4635 \%$ \\
\hline \begin{tabular}{|l|} 
XS0316515229 \\
\end{tabular} & USD & 22-Aug-2010 & $3,821,795$ & $104.1974 \%$ \\
\hline XS0314130369 & USD & 23-Aug-2010 & $7,335,681$ & $100.0000 \%$ \\
\hline \begin{tabular}{|l} 
XS0316937647 \\
\end{tabular} & USD & 24-Aug-2010 & 523,441 & $73.9435 \%$ \\
\hline \begin{tabular}{|l|} 
XS0317416880 \\
\end{tabular} & GBP & 27-Aug-2010 & $1,213,010$ & $94.2812 \%$ \\
\hline \begin{tabular}{|l|} 
XS0317422425 \\
\end{tabular} & USD & 27-Aug-2010 & 703,055 & $95.8405 \%$ \\
\hline XS0317422771 & EUR & 27-Aug-2010 & 949,537 & $94.9537 \%$ \\
\hline XS0318056354 & $\mathrm{CHF}$ & 31-Aug-2010 & $2,719,558$ & $95.9633 \%$ \\
\hline \begin{tabular}{|l|} 
XS0383554739 \\
\end{tabular} & USD & 31-Aug-2010 & 621,293 & $104.5614 \%$ \\
\hline \begin{tabular}{|l|} 
XS0383805081 \\
\end{tabular} & HKD & 31-Aug-2010 & $2,590,159$ & $104.2672 \%$ \\
\hline XS0383805750 & USD & 31-Aug-2010 & $2,767,798$ & $103.7981 \%$ \\
\hline \begin{tabular}{|l} 
XS0383806139 \\
\end{tabular} & $\mathrm{HKD}$ & 31-Aug-2010 & $3,446,141$ & $103.3559 \%$ \\
\hline XS0385434310 & USD & 31-Aug-2010 & 909,686 & $100.0068 \%$ \\
\hline \begin{tabular}{|l|} 
XS0384898440 \\
\end{tabular} & EUR & 2-Sep-2010 & $11,386,798$ & $113.8680 \%$ \\
\hline XS0383803540 & HKD & 3-Sep-2010 & $2,146,879$ & $103.3146 \%$ \\
\hline XS0383803896 & HKD & 3-Sep-2010 & $1,590,642$ & $103.3146 \%$ \\
\hline XS0384596515 & USD & 3-Sep-2010 & 736,094 & $125.4303 \%$ \\
\hline \begin{tabular}{|l|} 
XS0116900928 \\
\end{tabular} & JPY & 6-Sep-2010 & $7,233,549$ & $100.9152 \%$ \\
\hline XS0318191219 & JPY & 6-Sep-2010 & $1,479,998$ & $82.5535 \%$ \\
\hline XS0384213368 & HKD & 6-Sep-2010 & $2,068,001$ & $103.2742 \%$ \\
\hline XS0384553110 & HKD & 6-Sep-2010 & $2,077,718$ & $103.2724 \%$ \\
\hline \begin{tabular}{|l|} 
XS0384783113 \\
\end{tabular} & HKD & 6-Sep-2010 & 634,046 & $103.2724 \%$ \\
\hline XS0385433262 & HKD & 6-Sep-2010 & $2,721,518$ & $103.2724 \%$ \\
\hline XS0385433429 & HKD & 6-Sep-2010 & $1,830,335$ & $103.3490 \%$ \\
\hline XS0199536029 & EUR & 7-Sep-2010 & $1,702,463$ & $108.0243 \%$ \\
\hline \begin{tabular}{|l|} 
XS0258411239 \\
\end{tabular} & EUR & 7-Sep-2010 & $8,005,604$ & $102.9263 \%$ \\
\hline \begin{tabular}{|l|} 
XS0287235047 \\
\end{tabular} & EUR & 7-Sep-2010 & $3,000,000$ & $100.0000 \%$ \\
\hline \begin{tabular}{|l|} 
XS0312086456 \\
\end{tabular} & HUF & 7-Sep-2010 & $3,739,723$ & $90.7802 \%$ \\
\hline XS0312086530 & USD & 7-Sep-2010 & $2,914,674$ & $95.6957 \%$ \\
\hline XS0312086704 & EUR & 7-Sep-2010 & $2,459,007$ & $94.7960 \%$ \\
\hline \begin{tabular}{|l|} 
XS0318778734 \\
\end{tabular} & $\mathrm{CHF}$ & 7-Sep-2010 & $2,806,696$ & $96.8373 \%$ \\
\hline XS0319612387 & USD & 7-Sep-2010 & $1,284,647$ & $95.6957 \%$ \\
\hline XS0384984448 & USD & 7-Sep-2010 & $1,525,224$ & $103.7000 \%$ \\
\hline \begin{tabular}{|l|} 
XS0385433775 \\
\end{tabular} & USD & 7-Sep-2010 & 597,155 & $103.6996 \%$ \\
\hline \begin{tabular}{|l|} 
XS0386674088 \\
\end{tabular} & USD & 8-Sep-2010 & $5,171,418$ & $95.5770 \%$ \\
\hline XS0228154158 & $\mathrm{CHF}$ & 9-Sep-2010 & $5,901,959$ & $96.8133 \%$ \\
\hline XS0385433692 & HKD & 9-Sep-2010 & $1,477,230$ & $103.2316 \%$ \\
\hline XS0385823306 & HKD & 9-Sep-2010 & 867,812 & $103.2316 \%$ \\
\hline \begin{tabular}{|l|} 
XS0385823488 \\
\end{tabular} & HKD & 9-Sep-2010 & 441,273 & $103.8178 \%$ \\
\hline \begin{tabular}{|l|} 
XS0386290778 \\
\end{tabular} & $\mathrm{HKD}$ & 9-Sep-2010 & 731,302 & $103.2316 \%$ \\
\hline
\end{tabular}




\begin{tabular}{|c|c|c|c|c|}
\hline ISIN & Currency & $\begin{array}{c}\text { Maturity } \\
\text { date }\end{array}$ & $\begin{array}{c}\text { Admissible } \\
\text { Amount in EUR }\end{array}$ & $\begin{array}{c}\text { Admissible } \\
\text { Amount \% }\end{array}$ \\
\hline XS0319161518 & USD & 10-Sep-2010 & $1,192,038$ & $52.7593 \%$ \\
\hline XS0385822753 & USD & 10-Sep-2010 & 528,481 & $103.6582 \%$ \\
\hline \begin{tabular}{|l|} 
XS0319631098 \\
\end{tabular} & EUR & 12-Sep-2010 & $2,906,642$ & $96.8881 \%$ \\
\hline XS0117104843 & JPY & 13-Sep-2010 & $7,549,709$ & $105.3260 \%$ \\
\hline XS0386716699 & USD & 13-Sep-2010 & $2,032,394$ & $103.3791 \%$ \\
\hline XS0228149075 & EUR & 15-Sep-2010 & $2,977,273$ & $107.5993 \%$ \\
\hline XS0290836658 & EUR & 16-Sep-2010 & 489,727 & $65.2969 \%$ \\
\hline \begin{tabular}{|l}
$X S 0225190775$ \\
\end{tabular} & USD & 20-Sep-2010 & $7,617,668$ & $103.8441 \%$ \\
\hline $\begin{array}{l}\mathrm{XS} 0226254547 \\
\end{array}$ & EUR & 20-Sep-2010 & $9,950,388$ & $99.5039 \%$ \\
\hline XS0226711629 & USD & 20-Sep-2010 & $7,454,588$ & $101.6209 \%$ \\
\hline XS0230515834 & USD & 20-Sep-2010 & $14,452,835$ & $98.5105 \%$ \\
\hline XS0321124801 & USD & 20-Sep-2010 & $1,751,838$ & $95.5242 \%$ \\
\hline XS0117279058 & JPY & 21-Sep-2010 & $11,626,749$ & $101.3780 \%$ \\
\hline XS0307009372 & JPY & 21-Sep-2010 & $7,226,155$ & $100.8121 \%$ \\
\hline XS0319632906 & JPY & 21-Sep-2010 & 472,368 & $65.7017 \%$ \\
\hline \begin{tabular}{|l} 
XS0227965695 \\
\end{tabular} & USD & 22-Sep-2010 & $36,113,385$ & $98.4595 \%$ \\
\hline \begin{tabular}{|l} 
XS0231102459 \\
\end{tabular} & USD & 28-Sep-2010 & $3,858,568$ & $100.0000 \%$ \\
\hline XS0322152462 & USD & 1-Oct-2010 & $4,280,954$ & $97.2633 \%$ \\
\hline \begin{tabular}{|l|} 
XS0353382681 \\
\end{tabular} & USD & 1-Oct-2010 & $5,039,613$ & $100.0000 \%$ \\
\hline \begin{tabular}{|l|} 
XS0319211982 \\
\end{tabular} & USD & 4-Oct-2010 & $2,797,515$ & $95.3393 \%$ \\
\hline XS0323108265 & USD & 4-Oct-2010 & $1,778,213$ & $96.9624 \%$ \\
\hline \begin{tabular}{|l|} 
XS0323747781 \\
\end{tabular} & USD & 4-Oct-2010 & $1,020,065$ & $92.7035 \%$ \\
\hline XS0268364410 & PLN & 6-Oct-2010 & $1,186,798$ & $92.1782 \%$ \\
\hline \begin{tabular}{|l|} 
XS0284313847 \\
\end{tabular} & EUR & 6-Oct-2010 & 620,322 & $62.0322 \%$ \\
\hline \begin{tabular}{|l|} 
XS0165754531 \\
\end{tabular} & EUR & 7-Oct-2010 & $7,575,196$ & $103.3310 \%$ \\
\hline \begin{tabular}{|l} 
XS0323978162 \\
\end{tabular} & EUR & 9-Oct-2010 & $2,688,683$ & $89.6228 \%$ \\
\hline XS0268363289 & PLN & $12-$ Oct-2010 & 954,620 & $92.0564 \%$ \\
\hline XS0269670401 & SEK & $12-$ Oct-2010 & 347,023 & $95.7645 \%$ \\
\hline XS0323849199 & USD & $12-$ Oct-2010 & 907,076 & $95.1174 \%$ \\
\hline XS0323849355 & EUR & $12-$ Oct- 2010 & $2,178,116$ & $94.2907 \%$ \\
\hline XS0324091304 & USD & 12 -Oct-2010 & 698,602 & $95.2335 \%$ \\
\hline XS0324584670 & USD & $12-$ Oct- 2010 & $1,131,646$ & $90.7447 \%$ \\
\hline XS0324632404 & USD & $12-$ Oct-2010 & $1,397,205$ & $95.2335 \%$ \\
\hline XS0324851038 & EUR & $12-$ Oct- 2010 & $1,460,226$ & $102.8328 \%$ \\
\hline \begin{tabular}{|l|}
$\mathrm{XS} 0230607524$ \\
\end{tabular} & EUR & $13-$ Oct-2010 & $5,654,111$ & $99.0039 \%$ \\
\hline XS0267879475 & EUR & $13-$ Oct-2010 & $2,291,777$ & $103.4662 \%$ \\
\hline XS0348974337 & USD & $15-$ Oct-2010 & $2,706,653$ & $95.1937 \%$ \\
\hline XS0348974410 & EUR & $15-$ Oct- 2010 & $2,938,456$ & $94.2417 \%$ \\
\hline \begin{tabular}{|l} 
XS0325475084 \\
\end{tabular} & USD & 18 -Oct-2010 & $2,471,150$ & $96.2477 \%$ \\
\hline XS0325477379 & USD & $18-$ Oct-2010 & $1,593,177$ & $113.7078 \%$ \\
\hline $\mathrm{CH} 0027120838$ & $\mathrm{CHF}$ & $19-$ Oct-2010 & $1,899,750$ & $98.3184 \%$ \\
\hline XS0325776440 & EUR & $22-$ Oct- 2010 & $2,995,516$ & $106.9827 \%$ \\
\hline \begin{tabular}{|l}
$X S 0327275904$ \\
\end{tabular} & JPY & $22-$ Oct- 2010 & 390,247 & $53.8915 \%$ \\
\hline XS0326364386 & EUR & $23-$ Oct- 2010 & 941,111 & $94.1111 \%$ \\
\hline \begin{tabular}{|l} 
XS0326516746 \\
\end{tabular} & USD & $25-$ Oct-2010 & $1,070,618$ & $72.9733 \%$ \\
\hline XS0326865085 & USD & $25-$ Oct- 2010 & $2,579,950$ & $109.9059 \%$ \\
\hline XS0326866216 & USD & $26-$ Oct- 2010 & $1,497,787$ & $63.8057 \%$ \\
\hline \begin{tabular}{|l|} 
XS0154907991 \\
\end{tabular} & EUR & $28-O c t-2010$ & $18,480,839$ & $99.8964 \%$ \\
\hline \begin{tabular}{|l} 
XS0231346593 \\
\end{tabular} & EUR & $28-O c t-2010$ & 37,912 & $151.6497 \%$ \\
\hline $\mathrm{CH} 0027120853$ & $\mathrm{CHF}$ & $29-$ Oct- 2010 & $2,766,712$ & $66.8508 \%$ \\
\hline XS0327723580 & USD & $31-$ Oct-2010 & $1,431,014$ & $97.5379 \%$ \\
\hline XS0221394447 & EUR & 1-Nov-2010 & 504,264 & $100.8527 \%$ \\
\hline XS0232659150 & EUR & 1-Nov-2010 & $1,838,880$ & $89.2660 \%$ \\
\hline XS0327687843 & USD & 1-Nov-2010 & 706,043 & $96.2477 \%$ \\
\hline XS0328865406 & USD & 1-Nov-2010 & $1,052,080$ & $65.1907 \%$ \\
\hline $\mathrm{CH} 0027120861$ & $\mathrm{CHF}$ & 5-Nov-2010 & $3,493,473$ & $90.3994 \%$ \\
\hline $\mathrm{CH} 0027120879$ & EUR & 5-Nov-2010 & $3,643,281$ & $91.0820 \%$ \\
\hline XS0326215893 & USD & 5-Nov-2010 & $1,392,536$ & $94.9153 \%$ \\
\hline XS0328209720 & USD & 5-Nov-2010 & $1,324,152$ & $43.4960 \%$ \\
\hline \begin{tabular}{|l}
$\mathrm{XS} 0328401830$ \\
\end{tabular} & EUR & 5-Nov-2010 & $5,599,868$ & $95.3169 \%$ \\
\hline XS0274481786 & JPY & 6-Nov-2010 & $14,595,054$ & $101.8078 \%$ \\
\hline XS0330196295 & USD & 7-Nov-2010 & $1,000,525$ & $104.1157 \%$ \\
\hline XS0326072252 & GBP & 8-Nov-2010 & $2,094,750$ & $93.0368 \%$ \\
\hline \begin{tabular}{|l} 
XS0328587240 \\
\end{tabular} & USD & 8-Nov-2010 & 307,629 & $41.9360 \%$ \\
\hline XS0273666437 & EUR & 9-Nov-2010 & $4,879,359$ & $93.8338 \%$ \\
\hline \begin{tabular}{|l|} 
XS0329159221 \\
\end{tabular} & USD & 9-Nov-2010 & 296,131 & $9.3015 \%$ \\
\hline XS0330111641 & JPY & 12-Nov-2010 & 208,908 & $57.8500 \%$ \\
\hline \begin{tabular}{|l|} 
XS0234582178 \\
\end{tabular} & USD & $15-$ Nov-2010 & 385,376 & $105.0690 \%$ \\
\hline XS0329801715 & USD & 15-Nov-2010 & 465,152 & $94.7825 \%$ \\
\hline XS0329801806 & EUR & 15-Nov-2010 & 802,381 & $93.7361 \%$ \\
\hline XS0234421914 & EUR & $16-N o v-2010$ & $2,736,619$ & $93.7198 \%$ \\
\hline XS0330110833 & JPY & 16-Nov-2010 & 374,929 & $32.6915 \%$ \\
\hline \begin{tabular}{|l|} 
XS0331427061 \\
\end{tabular} & EUR & $16-N o v-2010$ & $2,301,439$ & $56.1327 \%$ \\
\hline \begin{tabular}{|l|} 
XS0234511821 \\
\end{tabular} & USD & 21-Nov-2010 & $2,250,856$ & $94.7027 \%$ \\
\hline \begin{tabular}{|l|} 
XS0274890523 \\
\end{tabular} & USD & 22-Nov-2010 & $3,723,815$ & $126.9076 \%$ \\
\hline \begin{tabular}{|l} 
XS0276072682 \\
\end{tabular} & EUR & $22-$ Nov-2010 & $4,889,193$ & $64.9037 \%$ \\
\hline XS0330437087 & JPY & 22-Nov-2010 & 273,623 & $75.0258 \%$ \\
\hline XS0330730622 & USD & 22-Nov-2010 & $2,989,247$ & $81.4988 \%$ \\
\hline \begin{tabular}{|l} 
XS0364513431 \\
\end{tabular} & USD & 23-Nov-2010 & 107,518 & $1.2971 \%$ \\
\hline
\end{tabular}




\begin{tabular}{|c|c|c|c|c|}
\hline ISIN & Currency & $\begin{array}{l}\text { Maturity } \\
\text { date }\end{array}$ & $\begin{array}{c}\text { Admissible } \\
\text { Amount in EUR }\end{array}$ & $\begin{array}{c}\text { Admissible } \\
\text { Amount \% } \\
\end{array}$ \\
\hline XS0366299831 & USD & 28-Nov-2010 & 31,261 & $1.2176 \%$ \\
\hline XS0330222984 & $\mathrm{CHF}$ & 29-Nov-2010 & $3,313,000$ & $88.3353 \%$ \\
\hline \begin{tabular}{|l|l}
$X S 0234123650$ \\
\end{tabular} & $\mathrm{CHF}$ & 30-Nov-2010 & $10,465,711$ & $95.5827 \%$ \\
\hline \begin{tabular}{|l|} 
XS0267365442 \\
\end{tabular} & EUR & 30-Nov-2010 & $11,447,408$ & $107.3060 \%$ \\
\hline \begin{tabular}{|l|} 
XS0276272936 \\
\end{tabular} & EUR & 30-Nov-2010 & $4,955,081$ & $93.4921 \%$ \\
\hline XS0333012358 & USD & 30-Nov-2010 & $1,040,745$ & $94.5829 \%$ \\
\hline XS0272617100 & GBP & 1-Dec-2010 & 953,522 & $92.6406 \%$ \\
\hline \begin{tabular}{|l|} 
XS0272617951 \\
\end{tabular} & USD & 1-Dec-2010 & 693,733 & $94.5696 \%$ \\
\hline \begin{tabular}{|l|} 
XS0272634535 \\
\end{tabular} & USD & 1-Dec-2010 & $1,566,448$ & $94.5696 \%$ \\
\hline \begin{tabular}{|l|}
$X S 0272635185$ \\
\end{tabular} & GBP & 1-Dec-2010 & $1,189,518$ & $92.6406 \%$ \\
\hline XS0302821086 & USD & 1-Dec-2010 & 561,087 & $63.7394 \%$ \\
\hline \begin{tabular}{|l|} 
XS0236406277 \\
\end{tabular} & JPY & 2-Dec-2010 & $2,148,831$ & $49.9560 \%$ \\
\hline XS0329284987 & USD & 4-Dec-2010 & $2,275,576$ & $96.2477 \%$ \\
\hline \begin{tabular}{|l|} 
XS0329288384 \\
\end{tabular} & USD & 4-Dec-2010 & 755,466 & $96.2477 \%$ \\
\hline XS0329905417 & EUR & 4-Dec-2010 & $1,019,290$ & $93.4271 \%$ \\
\hline \begin{tabular}{|l|} 
XS0334446134 \\
\end{tabular} & USD & 4-Dec-2010 & $2,140,016$ & $96.2477 \%$ \\
\hline XS0268043709 & EUR & 5-Dec-2010 & $51,390,531$ & $107.4644 \%$ \\
\hline \begin{tabular}{|l|} 
XS0301522719 \\
\end{tabular} & EUR & 6-Dec-2010 & $11,483,924$ & $102.4344 \%$ \\
\hline NO0010395965 & NOK & 7-Dec-2010 & 574,967 & $92.6693 \%$ \\
\hline XS0334814547 & EUR & 7-Dec-2010 & $1,040,235$ & $93.3784 \%$ \\
\hline XS0334815437 & USD & 7-Dec-2010 & 772,165 & $94.4897 \%$ \\
\hline XS0333793403 & USD & 8-Dec-2010 & $3,976,291$ & $108.4096 \%$ \\
\hline \begin{tabular}{|l} 
XS0236535679 \\
\end{tabular} & EUR & 9-Dec-2010 & 905,455 & $93.3459 \%$ \\
\hline XS0334382065 & EUR & 10-Dec-2010 & $3,832,183$ & $104.9913 \%$ \\
\hline \begin{tabular}{|l|} 
XS0332159598 \\
\end{tabular} & EUR & 13-Dec-2010 & 902,633 & $95.0140 \%$ \\
\hline XS0332181840 & EUR & 13-Dec-2010 & $5,178,261$ & $95.0140 \%$ \\
\hline \begin{tabular}{|l|} 
XS0332409969 \\
\end{tabular} & EUR & 13-Dec-2010 & $1,282,689$ & $95.0140 \%$ \\
\hline \begin{tabular}{|l|} 
XS0237053623 \\
\end{tabular} & USD & 14-Dec-2010 & $1,017,919$ & $94.3964 \%$ \\
\hline XS0278126510 & EUR & 14-Dec-2010 & $1,580,429$ & $61.9776 \%$ \\
\hline XS0332612844 & USD & 14-Dec-2010 & 692,462 & $94.3964 \%$ \\
\hline \begin{tabular}{|l|} 
XS0237709208 \\
\end{tabular} & EUR & 15-Dec-2010 & 290,935 & $93.2485 \%$ \\
\hline XS0276162327 & EUR & 15-Dec-2010 & $30,302,968$ & $93.2485 \%$ \\
\hline \begin{tabular}{|l|} 
DK0030068242 \\
\end{tabular} & DKK & 16-Dec-2010 & $9,724,884$ & $100.0000 \%$ \\
\hline DK0030096961 & DKK & 16-Dec-2010 & 455,624 & $100.0000 \%$ \\
\hline XS0122041675 & HKD & 20-Dec-2010 & $3,783,613$ & $114.4500 \%$ \\
\hline XS0239231573 & JPY & 20-Dec-2010 & 351,212 & $26.7081 \%$ \\
\hline XS0307499441 & USD & 20-Dec-2010 & $9,038,756$ & $102.6803 \%$ \\
\hline XS0330467746 & DKK & 20-Dec-2010 & 360,039 & $92.6454 \%$ \\
\hline XS0334475232 & USD & 20-Dec-2010 & $1,235,689$ & $89.6006 \%$ \\
\hline XS0336050058 & USD & 20-Dec-2010 & $1,504,290$ & $68.3549 \%$ \\
\hline \begin{tabular}{|l|} 
XS0278639579 \\
\end{tabular} & USD & 21-Dec-2010 & $270,846,756$ & $105.4909 \%$ \\
\hline XS0331533173 & EUR & 21-Dec-2010 & $2,626,832$ & $86.1256 \%$ \\
\hline \begin{tabular}{|l} 
XS0334693578 \\
\end{tabular} & EUR & 21-Dec-2010 & $1,851,185$ & $115.6990 \%$ \\
\hline \begin{tabular}{|l|l} 
XS0336951107 \\
\end{tabular} & EUR & 21-Dec-2010 & $1,558,136$ & $87.8814 \%$ \\
\hline \begin{tabular}{|l|} 
XS0334274098 \\
\end{tabular} & USD & 24-Dec-2010 & 691,483 & $94.2630 \%$ \\
\hline XS0375027074 & USD & 24-Dec-2010 & $1,583,447$ & $71.9518 \%$ \\
\hline XS0150823721 & USD & 25-Dec-2010 & $7,579,583$ & $96.8606 \%$ \\
\hline \begin{tabular}{|l|} 
XS0306345355 \\
\end{tabular} & AUD & 28-Dec-2010 & 825,699 & $62.0430 \%$ \\
\hline \begin{tabular}{|l|}
$\mathrm{XS} 0338071987$ \\
\end{tabular} & EUR & 28-Dec-2010 & $1,427,153$ & $142.7153 \%$ \\
\hline XS0250113502 & $\mathrm{CHF}$ & 29-Dec-2010 & $7,306,235$ & $74.6908 \%$ \\
\hline \begin{tabular}{|l|} 
XS0280527408 \\
\end{tabular} & USD & 29-Dec-2010 & $1,036,491$ & $94.1963 \%$ \\
\hline \begin{tabular}{|l|} 
XS0165754705 \\
\end{tabular} & EUR & 30-Dec-2010 & $2,222,208$ & $99.7266 \%$ \\
\hline \begin{tabular}{|l|} 
XS0223109926 \\
\end{tabular} & USD & 30-Dec-2010 & $2,463,916$ & $105.1271 \%$ \\
\hline XS0338049462 & USD & 31-Dec-2010 & $1,255,530$ & $81.5018 \%$ \\
\hline XS0338316093 & $\mathrm{CHF}$ & 31-Dec-2010 & $3,042,201$ & $94.4664 \%$ \\
\hline XS0238337439 & EUR & 3-Jan-2011 & $3,600,868$ & $95.8442 \%$ \\
\hline \begin{tabular}{|l|}
$\mathrm{XS} 0279675150$ \\
\end{tabular} & EUR & 3-Jan-2011 & $1,619,583$ & $66.6495 \%$ \\
\hline XS0334205795 & USD & 3-Jan-2011 & $1,242,877$ & $94.1272 \%$ \\
\hline XS0372634195 & SEK & 3-Jan-2011 & $1,383,614$ & $121.9323 \%$ \\
\hline XS0337488505 & USD & 4-Jan-2011 & 642,685 & $43.8054 \%$ \\
\hline \begin{tabular}{|l|} 
XS0276859609 \\
\end{tabular} & EUR & 5-Jan-2011 & $2,846,800$ & $110.0000 \%$ \\
\hline XS0338082752 & $\mathrm{CZK}$ & 10-Jan-2011 & $4,761,352$ & $102.3335 \%$ \\
\hline XS0209026805 & EUR & 13-Jan-2011 & 666,218 & $99.4355 \%$ \\
\hline XS0338056590 & EUR & 13-Jan-2011 & $1,817,976$ & $121.1984 \%$ \\
\hline \begin{tabular}{|l|} 
XS0338049975 \\
\end{tabular} & GBP & 14-Jan-2011 & $1,773,251$ & $91.8840 \%$ \\
\hline \begin{tabular}{|l|} 
XS0341743184 \\
\end{tabular} & USD & 19-Jan-2011 & $3,136,504$ & $20.8561 \%$ \\
\hline \begin{tabular}{|l} 
XS0341745635 \\
\end{tabular} & USD & 19-Jan-2011 & 697,041 & $20.8561 \%$ \\
\hline XS0341769221 & HKD & 19-Jan-2011 & 364,557 & $20.4212 \%$ \\
\hline NO0010402738 & NOK & 21-Jan-2011 & 619,759 & $99.8884 \%$ \\
\hline $\mathrm{CH} 0027120630$ & USD & 24-Jan-2011 & $2,189,196$ & $93.8463 \%$ \\
\hline XS0334494290 & EUR & 24-Jan-2011 & $3,437,654$ & $101.1075 \%$ \\
\hline XS0335964648 & EUR & 24-Jan-2011 & $3,920,598$ & $92.5980 \%$ \\
\hline \begin{tabular}{|l|} 
XS0339764028 \\
\end{tabular} & USD & 24-Jan-2011 & $1,796,927$ & $65.4965 \%$ \\
\hline \begin{tabular}{|l|} 
XS0339944943 \\
\end{tabular} & USD & 24-Jan-2011 & $11,978,618$ & $93.8463 \%$ \\
\hline \begin{tabular}{|l} 
XS0340460855 \\
\end{tabular} & USD & 24-Jan-2011 & $10,672,975$ & $120.2430 \%$ \\
\hline XS0340648657 & USD & 24-Jan-2011 & $1,380,729$ & $62.7403 \%$ \\
\hline $\mathrm{CH} 0034783636$ & $\mathrm{CHF}$ & 25-Jan-2011 & $3,638,659$ & $94.1564 \%$ \\
\hline $\mathrm{CH} 0034783651$ & EUR & 25-Jan-2011 & 925,818 & $92.5818 \%$ \\
\hline $\mathrm{CH} 0034783677$ & USD & 25-Jan-2011 & 688,328 & $93.8329 \%$ \\
\hline
\end{tabular}




\begin{tabular}{|c|c|c|c|c|}
\hline ISIN & Currency & $\begin{array}{l}\text { Maturity } \\
\text { date }\end{array}$ & $\begin{array}{c}\text { Admissible } \\
\text { Amount in EUR }\end{array}$ & $\begin{array}{c}\text { Admissible } \\
\text { Amount \% }\end{array}$ \\
\hline $\mathrm{CH} 0034783693$ & EUR & 25-Jan-2011 & 925,818 & $92.5818 \%$ \\
\hline \begin{tabular}{|l|l} 
XS0241421089 \\
\end{tabular} & EUR & 25-Jan-2011 & $42,929,617$ & $99.6070 \%$ \\
\hline XS0340950608 & $\mathrm{CHF}$ & 25-Jan-2011 & $3,032,216$ & $94.1564 \%$ \\
\hline XS0123488438 & HKD & 28-Jan-2011 & $15,851,307$ & $119.8710 \%$ \\
\hline XS0340530814 & USD & 28-Jan-2011 & $1,302,401$ & $93.4438 \%$ \\
\hline XS0241359180 & USD & 30-Jan-2011 & $2,245,787$ & $93.7659 \%$ \\
\hline XS0337437007 & USD & 30-Jan-2011 & 744,927 & $93.7659 \%$ \\
\hline XS0342839155 & GBP & 30-Jan-2011 & $1,944,836$ & $116.2788 \%$ \\
\hline XS0343872494 & USD & 30-Jan-2011 & $6,054,057$ & $103.1611 \%$ \\
\hline XS0277722772 & HUF & 31-Jan-2011 & $2,224,775$ & $87.1475 \%$ \\
\hline XS0342751905 & USD & 1-Feb-2011 & $18,206,105$ & $82.0448 \%$ \\
\hline XS0184310927 & EUR & 2-Feb-2011 & $19,633,938$ & $98.1697 \%$ \\
\hline XS0255689589 & EUR & 2-Feb-2011 & $15,550,799$ & $119.1632 \%$ \\
\hline XS0341731411 & USD & 4-Feb-2011 & $4,288,089$ & $116.9105 \%$ \\
\hline XS0335137120 & EUR & 7-Feb-2011 & $8,353,346$ & $92.8150 \%$ \\
\hline XS0343643036 & USD & 7-Feb-2011 & 926,248 & $126.2661 \%$ \\
\hline XS0345680655 & USD & 7-Feb-2011 & $2,470,752$ & $97.6269 \%$ \\
\hline XS0243065421 & EUR & 8-Feb-2011 & $1,531,260$ & $92.3558 \%$ \\
\hline XS0339537390 & EUR & 8-Feb-2011 & $15,456,111$ & $92.5516 \%$ \\
\hline DE000A0LU6X5 & EUR & $10-F e b-2011$ & $5,169,558$ & $67.7708 \%$ \\
\hline XS0346007320 & EUR & 11-Feb-2011 & $2,063,755$ & $103.1878 \%$ \\
\hline XS0242764735 & EUR & $14-F e b-2011$ & 830,332 & $83.0332 \%$ \\
\hline XS0242801958 & EUR & 14-Feb-2011 & 645,814 & $92.2591 \%$ \\
\hline XS0344899710 & AUD & 14-Feb-2011 & $2,390,561$ & $89.8134 \%$ \\
\hline XS0345003049 & USD & 14-Feb-2011 & 686,361 & $93.5647 \%$ \\
\hline XS0345445737 & EUR & 14-Feb-2011 & $1,789,827$ & $92.2591 \%$ \\
\hline XS0338483588 & EUR & 15-Feb-2011 & $3,282,990$ & $125.8815 \%$ \\
\hline XS0338483828 & USD & 15-Feb-2011 & $2,871,381$ & $127.6669 \%$ \\
\hline XS0339184615 & USD & 15-Feb-2011 & 686,262 & $93.5513 \%$ \\
\hline XS0339538448 & USD & $15-F e b-2011$ & $1,575,126$ & $95.8577 \%$ \\
\hline XS0341900388 & EUR & 15-Feb-2011 & $3,599,000$ & $100.0000 \%$ \\
\hline XS0344095871 & USD & $15-F e b-2011$ & $2,573,484$ & $93.5513 \%$ \\
\hline DE000A0LJV62 & EUR & $17-F e b-2011$ & $20,243,752$ & $42.5996 \%$ \\
\hline XS0347259185 & USD & 18-Feb-2011 & $2,359,726$ & $93.5110 \%$ \\
\hline XS0186755798 & USD & 25-Feb-2011 & $38,657,944$ & $105.3970 \%$ \\
\hline XS0245479810 & USD & 27-Feb-2011 & $1,141,878$ & $141.5098 \%$ \\
\hline XS0244837547 & EUR & 28-Feb-2011 & $1,472,539$ & $92.0337 \%$ \\
\hline XS0279950637 & SEK & $28-F e b-2011$ & $4,030,502$ & $92.2488 \%$ \\
\hline XS0287989031 & HKD & 28-Feb-2011 & $1,272,392$ & $94.5329 \%$ \\
\hline XS0287990047 & USD & $28-F e b-2011$ & $1,407,927$ & $94.6860 \%$ \\
\hline XS0345320799 & EUR & $28-F e b-2011$ & 954,033 & $95.4033 \%$ \\
\hline XS0345320872 & USD & 28-Feb-2011 & $1,899,961$ & $96.2477 \%$ \\
\hline XS0347452426 & USD & 28-Feb-2011 & 876,776 & $93.3767 \%$ \\
\hline XS0348072561 & USD & 28-Feb-2011 & 896,916 & $122.2676 \%$ \\
\hline XS0348072728 & USD & 28-Feb-2011 & $1,006,783$ & $137.2447 \%$ \\
\hline XS0349809342 & EUR & $28-F e b-2011$ & $1,486,344$ & $87.4320 \%$ \\
\hline XS0215568667 & USD & 2-Mar-2011 & $4,327,759$ & $98.3267 \%$ \\
\hline XS0246362916 & EUR & 3-Mar-2011 & $2,759,562$ & $91.9854 \%$ \\
\hline XS0349924109 & USD & 3-Mar-2011 & 391,726 & $49.8601 \%$ \\
\hline XS0349924281 & USD & 3-Mar-2011 & 589,785 & $49.8601 \%$ \\
\hline XS0349159623 & USD & 4-Mar-2011 & 591,745 & $37.9608 \%$ \\
\hline XS0349282151 & EUR & 4-Mar-2011 & $9,000,000$ & $100.0000 \%$ \\
\hline XS0350892336 & JPY & 4-Mar-2011 & 699,842 & $97.0151 \%$ \\
\hline XS0349842558 & EUR & 5-Mar-2011 & 919,532 & $91.9532 \%$ \\
\hline XS0351272322 & EUR & 6-Mar-2011 & $2,027,455$ & $135.1637 \%$ \\
\hline DE000AOMHVVO & EUR & 7-Mar-2011 & $62,903,195$ & $65.5016 \%$ \\
\hline XS0340076321 & EUR & 7-Mar-2011 & $6,301,829$ & $87.5254 \%$ \\
\hline XS0344460323 & EUR & 7-Mar-2011 & $2,132,569$ & $91.9211 \%$ \\
\hline XS0344460752 & USD & 7-Mar-2011 & $2,730,320$ & $93.2825 \%$ \\
\hline XS0350318399 & USD & 7-Mar-2011 & 706,251 & $96.2761 \%$ \\
\hline XS0286897219 & EUR & 8-Mar-2011 & $3,216,675$ & $91.9050 \%$ \\
\hline XS0286900708 & $\mathrm{CHF}$ & 8-Mar-2011 & $8,443,658$ & $93.6402 \%$ \\
\hline XS0349166917 & USD & 10-Mar-2011 & $1,396,892$ & $86.8328 \%$ \\
\hline XS0350394499 & EUR & 10-Mar-2011 & $1,033,406$ & $103.3406 \%$ \\
\hline XS0319831854 & GBP & 13-Mar-2011 & $1,522,696$ & $90.8998 \%$ \\
\hline XS0163559841 & EUR & 14-Mar-2011 & $38,157,000$ & $100.8324 \%$ \\
\hline XS0245046114 & USD & 14-Mar-2011 & $1,428,724$ & $93.1883 \%$ \\
\hline XS0344461214 & PLN & 14-Mar-2011 & $1,079,940$ & $94.8193 \%$ \\
\hline XS0344576110 & EUR & 14-Mar-2011 & $2,661,819$ & $108.7789 \%$ \\
\hline XS0344583249 & HUF & 14-Mar-2011 & $6,098,420$ & $112.6909 \%$ \\
\hline XS0345668528 & EUR & 14-Mar-2011 & $5,949,197$ & $91.8086 \%$ \\
\hline XS0348914606 & EUR & 14-Mar-2011 & $2,013,172$ & $100.1578 \%$ \\
\hline XS0350234455 & USD & 14-Mar-2011 & $1,879,900$ & $93.1883 \%$ \\
\hline XS0350390406 & EUR & 14-Mar-2011 & $7,033,456$ & $91.8086 \%$ \\
\hline XS0350847116 & EUR & 14-Mar-2011 & $3,740,334$ & $93.5084 \%$ \\
\hline XS0351979587 & $\mathrm{CHF}$ & 14-Mar-2011 & $1,081,144$ & $93.5665 \%$ \\
\hline XS0247457087 & EUR & 15-Mar-2011 & $3,795,035$ & $125.6634 \%$ \\
\hline XS0292336673 & USD & 16-Mar-2011 & $3,213,384$ & $84.9425 \%$ \\
\hline XS0246504210 & EUR & 17-Mar-2011 & $1,350,820$ & $67.8804 \%$ \\
\hline
\end{tabular}




\begin{tabular}{|c|c|c|c|c|}
\hline ISIN & Currency & $\begin{array}{l}\text { Maturity } \\
\text { date }\end{array}$ & $\begin{array}{c}\text { Admissible } \\
\text { Amount in EUR }\end{array}$ & $\begin{array}{c}\text { Admissible } \\
\text { Amount \% } \\
\end{array}$ \\
\hline \begin{tabular}{|l|} 
XS0346461634 \\
\end{tabular} & USD & 18-Mar-2011 & $6,148,843$ & $93.1345 \%$ \\
\hline XS0350894209 & JPY & 18-Mar-2011 & 793,473 & $108.2933 \%$ \\
\hline \begin{tabular}{|l|l} 
XS0352109465 \\
\end{tabular} & EUR & 18-Mar-2011 & $5,000,000$ & $100.0000 \%$ \\
\hline XS0352549603 & HUF & 18-Mar-2011 & $3,466,062$ & $100.0000 \%$ \\
\hline XS0213378119 & EUR & 20-Mar-2011 & $9,544,446$ & $95.4445 \%$ \\
\hline XS0243626123 & USD & 20-Mar-2011 & $15,951,263$ & $108.7238 \%$ \\
\hline \begin{tabular}{|l} 
XS0186349535 \\
\end{tabular} & JPY & 21-Mar-2011 & $3,460,290$ & $96.5490 \%$ \\
\hline \begin{tabular}{|l|} 
XS0245973770 \\
\end{tabular} & USD & 22-Mar-2011 & $2,329,538$ & $105.8542 \%$ \\
\hline \begin{tabular}{|l|} 
XS0369799845 \\
\end{tabular} & USD & 22-Mar-2011 & $4,882,089$ & $93.0806 \%$ \\
\hline \begin{tabular}{|l|} 
XS0369799928 \\
\end{tabular} & HKD & 22-Mar-2011 & $1,277,701$ & $93.2907 \%$ \\
\hline \begin{tabular}{|l|} 
XS0247770067 \\
\end{tabular} & EUR & 24-Mar-2011 & $1,658,830$ & $91.6480 \%$ \\
\hline \begin{tabular}{|l|} 
XS0247886442 \\
\end{tabular} & JPY & 24-Mar-2011 & 158,266 & $15.3671 \%$ \\
\hline \begin{tabular}{|l|} 
XS0352970650 \\
\end{tabular} & EUR & 26-Mar-2011 & $4,000,000$ & $100.0000 \%$ \\
\hline \begin{tabular}{|l|} 
XS0353499790 \\
\end{tabular} & JPY & 26-Mar-2011 & 491,158 & $68.5214 \%$ \\
\hline \begin{tabular}{|l|} 
XS0292505459 \\
\end{tabular} & EUR & 27-Mar-2011 & 164,880 & $82.4399 \%$ \\
\hline \begin{tabular}{|l|} 
XS0343843479 \\
\end{tabular} & EUR & 28-Mar-2011 & $1,740,094$ & $87.0047 \%$ \\
\hline XS0249055350 & USD & 30-Mar-2011 & 61,382 & $92.9728 \%$ \\
\hline \begin{tabular}{|l} 
XS0286535223 \\
\end{tabular} & EUR & 30-Mar-2011 & $14,748,121$ & $103.1409 \%$ \\
\hline \begin{tabular}{|l|} 
XS0247028391 \\
\end{tabular} & USD & 31-Mar-2011 & $2,639,030$ & $92.9593 \%$ \\
\hline $\mathrm{CH} 0036891239$ & $\mathrm{CHF}$ & 2-Apr-2011 & $2,316,730$ & $102.7701 \%$ \\
\hline \begin{tabular}{|l|} 
XS0247687162 \\
\end{tabular} & EUR & 4-Apr-2011 & $29,765,313$ & $99.2177 \%$ \\
\hline XS0354856196 & USD & 4-Apr-2011 & 681,524 & $92.9054 \%$ \\
\hline XS0249046284 & JPY & 6-Apr-2011 & 685,352 & $95.3712 \%$ \\
\hline \begin{tabular}{|l|} 
XS0283319837 \\
\end{tabular} & EUR & 6-Apr-2011 & $11,999,171$ & $109.9530 \%$ \\
\hline \begin{tabular}{|l|} 
XS0353289399 \\
\end{tabular} & PLN & 8-Apr-2011 & $1,067,926$ & $101.8386 \%$ \\
\hline XS0353289472 & PLN & 8-Apr-2011 & 947,775 & $101.6785 \%$ \\
\hline \begin{tabular}{|l} 
XS0294497085 \\
\end{tabular} & EUR & 10-Apr-2011 & $1,297,532$ & $91.3755 \%$ \\
\hline \begin{tabular}{|l|} 
XS0354190554 \\
\end{tabular} & GBP & 10-Apr-2011 & $1,163,440$ & $90.4284 \%$ \\
\hline \begin{tabular}{|l|} 
XS0372051762 \\
\end{tabular} & USD & 10-Apr-2011 & $40,773,390$ & $67.0257 \%$ \\
\hline $\mathrm{CH} 0036891189$ & $\mathrm{CHF}$ & 11-Apr-2011 & 680,506 & $105.6554 \%$ \\
\hline $\mathrm{CH} 0036891197$ & EUR & 11-Apr-2011 & 701,223 & $107.8805 \%$ \\
\hline XS0286179923 & SEK & 11-Apr-2011 & $3,748,140$ & $92.3515 \%$ \\
\hline \begin{tabular}{|l|} 
XS0286181077 \\
\end{tabular} & SEK & 11-Apr-2011 & $4,596,818$ & $94.0653 \%$ \\
\hline XS0356365360 & USD & 11-Apr-2011 & $1,361,663$ & $92.8109 \%$ \\
\hline XS0250656542 & USD & 12-Apr-2011 & $15,586,364$ & $106.2367 \%$ \\
\hline $\mathrm{CH} 0027120812$ & $\mathrm{CHF}$ & 13-Apr-2011 & $15,006,868$ & $93.1987 \%$ \\
\hline $\mathrm{CH} 0027120820$ & EUR & 13-Apr-2011 & $3,580,951$ & $91.3275 \%$ \\
\hline XS0248620899 & $\mathrm{CHF}$ & 13-Apr-2011 & $35,894,605$ & $104.7477 \%$ \\
\hline \begin{tabular}{|l}
$\mathrm{XS} 0251360714$ \\
\end{tabular} & USD & 14-Apr-2011 & 197,922 & $26.9807 \%$ \\
\hline XS0346707903 & EUR & 15-Apr-2011 & $1,466,946$ & $97.7964 \%$ \\
\hline \begin{tabular}{|l|} 
XS0357486447 \\
\end{tabular} & EUR & 17-Apr-2011 & 912,635 & $91.2635 \%$ \\
\hline DE000A0TR749 & EUR & 18-Apr-2011 & 352,841 & $100.8118 \%$ \\
\hline $\mathrm{CH} 0036891254$ & EUR & 21-Apr-2011 & $4,103,977$ & $91.1995 \%$ \\
\hline \begin{tabular}{|l|} 
XS0251050364 \\
\end{tabular} & JPY & 21-Apr-2011 & 732,125 & $95.3677 \%$ \\
\hline \begin{tabular}{|l|l} 
XS0251683214 \\
\end{tabular} & JPY & 21-Apr-2011 & 223,185 & $17.1472 \%$ \\
\hline XS0251909395 & JPY & 21-Apr-2011 & 592,185 & $17.4589 \%$ \\
\hline XS0166188457 & EUR & 22-Apr-2011 & $18,316,485$ & $99.6816 \%$ \\
\hline XS0357658672 & EUR & 25-Apr-2011 & $2,050,549$ & $82.0220 \%$ \\
\hline \begin{tabular}{|l|} 
XS0298200238 \\
\end{tabular} & USD & 26-Apr-2011 & 917,535 & $84.6840 \%$ \\
\hline XS0250416582 & USD & 28-Apr-2011 & $4,904,661$ & $95.5148 \%$ \\
\hline \begin{tabular}{|l|} 
XS0295698947 \\
\end{tabular} & EUR & 29-Apr-2011 & $4,087,293$ & $91.0716 \%$ \\
\hline XS0354002577 & EUR & 2-May-2011 & $6,393,502$ & $91.0237 \%$ \\
\hline \begin{tabular}{|l} 
XS0360205479 \\
\end{tabular} & USD & 2-May-2011 & $3,138,355$ & $80.7209 \%$ \\
\hline DE000A0NMJ46 & EUR & 3-May-2011 & $6,022,198$ & $62.9542 \%$ \\
\hline XS0359152658 & USD & 3-May-2011 & $3,909,028$ & $92.5137 \%$ \\
\hline XS0361886699 & USD & 5-May-2011 & $1,831,821$ & $83.2379 \%$ \\
\hline \begin{tabular}{|l|} 
XS0360926298 \\
\end{tabular} & EUR & 6-May-2011 & $3,504,803$ & $116.8268 \%$ \\
\hline XS0360993991 & $\mathrm{CHF}$ & 6-May-2011 & $6,275,546$ & $92.7944 \%$ \\
\hline \begin{tabular}{|l} 
XS0363204941 \\
\end{tabular} & USD & 7-May-2011 & 773,209 & $87.8366 \%$ \\
\hline XS0253216005 & JPY & 9-May-2011 & 694,477 & $96.8787 \%$ \\
\hline \begin{tabular}{|l|} 
XS0329133341 \\
\end{tabular} & EUR & 9-May-2011 & 727,295 & $90.9119 \%$ \\
\hline XS0251180906 & $\mathrm{CHF}$ & 12-May-2011 & $29,161,226$ & $107.2173 \%$ \\
\hline XS0362892951 & JPY & 12-May-2011 & 185,105 & $51.5500 \%$ \\
\hline XS0362178989 & EUR & 15-May-2011 & $3,470,641$ & $102.0777 \%$ \\
\hline \begin{tabular}{|l|} 
XS0253223555 \\
\end{tabular} & JPY & 16-May-2011 & 711,687 & $99.0893 \%$ \\
\hline \begin{tabular}{|l|} 
XS0299624568 \\
\end{tabular} & SEK & 18-May-2011 & $5,592,296$ & $82.6151 \%$ \\
\hline \begin{tabular}{|l|} 
XS0363981324 \\
\end{tabular} & JPY & 20-May-2011 & 227,392 & $62.6946 \%$ \\
\hline XS0364508514 & JPY & 20-May-2011 & 524,920 & $64.6980 \%$ \\
\hline XS0364976299 & JPY & 20-May-2011 & $1,002,145$ & $80.8482 \%$ \\
\hline XS0364173665 & EUR & 21-May-2011 & $3,175,217$ & $90.7205 \%$ \\
\hline XS0365671121 & USD & 22-May-2011 & $1,218,175$ & $83.0308 \%$ \\
\hline XS0255006446 & JPY & 24-May-2011 & 958,845 & $95.3582 \%$ \\
\hline \begin{tabular}{|l|} 
XS0364806884 \\
\end{tabular} & JPY & 25-May-2011 & 287,134 & $79.8525 \%$ \\
\hline \begin{tabular}{|l|} 
XS0364948918 \\
\end{tabular} & JPY & 25-May-2011 & 169,700 & $46.2400 \%$ \\
\hline \begin{tabular}{|l|} 
XS0364976372 \\
\end{tabular} & JPY & 25-May-2011 & 490,134 & $79.6507 \%$ \\
\hline XS0364976539 & JPY & 25-May-2011 & 340,289 & $78.6353 \%$ \\
\hline XS0364976703 & JPY & 25-May-2011 & 283,199 & $75.7969 \%$ \\
\hline XS0365324325 & JPY & 25-May-2011 & 283,593 & $78.3369 \%$ \\
\hline \begin{tabular}{|l|} 
XS0365822864 \\
\end{tabular} & JPY & 25-May-2011 & 199,862 & $54.6077 \%$ \\
\hline
\end{tabular}




\begin{tabular}{|c|c|c|c|c|}
\hline ISIN & Currency & $\begin{array}{c}\text { Maturity } \\
\text { date }\end{array}$ & $\begin{array}{c}\text { Admissible } \\
\text { Amount in EUR }\end{array}$ & $\begin{array}{c}\text { Admissible } \\
\text { Amount \% }\end{array}$ \\
\hline XS0365823243 & JPY & 25-May-2011 & 516,814 & $80.0319 \%$ \\
\hline \begin{tabular}{|l|} 
XS0365880987 \\
\end{tabular} & JPY & 25-May-2011 & 123,454 & $24.2576 \%$ \\
\hline \begin{tabular}{|l} 
XS0219677423 \\
\end{tabular} & EUR & 27-May-2011 & $1,359,373$ & $90.6249 \%$ \\
\hline $\mathrm{CH} 0039308678$ & USD & 30-May-2011 & $8,449,603$ & $92.1480 \%$ \\
\hline XS0362343930 & EUR & 30-May-2011 & $1,908,066$ & $95.4033 \%$ \\
\hline XS0362725540 & USD & 30-May-2011 & $9,427,696$ & $99.6653 \%$ \\
\hline XS0365822781 & JPY & 30-May-2011 & 772,614 & $53.8937 \%$ \\
\hline XS0256259606 & PLN & 31-May-2011 & $1,326,147$ & $87.5512 \%$ \\
\hline \begin{tabular}{|l} 
XS0365873347 \\
\end{tabular} & USD & 31-May-2011 & $1,581,933$ & $107.8245 \%$ \\
\hline \begin{tabular}{|l|} 
XS0366374394 \\
\end{tabular} & JPY & 3-Jun-2011 & $1,455,021$ & $101.4950 \%$ \\
\hline XS0366664711 & JPY & 3-Jun-2011 & 305,027 & $83.4399 \%$ \\
\hline XS0366986916 & JPY & 3-Jun-2011 & 388,753 & $74.5702 \%$ \\
\hline \begin{tabular}{|l} 
XS0368698444 \\
\end{tabular} & USD & 5-Jun-2011 & $6,580,739$ & $102.6767 \%$ \\
\hline XS0256233122 & USD & 6-Jun-2011 & 955,644 & $113.4785 \%$ \\
\hline XS0368358932 & NOK & 6-Jun-2011 & $31,042,320$ & $104.0663 \%$ \\
\hline \begin{tabular}{|l} 
XS0359895876 \\
\end{tabular} & EUR & 9-Jun-2011 & $2,249,600$ & $90.4180 \%$ \\
\hline \begin{tabular}{|l} 
XS0359896098 \\
\end{tabular} & USD & 9-Jun-2011 & $2,078,917$ & $92.0123 \%$ \\
\hline XS0367990057 & EUR & 10-Jun-2011 & 683,440 & $97.6343 \%$ \\
\hline \begin{tabular}{|l|} 
XS0368198718 \\
\end{tabular} & JPY & 10-Jun-2011 & 270,603 & $61.1109 \%$ \\
\hline XS0368366877 & JPY & 10-Jun-2011 & 242,432 & $66.1873 \%$ \\
\hline XS0368582739 & JPY & 10-Jun-2011 & 256,120 & $67.5195 \%$ \\
\hline \begin{tabular}{|l} 
XS0368801717 \\
\end{tabular} & JPY & 10-Jun-2011 & 626,828 & $78.8679 \%$ \\
\hline XS0369744940 & JPY & 10-Jun-2011 & 435,812 & $84.2949 \%$ \\
\hline \begin{tabular}{|l|} 
DK0030106190 \\
\end{tabular} & DKK & 12-Jun-2011 & 694,156 & $100.0000 \%$ \\
\hline \begin{tabular}{|l|} 
XS0368448683 \\
\end{tabular} & USD & 12-Jun-2011 & $3,117,399$ & $101.9098 \%$ \\
\hline \begin{tabular}{|l}
$\mathrm{XS} 0220326408$ \\
\end{tabular} & $\mathrm{CHF}$ & 13-Jun-2011 & $3,938,477$ & $101.9147 \%$ \\
\hline XS0368497623 & EUR & 14-Jun-2011 & $6,970,632$ & $94.1977 \%$ \\
\hline XS0368497896 & EUR & 14-Jun-2011 & $6,970,632$ & $94.1977 \%$ \\
\hline XS0257587815 & JPY & 16-Jun-2011 & 168,042 & $23.1724 \%$ \\
\hline XS0368800156 & JPY & 16-Jun-2011 & 163,872 & $45.4418 \%$ \\
\hline XS0301522396 & EUR & 17-Jun-2011 & 451,454 & $90.2908 \%$ \\
\hline XS0249955930 & USD & 20-Jun-2011 & $29,841,675$ & $95.1583 \%$ \\
\hline \begin{tabular}{|l} 
XS0356376995 \\
\end{tabular} & EUR & 20-Jun-2011 & $7,500,000$ & $100.0000 \%$ \\
\hline XS0368739495 & JPY & 20-Jun-2011 & $7,266,419$ & $101.3738 \%$ \\
\hline XS0293677281 & EUR & 21-Jun-2011 & $22,556,820$ & $90.2273 \%$ \\
\hline XS0328851794 & EUR & 21-Jun-2011 & $9,518,184$ & $95.1818 \%$ \\
\hline XS0330181776 & EUR & 21-Jun-2011 & $3,687,101$ & $92.1775 \%$ \\
\hline XS0260996334 & JPY & 22-Jun-2011 & 700,872 & $97.7298 \%$ \\
\hline \begin{tabular}{|l|} 
XS0261618606 \\
\end{tabular} & JPY & 22-Jun-2011 & 701,664 & $97.7298 \%$ \\
\hline DE000A0NPV47 & EUR & 24-Jun-2011 & $11,272,456$ & $90.1796 \%$ \\
\hline \begin{tabular}{|l|} 
XS0259691383 \\
\end{tabular} & EUR & 27-Jun-2011 & $4,592,366$ & $91.8473 \%$ \\
\hline XS0306249045 & USD & 27-Jun-2011 & $3,732,634$ & $101.7665 \%$ \\
\hline \begin{tabular}{|l} 
XS0373013027 \\
\end{tabular} & USD & 27-Jun-2011 & $2,808,326$ & $103.6359 \%$ \\
\hline XS0368249487 & USD & 28-Jun-2011 & $1,683,206$ & $96.2477 \%$ \\
\hline XS0368298187 & EUR & 28-Jun-2011 & $1,774,196$ & $99.2280 \%$ \\
\hline XS0297221458 & SEK & 29-Jun-2011 & $1,237,768$ & $89.8880 \%$ \\
\hline \begin{tabular}{|l} 
XS0297365024 \\
\end{tabular} & SEK & 29-Jun-2011 & $1,833,385$ & $89.8880 \%$ \\
\hline \begin{tabular}{|l|} 
XS0221564387 \\
\end{tabular} & USD & 30-Jun-2011 & 768,020 & $128.6198 \%$ \\
\hline \begin{tabular}{|l|} 
XS0251832662 \\
\end{tabular} & EUR & 30-Jun-2011 & $38,243,487$ & $95.6087 \%$ \\
\hline XS0258962975 & EUR & 30-Jun-2011 & $7,648,697$ & $95.6087 \%$ \\
\hline $\mathrm{CH} 0043088605$ & USD & 4-Jul-2011 & $3,610,181$ & $123.0350 \%$ \\
\hline $\mathrm{CH} 0043088613$ & EUR & 4-Jul-2011 & $1,237,483$ & $123.7483 \%$ \\
\hline $\mathrm{CH} 0043088621$ & $\mathrm{CHF}$ & 4-Jul-2011 & $1,592,230$ & $123.6048 \%$ \\
\hline XS0301086475 & EUR & 4-Jul-2011 & $23,337,636$ & $72.2460 \%$ \\
\hline XS0308319341 & EUR & 4-Jul-2011 & 900,210 & $90.0210 \%$ \\
\hline XS0296894669 & EUR & 6-Jul-2011 & $8,901,572$ & $113.8745 \%$ \\
\hline \begin{tabular}{|l|} 
DE000AONMGK2 \\
\end{tabular} & EUR & 7-Jul-2011 & $1,551,897$ & $38.7974 \%$ \\
\hline \begin{tabular}{|l}
$\mathrm{XS} 0375278313$ \\
\end{tabular} & USD & 7-Jul-2011 & $1,513,259$ & $91.2776 \%$ \\
\hline \begin{tabular}{|l} 
XS0374132594 \\
\end{tabular} & AUD & 11-Jul-2011 & 496,761 & $93.3166 \%$ \\
\hline XS0281706704 & EUR & 18-Jul-2011 & $5,000,000$ & $100.0000 \%$ \\
\hline XS0223920348 & USD & 20-Jul-2011 & $4,460,525$ & $95.0092 \%$ \\
\hline XS0132961896 & HKD & 22-Jul-2011 & $10,285,601$ & $108.8947 \%$ \\
\hline XS0311764509 & EUR & 25-Jul-2011 & $1,092,647$ & $84.0497 \%$ \\
\hline XS0260874655 & USD & 26-Jul-2011 & $3,432,935$ & $93.5956 \%$ \\
\hline XS0299701499 & EUR & 27-Jul-2011 & $1,119,908$ & $95.7187 \%$ \\
\hline \begin{tabular}{|l} 
XS0305646696 \\
\end{tabular} & EUR & 27-Jul-2011 & $19,551,000$ & $100.0000 \%$ \\
\hline \begin{tabular}{|l|} 
XS0316834083 \\
\end{tabular} & USD & 27-Jul-2011 & 514,031 & $91.3594 \%$ \\
\hline CH0043088639 & $\mathrm{CHF}$ & 4-Aug-2011 & 650,524 & $101.0003 \%$ \\
\hline $\mathrm{CH} 0043088647$ & EUR & 4-Aug-2011 & $1,074,365$ & $107.4365 \%$ \\
\hline $\mathrm{CH} 0043088654$ & USD & 4-Aug-2011 & $1,104,486$ & $100.3757 \%$ \\
\hline XS0226127784 & GBP & 8-Aug-2011 & $2,565,247$ & $99.6919 \%$ \\
\hline XS0313345604 & EUR & 9-Aug-2011 & $1,187,161$ & $27.3470 \%$ \\
\hline XS0263244914 & USD & 11-Aug-2011 & $1,198,280$ & $116.6782 \%$ \\
\hline \begin{tabular}{|l} 
XS0197173643 \\
\end{tabular} & EUR & 12-Aug-2011 & $16,730,438$ & $98.7804 \%$ \\
\hline XS0226717238 & USD & 12 -Aug-2011 & 533,222 & $103.8412 \%$ \\
\hline \begin{tabular}{|l|l} 
XS0314774257 \\
\end{tabular} & EUR & 13-Aug-2011 & $5,816,790$ & $58.2611 \%$ \\
\hline XS0226787447 & $\mathrm{CHF}$ & 16-Aug-2011 & $1,498,995$ & $93.0936 \%$ \\
\hline $\mathrm{CH} 0027120994$ & EUR & 17-Aug-2011 & $4,378,714$ & $89.3250 \%$ \\
\hline XS0316485563 & $\mathrm{CHF}$ & 17-Aug-2011 & 915,068 & $91.6603 \%$ \\
\hline
\end{tabular}




\begin{tabular}{|c|c|c|c|c|}
\hline ISIN & Currency & $\begin{array}{l}\text { Maturity } \\
\text { date }\end{array}$ & $\begin{array}{c}\text { Admissible } \\
\text { Amount in EUR }\end{array}$ & $\begin{array}{c}\text { Admissible } \\
\text { Amount \% }\end{array}$ \\
\hline XS0380296144 & USD & 22-Aug-2011 & 726,955 & $99.0985 \%$ \\
\hline \begin{tabular}{|l|l} 
XS0264674549 \\
\end{tabular} & GBP & 23-Aug-2011 & $2,103,824$ & $11.1618 \%$ \\
\hline AU300LBTC011 & AUD & 24-Aug-2011 & $142,449,255$ & $107.0364 \%$ \\
\hline AU300LBTC029 & AUD & 24-Aug-2011 & $196,447,253$ & $105.4360 \%$ \\
\hline XS0383940292 & EUR & 26-Aug-2011 & $5,433,868$ & $108.6774 \%$ \\
\hline XS0317359718 & EUR & 28-Aug-2011 & 553,196 & $49.3925 \%$ \\
\hline XS0384883251 & AUD & 29-Aug-2011 & $2,890,940$ & $109.2243 \%$ \\
\hline XS0227570750 & EUR & 1-Sep-2011 & 899,895 & $89.9895 \%$ \\
\hline XS0264966671 & USD & 1-Sep-2011 & $2,878,702$ & $113.1885 \%$ \\
\hline DE000A0TX6H7 & EUR & 5-Sep-2011 & $2,234,435$ & $106.4017 \%$ \\
\hline XS0266912228 & USD & 6-Sep-2011 & $7,467,723$ & $100.0000 \%$ \\
\hline DE000A0NTS89 & EUR & 8-Sep-2011 & $1,334,676$ & $88.9784 \%$ \\
\hline $\mathrm{CH} 0043088670$ & EUR & 12-Sep-2011 & 620,283 & $95.4282 \%$ \\
\hline $\mathrm{CH} 0043088704$ & $\mathrm{CHF}$ & 12-Sep-2011 & 651,790 & $101.1969 \%$ \\
\hline XS0225999258 & USD & 20-Sep-2011 & $7,651,333$ & $104.3030 \%$ \\
\hline XS0256257907 & USD & 20-Sep-2011 & $15,816,977$ & $107.8085 \%$ \\
\hline XS0321019258 & EUR & 20-Sep-2011 & $6,930,048$ & $62.8861 \%$ \\
\hline $\mathrm{CH} 0036891247$ & EUR & 21-Sep-2011 & 887,740 & $88.7740 \%$ \\
\hline XS0260371827 & EUR & 21-Sep-2011 & $1,003,714$ & $91.2467 \%$ \\
\hline XS0267460359 & EUR & 21-Sep-2011 & $1,519,933$ & $88.3682 \%$ \\
\hline XS0268040192 & SGD & 21-Sep-2011 & $31,843,030$ & $105.8675 \%$ \\
\hline XS0311769219 & EUR & 22-Sep-2011 & $2,860,575$ & $107.5000 \%$ \\
\hline XS0268997532 & USD & 26-Sep-2011 & 511,514 & $11.4311 \%$ \\
\hline XS0227081634 & EUR & 28-Sep-2011 & $4,400,792$ & $97.4770 \%$ \\
\hline XS0323526854 & GBP & 28-Sep-2011 & $1,972,359$ & $87.6009 \%$ \\
\hline XS0268576609 & $\mathrm{CHF}$ & 29-Sep-2011 & $3,107,076$ & $94.9615 \%$ \\
\hline XS0269529136 & $\mathrm{CHF}$ & 29-Sep-2011 & $5,198,847$ & $94.9615 \%$ \\
\hline XS0288215220 & USD & 30-Sep-2011 & 868,076 & $90.4710 \%$ \\
\hline XS0288216111 & GBP & 30-Sep-2011 & $1,279,867$ & $87.5684 \%$ \\
\hline XS0288291593 & GBP & 30-Sep-2011 & $1,126,644$ & $87.5684 \%$ \\
\hline XS0288781502 & USD & 30-Sep-2011 & 796,400 & $90.4710 \%$ \\
\hline DE000AOLHNW7 & EUR & 3-Oct-2011 & $1,882,909$ & $44.4817 \%$ \\
\hline XS0268620514 & ILS & 5-Oct-2011 & $2,168,487$ & $89.7209 \%$ \\
\hline DE000A0N8MX9 & EUR & 6-Oct-2011 & 436,295 & $43.6295 \%$ \\
\hline \begin{tabular}{|l|} 
XS0269492038 \\
\end{tabular} & JPY & 11-Oct-2011 & $1,403,347$ & $62.5818 \%$ \\
\hline XS0269500665 & JPY & 11-Oct-2011 & 83,190 & $11.5562 \%$ \\
\hline XS0269969027 & EUR & 13-Oct-2011 & $4,567,151$ & $94.1681 \%$ \\
\hline XS0323493584 & USD & $17-$ Oct-2011 & $4,420,233$ & $109.5575 \%$ \\
\hline XS0230522962 & EUR & 18-Oct-2011 & $5,080,000$ & $100.0000 \%$ \\
\hline XS0271141565 & GBP & $18-O c t-2011$ & 582,580 & $3.6254 \%$ \\
\hline XS0325813409 & USD & $18-O c t-2011$ & $4,532,592$ & $81.1936 \%$ \\
\hline XS0326085742 & EUR & 18-Oct-2011 & $2,325,886$ & $86.1439 \%$ \\
\hline \begin{tabular}{|l|l} 
XS0326108973 \\
\end{tabular} & SEK & 18-Oct-2011 & $1,868,786$ & $86.9872 \%$ \\
\hline XS0230178658 & EUR & 21-Oct-2011 & $17,148,384$ & $85.7419 \%$ \\
\hline XS0272052753 & USD & 21-Oct-2011 & $2,821,817$ & $48.0838 \%$ \\
\hline XS0270174013 & USD & $24-O c t-2011$ & $4,559,645$ & $103.5951 \%$ \\
\hline XS0271201484 & EUR & $25-O c t-2011$ & $2,819,105$ & $93.9702 \%$ \\
\hline DE000A0N1VM8 & EUR & 26-Oct-2011 & $7,499,494$ & $88.2293 \%$ \\
\hline XS0268992145 & USD & $26-$ Oct-2011 & $1,665,272$ & $120.5576 \%$ \\
\hline XS0204199466 & USD & $27-$ Oct-2011 & $3,430,927$ & $105.8154 \%$ \\
\hline XS0204199540 & EUR & 27-Oct-2011 & $1,843,875$ & $104.7656 \%$ \\
\hline XS0266559433 & HUF & 31-Oct-2011 & 994,037 & $80.9296 \%$ \\
\hline XS0271671793 & USD & 31-Oct-2011 & $15,181,918$ & $103.4800 \%$ \\
\hline XS0272574889 & SEK & $31-O c t-2011$ & 850,657 & $82.1615 \%$ \\
\hline XS0272095216 & EUR & 3-Nov-2011 & $10,177,159$ & $77.8249 \%$ \\
\hline XS0314918276 & EUR & 7-Nov-2011 & $8,840,000$ & $110.5000 \%$ \\
\hline XS0326086716 & $\mathrm{CHF}$ & 9-Nov-2011 & $11,549,445$ & $95.6356 \%$ \\
\hline XS0384379847 & $\mathrm{CHF}$ & 9-Nov-2011 & 615,970 & $95.6356 \%$ \\
\hline XS0329219819 & EUR & 9-Nov-2011 & $2,132,615$ & $106.6308 \%$ \\
\hline XS0329670946 & AUD & 13-Nov-2011 & 350,181 & $14.9503 \%$ \\
\hline XS0273678283 & EUR & 16-Nov-2011 & $8,790,606$ & $87.9061 \%$ \\
\hline XS0274443422 & EUR & 18-Nov-2011 & $3,816,425$ & $87.8753 \%$ \\
\hline XS0329571292 & EUR & 21-Nov-2011 & 720,200 & $87.8292 \%$ \\
\hline \begin{tabular}{|l}
$\mathrm{XS} 0332675338$ \\
\end{tabular} & USD & 21-Nov-2011 & $2,627,904$ & $89.7160 \%$ \\
\hline XS0331333160 & EUR & 22-Nov-2011 & $17,884,430$ & $59.6148 \%$ \\
\hline XS0331249531 & USD & 23-Nov-2011 & $4,195,272$ & $99.4608 \%$ \\
\hline \begin{tabular}{|l|} 
DE000A0G0Y08 \\
\end{tabular} & EUR & 24-Nov-2011 & $6,410,657$ & $91.5808 \%$ \\
\hline DE000A0TLG93 & EUR & 30-Nov-2011 & $4,647,627$ & $87.6911 \%$ \\
\hline XS0277119797 & EUR & 30-Nov-2011 & $5,153,804$ & $106.2202 \%$ \\
\hline XS0277120027 & USD & 30-Nov-2011 & $4,855,851$ & $114.1292 \%$ \\
\hline XS0277120456 & $\mathrm{CHF}$ & 30-Nov-2011 & $3,301,876$ & $101.9386 \%$ \\
\hline \begin{tabular}{|l} 
XS0271720673 \\
\end{tabular} & EUR & 1-Dec-2011 & 721,571 & $87.6757 \%$ \\
\hline XS0206444191 & EUR & 6-Dec-2011 & $5,500,011$ & $110.0002 \%$ \\
\hline XS0276619805 & EUR & 6-Dec-2011 & $8,221,841$ & $45.6769 \%$ \\
\hline XS0278544274 & USD & 6-Dec-2011 & $3,747,065$ & $102.1600 \%$ \\
\hline XS0277185152 & EUR & 8-Dec-2011 & $9,562,657$ & $91.8603 \%$ \\
\hline XS0277470943 & USD & 11-Dec-2011 & $1,677,794$ & $7.7452 \%$ \\
\hline XS0327165477 & EUR & $12-$ Dec-2011 & $3,516,378$ & $100.1817 \%$ \\
\hline XS0327165634 & EUR & 12-Dec-2011 & $3,087,418$ & $91.0743 \%$ \\
\hline
\end{tabular}




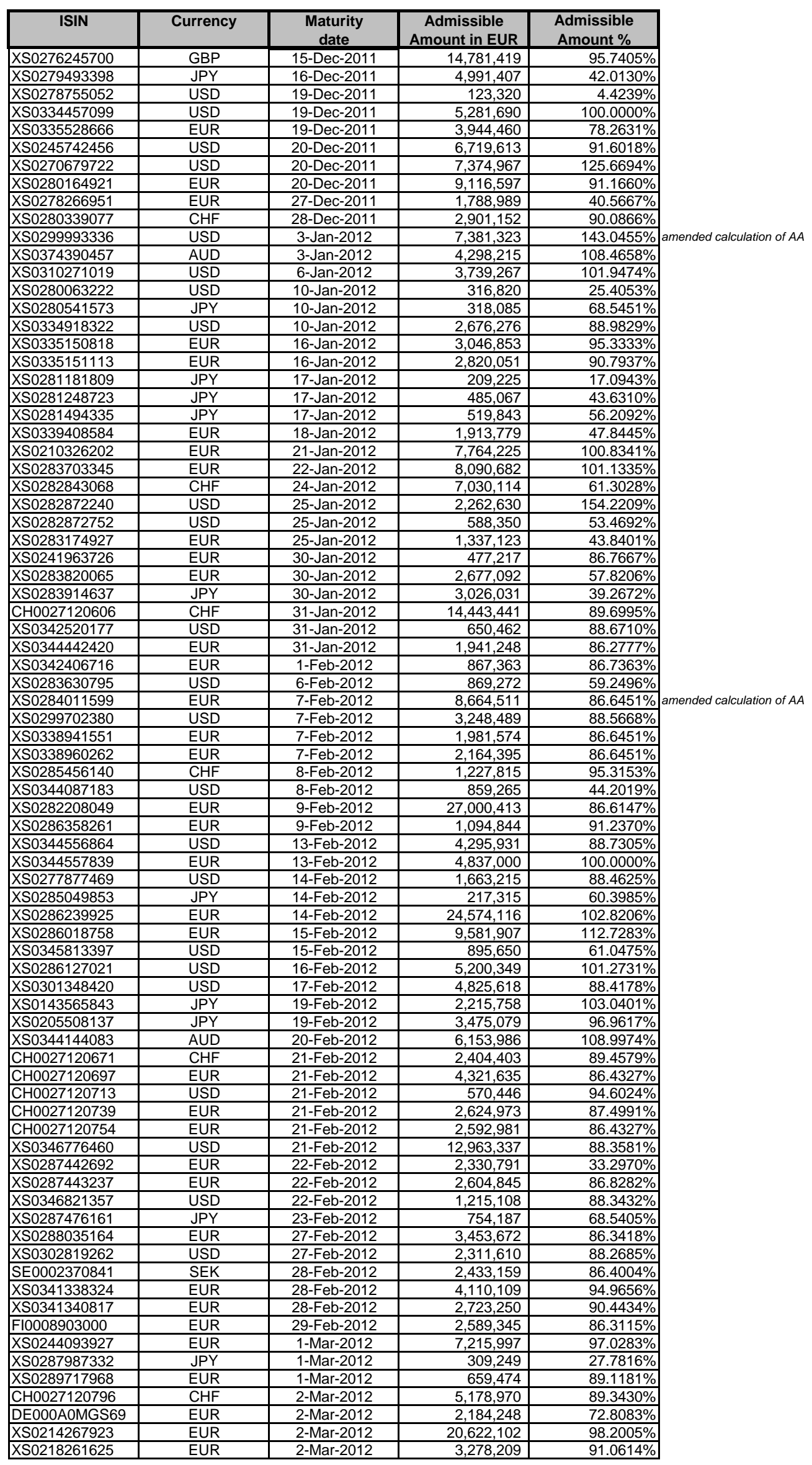




\begin{tabular}{|c|c|c|c|c|}
\hline ISIN & Currency & $\begin{array}{l}\text { Maturity } \\
\text { date }\end{array}$ & $\begin{array}{c}\text { Admissible } \\
\text { Amount in EUR }\end{array}$ & $\begin{array}{c}\text { Admissible } \\
\text { Amount \% } \\
\end{array}$ \\
\hline XS0287160104 & EUR & 2-Mar-2012 & $1,597,961$ & $50.5684 \%$ \\
\hline XS0289151283 & JPY & 2-Mar-2012 & 294,240 & $40.8290 \%$ \\
\hline \begin{tabular}{|l|} 
XS0303866049 \\
\end{tabular} & USD & 5-Mar-2012 & $2,192,457$ & $88.1639 \%$ \\
\hline XS0289002957 & JPY & 6-Mar-2012 & 345,615 & $42.4537 \%$ \\
\hline \begin{tabular}{|l|} 
XS0289100967 \\
\end{tabular} & JPY & 6-Mar-2012 & 691,522 & $45.2675 \%$ \\
\hline XS0289323320 & JPY & 6-Mar-2012 & 116,432 & $26.8150 \%$ \\
\hline \begin{tabular}{|l|} 
XS0289482639 \\
\end{tabular} & JPY & 6-Mar-2012 & 138,219 & $38.3144 \%$ \\
\hline \begin{tabular}{|l|}
$\mathrm{XS} 0289837436$ \\
\end{tabular} & JPY & 6-Mar-2012 & 351,217 & $48.8517 \%$ \\
\hline $\mathrm{CH} 0036891148$ & $\mathrm{CHF}$ & 7-Mar-2012 & $2,300,286$ & $89.2856 \%$ \\
\hline XS0342523197 & EUR & 7-Mar-2012 & $2,893,922$ & $86.2056 \%$ \\
\hline \begin{tabular}{|l|}
$\mathrm{XS} 0245314579$ \\
\end{tabular} & EUR & 8-Mar-2012 & $12,157,703$ & $81.0514 \%$ \\
\hline \begin{tabular}{|l|l|} 
XS0289154972 \\
\end{tabular} & JPY & 8-Mar-2012 & 346,226 & $12.4046 \%$ \\
\hline \begin{tabular}{|l|} 
XS0289487943 \\
\end{tabular} & JPY & 9-Mar-2012 & 182,975 & $25.2927 \%$ \\
\hline SE0002379271 & SEK & 12-Mar-2012 & 967,860 & $98.4018 \%$ \\
\hline XS0350817630 & USD & 12-Mar-2012 & 724,810 & $65.8707 \%$ \\
\hline \begin{tabular}{|l|} 
XS0350847033 \\
\end{tabular} & USD & 12-Mar-2012 & $4,621,479$ & $100.0000 \%$ \\
\hline \begin{tabular}{|l|l} 
XS0386331127 \\
\end{tabular} & USD & 12-Mar-2012 & $1,514,830$ & $68.8339 \%$ \\
\hline XS0289830936 & JPY & 13-Mar-2012 & 146,633 & $40.6955 \%$ \\
\hline \begin{tabular}{|l|} 
XS0290100139 \\
\end{tabular} & JPY & 13-Mar-2012 & $1,421,465$ & $60.0324 \%$ \\
\hline XS0290250454 & EUR & 13-Mar-2012 & $3,040,875$ & $114.7500 \%$ \\
\hline XS0290251007 & EUR & 13-Mar-2012 & $5,992,452$ & $52.0630 \%$ \\
\hline \begin{tabular}{|l|} 
XS0290107225 \\
\end{tabular} & JPY & 14-Mar-2012 & 204,922 & $27.7023 \%$ \\
\hline \begin{tabular}{|l|} 
XS0290766269 \\
\end{tabular} & JPY & 16-Mar-2012 & 706,076 & $52.3682 \%$ \\
\hline XS0290980340 & JPY & 16-Mar-2012 & 183,296 & $25.5308 \%$ \\
\hline \begin{tabular}{|l|} 
XS0291131141 \\
\end{tabular} & EUR & 16-Mar-2012 & 860,696 & $86.0696 \%$ \\
\hline XS0290106508 & JPY & 19-Mar-2012 & 567,224 & $65.2142 \%$ \\
\hline XS0290977049 & JPY & 19-Mar-2012 & 111,949 & $31.0744 \%$ \\
\hline \begin{tabular}{|l|} 
XS0292467189 \\
\end{tabular} & JPY & 19-Mar-2012 & 143,924 & $38.6318 \%$ \\
\hline \begin{tabular}{|l|} 
XS0352483746 \\
\end{tabular} & USD & 19-Mar-2012 & 819,872 & $111.7650 \%$ \\
\hline \begin{tabular}{|l|} 
XS0291347234 \\
\end{tabular} & EUR & 20-Mar-2012 & $1,529,783$ & $47.8057 \%$ \\
\hline \begin{tabular}{|l|} 
XS0290563740 \\
\end{tabular} & JPY & 21-Mar-2012 & 119,745 & $33.4112 \%$ \\
\hline \begin{tabular}{|l|} 
XS0290986206 \\
\end{tabular} & AUD & 21-Mar-2012 & 426,494 & $57.2264 \%$ \\
\hline XS0291662343 & JPY & 21-Mar-2012 & 226,610 & $28.2238 \%$ \\
\hline \begin{tabular}{|l|} 
XS0298326256 \\
\end{tabular} & JPY & 21-Mar-2012 & 430,005 & $59.9660 \%$ \\
\hline XS0289253287 & EUR & 22-Mar-2012 & $3,150,092$ & $61.8879 \%$ \\
\hline XS0290111177 & JPY & 22-Mar-2012 & 577,980 & $42.4389 \%$ \\
\hline \begin{tabular}{|l|} 
XS0291659471 \\
\end{tabular} & JPY & 22-Mar-2012 & 142,049 & $24.2384 \%$ \\
\hline \begin{tabular}{|l|} 
XS0306148288 \\
\end{tabular} & USD & 22-Mar-2012 & $2,134,538$ & $87.9095 \%$ \\
\hline XS0293572425 & EUR & 23-Mar-2012 & $2,688,701$ & $53.7740 \%$ \\
\hline XS0353821860 & USD & 23-Mar-2012 & $9,026,720$ & $87.8945 \%$ \\
\hline XS0355597104 & AUD & 27-Mar-2012 & 439,738 & $82.6049 \%$ \\
\hline DE000A0NLZG2 & EUR & 30-Mar-2012 & 577,652 & $57.7652 \%$ \\
\hline XS0343090196 & EUR & 31-Mar-2012 & 256,671 & $85.8432 \%$ \\
\hline \begin{tabular}{|l|} 
XS0294839146 \\
\end{tabular} & USD & 2-Apr-2012 & $3,857,576$ & $105.1729 \%$ \\
\hline XS0294839575 & USD & 2-Apr-2012 & 818,831 & $91.1209 \%$ \\
\hline \begin{tabular}{|l|} 
XS0291655057 \\
\end{tabular} & JPY & 3-Apr-2012 & 157,728 & $21.9200 \%$ \\
\hline $\mathrm{CH} 0036891163$ & $\mathrm{CHF}$ & 4-Apr-2012 & 859,509 & $88.9649 \%$ \\
\hline \begin{tabular}{|l|} 
XS0352785751 \\
\end{tabular} & EUR & 4-Apr-2012 & $1,347,662$ & $116.1778 \%$ \\
\hline \begin{tabular}{|l|} 
XS0293062146 \\
\end{tabular} & EUR & 5-Apr-2012 & $1,265,194$ & $63.2597 \%$ \\
\hline DE000A0MHXQ6 & EUR & 6-Apr-2012 & $30,893,702$ & $90.7864 \%$ \\
\hline \begin{tabular}{|l|} 
XS0216140417 \\
\end{tabular} & EUR & 6-Apr-2012 & $6,895,102$ & $115.1102 \%$ \\
\hline XS0348646919 & EUR & 9-Apr-2012 & $3,594,578$ & $85.7076 \%$ \\
\hline XS0294059307 & JPY & 10-Apr-2012 & 125,439 & $33.7772 \%$ \\
\hline \begin{tabular}{|l|} 
XS0310085492 \\
\end{tabular} & USD & 10-Apr-2012 & $3,471,034$ & $87.6243 \%$ \\
\hline \begin{tabular}{|l|} 
XS0292985644 \\
\end{tabular} & JPY & 11-Apr-2012 & 88,639 & $24.4171 \%$ \\
\hline XS0294561351 & JPY & 11-Apr-2012 & 136,686 & $37.8363 \%$ \\
\hline \begin{tabular}{|l|} 
XS0356420215 \\
\end{tabular} & AUD & 11-Apr-2012 & $1,268,040$ & $85.6223 \%$ \\
\hline XS0292153672 & USD & 12-Apr-2012 & $4,138,495$ & $88.4263 \%$ \\
\hline XS0294922801 & EUR & 12-Apr-2012 & $9,098,261$ & $90.9826 \%$ \\
\hline \begin{tabular}{|l|} 
XS0295002231 \\
\end{tabular} & JPY & 12-Apr-2012 & 220,179 & $30.7172 \%$ \\
\hline SE0002419242 & SEK & 16-Apr-2012 & 594,467 & $95.6954 \%$ \\
\hline XS0309186145 & USD & 16-Apr-2012 & $1,181,505$ & $87.5341 \%$ \\
\hline \begin{tabular}{|l|} 
XS0294815047 \\
\end{tabular} & JPY & 17-Apr-2012 & 170,418 & $38.4299 \%$ \\
\hline \begin{tabular}{|l|} 
XS0296280927 \\
\end{tabular} & EUR & 17-Apr-2012 & $2,601,347$ & $86.7116 \%$ \\
\hline \begin{tabular}{|l|} 
XS0309790797 \\
\end{tabular} & USD & 17-Apr-2012 & $1,675,651$ & $87.5191 \%$ \\
\hline XS0310085062 & USD & 17-Apr-2012 & 789,675 & $87.5191 \%$ \\
\hline $\mathrm{CH} 0036891262$ & $\mathrm{CHF}$ & 18-Apr-2012 & 857,963 & $88.8049 \%$ \\
\hline XS0295861107 & JPY & 20-Apr-2012 & 633,713 & $51.1036 \%$ \\
\hline \begin{tabular}{|l|} 
XS0312196123 \\
\end{tabular} & AUD & 20-Apr-2012 & 769,810 & $82.1641 \%$ \\
\hline \begin{tabular}{|l|} 
XS0311101652 \\
\end{tabular} & USD & 23-Apr-2012 & $1,872,741$ & $87.4288 \%$ \\
\hline \begin{tabular}{|l|} 
XS0296787236 \\
\end{tabular} & JPY & 24-Apr-2012 & 255,476 & $38.7226 \%$ \\
\hline XS0297060856 & USD & 27-Apr-2012 & 45,196 & $4.1074 \%$ \\
\hline XS0191748242 & EUR & 28-Apr-2012 & 701,673 & $100.2390 \%$ \\
\hline \begin{tabular}{|l|} 
XS0359314225 \\
\end{tabular} & SEK & 30-Apr-2012 & $47,385,382$ & $93.4034 \%$ \\
\hline XS0294778336 & EUR & 3-May-2012 & $2,855,188$ & $79.7539 \%$ \\
\hline DE000AONMXZ5 & EUR & 4-May-2012 & $12,562,223$ & $86.8997 \%$ \\
\hline \begin{tabular}{|l|} 
XS0296156085 \\
\end{tabular} & EUR & 4-May-2012 & $7,306,219$ & $97.4163 \%$ \\
\hline XS0313536962 & USD & 7-May-2012 & $2,302,524$ & $93.4167 \%$ \\
\hline XS0292248977 & USD & 8-May-2012 & $7,497,518$ & $97.9549 \%$ \\
\hline
\end{tabular}




\begin{tabular}{|c|c|c|c|c|}
\hline ISIN & Currency & $\begin{array}{l}\text { Maturity } \\
\text { date }\end{array}$ & $\begin{array}{c}\text { Admissible } \\
\text { Amount in EUR }\end{array}$ & $\begin{array}{c}\text { Admissible } \\
\text { Amount \% } \\
\end{array}$ \\
\hline XS0299354919 & USD & 9-May-2012 & $1,501,530$ & $32.5419 \%$ \\
\hline XS0313537184 & USD & 9-May-2012 & $2,471,634$ & $93.8532 \%$ \\
\hline \begin{tabular}{|l|} 
XS0313950031 \\
\end{tabular} & USD & 9-May-2012 & $2,161,691$ & $93.8477 \%$ \\
\hline XS0362447558 & EUR & 9-May-2012 & $1,805,974$ & $90.2987 \%$ \\
\hline XS0294484422 & USD & 11-May-2012 & $2,757,718$ & $88.2470 \%$ \\
\hline XS0299642628 & USD & 11-May-2012 & $2,484,401$ & $99.6099 \%$ \\
\hline \begin{tabular}{|l|} 
XS0354043258 \\
\end{tabular} & EUR & 13-May-2012 & $2,391,682$ & $92.0232 \%$ \\
\hline \begin{tabular}{|l|} 
XS0354826017 \\
\end{tabular} & HUF & 13-May-2012 & $1,841,071$ & $91.4953 \%$ \\
\hline \begin{tabular}{|l|} 
XS0362500380 \\
\end{tabular} & USD & 14-May-2012 & $2,011,323$ & $89.3106 \%$ \\
\hline XS0298933143 & JPY & 17-May-2012 & 570,413 & $52.9020 \%$ \\
\hline XS0300460721 & EUR & 18-May-2012 & $7,069,989$ & $68.2893 \%$ \\
\hline \begin{tabular}{|l|} 
XS0299667963 \\
\end{tabular} & JPY & 21-May-2012 & 148,296 & $41.1488 \%$ \\
\hline \begin{tabular}{|l|} 
XS0300418281 \\
\end{tabular} & EUR & 22-May-2012 & $4,367,258$ & $85.6325 \%$ \\
\hline \begin{tabular}{|l} 
XS0276235495 \\
\end{tabular} & CZK & 23-May-2012 & $3,689,620$ & $86.3366 \%$ \\
\hline XS0360915176 & AUD & 23-May-2012 & $6,930,849$ & $105.4816 \%$ \\
\hline \begin{tabular}{|l|} 
XS0301519681 \\
\end{tabular} & USD & 24-May-2012 & $1,853,010$ & $50.9279 \%$ \\
\hline XS0301665401 & USD & 25-May-2012 & 525,406 & $35.8117 \%$ \\
\hline \begin{tabular}{|l} 
XS0318362711 \\
\end{tabular} & USD & 28-May-2012 & $1,401,742$ & $107.3514 \%$ \\
\hline \begin{tabular}{|l|} 
XS0318538260 \\
\end{tabular} & AUD & 29-May-2012 & $3,597,108$ & $101.0040 \%$ \\
\hline XS0301335286 & USD & 30-May-2012 & 800,216 & $96.5358 \%$ \\
\hline DE000A0N6GH8 & EUR & 1-Jun-2012 & $38,983,781$ & $92.8185 \%$ \\
\hline \begin{tabular}{|l|} 
XS0319159538 \\
\end{tabular} & NZD & 4-Jun-2012 & 676,809 & $96.0845 \%$ \\
\hline \begin{tabular}{|l|} 
XS0363169268 \\
\end{tabular} & USD & 4-Jun-2012 & $3,727,757$ & $101.8781 \%$ \\
\hline XS0301956800 & JPY & 5-Jun-2012 & 269,598 & $46.5583 \%$ \\
\hline \begin{tabular}{|l|} 
XS0319159702 \\
\end{tabular} & USD & 7-Jun-2012 & $2,672,560$ & $93.8978 \%$ \\
\hline \begin{tabular}{|l|} 
XS0320033201 \\
\end{tabular} & AUD & 7-Jun-2012 & $2,960,140$ & $99.4745 \%$ \\
\hline \begin{tabular}{|l|l} 
XS0319159454 \\
\end{tabular} & USD & 11-Jun-2012 & $3,055,998$ & $93.6166 \%$ \\
\hline \begin{tabular}{|l|} 
XS0303174832 \\
\end{tabular} & JPY & 13-Jun-2012 & 165,725 & $46.1373 \%$ \\
\hline \begin{tabular}{|l|} 
XS0303557259 \\
\end{tabular} & JPY & 13-Jun-2012 & 328,315 & $45.5626 \%$ \\
\hline XS0303756299 & JPY & 13-Jun-2012 & 336,340 & $46.3435 \%$ \\
\hline XS0303962780 & JPY & 13-Jun-2012 & 212,010 & $29.5185 \%$ \\
\hline \begin{tabular}{|l|} 
XS0296789281 \\
\end{tabular} & EUR & 14-Jun-2012 & $2,865,284$ & $85.2763 \%$ \\
\hline \begin{tabular}{|l|} 
XS0299929595 \\
\end{tabular} & USD & 14-Jun-2012 & 894,081 & $88.8347 \%$ \\
\hline XS0304832784 & JPY & 14-Jun-2012 & 102,442 & $28.3059 \%$ \\
\hline DE000A0NTKC6 & EUR & 15-Jun-2012 & 252,951 & $84.3168 \%$ \\
\hline XS0303862998 & JPY & 15-Jun-2012 & 241,675 & $66.6430 \%$ \\
\hline XS0305000837 & EUR & 15-Jun-2012 & 486,302 & $88.4186 \%$ \\
\hline XS0311947682 & USD & 16-Jun-2012 & $3,858,322$ & $105.1933 \%$ \\
\hline XS0311955511 & USD & 16-Jun-2012 & $3,858,147$ & $105.1885 \%$ \\
\hline \begin{tabular}{|l} 
XS0370988338 \\
\end{tabular} & USD & 18-Jun-2012 & $1,270,562$ & $21.0464 \%$ \\
\hline \begin{tabular}{|l|} 
XS0371134411 \\
\end{tabular} & HKD & 18-Jun-2012 & 38,805 & $7.7223 \%$ \\
\hline XS0304836264 & JPY & 19-Jun-2012 & 284,351 & $79.3396 \%$ \\
\hline \begin{tabular}{|l} 
XS0304838559 \\
\end{tabular} & JPY & 19-Jun-2012 & 187,545 & $52.0685 \%$ \\
\hline XS0304909327 & JPY & 19-Jun-2012 & 195,743 & $54.6161 \%$ \\
\hline \begin{tabular}{|l|} 
XS0304909830 \\
\end{tabular} & JPY & 19-Jun-2012 & 354,860 & $99.0132 \%$ \\
\hline XS0304910416 & JPY & 19-Jun-2012 & 314,863 & $87.8531 \%$ \\
\hline XS0304910929 & JPY & 19-Jun-2012 & 333,337 & $93.0076 \%$ \\
\hline \begin{tabular}{|l|} 
XS0304911570 \\
\end{tabular} & JPY & 19-Jun-2012 & 290,411 & $81.0305 \%$ \\
\hline \begin{tabular}{|l|} 
XS0305339417 \\
\end{tabular} & JPY & 19-Jun-2012 & 271,911 & $75.1324 \%$ \\
\hline XS0305340779 & JPY & 19-Jun-2012 & 338,718 & $46.3643 \%$ \\
\hline XS0306311373 & JPY & 19-Jun-2012 & 183,074 & $31.3244 \%$ \\
\hline XS0258731909 & USD & 20-Jun-2012 & $19,268,184$ & $92.1628 \%$ \\
\hline XS0305163460 & JPY & 20-Jun-2012 & 216,642 & $42.7620 \%$ \\
\hline XS0305889593 & JPY & 20-Jun-2012 & 230,229 & $56.9490 \%$ \\
\hline XS0306232744 & JPY & 20-Jun-2012 & 444,169 & $60.5907 \%$ \\
\hline XS0306694448 & JPY & 20-Jun-2012 & 72,536 & $16.7668 \%$ \\
\hline \begin{tabular}{|l|} 
XS0306029512 \\
\end{tabular} & JPY & 21-Jun-2012 & 181,020 & $25.2151 \%$ \\
\hline XS0307252980 & JPY & 22-Jun-2012 & 125,643 & $21.8303 \%$ \\
\hline \begin{tabular}{|l|} 
XS0272318709 \\
\end{tabular} & EUR & 28-Jun-2012 & $17,894,370$ & $91.0516 \%$ \\
\hline XS0296489304 & EUR & 29-Jun-2012 & $38,867,819$ & $84.4953 \%$ \\
\hline XS0300658597 & $\mathrm{CHF}$ & 29-Jun-2012 & $11,596,325$ & $89.3876 \%$ \\
\hline XS0372320928 & AUD & 2-Jul-2012 & 435,206 & $109.2960 \%$ \\
\hline \begin{tabular}{|l} 
XS0324476869 \\
\end{tabular} & NZD & 5-Jul-2012 & 730,509 & $94.9086 \%$ \\
\hline DE000A0NTV01 & EUR & 6-Jul-2012 & $4,837,219$ & $87.9494 \%$ \\
\hline \begin{tabular}{|l|} 
XS0373609295 \\
\end{tabular} & USD & 8-Jul-2012 & $4,741,013$ & $91.0018 \%$ \\
\hline \begin{tabular}{|l|} 
XS0308983203 \\
\end{tabular} & JPY & 10-Jul-2012 & 139,696 & $31.8700 \%$ \\
\hline \begin{tabular}{|l} 
XS0308736296 \\
\end{tabular} & JPY & 11-Jul-2012 & 444,950 & $61.8769 \%$ \\
\hline XS0309823044 & USD & 11-Jul-2012 & $4,081,499$ & $97.9560 \%$ \\
\hline XS0309843232 & AUD & 11-Jul-2012 & $5,843,589$ & $94.0633 \%$ \\
\hline XS0308391704 & JPY & 12-Jul-2012 & 539,602 & $18.3893 \%$ \\
\hline XS0308481794 & JPY & 12-Jul-2012 & 233,708 & $21.7119 \%$ \\
\hline XS0308935575 & EUR & 12-Jul-2012 & $2,466,157$ & $61.6539 \%$ \\
\hline \begin{tabular}{|l|} 
XS0308937605 \\
\end{tabular} & USD & 12-Jul-2012 & $1,174,922$ & $80.0827 \%$ \\
\hline \begin{tabular}{|l|} 
XS0309186731 \\
\end{tabular} & JPY & 12-Jul-2012 & 897,962 & $41.7582 \%$ \\
\hline \begin{tabular}{|l} 
XS0309334356 \\
\end{tabular} & EUR & 12-Jul-2012 & $1,397,776$ & $69.8888 \%$ \\
\hline XS0309351103 & JPY & 12-Jul-2012 & 306,452 & $50.6074 \%$ \\
\hline XS0307734037 & JPY & 13-Jul-2012 & 299,725 & $41.7654 \%$ \\
\hline DE000A0N7XQ2 & EUR & 17-Jul-2012 & $39,349,148$ & $95.9735 \%$ \\
\hline XS0309435039 & JPY & 18-Jul-2012 & 205,783 & $28.5362 \%$ \\
\hline
\end{tabular}




\begin{tabular}{|c|c|c|c|c|}
\hline ISIN & Currency & $\begin{array}{c}\text { Maturity } \\
\text { date }\end{array}$ & $\begin{array}{c}\text { Admissible } \\
\text { Amount in EUR }\end{array}$ & $\begin{array}{c}\text { Admissible } \\
\text { Amount \% }\end{array}$ \\
\hline XS0309435898 & JPY & 18-Jul-2012 & 218,442 & $19.2976 \%$ \\
\hline \begin{tabular}{|l|} 
XS0311301070 \\
\end{tabular} & USD & 18-Jul-2012 & $3,351,822$ & $91.3841 \%$ \\
\hline \begin{tabular}{|l} 
XS0251910997 \\
\end{tabular} & EUR & 19-Jul-2012 & $2,462,975$ & $91.2213 \%$ \\
\hline XS0259295607 & EUR & 19-Jul-2012 & $2,414,298$ & $96.5719 \%$ \\
\hline \begin{tabular}{|l} 
XS0309183043 \\
\end{tabular} & JPY & 19-Jul-2012 & 96,539 & $26.2053 \%$ \\
\hline XS0309183555 & JPY & 19-Jul-2012 & 292,890 & $50.3562 \%$ \\
\hline \begin{tabular}{|l|} 
XS0309184793 \\
\end{tabular} & JPY & 19-Jul-2012 & 312,875 & $61.0973 \%$ \\
\hline \begin{tabular}{|l|} 
XS0310412019 \\
\end{tabular} & JPY & 19-Jul-2012 & 199,036 & $54.0223 \%$ \\
\hline XS0310863021 & JPY & 19-Jul-2012 & $2,111,155$ & $65.1609 \%$ \\
\hline XS0311753130 & JPY & 19-Jul-2012 & 238,709 & $64.5207 \%$ \\
\hline XS0302634059 & EUR & 20-Jul-2012 & $13,398,196$ & $92.7724 \%$ \\
\hline XS0312432114 & AUD & 23-Jul-2012 & $4,029,148$ & $88.5234 \%$ \\
\hline XS0312433948 & USD & 23-Jul-2012 & $3,519,094$ & $93.6959 \%$ \\
\hline \begin{tabular}{|l} 
XS0311754963 \\
\end{tabular} & JPY & 24-Jul-2012 & 198,239 & $54.2280 \%$ \\
\hline XS0311223688 & EUR & 25-Jul-2012 & 367,316 & $36.7316 \%$ \\
\hline \begin{tabular}{|l} 
XS0310478978 \\
\end{tabular} & JPY & 26-Jul-2012 & 291,284 & $18.6751 \%$ \\
\hline XS0311226608 & JPY & 26-Jul-2012 & 394,541 & $54.7326 \%$ \\
\hline XS0311745383 & JPY & 26-Jul-2012 & 308,220 & $16.8975 \%$ \\
\hline \begin{tabular}{|l|} 
XS0311855729 \\
\end{tabular} & JPY & 26-Jul-2012 & 238,362 & $66.1059 \%$ \\
\hline XS0311857428 & JPY & 26-Jul-2012 & 193,786 & $43.3087 \%$ \\
\hline XS0311864986 & JPY & 26-Jul-2012 & 579,726 & $57.6112 \%$ \\
\hline \begin{tabular}{|l} 
XS0312175473 \\
\end{tabular} & JPY & 26-Jul-2012 & $2,192,743$ & $53.3801 \%$ \\
\hline XS0312197360 & JPY & 26-Jul-2012 & 234,264 & $44.2969 \%$ \\
\hline \begin{tabular}{|l|} 
XS0309156668 \\
\end{tabular} & EUR & 27-Jul-2012 & $5,978,887$ & $84.0794 \%$ \\
\hline \begin{tabular}{|l|} 
XS0309471182 \\
\end{tabular} & AUD & 27-Jul-2012 & 250,023 & $33.5477 \%$ \\
\hline XS0311621816 & JPY & 27-Jul-2012 & 181,265 & $12.6250 \%$ \\
\hline XS0312198251 & JPY & 27-Jul-2012 & 340,662 & $34.6721 \%$ \\
\hline XS0313103003 & USD & 27-Jul-2012 & $2,026,286$ & $62.7780 \%$ \\
\hline XS0334227096 & USD & 29-Jul-2012 & $3,083,381$ & $84.0653 \%$ \\
\hline XS0334227336 & USD & 29-Jul-2012 & $3,083,381$ & $84.0653 \%$ \\
\hline XS0334227682 & USD & 29-Jul-2012 & $6,166,762$ & $84.0653 \%$ \\
\hline XS0312173262 & JPY & 30-Jul-2012 & 159,399 & $44.3521 \%$ \\
\hline \begin{tabular}{|l} 
XS0312196719 \\
\end{tabular} & JPY & 30-Jul-2012 & 159,387 & $44.4208 \%$ \\
\hline XS0313782814 & USD & 30-Jul-2012 & $2,832,275$ & $85.7991 \%$ \\
\hline XS0225471431 & EUR & 1-Aug-2012 & $1,098,909$ & $99.9008 \%$ \\
\hline XS0311860562 & JPY & 1-Aug-2012 & 410,514 & $46.9303 \%$ \\
\hline XS0312924334 & SGD & 1-Aug-2012 & $1,125,031$ & $56.1053 \%$ \\
\hline XS0312938045 & SGD & 1-Aug-2012 & 810,847 & $40.4370 \%$ \\
\hline \begin{tabular}{|l|} 
XS0307992676 \\
\end{tabular} & EUR & 2-Aug-2012 & $5,673,481$ & $87.2843 \%$ \\
\hline \begin{tabular}{|l} 
XS0312197956 \\
\end{tabular} & JPY & 2-Aug-2012 & 88,175 & $24.5436 \%$ \\
\hline \begin{tabular}{|l} 
XS0311102544 \\
\end{tabular} & JPY & 3-Aug-2012 & 154,170 & $21.4602 \%$ \\
\hline XS0311225469 & JPY & 3-Aug-2012 & 727,140 & $43.3941 \%$ \\
\hline \begin{tabular}{|l} 
XS0311748130 \\
\end{tabular} & JPY & 3-Aug-2012 & 315,393 & $43.9600 \%$ \\
\hline XS0311866767 & JPY & 3-Aug-2012 & 397,545 & $55.3673 \%$ \\
\hline \begin{tabular}{|l} 
XS0312726705 \\
\end{tabular} & USD & 3-Aug-2012 & $1,224,033$ & $52.1438 \%$ \\
\hline XS0312729634 & JPY & 3-Aug-2012 & 407,263 & $19.3477 \%$ \\
\hline \begin{tabular}{|l} 
XS0312938557 \\
\end{tabular} & JPY & 3-Aug-2012 & 558,554 & $20.9642 \%$ \\
\hline \begin{tabular}{|l|} 
DE000AONXKZ9 \\
\end{tabular} & EUR & 7-Aug-2012 & $37,154,677$ & $120.6830 \%$ \\
\hline \begin{tabular}{|l} 
XS0311866171 \\
\end{tabular} & JPY & 7-Aug-2012 & 416,421 & $54.1677 \%$ \\
\hline XS0312938714 & JPY & 7-Aug-2012 & 680,787 & $58.5755 \%$ \\
\hline XS0313437716 & JPY & 7-Aug-2012 & 162,681 & $43.7718 \%$ \\
\hline XS0313528944 & EUR & 7-Aug-2012 & 622,124 & $62.2124 \%$ \\
\hline XS0313532623 & EUR & 7-Aug-2012 & 795,323 & $79.5323 \%$ \\
\hline XS0313893561 & USD & 7-Aug-2012 & $11,169,392$ & $114.0533 \%$ \\
\hline XS0314160358 & JPY & 7-Aug-2012 & 149,512 & $10.4199 \%$ \\
\hline XS0314159855 & JPY & 8-Aug-2012 & 227,732 & $45.7399 \%$ \\
\hline \begin{tabular}{|l|} 
XS0312463184 \\
\end{tabular} & EUR & 9-Aug-2012 & $13,286,263$ & $66.4313 \%$ \\
\hline \begin{tabular}{|l} 
XS0314250779 \\
\end{tabular} & USD & 9-Aug-2012 & 327,991 & $29.8078 \%$ \\
\hline XS0314763052 & EUR & 9-Aug-2012 & $4,584,016$ & $68.7568 \%$ \\
\hline XS0314774505 & USD & 13-Aug-2012 & $8,366,094$ & $114.0466 \%$ \\
\hline XS0313662321 & JPY & 14-Aug-2012 & 101,025 & $24.5113 \%$ \\
\hline XS0314637348 & JPY & 14-Aug-2012 & 145,912 & $40.3412 \%$ \\
\hline XS0313436072 & JPY & 15-Aug-2012 & 180,820 & $25.0707 \%$ \\
\hline XS0376511928 & $\mathrm{CHF}$ & 15-Aug-2012 & 729,854 & $99.4010 \%$ \\
\hline XS0315804475 & JPY & 16-Aug-2012 & 458,155 & $41.8786 \%$ \\
\hline \begin{tabular}{|l} 
XS0315805019 \\
\end{tabular} & JPY & 16-Aug-2012 & 560,186 & $77.5312 \%$ \\
\hline $\mathrm{CH} 0027120986$ & $\mathrm{CHF}$ & 17-Aug-2012 & $4,143,775$ & $91.9089 \%$ \\
\hline \begin{tabular}{|l} 
XS0316395739 \\
\end{tabular} & JPY & 21-Aug-2012 & 103,013 & $27.4315 \%$ \\
\hline XS0316842698 & GBP & 23-Aug-2012 & 749,727 & $97.1209 \%$ \\
\hline XS0315548296 & JPY & 24-Aug-2012 & 89,412 & $12.4539 \%$ \\
\hline XS0316829919 & JPY & 24-Aug-2012 & 277,093 & $9.3873 \%$ \\
\hline XS0317366333 & JPY & 24-Aug-2012 & 162,940 & $22.3518 \%$ \\
\hline XS0317292117 & EUR & $28-A u g-2012$ & $1,704,360$ & $83.1395 \%$ \\
\hline DE000A0NZAV4 & EUR & 29-Aug-2012 & $13,918,778$ & $75.2366 \%$ \\
\hline XS0342098398 & $\mathrm{CHF}$ & 29-Aug-2012 & $3,075,611$ & $95.5039 \%$ \\
\hline \begin{tabular}{|l} 
XS0310995955 \\
\end{tabular} & CZK & 30-Aug-2012 & $2,510,364$ & $89.2574 \%$ \\
\hline XS0316394336 & JPY & 4-Sep-2012 & 155,001 & $12.3544 \%$ \\
\hline XS0316527828 & JPY & 5-Sep-2012 & 372,317 & $43.2850 \%$ \\
\hline \begin{tabular}{|l} 
XS0316993475 \\
\end{tabular} & JPY & 5-Sep-2012 & 198,671 & $27.6392 \%$ \\
\hline
\end{tabular}




\begin{tabular}{|c|c|c|c|c|}
\hline ISIN & Currency & $\begin{array}{c}\text { Maturity } \\
\text { date }\end{array}$ & $\begin{array}{c}\text { Admissible } \\
\text { Amount in EUR }\end{array}$ & $\begin{array}{c}\text { Admissible } \\
\text { Amount \% }\end{array}$ \\
\hline XS0317366416 & JPY & 5-Sep-2012 & 381,338 & $53.4141 \%$ \\
\hline \begin{tabular}{|l|l} 
XS0317416377 \\
\end{tabular} & JPY & 5-Sep-2012 & 380,080 & $12.6421 \%$ \\
\hline \begin{tabular}{|l|} 
XS0319729579 \\
\end{tabular} & GBP & 5-Sep-2012 & $4,137,308$ & $90.5837 \%$ \\
\hline XS0312439556 & EUR & 6-Sep-2012 & $2,550,896$ & $83.0911 \%$ \\
\hline \begin{tabular}{|l} 
XS0318538930 \\
\end{tabular} & JPY & 6-Sep-2012 & 397,174 & $27.7049 \%$ \\
\hline XS0313102377 & EUR & 7-Sep-2012 & $8,857,091$ & $86.4359 \%$ \\
\hline XS0315845155 & USD & 7-Sep-2012 & 363,912 & $81.3253 \%$ \\
\hline \begin{tabular}{|l|} 
XS0317961729 \\
\end{tabular} & EUR & 7-Sep-2012 & 824,375 & $85.4274 \%$ \\
\hline XS0318224598 & USD & 7-Sep-2012 & $1,492,069$ & $87.1087 \%$ \\
\hline \begin{tabular}{|l|} 
XS0319358650 \\
\end{tabular} & JPY & 12-Sep-2012 & 126,354 & $17.3998 \%$ \\
\hline \begin{tabular}{|l|} 
XS0318999827 \\
\end{tabular} & JPY & 13-Sep-2012 & 247,450 & $15.9663 \%$ \\
\hline XS0315528777 & CZK & 14-Sep-2012 & $1,671,535$ & $86.8772 \%$ \\
\hline XS0318192704 & JPY & 14-Sep-2012 & 111,449 & $15.5405 \%$ \\
\hline XS0318538005 & JPY & 14-Sep-2012 & 362,425 & $50.5619 \%$ \\
\hline XS0319358064 & JPY & 14-Sep-2012 & 496,843 & $49.5105 \%$ \\
\hline \begin{tabular}{|l|} 
XS0319359039 \\
\end{tabular} & JPY & 14-Sep-2012 & 488,789 & $22.7303 \%$ \\
\hline \begin{tabular}{|l|} 
XS0319611819 \\
\end{tabular} & JPY & 14-Sep-2012 & 504,127 & $50.2363 \%$ \\
\hline XS0320031684 & USD & 14-Sep-2012 & $1,351,392$ & $61.4072 \%$ \\
\hline \begin{tabular}{|l|} 
XS0321395583 \\
\end{tabular} & EUR & 18-Sep-2012 & $5,484,055$ & $78.3436 \%$ \\
\hline XS0319816897 & JPY & 19-Sep-2012 & 83,412 & $12.6341 \%$ \\
\hline XS0224858737 & USD & 20-Sep-2012 & $10,006,171$ & $90.9361 \%$ \\
\hline \begin{tabular}{|l} 
XS0313734922 \\
\end{tabular} & USD & 20-Sep-2012 & $15,212,406$ & $103.6878 \%$ \\
\hline XS0313737271 & USD & 20-Sep-2012 & $7,608,940$ & $103.7251 \%$ \\
\hline \begin{tabular}{|l|} 
XS0314746479 \\
\end{tabular} & USD & 20-Sep-2012 & $7,662,886$ & $104.4605 \%$ \\
\hline \begin{tabular}{|l|}
$X S 0335622501$ \\
\end{tabular} & USD & 26-Sep-2012 & $7,499,474$ & $102.2328 \%$ \\
\hline $\begin{array}{l}\text { XS0321125014 } \\
\end{array}$ & JPY & 28-Sep-2012 & $1,322,027$ & $78.8188 \%$ \\
\hline XS0323097120 & USD & 28-Sep-2012 & $1,577,250$ & $102.3861 \%$ \\
\hline XS0324072858 & USD & 4-Oct-2012 & 969,076 & $88.0696 \%$ \\
\hline XS0155540700 & USD & 8-Oct-2012 & $4,293,615$ & $117.0611 \%$ \\
\hline XS0319193396 & EUR & 8-Oct-2012 & $10,712,337$ & $89.8385 \%$ \\
\hline XS0325152154 & EUR & 8-Oct-2012 & 180,054 & $51.7396 \%$ \\
\hline XS0314034728 & EUR & 9-Oct-2012 & $3,500,942$ & $87.0448 \%$ \\
\hline \begin{tabular}{|l} 
XS0321793803 \\
\end{tabular} & JPY & $10-$ Oct-2012 & 94,597 & $13.1665 \%$ \\
\hline XS0322031757 & JPY & $10-$ Oct-2012 & 334,936 & $13.2881 \%$ \\
\hline \begin{tabular}{|l|} 
XS0323882059 \\
\end{tabular} & AUD & $10-$ Oct-2012 & 90,411 & $12.1312 \%$ \\
\hline \begin{tabular}{|l|} 
XS0325385176 \\
\end{tabular} & EUR & $15-$ Oct-2012 & $7,145,366$ & $89.3171 \%$ \\
\hline XS0323634583 & JPY & 16-Oct-2012 & 632,558 & $61.2937 \%$ \\
\hline XS0323634740 & JPY & $16-$ Oct-2012 & 72,904 & $10.1703 \%$ \\
\hline \begin{tabular}{|l} 
XS0323881838 \\
\end{tabular} & JPY & $16-$ Oct- 2012 & 525,954 & $27.9476 \%$ \\
\hline \begin{tabular}{|l|} 
XS0324078384 \\
\end{tabular} & USD & $16-$ Oct-2012 & $1,490,674$ & $101.6044 \%$ \\
\hline \begin{tabular}{|l} 
XS0324072346 \\
\end{tabular} & EUR & 17-Oct-2012 & $14,468,009$ & $96.4534 \%$ \\
\hline XS0324409837 & JPY & $18-$ Oct-2012 & 207,888 & $22.1325 \%$ \\
\hline $\mathrm{CH} 0027120846$ & EUR & $19-$ Oct-2012 & $4,641,010$ & $92.8202 \%$ \\
\hline $\mathrm{CH} 0027121026$ & $\mathrm{CHF}$ & 19-Oct-2012 & $2,158,089$ & $83.7662 \%$ \\
\hline XS0262375487 & EUR & 19-Oct-2012 & 303,736 & $101.2454 \%$ \\
\hline XS0264967307 & $\mathrm{CHF}$ & 19-Oct-2012 & $6,788,742$ & $105.4020 \%$ \\
\hline XS0325840980 & EUR & $22-$ Oct- 2012 & $4,243,876$ & $84.8775 \%$ \\
\hline \begin{tabular}{|l|} 
XS0324341345 \\
\end{tabular} & JPY & 23-Oct-2012 & 145,394 & $10.1194 \%$ \\
\hline \begin{tabular}{|l} 
XS0272317131 \\
\end{tabular} & EUR & $24-O c t-2012$ & $4,512,158$ & $90.2432 \%$ \\
\hline NO0010387749 & NOK & $25-O c t-2012$ & 302,293 & $84.4506 \%$ \\
\hline \begin{tabular}{|l|} 
XS0270828584 \\
\end{tabular} & $\mathrm{CHF}$ & $25-O c t-2012$ & $15,675,910$ & $86.2544 \%$ \\
\hline XS0294585889 & $\mathrm{CHF}$ & $25-$ Oct-2012 & $5,555,484$ & $86.2544 \%$ \\
\hline FI0003025379 & EUR & 26-Oct-2012 & $4,306,183$ & $85.6270 \%$ \\
\hline XS0325841525 & JPY & $26-$ Oct- 2012 & 146,707 & $20.4217 \%$ \\
\hline \begin{tabular}{|l} 
XS0326708657 \\
\end{tabular} & JPY & $26-$ Oct- 2012 & 432,246 & $11.8211 \%$ \\
\hline XS0326907697 & USD & $26-$ Oct- 2012 & 745,896 & $101.6806 \%$ \\
\hline \begin{tabular}{|l} 
XS0325287166 \\
\end{tabular} & USD & $29-$ Oct-2012 & $3,519,488$ & $95.9553 \%$ \\
\hline \begin{tabular}{|l} 
XS0327328281 \\
\end{tabular} & USD & $29-$ Oct-2012 & 574,921 & $78.3732 \%$ \\
\hline NO0010393507 & NOK & $30-$ Oct-2012 & 859,275 & $84.7245 \%$ \\
\hline XS0325550555 & EUR & $30-$ Oct-2012 & $12,585,505$ & $96.8116 \%$ \\
\hline XS0327165550 & USD & $30-$ Oct-2012 & $5,172,599$ & $91.8974 \%$ \\
\hline XS0327236914 & EUR & 30-Oct-2012 & $2,783,378$ & $69.5845 \%$ \\
\hline XS0327398656 & USD & $31-$ Oct-2012 & 437,991 & $49.7557 \%$ \\
\hline XS0322779264 & EUR & 1-Nov-2012 & $1,763,769$ & $88.1884 \%$ \\
\hline XS0327576772 & GBP & 1-Nov-2012 & $3,747,436$ & $83.2199 \%$ \\
\hline DE000A0TLL96 & EUR & 2-Nov-2012 & $9,721,865$ & $84.5380 \%$ \\
\hline XS0273044940 & EUR & 2-Nov-2012 & $4,114,629$ & $82.2926 \%$ \\
\hline \begin{tabular}{|l|} 
XS0321299868 \\
\end{tabular} & EUR & 6-Nov-2012 & $2,083,625$ & $104.8629 \%$ \\
\hline XS0327465786 & JPY & 6-Nov-2012 & 526,488 & $38.8848 \%$ \\
\hline \begin{tabular}{|l} 
XS0327465869 \\
\end{tabular} & JPY & 6-Nov-2012 & 742,551 & $48.6491 \%$ \\
\hline XS0327713359 & JPY & 6-Nov-2012 & 421,153 & $19.5850 \%$ \\
\hline DE000A0S5NN9 & EUR & 7-Nov-2012 & $12,447,269$ & $75.7087 \%$ \\
\hline \begin{tabular}{|l} 
XS0328922645 \\
\end{tabular} & USD & 7-Nov-2012 & $1,248,781$ & $94.5743 \%$ \\
\hline \begin{tabular}{|l|} 
XS0328923379 \\
\end{tabular} & EUR & 7-Nov-2012 & $3,768,195$ & $94.2049 \%$ \\
\hline $\begin{array}{l}\text { XS0235076097 } \\
\end{array}$ & USD & 13-Nov-2012 & $32,204,401$ & $98.2886 \%$ \\
\hline XS0324445807 & EUR & 15-Nov-2012 & $4,049,803$ & $98.8239 \%$ \\
\hline XS0324446011 & USD & 15-Nov-2012 & $6,866,446$ & $103.6697 \%$ \\
\hline XS0330195560 & HKD & 16-Nov-2012 & 986,975 & $104.4921 \%$ \\
\hline \begin{tabular}{|l|} 
XS0330196022 \\
\end{tabular} & JPY & 16-Nov-2012 & 374,254 & $43.2851 \%$ \\
\hline
\end{tabular}




\begin{tabular}{|c|c|c|c|c|}
\hline ISIN & Currency & $\begin{array}{c}\text { Maturity } \\
\text { date }\end{array}$ & $\begin{array}{c}\text { Admissible } \\
\text { Amount in EUR }\end{array}$ & $\begin{array}{c}\text { Admissible } \\
\text { Amount \% }\end{array}$ \\
\hline XS0330111997 & JPY & 20-Nov-2012 & 223,010 & $62.1621 \%$ \\
\hline XS0235808457 & USD & 21-Nov-2012 & $39,557,033$ & $90.7220 \%$ \\
\hline XS0372842202 & EUR & 22-Nov-2012 & $2,121,417$ & $106.0708 \%$ \\
\hline XS0236268024 & USD & 23-Nov-2012 & $27,925,244$ & $98.1327 \%$ \\
\hline XS0329670433 & EUR & 23-Nov-2012 & $1,977,612$ & $68.1465 \%$ \\
\hline XS0276510111 & USD & 24-Nov-2012 & $2,318,745$ & $86.6004 \%$ \\
\hline XS0330111567 & AUD & 27-Nov-2012 & 356,498 & $47.8343 \%$ \\
\hline XS0231442046 & EUR & 29-Nov-2012 & $17,844,642$ & $89.8843 \%$ \\
\hline NO0010392731 & NOK & 30-Nov-2012 & 268,826 & $84.0684 \%$ \\
\hline XS0324188134 & EUR & 30-Nov-2012 & $2,016,008$ & $100.8004 \%$ \\
\hline XS0331334481 & CZK & 30-Nov-2012 & $6,953,341$ & $98.4772 \%$ \\
\hline XS0332756849 & EUR & 30-Nov-2012 & $1,707,263$ & $53.5192 \%$ \\
\hline XS0276438255 & EUR & 1-Dec-2012 & $10,016,195$ & $100.1619 \%$ \\
\hline XS0273255058 & EUR & 3-Dec-2012 & $2,535,835$ & $90.5655 \%$ \\
\hline XS0331248723 & EUR & 3-Dec-2012 & $5,230,103$ & $104.6021 \%$ \\
\hline XS0333757606 & EUR & 3-Dec-2012 & $1,423,589$ & $92.6213 \%$ \\
\hline XS0333940129 & USD & 3-Dec-2012 & 541,433 & $36.9041 \%$ \\
\hline DE000A0S1160 & EUR & 7-Dec-2012 & $31,488,753$ & $87.3959 \%$ \\
\hline XS0327774732 & EUR & 7-Dec-2012 & $1,236,067$ & $82.4045 \%$ \\
\hline FI0003025882 & EUR & 12-Dec-2012 & $1,709,069$ & $82.6036 \%$ \\
\hline FI0003026559 & EUR & 12-Dec-2012 & $1,779,395$ & $82.7626 \%$ \\
\hline XS0334419321 & GBP & 12-Dec-2012 & $5,170,168$ & $80.3703 \%$ \\
\hline XS0334634648 & $\mathrm{CHF}$ & 13-Dec-2012 & $3,182,359$ & $96.8810 \%$ \\
\hline XS0324872893 & EUR & 14-Dec-2012 & $7,893,178$ & $98.4064 \%$ \\
\hline XS0324872976 & USD & 14-Dec-2012 & $6,924,212$ & $103.2497 \%$ \\
\hline XS0334854410 & USD & 14-Dec-2012 & $2,368,010$ & $93.5673 \%$ \\
\hline XS0336218762 & USD & 14-Dec-2012 & 459,855 & $62.6874 \%$ \\
\hline XS0333420395 & USD & 18-Dec-2012 & 950,853 & $83.6260 \%$ \\
\hline XS0334476552 & EUR & 19-Dec-2012 & $3,111,758$ & $103.7253 \%$ \\
\hline XS0228868195 & USD & 20-Dec-2012 & $11,982,602$ & $108.8979 \%$ \\
\hline XS0238959273 & USD & 20-Dec-2012 & $32,254,980$ & $98.2495 \%$ \\
\hline XS0332587715 & EUR & 20-Dec-2012 & $5,671,333$ & $113.4267 \%$ \\
\hline XS0196987779 & USD & 21-Dec-2012 & $17,546,338$ & $95.6767 \%$ \\
\hline XS0336320022 & USD & 21-Dec-2012 & $1,480,398$ & $40.3616 \%$ \\
\hline XS0337388382 & EUR & 22-Dec-2012 & $9,762,909$ & $93.2198 \%$ \\
\hline XS0183360063 & USD & 23-Dec-2012 & $60,982,308$ & $127.4040 \%$ \\
\hline XS0237410831 & EUR & 28-Dec-2012 & 274,323 & $91.4409 \%$ \\
\hline FI0003026351 & EUR & 3-Jan-2013 & $7,446,990$ & $81.4769 \%$ \\
\hline DE000A0TLKY4 & EUR & 4-Jan-2013 & $5,232,834$ & $87.2139 \%$ \\
\hline XS0335352877 & USD & 4-Jan-2013 & 626,386 & $25.8754 \%$ \\
\hline XS0334488995 & USD & 7-Jan-2013 & $2,423,058$ & $100.4596 \%$ \\
\hline XS0336893499 & USD & 11-Jan-2013 & $192,193,763$ & $87.3328 \%$ \\
\hline XS0338138307 & EUR & 11-Jan-2013 & $6,367,753$ & $81.3251 \%$ \\
\hline XS0159166056 & EUR & 16-Jan-2013 & $6,936,307$ & $138.7261 \%$ \\
\hline XS0242676285 & USD & 20-Jan-2013 & $37,621,590$ & $102.5715 \%$ \\
\hline XS0278983191 & EUR & 21-Jan-2013 & $5,950,621$ & $92.5159 \%$ \\
\hline XS0339408238 & USD & 22-Jan-2013 & $1,055,933$ & $84.6734 \%$ \\
\hline DE000A0SUEV6 & EUR & 23-Jan-2013 & $41,094,965$ & $89.9607 \%$ \\
\hline $\mathrm{CH} 0034783644$ & $\mathrm{CHF}$ & 25-Jan-2013 & $1,243,710$ & $96.5492 \%$ \\
\hline $\mathrm{CH} 0034783669$ & EUR & 25-Jan-2013 & 893,971 & $89.3971 \%$ \\
\hline $\mathrm{CH} 0034783685$ & USD & 25-Jan-2013 & 715,624 & $97.5539 \%$ \\
\hline $\mathrm{CH} 0034783701$ & EUR & 25-Jan-2013 & $1,013,102$ & $101.3102 \%$ \\
\hline XS0341781432 & EUR & 29-Jan-2013 & 733,035 & $91.6293 \%$ \\
\hline XS0342422838 & USD & 31-Jan-2013 & $1,582,508$ & $71.9092 \%$ \\
\hline XS0344143945 & AUD & 31-Jan-2013 & 574,461 & $107.9125 \%$ \\
\hline XS0210782552 & EUR & 1-Feb-2013 & $78,846,362$ & $98.1995 \%$ \\
\hline XS0344537997 & USD & 1-Feb-2013 & 181,272 & $88.2536 \%$ \\
\hline XS0331517564 & GBP & 5-Feb-2013 & 20,829 & $97.3831 \%$ \\
\hline XS0331517994 & GBP & 5-Feb-2013 & 349,225 & $126.4514 \%$ \\
\hline XS0343530340 & EUR & 6-Feb-2013 & 404,853 & $80.9706 \%$ \\
\hline XS0343843982 & EUR & 7-Feb-2013 & $2,184,041$ & $104.0019 \%$ \\
\hline XS0344142202 & JPY & 8-Feb-2013 & 665,530 & $92.8481 \%$ \\
\hline XS0344485312 & USD & 11-Feb-2013 & $1,369,432$ & $62.2270 \%$ \\
\hline XS0343647706 & EUR & 12-Feb-2013 & $1,766,102$ & $128.9125 \%$ \\
\hline XS0345204613 & SEK & 14-Feb-2013 & $1,890,839$ & $73.0514 \%$ \\
\hline XS0347107673 & USD & 14-Feb-2013 & $4,632,953$ & $105.2607 \%$ \\
\hline XS0243541215 & AUD & $15-F e b-2013$ & $1,191,739$ & $89.5473 \%$ \\
\hline XS0336931331 & USD & 15-Feb-2013 & $5,036,036$ & $98.7503 \%$ \\
\hline XS0336943427 & EUR & 15-Feb-2013 & $2,815,264$ & $96.6780 \%$ \\
\hline XS0337763576 & EUR & 15-Feb-2013 & 361,898 & $104.8978 \%$ \\
\hline XS0345213796 & AUD & 15-Feb-2013 & $2,298,748$ & $86.3640 \%$ \\
\hline XS0346687287 & $\mathrm{CHF}$ & 19-Feb-2013 & $3,212,883$ & $102.4296 \%$ \\
\hline XS0346687360 & EUR & 19-Feb-2013 & $1,623,984$ & $103.4384 \%$ \\
\hline XS0343832191 & EUR & 20-Feb-2013 & $5,152,805$ & $85.8801 \%$ \\
\hline XS0121855026 & EUR & $25-F e b-2013$ & $1,621,316$ & $81.0658 \%$ \\
\hline XS0346785537 & EUR & 27-Feb-2013 & $2,000,000$ & $100.0000 \%$ \\
\hline XS0346802050 & EUR & $27-F e b-2013$ & $1,000,000$ & $100.0000 \%$ \\
\hline XS0349362003 & USD & 27-Feb-2013 & 935,608 & $98.1093 \%$ \\
\hline XS0342777371 & EUR & 3-Mar-2013 & $8,599,663$ & $104.2383 \%$ \\
\hline
\end{tabular}




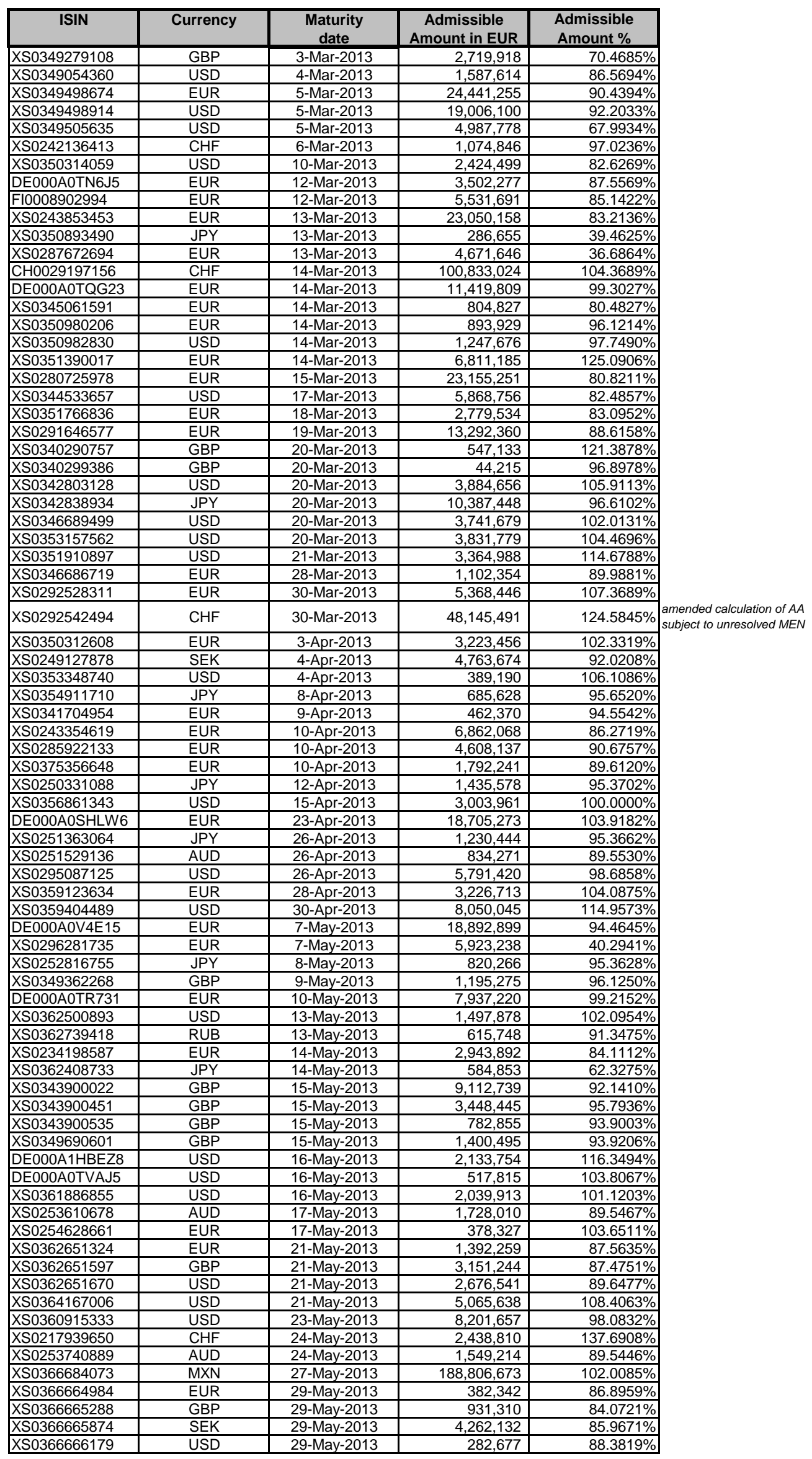




\begin{tabular}{|c|c|c|c|c|c|}
\hline ISIN & Currency & $\begin{array}{l}\text { Maturity } \\
\text { date }\end{array}$ & $\begin{array}{c}\text { Admissible } \\
\text { Amount in EUR }\end{array}$ & $\begin{array}{c}\text { Admissible } \\
\text { Amount \% }\end{array}$ & \\
\hline XS0365839751 & USD & 30-May-2013 & $2,979,175$ & $94.1839 \%$ & \\
\hline XS0365881019 & JPY & 4-Jun-2013 & 545,418 & $60.0923 \%$ & \\
\hline XS0368882535 & USD & 6-Jun-2013 & $4,521,057$ & $92.1793 \%$ & \\
\hline XS0295760093 & EUR & 10-Jun-2013 & $1,953,014$ & $71.1999 \%$ & \\
\hline XS0355133454 & EUR & 10-Jun-2013 & $2,752,179$ & $78.6337 \%$ & \\
\hline XS0379217184 & EUR & 10-Jun-2013 & $2,505,085$ & $83.5028 \%$ & \\
\hline XS0366385598 & JPY & 11-Jun-2013 & 363,307 & $62.4569 \%$ & \\
\hline XS0366387024 & JPY & 11-Jun-2013 & 447,196 & $55.2794 \%$ & \\
\hline XS0367656237 & JPY & 11-Jun-2013 & 448,219 & $62.0359 \%$ & \\
\hline XS0257915503 & JPY & 15-Jun-2013 & $3,533,960$ & $98.6045 \%$ & \\
\hline XS0257916063 & JPY & 15-Jun-2013 & $3,497,637$ & $97.5911 \%$ & \\
\hline XS0368801477 & JPY & 18-Jun-2013 & 280,732 & $64.7569 \%$ & \\
\hline XS0366384609 & JPY & 19-Jun-2013 & 534,309 & $56.4033 \%$ & \\
\hline XS0358366754 & GBP & 20-Jun-2013 & 244,098 & $88.6947 \%$ & \\
\hline XS0371797100 & EUR & 20-Jun-2013 & 982,840 & $98.2840 \%$ & \\
\hline XS0371847210 & USD & 20-Jun-2013 & $4,678,934$ & $106.3054 \%$ & \\
\hline XS0372528165 & USD & 21-Jun-2013 & $4,376,467$ & $119.3200 \%$ & amended calculation of $A A$ \\
\hline XS0353141137 & GBP & 24-Jun-2013 & $2,146,088$ & $121.1497 \%$ & \\
\hline XS0371621672 & EUR & 24-Jun-2013 & $3,175,335$ & $105.8445 \%$ & \\
\hline XS0371764514 & USD & 24-Jun-2013 & $7,335,681$ & $100.0000 \%$ & \\
\hline DE000A0SG1J6 & EUR & 25-Jun-2013 & $25,899,630$ & $99.6140 \%$ & \\
\hline XS0169939211 & USD & 27-Jun-2013 & $7,390,601$ & $100.7487 \%$ & \\
\hline XS0366066495 & EUR & 27-Jun-2013 & $2,215,389$ & $107.0236 \%$ & \\
\hline XS0372294313 & EUR & 27-Jun-2013 & $10,183,056$ & $50.9153 \%$ & \\
\hline XS0302315386 & EUR & 29-Jun-2013 & $137,284,810$ & $87.0864 \%$ & \\
\hline XS0304219818 & EUR & 29-Jun-2013 & $12,703,628$ & $79.3977 \%$ & \\
\hline XS0366304854 & USD & 30-Jun-2013 & $13,895,570$ & $94.7122 \%$ & \\
\hline XS0360445786 & GBP & 4-Jul-2013 & $1,055,010$ & $127.6493 \%$ & \\
\hline DE000A0TVPR6 & EUR & 8-Jul-2013 & $4,274,115$ & $99.3980 \%$ & \\
\hline XS0362676826 & EUR & 8-Jul-2013 & $5,200,844$ & $102.4191 \%$ & \\
\hline XS0305948860 & EUR & 11-Jul-2013 & $8,022,525$ & $58.8593 \%$ & \\
\hline XS0222780701 & EUR & $12-\mathrm{Jul}-2013$ & $1,401,661$ & $93.4441 \%$ & \\
\hline XS0170498280 & USD & 15-Jul-2013 & $7,381,077$ & $100.6188 \%$ & \\
\hline US52521XAC20 & USD & 16-Jul-2013 & $5,938,316$ & $80.9511 \%$ & \\
\hline XS0230176793 & USD & 17-Jul-2013 & $34,598,372$ & $102.0877 \%$ & \\
\hline XS0261749450 & USD & $17-J u l-2013$ & 864,090 & $92.4589 \%$ & \\
\hline XS0220691017 & EUR & 18-Jul-2013 & $114,396,411$ & $83.1853 \%$ & \\
\hline XS0306937953 & EUR & 31-Jul-2013 & $18,217,004$ & $95.9345 \%$ & \\
\hline XS0366064870 & GBP & 31-Jul-2013 & 908,270 & $118.6475 \%$ & \\
\hline XS0366064953 & GBP & 31-Jul-2013 & 232,946 & $119.9054 \%$ & \\
\hline XS0366065174 & GBP & 31-Jul-2013 & 825,752 & $115.0207 \%$ & \\
\hline XS0366065257 & GBP & 31-Jul-2013 & $4,022,843$ & $114.3656 \%$ & \\
\hline XS0368699764 & EUR & 31-Jul-2013 & $6,992,036$ & $107.5698 \%$ & \\
\hline XS0364263144 & EUR & 1-Aug-2013 & $4,362,647$ & $87.2529 \%$ & \\
\hline XS0313326992 & USD & 6-Aug-2013 & $9,991,061$ & $71.6832 \%$ & \\
\hline XS0313327453 & USD & 6-Aug-2013 & $3,706,461$ & $77.7330 \%$ & \\
\hline DE000A0TV576 & EUR & 7-Aug-2013 & $1,511,085$ & $100.7390 \%$ & \\
\hline \begin{tabular}{|l} 
XS0171428369 \\
\end{tabular} & EUR & 8-Aug-2013 & $12,450,197$ & $92.2237 \%$ & \\
\hline XS0173177766 & EUR & 8-Aug-2013 & $10,373,886$ & $103.7389 \%$ & \\
\hline XS0364507383 & GBP & 9-Aug-2013 & $1,863,661$ & $122.4870 \%$ & \\
\hline XS0380855220 & AUD & 12-Aug-2013 & $2,087,303$ & $116.6225 \%$ & \\
\hline XS0382587888 & AUD & 12-Aug-2013 & $4,382,131$ & $111.0909 \%$ & \\
\hline XS0361857674 & GBP & 16-Aug-2013 & $4,263,834$ & $95.5613 \%$ & \\
\hline XS0361858136 & GBP & $16-A u g-2013$ & $11,250,183$ & $95.6278 \%$ & \\
\hline XS0307348234 & EUR & 17-Aug-2013 & $109,215,570$ & $95.4765 \%$ & \\
\hline XS0315529312 & USD & 20-Aug-2013 & $7,692,379$ & $79.4413 \%$ & \\
\hline XS0316372522 & EUR & 21-Aug-2013 & $1,709,120$ & $74.3095 \%$ & \\
\hline XS0301517552 & EUR & 25-Aug-2013 & $4,799,325$ & $79.9887 \%$ & \\
\hline XS0369661813 & GBP & 29-Aug-2013 & $2,286,833$ & $128.0016 \%$ & \\
\hline XS0314067140 & EUR & 3-Sep-2013 & $1,666,862$ & $39.5741 \%$ & \\
\hline XS0319210661 & USD & 7-Sep-2013 & $1,259,800$ & $68.6944 \%$ & \\
\hline XS0373858249 & GBP & 17-Sep-2013 & 78,625 & $107.2134 \%$ & \\
\hline XS0267225273 & EUR & 19-Sep-2013 & 447,492 & $89.4984 \%$ & \\
\hline XS0317188646 & EUR & 26-Sep-2013 & $23,532,729$ & $98.0530 \%$ & \\
\hline XS0317188059 & EUR & 26-Sep-2013 & $40,597,790$ & $99.0190 \%$ & \\
\hline XS0247984965 & EUR & 28-Sep-2013 & $2,222,497$ & $88.8999 \%$ & \\
\hline DE000A0SHPH8 & EUR & 7-Oct-2013 & $10,974,984$ & $99.7726 \%$ & \\
\hline XS0177758801 & USD & 8-Oct-2013 & $23,423,593$ & $106.4368 \%$ & \\
\hline XS0317240157 & EUR & 9-Oct-2013 & $3,546,797$ & $52.5374 \%$ & \\
\hline XS0176153350 & EUR & 10-Oct-2013 & $243,924,347$ & $100.9805 \%$ & \\
\hline XS0177328548 & EUR & $31-$ Oct-2013 & 649,998 & $77.3807 \%$ & \\
\hline XS0274087294 & GBP & 1-Nov-2013 & $13,614,613$ & $105.8196 \%$ & \\
\hline XS0204960610 & EUR & 4-Nov-2013 & $21,527,412$ & $107.6371 \%$ & \\
\hline XS0234443488 & EUR & 18-Nov-2013 & $11,546,558$ & $76.9771 \%$ & amended calculation of $A A$ \\
\hline DE000AOLHVD0 & EUR & 22-Nov-2013 & $18,089,820$ & $66.5116 \%$ & \\
\hline XS0347006131 & EUR & 22-Nov-2013 & $8,537,530$ & $56.9169 \%$ & \\
\hline XS0332714764 & GBP & 23-Nov-2013 & $1,658,162$ & $85.2949 \%$ & \\
\hline XS0178969209 & EUR & 26-Nov-2013 & $42,404,590$ & $101.0644 \%$ & \\
\hline XS0236536644 & USD & 1-Dec-2013 & $4,411,141$ & $105.4959 \%$ & \\
\hline
\end{tabular}




\begin{tabular}{|c|c|c|c|c|}
\hline ISIN & Currency & $\begin{array}{c}\text { Maturity } \\
\text { date }\end{array}$ & $\begin{array}{c}\text { Admissible } \\
\text { Amount in EUR }\end{array}$ & $\begin{array}{c}\text { Admissible } \\
\text { Amount \% }\end{array}$ \\
\hline XS0273084656 & EUR & 9-Dec-2013 & $1,735,156$ & $78.0898 \%$ \\
\hline XS0327236757 & EUR & 10-Dec-2013 & $6,802,603$ & $75.6601 \%$ \\
\hline XS0181881474 & USD & 18-Dec-2013 & $8,570,015$ & $116.8264 \%$ \\
\hline XS0178999537 & EUR & 19-Dec-2013 & $3,606,371$ & $77.0592 \%$ \\
\hline XS0332050078 & EUR & 27-Dec-2013 & $1,116,723$ & $74.4482 \%$ \\
\hline XS0377288450 & EUR & 27-Dec-2013 & $1,549,446$ & $77.4723 \%$ \\
\hline XS0259672599 & EUR & 29-Dec-2013 & $4,174,311$ & $83.4862 \%$ \\
\hline DE000A0SUT07 & EUR & 3-Jan-2014 & $2,831,071$ & $94.3690 \%$ \\
\hline DE000A0SUA81 & EUR & 6-Jan-2014 & $7,996,645$ & $56.5134 \%$ \\
\hline DE000A0SUA99 & EUR & 6-Jan-2014 & $10,817,353$ & $65.5597 \%$ \\
\hline XS0181945972 & EUR & 14-Jan-2014 & $103,077,099$ & $102.5000 \%$ \\
\hline XS0282866192 & USD & 31-Jan-2014 & $3,449,567$ & $60.6298 \%$ \\
\hline XS0321471517 & USD & 31-Jan-2014 & 880,815 & $60.0364 \%$ \\
\hline XS0358300571 & USD & 31-Jan-2014 & 672,562 & $61.1225 \%$ \\
\hline XS0284162533 & EUR & 2-Feb-2014 & $5,768,592$ & $62.2286 \%$ \\
\hline XS0341923083 & USD & 4-Feb-2014 & $3,068,690$ & $104.5810 \%$ \\
\hline XS0284511994 & EUR & 7-Feb-2014 & $55,165,518$ & $86.6701 \%$ \\
\hline XS0284892261 & EUR & 8-Feb-2014 & $2,469,718$ & $86.6568 \%$ \\
\hline XS0285422597 & EUR & 8-Feb-2014 & $3,379,614$ & $86.6568 \%$ \\
\hline XS0345439334 & GBP & 8-Feb-2014 & $2,774,527$ & $91.5712 \%$ \\
\hline XS0242448578 & USD & 9-Feb-2014 & $1,935,015$ & $87.9271 \%$ \\
\hline XS0285200852 & AUD & 10-Feb-2014 & 219,986 & $17.2185 \%$ \\
\hline XS0332049815 & EUR & 14-Feb-2014 & $3,583,598$ & $81.5010 \%$ \\
\hline XS0286586648 & EUR & 16-Feb-2014 & 825,130 & $36.8362 \%$ \\
\hline XS0287004310 & USD & 20-Feb-2014 & $1,022,237$ & $92.9009 \%$ \\
\hline XS0287234313 & EUR & 20-Feb-2014 & $10,458,992$ & $95.0817 \%$ \\
\hline XS0358299542 & USD & $20-F e b-2014$ & 821,321 & $101.7840 \%$ \\
\hline XS0286034870 & AUD & 21-Feb-2014 & 120,050 & $18.0412 \%$ \\
\hline XS0288341448 & EUR & 23-Feb-2014 & $7,967,388$ & $87.0753 \%$ \\
\hline XS0287474976 & AUD & 24-Feb-2014 & 217,671 & $18.1731 \%$ \\
\hline XS0286531156 & EUR & 26-Feb-2014 & $20,756,887$ & $59.4753 \%$ \\
\hline DE000A0NLYL5 & EUR & 27-Feb-2014 & $11,362,356$ & $59.2376 \%$ \\
\hline XS0185655445 & EUR & 27-Feb-2014 & $39,518,477$ & $99.0438 \%$ \\
\hline XS0285769278 & EUR & 28-Feb-2014 & $5,356,106$ & $96.5238 \%$ \\
\hline XS0339810078 & EUR & 4-Mar-2014 & $1,228,108$ & $61.4054 \%$ \\
\hline XS0289152331 & AUD & 7-Mar-2014 & 168,918 & $15.4787 \%$ \\
\hline XS0289153651 & AUD & 7-Mar-2014 & 164,798 & $15.4787 \%$ \\
\hline XS0289483017 & JPY & 7-Mar-2014 & 262,014 & $17.4065 \%$ \\
\hline XS0289484171 & AUD & 7-Mar-2014 & 133,976 & $16.2370 \%$ \\
\hline XS0289659400 & EUR & 7-Mar-2014 & 726,572 & $63.7344 \%$ \\
\hline XS0288610016 & USD & 9-Mar-2014 & 337,164 & $14.5912 \%$ \\
\hline XS0289940289 & USD & 12-Mar-2014 & 693,489 & $94.5364 \%$ \\
\hline XS0353349474 & USD & 14-Mar-2014 & 652,064 & $91.6386 \%$ \\
\hline XS0290366243 & AUD & 20-Mar-2014 & 126,351 & $13.9618 \%$ \\
\hline XS0290772077 & AUD & 20-Mar-2014 & 99,408 & $16.9761 \%$ \\
\hline XS0290975340 & AUD & 20-Mar-2014 & 238,287 & $18.2703 \%$ \\
\hline XS0290993590 & USD & 20-Mar-2014 & 232,425 & $21.1228 \%$ \\
\hline XS0352980022 & USD & 20-Mar-2014 & $1,162,831$ & $105.6780 \%$ \\
\hline DE000A1HBEW5 & EUR & 25-Mar-2014 & 828,868 & $81.5013 \%$ \\
\hline DE000A0G4LS9 & EUR & 25-Mar-2014 & $7,246,172$ & $80.6654 \%$ \\
\hline XS0290294742 & EUR & 27-Mar-2014 & $3,563,310$ & $106.4851 \%$ \\
\hline XS0295664535 & EUR & 27-Mar-2014 & $1,627,324$ & $101.5238 \%$ \\
\hline XS0342412284 & EUR & 28-Mar-2014 & $26,488,884$ & $75.6825 \%$ \\
\hline XS0289261546 & USD & 31-Mar-2014 & $1,470,231$ & $107.5802 \%$ \\
\hline XS0352310485 & EUR & 31-Mar-2014 & $4,855,882$ & $97.1176 \%$ \\
\hline XS0293628748 & EUR & $2-A p r-2014$ & $17,677,826$ & $64.5412 \%$ \\
\hline XS0356420728 & AUD & 2-Apr-2014 & $4,587,559$ & $113.4061 \%$ \\
\hline XS0292221776 & JPY & 5-Apr-2014 & 480,245 & $55.8325 \%$ \\
\hline XS0188232507 & USD & 8-Apr-2014 & $3,982,983$ & $118.0348 \%$ \\
\hline XS0352601537 & HKD & 11-Apr-2014 & $1,354,283$ & $102.4870 \%$ \\
\hline XS0189914111 & USD & 13-Apr-2014 & $4,307,760$ & $117.4468 \%$ \\
\hline XS0295005333 & AUD & 17-Apr-2014 & 72,672 & $18.2020 \%$ \\
\hline XS0358735032 & GBP & 18-Apr-2014 & $5,982,604$ & $124.8317 \%$ \\
\hline XS0360716566 & MXN & 22-Apr-2014 & $4,065,945$ & $114.4140 \%$ \\
\hline XS0189294225 & EUR & 23-Apr-2014 & $61,656,962$ & $97.5832 \%$ \\
\hline XS0355509257 & EUR & 23-Apr-2014 & $1,789,509$ & $101.4461 \%$ \\
\hline XS0356376300 & EUR & 25-Apr-2014 & $15,059,448$ & $75.2972 \%$ \\
\hline XS0297155136 & EUR & 26-Apr-2014 & $2,348,251$ & $65.2292 \%$ \\
\hline XS0297183187 & EUR & 27-Apr-2014 & $10,846,003$ & $108.4600 \%$ \\
\hline XS0191248607 & JPY & 28-Apr-2014 & $7,396,803$ & $103.1928 \%$ \\
\hline XS0294695043 & USD & 28-Apr-2014 & $3,457,681$ & $82.6932 \%$ \\
\hline XS0297155565 & EUR & 7-May-2014 & $32,548,665$ & $62.1989 \%$ \\
\hline XS0297022419 & AUD & 9-May-2014 & 210,819 & $16.8520 \%$ \\
\hline XS0297023813 & AUD & 9-May-2014 & 219,790 & $16.8520 \%$ \\
\hline XS0297501065 & AUD & 9-May-2014 & 200,601 & $18.3819 \%$ \\
\hline XS0298202952 & USD & 9-May-2014 & 291,825 & $20.9377 \%$ \\
\hline XS0356612043 & HKD & 13-May-2014 & 830,504 & $102.4782 \%$ \\
\hline XS0299886092 & USD & 21-May-2014 & $1,213,961$ & $55.1624 \%$ \\
\hline XS0299211721 & AUD & 22-May-2014 & 144,227 & $17.4794 \%$ \\
\hline
\end{tabular}




\begin{tabular}{|c|c|c|c|c|}
\hline ISIN & Currency & $\begin{array}{l}\text { Maturity } \\
\text { date }\end{array}$ & $\begin{array}{c}\text { Admissible } \\
\text { Amount in EUR }\end{array}$ & $\begin{array}{c}\text { Admissible } \\
\text { Amount \% } \\
\end{array}$ \\
\hline DE000A1HBEY1 & EUR & 23-May-2014 & $2,731,801$ & $103.5558 \%$ \\
\hline DE000A0TVK20 & EUR & 23-May-2014 & $9,291,601$ & $94.2162 \%$ \\
\hline XS0253857642 & EUR & 23-May-2014 & $7,062,444$ & $94.1659 \%$ \\
\hline XS0301547542 & EUR & 29-May-2014 & 969,131 & $34.6118 \%$ \\
\hline XS0301338546 & AUD & 5-Jun-2014 & 205,215 & $15.7345 \%$ \\
\hline XS0301347968 & USD & 5-Jun-2014 & 289,334 & $19.7210 \%$ \\
\hline XS0301885272 & AUD & 5-Jun-2014 & 214,411 & $17.5118 \%$ \\
\hline XS0302904296 & AUD & 6-Jun-2014 & 215,848 & $16.8946 \%$ \\
\hline XS0358366168 & EUR & 7-Jun-2014 & $2,133,668$ & $100.0782 \%$ \\
\hline XS0194244645 & SGD & 10-Jun-2014 & $25,253,854$ & $100.7528 \%$ \\
\hline XS0303838006 & EUR & 13-Jun-2014 & $5,044,646$ & $85.2136 \%$ \\
\hline XS0305645375 & EUR & 20-Jun-2014 & $5,775,917$ & $72.1990 \%$ \\
\hline XS0306151662 & AUD & 20-Jun-2014 & 191,867 & $15.6705 \%$ \\
\hline XS0306637306 & USD & 20-Jun-2014 & 129,698 & $17.6804 \%$ \\
\hline XS0371606012 & USD & 20-Jun-2014 & 594,531 & $38.8257 \%$ \\
\hline XS0304195026 & USD & 23-Jun-2014 & $4,438,294$ & $80.6704 \%$ \\
\hline XS0371026443 & USD & 25-Jun-2014 & 43,315 & $3.9365 \%$ \\
\hline XS0358734811 & GBP & 30-Jun-2014 & $3,930,702$ & $98.8718 \%$ \\
\hline XS0372163054 & EUR & 8-Jul-2014 & $5,688,421$ & $113.7684 \%$ \\
\hline XS0306849745 & AUD & 9-Jul-2014 & 120,009 & $16.1027 \%$ \\
\hline XS0307752955 & AUD & 9-Jul-2014 & 145,451 & $13.3283 \%$ \\
\hline XS0195431613 & EUR & 14-Jul-2014 & $28,773,126$ & $97.6651 \%$ \\
\hline XS0309485729 & EUR & 14-Jul-2014 & $17,652,992$ & $80.3504 \%$ \\
\hline DE000A1HB472 & USD & 17-Jul-2014 & $1,361,739$ & $82.5032 \%$ \\
\hline DE000A1HBEX3 & USD & 17-Jul-2014 & $1,516,171$ & $82.5088 \%$ \\
\hline DE000A0TPVQ8 & USD & 17-Jul-2014 & 677,585 & $77.9480 \%$ \\
\hline XS0301569603 & USD & 17-Jul-2014 & $8,372,880$ & $96.7281 \%$ \\
\hline XS0309363371 & AUD & 18-Jul-2014 & 245,501 & $38.4311 \%$ \\
\hline XS0309436359 & JPY & 18-Jul-2014 & 198,398 & $17.2991 \%$ \\
\hline XS0310410823 & USD & 18-Jul-2014 & 204,069 & $15.4548 \%$ \\
\hline XS0363950527 & GBP & 18-Jul-2014 & $2,032,762$ & $98.4401 \%$ \\
\hline XS0258779775 & EUR & 21-Jul-2014 & $7,988,546$ & $104.4254 \%$ \\
\hline XS0196767064 & EUR & 22-Jul-2014 & $14,590,724$ & $97.2715 \%$ \\
\hline XS0260303580 & EUR & 24-Jul-2014 & $2,817,047$ & $86.6784 \%$ \\
\hline XS0310856678 & AUD & 25-Jul-2014 & 163,261 & $13.9402 \%$ \\
\hline XS0311622038 & AUD & 25-Jul-2014 & 82,977 & $14.1702 \%$ \\
\hline XS0299929165 & EUR & 27-Jul-2014 & $3,701,375$ & $74.0275 \%$ \\
\hline XS0100289064 & EUR & 28-Jul-2014 & $9,457,049$ & $105.0783 \%$ \\
\hline XS0197088296 & EUR & 28-Jul-2014 & $14,019,046$ & $93.4603 \%$ \\
\hline XS0368094420 & GBP & 30-Jul-2014 & 62,125 & $127.0694 \%$ \\
\hline XS0368094693 & GBP & 30-Jul-2014 & 379,656 & $97.0684 \%$ \\
\hline XS0368198635 & GBP & 30-Jul-2014 & 88,560 & $91.7778 \%$ \\
\hline XS0100490084 & EUR & 4-Aug-2014 & $5,518,483$ & $110.3697 \%$ \\
\hline XS0366211927 & GBP & 7-Aug-2014 & $1,475,487$ & $117.2879 \%$ \\
\hline XS0366213626 & GBP & 7-Aug-2014 & 69,360 & $83.4117 \%$ \\
\hline XS0313948480 & JPY & 14-Aug-2014 & 216,302 & $18.8602 \%$ \\
\hline XS0314855338 & AUD & 14-Aug-2014 & 137,566 & $17.8219 \%$ \\
\hline XS0368727722 & GBP & 15-Aug-2014 & $2,581,681$ & $117.1402 \%$ \\
\hline XS0315549187 & JPY & 21-Aug-2014 & 171,770 & $23.9636 \%$ \\
\hline XS0316206357 & EUR & 21-Aug-2014 & 975,030 & $68.1839 \%$ \\
\hline XS0316994010 & JPY & 5-Sep-2014 & 237,853 & $25.5253 \%$ \\
\hline XS0317366846 & JPY & 5-Sep-2014 & 189,281 & $26.4065 \%$ \\
\hline XS0318191565 & USD & 11-Sep-2014 & 222,456 & $30.3253 \%$ \\
\hline XS0318999744 & AUD & 12-Sep-2014 & 286,925 & $22.9357 \%$ \\
\hline XS0376548334 & GBP & 12-Sep-2014 & 380,848 & $106.8644 \%$ \\
\hline XS0258396927 & $\mathrm{CHF}$ & 18-Sep-2014 & 403,764 & $86.4667 \%$ \\
\hline XS0319000187 & JPY & 19-Sep-2014 & 168,477 & $47.0083 \%$ \\
\hline XS0319611900 & AUD & 19-Sep-2014 & 252,022 & $25.5905 \%$ \\
\hline XS0319633037 & JPY & 19-Sep-2014 & 311,562 & $28.9773 \%$ \\
\hline XS0380777671 & AUD & 20-Sep-2014 & $7,400,261$ & $112.1080 \%$ \\
\hline XS0200284247 & EUR & 22-Sep-2014 & $82,124,933$ & $99.1655 \%$ \\
\hline XS0323312974 & EUR & 11-Oct-2014 & $7,085,538$ & $59.7936 \%$ \\
\hline XS0324844769 & EUR & 16-Oct-2014 & $1,264,803$ & $98.8127 \%$ \\
\hline XS0324929164 & EUR & $16-$ Oct-2014 & $1,254,313$ & $68.6542 \%$ \\
\hline XS0263715467 & EUR & $17-$ Oct-2014 & $16,321,058$ & $88.1981 \%$ \\
\hline XS0323881911 & AUD & $17-O c t-2014$ & 188,395 & $22.1187 \%$ \\
\hline XS0324409241 & JPY & $17-$ Oct-2014 & 411,764 & $24.9762 \%$ \\
\hline XS0203783526 & USD & 22-Oct-2014 & $16,562,507$ & $104.5278 \%$ \\
\hline XS0324405173 & USD & 23-Oct-2014 & 268,900 & $24.4376 \%$ \\
\hline XS0323848977 & EUR & $25-O c t-2014$ & $7,777,990$ & $65.6370 \%$ \\
\hline XS0202417050 & EUR & $27-O c t-2014$ & $19,845,608$ & $91.8991 \%$ \\
\hline XS0324269488 & EUR & $30-O c t-2014$ & $3,822,458$ & $66.2701 \%$ \\
\hline XS0324269561 & USD & 30-Oct-2014 & $1,631,273$ & $42.3410 \%$ \\
\hline XS0326730313 & USD & 30-Oct-2014 & $1,527,908$ & $40.1551 \%$ \\
\hline XS0327421060 & EUR & 31-Oct-2014 & $1,446,582$ & $60.2743 \%$ \\
\hline XS0327940259 & AUD & 6-Nov-2014 & 444,400 & $20.8701 \%$ \\
\hline XS0327941067 & USD & 6-Nov-2014 & 539,103 & $24.4968 \%$ \\
\hline XS0327714837 & JPY & 7-Nov-2014 & 201,233 & $23.3950 \%$ \\
\hline XS0328587323 & AUD & 14-Nov-2014 & 102,611 & $21.4173 \%$ \\
\hline
\end{tabular}




\begin{tabular}{|c|c|c|c|c|}
\hline ISIN & Currency & $\begin{array}{c}\text { Maturity } \\
\text { date }\end{array}$ & $\begin{array}{c}\text { Admissible } \\
\text { Amount in EUR }\end{array}$ & $\begin{array}{c}\text { Admissible } \\
\text { Amount \% }\end{array}$ \\
\hline XS0270174872 & EUR & 17-Nov-2014 & 797,603 & $79.7603 \%$ \\
\hline XS0205443764 & EUR & 25-Nov-2014 & $10,388,717$ & $69.2581 \%$ \\
\hline \begin{tabular}{|l|} 
XS0329243108 \\
\end{tabular} & USD & 28-Nov-2014 & 623,537 & $36.9246 \%$ \\
\hline XS0329243876 & EUR & 28-Nov-2014 & 850,950 & $63.7416 \%$ \\
\hline XS0329289192 & USD & 28-Nov-2014 & 479,844 & $37.8763 \%$ \\
\hline XS0326999959 & EUR & 29-Nov-2014 & $75,314,680$ & $86.5985 \%$ \\
\hline \begin{tabular}{|l|} 
XS0266165736 \\
\end{tabular} & EUR & 1-Dec-2014 & $2,822,017$ & $88.7985 \%$ \\
\hline XS0331653823 & JPY & 11-Dec-2014 & 565,373 & $78.8752 \%$ \\
\hline XS0332759272 & EUR & 11-Dec-2014 & $4,307,906$ & $60.6576 \%$ \\
\hline \begin{tabular}{|l|} 
XS0276868774 \\
\end{tabular} & EUR & 13-Dec-2014 & $2,785,299$ & $79.5800 \%$ \\
\hline XS0332976884 & EUR & 13-Dec-2014 & $1,981,547$ & $70.7695 \%$ \\
\hline XS0280432526 & EUR & 15-Dec-2014 & $2,617,412$ & $87.2471 \%$ \\
\hline $\begin{array}{l}\text { XS0334641346 } \\
\end{array}$ & USD & 17-Dec-2014 & 245,730 & $31.9028 \%$ \\
\hline XS0334492757 & AUD & 19-Dec-2014 & 392,292 & $31.3583 \%$ \\
\hline XS0334496154 & AUD & 19-Dec-2014 & 93,283 & $29.2052 \%$ \\
\hline XS0334641692 & USD & 19-Dec-2014 & 241,032 & $32.8574 \%$ \\
\hline XS0332632446 & USD & 20-Dec-2014 & $5,967,696$ & $71.1240 \%$ \\
\hline XS0332634657 & EUR & 20-Dec-2014 & $1,274,220$ & $63.7110 \%$ \\
\hline XS0336218176 & USD & 21-Dec-2014 & 270,267 & $24.5619 \%$ \\
\hline XS0337869720 & AUD & 9-Jan-2015 & 153,433 & $28.8225 \%$ \\
\hline XS0337915267 & AUD & 9-Jan-2015 & $1,186,443$ & $44.5747 \%$ \\
\hline \begin{tabular}{|l|} 
XS0337915853 \\
\end{tabular} & AUD & 9-Jan-2015 & $1,539,551$ & $55.6163 \%$ \\
\hline XS0338069494 & AUD & 9-Jan-2015 & 100,971 & $29.1805 \%$ \\
\hline \begin{tabular}{|l|} 
XS0209131001 \\
\end{tabular} & EUR & 14-Jan-2015 & $5,230,502$ & $104.6100 \%$ \\
\hline XS0209308294 & JPY & 14-Jan-2015 & $66,358,051$ & $92.5761 \%$ \\
\hline XS0284611869 & EUR & 26-Jan-2015 & $4,971,993$ & $87.2279 \%$ \\
\hline \begin{tabular}{|l|} 
XS0342236295 \\
\end{tabular} & EUR & 29-Jan-2015 & 362,370 & $14.3229 \%$ \\
\hline XS0216921741 & EUR & 31-Jan-2015 & $6,129,410$ & $94.2986 \%$ \\
\hline XS0338464950 & USD & 31-Jan-2015 & 379,904 & $51.7885 \%$ \\
\hline XS0338465098 & EUR & 31-Jan-2015 & 706,118 & $14.6650 \%$ \\
\hline XS0338465171 & USD & 31-Jan-2015 & 532,770 & $72.6272 \%$ \\
\hline \begin{tabular}{|l|} 
XS0338465254 \\
\end{tabular} & EUR & 31-Jan-2015 & $2,661,715$ & $72.9237 \%$ \\
\hline \begin{tabular}{|l} 
XS0210715289 \\
\end{tabular} & EUR & 4-Feb-2015 & $74,714,573$ & $149.4291 \%$ \\
\hline XS0285498902 & EUR & 6-Feb-2015 & $4,150,762$ & $103.7691 \%$ \\
\hline XS0211093041 & EUR & 16-Feb-2015 & $89,850,740$ & $102.5951 \%$ \\
\hline XS0211244941 & EUR & 17-Feb-2015 & $10,903,270$ & $109.0327 \%$ \\
\hline XS0212011547 & USD & 23-Feb-2015 & $11,551,712$ & $104.9820 \%$ \\
\hline \begin{tabular}{|l} 
XS0212990732 \\
\end{tabular} & EUR & 25-Feb-2015 & $23,394,886$ & $93.5795 \%$ \\
\hline XS0288391971 & EUR & 27-Feb-2015 & $8,143,977$ & $103.6129 \%$ \\
\hline \begin{tabular}{|l|} 
XS0344072318 \\
\end{tabular} & EUR & 28-Feb-2015 & $2,151,968$ & $71.7323 \%$ \\
\hline \begin{tabular}{|l|} 
XS0344087340 \\
\end{tabular} & EUR & 28-Feb-2015 & $2,480,943$ & $85.6088 \%$ \\
\hline XS0344834691 & USD & 28-Feb-2015 & 484,834 & $60.0842 \%$ \\
\hline XS0345215148 & EUR & 28-Feb-2015 & 581,029 & $58.1029 \%$ \\
\hline XS0345439250 & EUR & 28-Feb-2015 & 807,145 & $80.7145 \%$ \\
\hline XS0212915523 & EUR & 1-Mar-2015 & 100,477 & $71.7690 \%$ \\
\hline XS0348936161 & JPY & 4-Mar-2015 & 317,276 & $88.5264 \%$ \\
\hline XS0349177955 & USD & 4-Mar-2015 & $2,547,592$ & $102.4448 \%$ \\
\hline \begin{tabular}{|l|} 
XS0287860265 \\
\end{tabular} & EUR & 5-Mar-2015 & $26,923,781$ & $89.7459 \%$ \\
\hline \begin{tabular}{|l} 
XS0351275853 \\
\end{tabular} & EUR & 12-Mar-2015 & $3,063,573$ & $102.1191 \%$ \\
\hline \begin{tabular}{|l} 
XS0290654978 \\
\end{tabular} & EUR & 16-Mar-2015 & $11,654,683$ & $84.8848 \%$ \\
\hline XS0213971210 & EUR & 18-Mar-2015 & $24,943,829$ & $101.8115 \%$ \\
\hline XS0346466781 & USD & 18-Mar-2015 & $20,134,359$ & $104.0848 \%$ \\
\hline XS0351984660 & USD & 18-Mar-2015 & 533,830 & $97.0289 \%$ \\
\hline XS0291152576 & EUR & 19-Mar-2015 & 733,295 & $73.3295 \%$ \\
\hline XS0214347360 & EUR & 23-Mar-2015 & $2,982,858$ & $99.4286 \%$ \\
\hline XS0353507642 & EUR & 25-Mar-2015 & 627,486 & $69.7206 \%$ \\
\hline \begin{tabular}{|l|} 
XS0350310909 \\
\end{tabular} & EUR & 30-Mar-2015 & 677,465 & $64.5205 \%$ \\
\hline \begin{tabular}{|l} 
XS0354397654 \\
\end{tabular} & USD & 1-Apr-2015 & $1,500,956$ & $102.3051 \%$ \\
\hline XS0215760777 & EUR & 7-Apr-2015 & $37,806,951$ & $126.0232 \%$ \\
\hline XS0353876179 & USD & 8-Apr-2015 & $3,983,589$ & $108.6086 \%$ \\
\hline \begin{tabular}{|l} 
XS0359631974 \\
\end{tabular} & EUR & 30-Apr-2015 & $1,470,464$ & $81.2411 \%$ \\
\hline XS0362407768 & AUD & 6-May-2015 & $1,030,996$ & $108.3786 \%$ \\
\hline XS0366665015 & EUR & 29-May-2015 & 455,563 & $79.2284 \%$ \\
\hline XS0366665361 & GBP & 29-May-2015 & $1,530,836$ & $75.8344 \%$ \\
\hline \begin{tabular}{|l|} 
XS0366665957 \\
\end{tabular} & SEK & 29-May-2015 & $3,030,200$ & $77.9884 \%$ \\
\hline \begin{tabular}{|l|} 
XS0366666336 \\
\end{tabular} & USD & 29-May-2015 & 113,023 & $80.2466 \%$ \\
\hline \begin{tabular}{|l} 
XS0367656583 \\
\end{tabular} & AUD & 2-Jun-2015 & 830,945 & $107.7246 \%$ \\
\hline XS0366803269 & EUR & 10-Jun-2015 & $4,926,773$ & $109.4838 \%$ \\
\hline XS0217027068 & USD & 20-Jun-2015 & 552,068 & $75.2579 \%$ \\
\hline XS0223158386 & EUR & 30-Jun-2015 & $31,728,543$ & $105.7618 \%$ \\
\hline XS0223929489 & EUR & 30-Jun-2015 & $26,186,097$ & $104.7444 \%$ \\
\hline XS0295736622 & EUR & 1-Jul-2015 & $2,180,953$ & $80.7461 \%$ \\
\hline XS0306090423 & EUR & 9-Jul-2015 & $13,638,570$ & $54.0377 \%$ \\
\hline \begin{tabular}{|l|} 
XS0308834547 \\
\end{tabular} & EUR & 9-Jul-2015 & $8,008,857$ & $80.0886 \%$ \\
\hline XS0223938803 & EUR & 13-Jul-2015 & 929,551 & $69.3695 \%$ \\
\hline XS0378532245 & AUD & 29-Jul-2015 & $4,656,535$ & $120.1950 \%$ \\
\hline XS0378532161 & AUD & 30-Jul-2015 & 496,737 & $124.2503 \%$ \\
\hline XS0225326858 & $\mathrm{CHF}$ & 10-Aug-2015 & $4,120,626$ & $91.3955 \%$ \\
\hline \begin{tabular}{|l|} 
XS0382589405 \\
\end{tabular} & AUD & 14-Aug-2015 & $4,682,421$ & $116.1267 \%$ \\
\hline
\end{tabular}




\begin{tabular}{|c|c|c|c|c|}
\hline ISIN & Currency & $\begin{array}{l}\text { Maturity } \\
\text { date }\end{array}$ & $\begin{array}{c}\text { Admissible } \\
\text { Amount in EUR }\end{array}$ & $\begin{array}{c}\text { Admissible } \\
\text { Amount \% } \\
\end{array}$ \\
\hline XS0226456258 & EUR & 23-Aug-2015 & $10,282,238$ & $68.5483 \%$ \\
\hline XS0383364873 & USD & 29-Aug-2015 & 353,890 & $96.4846 \%$ \\
\hline \begin{tabular}{|l|l} 
XS0387561680 \\
\end{tabular} & AUD & 15-Sep-2015 & $1,780,977$ & $115.3372 \%$ \\
\hline XS0367280277 & USD & 20-Sep-2015 & $7,076,385$ & $96.4653 \%$ \\
\hline XS0322927046 & USD & 10-Oct-2015 & 429,891 & $58.6027 \%$ \\
\hline XS0324632669 & EUR & 24-Oct-2015 & $2,893,218$ & $71.4375 \%$ \\
\hline \begin{tabular}{|l|}
$X S 0232254259$ \\
\end{tabular} & JPY & $26-$ Oct-2015 & 659,562 & $92.0155 \%$ \\
\hline \begin{tabular}{|l|} 
XS0233114882 \\
\end{tabular} & EUR & 27-Oct-2015 & $5,544,460$ & $110.8892 \%$ \\
\hline \begin{tabular}{|l|} 
XS0233752145 \\
\end{tabular} & EUR & 3-Nov-2015 & $7,395,434$ & $73.9543 \%$ \\
\hline \begin{tabular}{|l|} 
XS0234203411 \\
\end{tabular} & EUR & 9-Nov-2015 & $6,859,082$ & $105.5243 \%$ \\
\hline XS0234065786 & EUR & 23-Nov-2015 & 944,030 & $94.4030 \%$ \\
\hline \begin{tabular}{|l|l|}
$X S 0231181222$ \\
\end{tabular} & EUR & 30-Nov-2015 & $2,569,536$ & $82.6217 \%$ \\
\hline \begin{tabular}{|l|} 
XS0236377239 \\
\end{tabular} & USD & 9-Dec-2015 & 341,910 & $93.2183 \%$ \\
\hline \begin{tabular}{|l} 
XS0237049605 \\
\end{tabular} & JPY & 9-Dec-2015 & 659,562 & $92.0155 \%$ \\
\hline \begin{tabular}{|l|}
$X S 0237048623$ \\
\end{tabular} & JPY & 15-Dec-2015 & 659,562 & $92.0155 \%$ \\
\hline \begin{tabular}{|l|} 
XS0334595138 \\
\end{tabular} & $\mathrm{CHF}$ & 17-Dec-2015 & $1,082,043$ & $65.7527 \%$ \\
\hline XS0238796204 & USD & 20-Dec-2015 & $15,766,420$ & $107.4639 \%$ \\
\hline \begin{tabular}{|l|} 
XS0289069519 \\
\end{tabular} & EUR & 20-Dec-2015 & $15,093,367$ & $100.6224 \%$ \\
\hline \begin{tabular}{|l|} 
XS0312300477 \\
\end{tabular} & EUR & 28-Dec-2015 & $6,054,578$ & $97.6545 \%$ \\
\hline XS0324491660 & EUR & 10-Jan-2016 & $1,600,434$ & $99.2209 \%$ \\
\hline \begin{tabular}{|l|} 
XS0237304059 \\
\end{tabular} & EUR & 19-Jan-2016 & $2,458,945$ & $79.3208 \%$ \\
\hline \begin{tabular}{|l} 
XS0239997496 \\
\end{tabular} & JPY & 19-Jan-2016 & 659,562 & $92.0155 \%$ \\
\hline XS0238228901 & EUR & 3-Feb-2016 & $4,751,363$ & $82.2747 \%$ \\
\hline XS0240142827 & EUR & 15-Feb-2016 & $1,677,469$ & $75.6298 \%$ \\
\hline \begin{tabular}{|l|} 
XS0332049229 \\
\end{tabular} & EUR & 15-Feb-2016 & $4,389,126$ & $93.3857 \%$ \\
\hline \begin{tabular}{|l|} 
XS0346080590 \\
\end{tabular} & EUR & 15-Feb-2016 & $7,068,203$ & $94.2427 \%$ \\
\hline \begin{tabular}{|l|} 
XS0373219582 \\
\end{tabular} & EUR & 15-Feb-2016 & $2,024,969$ & $101.2484 \%$ \\
\hline \begin{tabular}{|l|} 
XS0276441044 \\
\end{tabular} & EUR & 16-Feb-2016 & $20,412,293$ & $74.4974 \%$ \\
\hline \begin{tabular}{|l|} 
XS0342637872 \\
\end{tabular} & EUR & 18-Feb-2016 & $30,471,172$ & $82.5017 \%$ \\
\hline XS0346439200 & EUR & 21-Feb-2016 & $1,680,687$ & $93.3715 \%$ \\
\hline \begin{tabular}{|l|} 
XS0247938938 \\
\end{tabular} & EUR & 23-Mar-2016 & $12,254,021$ & $122.5402 \%$ \\
\hline XS0248282120 & EUR & 27-Mar-2016 & $22,637,127$ & $98.4223 \%$ \\
\hline \begin{tabular}{|l|} 
XS0341920220 \\
\end{tabular} & EUR & 8-Apr-2016 & $55,684,123$ & $111.3682 \%$ \\
\hline XS0250266169 & $\mathrm{CZK}$ & 12-Apr-2016 & $2,708,239$ & $88.3969 \%$ \\
\hline XS0349530823 & EUR & 18-Apr-2016 & $1,479,527$ & $98.6351 \%$ \\
\hline XS0360242910 & EUR & 2-May-2016 & $1,308,510$ & $87.2340 \%$ \\
\hline \begin{tabular}{|l|} 
XS0250573689 \\
\end{tabular} & SKK & 4-May-2016 & $5,973,857$ & $90.7877 \%$ \\
\hline XS0189452153 & USD & 14-May-2016 & $6,649,645$ & $122.4973 \%$ \\
\hline XS0340891240 & EUR & 30-May-2016 & $2,582,407$ & $86.0802 \%$ \\
\hline XS0366298866 & GBP & 3-Jun-2016 & 844,402 & $109.3853 \%$ \\
\hline \begin{tabular}{|l|} 
XS0255988817 \\
\end{tabular} & EUR & 5-Jun-2016 & $57,662,744$ & $115.3255 \%$ \\
\hline \begin{tabular}{|l|} 
XS0328705115 \\
\end{tabular} & EUR & 6-Jun-2016 & $156,666,455$ & $104.4443 \%$ \\
\hline XS0256738757 & USD & 20-Jun-2016 & $4,432,163$ & $60.4192 \%$ \\
\hline \begin{tabular}{|l} 
XS0257328392 \\
\end{tabular} & USD & 20-Jun-2016 & $4,458,777$ & $60.7820 \%$ \\
\hline \begin{tabular}{|l|l} 
XS0258128916 \\
\end{tabular} & USD & 20-Jun-2016 & $9,366,089$ & $127.6785 \%$ \\
\hline XS0341922358 & EUR & 24-Jun-2016 & $41,637,304$ & $88.5900 \%$ \\
\hline XS0252173066 & EUR & 5-Jul-2016 & $3,089,313$ & $77.2328 \%$ \\
\hline \begin{tabular}{|l|} 
XS0258715456 \\
\end{tabular} & EUR & 6-Jul-2016 & $51,031,609$ & $102.0632 \%$ \\
\hline \begin{tabular}{|l|} 
XS0258128247 \\
\end{tabular} & USD & 7-Jul-2016 & $4,358,970$ & $59.4215 \%$ \\
\hline XS0361379166 & EUR & 22-Jul-2016 & $2,971,200$ & $99.0400 \%$ \\
\hline \begin{tabular}{|l} 
XS0132969360 \\
\end{tabular} & EUR & 31-Jul-2016 & $13,409,846$ & $67.0492 \%$ \\
\hline XS0262983264 & SGD & 8-Aug-2016 & $65,761,769$ & $104.9453 \%$ \\
\hline XS0267959665 & EUR & 21-Sep-2016 & $10,325,389$ & $94.7283 \%$ \\
\hline XS0324731990 & EUR & 12-Oct-2016 & $6,617,540$ & $64.8778 \%$ \\
\hline \begin{tabular}{|l|} 
XS0269969704 \\
\end{tabular} & EUR & 13-Oct-2016 & $3,000,599$ & $100.0200 \%$ \\
\hline XS0270326217 & JPY & 17-Oct-2016 & $1,462,944$ & $98.5968 \%$ \\
\hline \begin{tabular}{|l|} 
XS0270926081 \\
\end{tabular} & USD & 20-Oct-2016 & $8,318,139$ & $113.3929 \%$ \\
\hline XS0273043629 & EUR & 10-Nov-2016 & $1,445,446$ & $56.5954 \%$ \\
\hline \begin{tabular}{|l|} 
XS0323978089 \\
\end{tabular} & USD & 10-Nov-2016 & 311,063 & $56.5388 \%$ \\
\hline XS0276341418 & EUR & 24-Nov-2016 & $5,814,455$ & $77.5261 \%$ \\
\hline \begin{tabular}{|l|}
$X S 0205437527$ \\
\end{tabular} & USD & 1-Dec-2016 & $1,974,071$ & $96.1091 \%$ \\
\hline \begin{tabular}{|l} 
XS0207897199 \\
\end{tabular} & USD & 6-Dec-2016 & $1,828,406$ & $65.4195 \%$ \\
\hline XS0278320832 & EUR & 6-Dec-2016 & $3,343,935$ & $66.8787 \%$ \\
\hline XS0209163624 & EUR & 19-Dec-2016 & $37,267,669$ & $124.2256 \%$ \\
\hline \begin{tabular}{|l|}
$\mathrm{XS} 0279324957$ \\
\end{tabular} & JPY & 22-Dec-2016 & $1,319,124$ & $92.0155 \%$ \\
\hline \begin{tabular}{|l|} 
XS0280166116 \\
\end{tabular} & EUR & 28-Dec-2016 & $3,568,656$ & $70.6665 \%$ \\
\hline \begin{tabular}{|l|} 
XS0279612823 \\
\end{tabular} & EUR & 29-Dec-2016 & $9,259,749$ & $92.5975 \%$ \\
\hline XS0208459023 & EUR & 30-Dec-2016 & $72,445,069$ & $99.1027 \%$ \\
\hline XS0270685968 & EUR & 30-Dec-2016 & $1,005,669$ & $74.4940 \%$ \\
\hline XS0270686859 & EUR & 30-Dec-2016 & $4,587,196$ & $83.4036 \%$ \\
\hline \begin{tabular}{|l} 
XS0269657994 \\
\end{tabular} & EUR & 31-Jan-2017 & $8,335,228$ & $79.3831 \%$ \\
\hline XS0283497005 & EUR & 31-Jan-2017 & $428,126,124$ & $104.3698 \%$ \\
\hline \begin{tabular}{|l|} 
XS0272783530 \\
\end{tabular} & EUR & 7-Feb-2017 & $4,527,917$ & $73.3741 \%$ \\
\hline \begin{tabular}{|l|} 
XS0209163897 \\
\end{tabular} & EUR & 8-Feb-2017 & $36,548,663$ & $121.8289 \%$ \\
\hline \begin{tabular}{|l|} 
XS0211814123 \\
\end{tabular} & EUR & 16-Feb-2017 & $55,221,854$ & $97.6738 \%$ \\
\hline XS0286747836 & EUR & 19-Feb-2017 & $9,667,764$ & $96.6776 \%$ \\
\hline XS0286529093 & EUR & 23-Feb-2017 & $32,639,411$ & $108.7980 \%$ \\
\hline XS0270683161 & EUR & 28-Feb-2017 & $15,107,981$ & $80.3616 \%$ \\
\hline \begin{tabular}{|l}
$\mathrm{XS} 0270684565$ \\
\end{tabular} & EUR & 28-Feb-2017 & $2,175,388$ & $75.0134 \%$ \\
\hline
\end{tabular}




\begin{tabular}{|c|c|c|c|c|}
\hline ISIN & Currency & $\begin{array}{l}\text { Maturity } \\
\text { date }\end{array}$ & $\begin{array}{c}\text { Admissible } \\
\text { Amount in EUR }\end{array}$ & $\begin{array}{c}\text { Admissible } \\
\text { Amount \% } \\
\end{array}$ \\
\hline XS0213593865 & EUR & 1-Mar-2017 & $17,269,809$ & $115.1321 \%$ \\
\hline XS0269657135 & EUR & 2-Mar-2017 & $2,222,659$ & $74.0886 \%$ \\
\hline \begin{tabular}{|l|} 
XS0287569924 \\
\end{tabular} & EUR & 9-Mar-2017 & $3,273,366$ & $100.5025 \%$ \\
\hline XS0289922113 & $\mathrm{CHF}$ & 12-Mar-2017 & $3,012,144$ & $93.5331 \%$ \\
\hline XS0290092955 & JPY & 16-Mar-2017 & $2,638,248$ & $92.0155 \%$ \\
\hline XS0290094738 & AUD & 16-Mar-2017 & 471,014 & $88.4799 \%$ \\
\hline \begin{tabular}{|l|} 
XS0290095628 \\
\end{tabular} & JPY & 16-Mar-2017 & $1,068,990$ & $93.2092 \%$ \\
\hline \begin{tabular}{|l|} 
XS0290096600 \\
\end{tabular} & JPY & 16-Mar-2017 & $1,202,614$ & $93.2092 \%$ \\
\hline \begin{tabular}{|l|} 
XS0290989994 \\
\end{tabular} & JPY & 20-Mar-2017 & $3,314,909$ & $92.4926 \%$ \\
\hline XS0292502514 & USD & 20-Mar-2017 & $3,889,498$ & $106.0433 \%$ \\
\hline \begin{tabular}{|l|}
$X S 0294106314$ \\
\end{tabular} & EUR & 30-Mar-2017 & $3,856,735$ & $85.7052 \%$ \\
\hline \begin{tabular}{|l|l|} 
XS0294106405 \\
\end{tabular} & EUR & 30-Mar-2017 & $4,147,625$ & $82.9525 \%$ \\
\hline \begin{tabular}{|l|} 
XS0288524795 \\
\end{tabular} & EUR & 6-Apr-2017 & $6,501,494$ & $73.0505 \%$ \\
\hline \begin{tabular}{|l} 
XS0294325203 \\
\end{tabular} & USD & 13-Apr-2017 & $1,693,991$ & $115.4624 \%$ \\
\hline XS0296282386 & EUR & 24-Apr-2017 & $13,445,583$ & $76.8319 \%$ \\
\hline \begin{tabular}{|l|} 
XS0297741539 \\
\end{tabular} & USD & 25-Apr-2017 & $9,125,661$ & $71.9081 \%$ \\
\hline XS0295087042 & USD & 26-Apr-2017 & $27,577,104$ & $75.1862 \%$ \\
\hline \begin{tabular}{|l|} 
XS0297392770 \\
\end{tabular} & EUR & 2-May-2017 & $10,454,150$ & $104.5415 \%$ \\
\hline \begin{tabular}{|l|} 
XS0297186958 \\
\end{tabular} & USD & 4-May-2017 & $12,475,179$ & $113.3744 \%$ \\
\hline \begin{tabular}{|l|} 
XS0298692434 \\
\end{tabular} & HKD & 8-May-2017 & $51,049,976$ & $107.0240 \%$ \\
\hline XS0282452621 & EUR & 12-May-2017 & $8,742,648$ & $69.3366 \%$ \\
\hline XS0301316906 & EUR & 25-May-2017 & $3,926,659$ & $78.5332 \%$ \\
\hline \begin{tabular}{|l|l} 
XS0301705041 \\
\end{tabular} & EUR & 25-May-2017 & $9,397,633$ & $93.9763 \%$ \\
\hline XS0302118632 & JPY & 30-May-2017 & $1,241,736$ & $86.6173 \%$ \\
\hline \begin{tabular}{|l|} 
XS0220152069 \\
\end{tabular} & EUR & 6-Jun-2017 & $26,443,352$ & $90.9206 \%$ \\
\hline XS0220704109 & EUR & 13-Jun-2017 & $19,378,644$ & $87.3699 \%$ \\
\hline \begin{tabular}{|l|} 
XS0304490963 \\
\end{tabular} & USD & 15-Jun-2017 & $12,511,928$ & $113.7084 \%$ \\
\hline \begin{tabular}{|l|} 
XS0303465214 \\
\end{tabular} & EUR & 18-Jun-2017 & 686,954 & $26.5131 \%$ \\
\hline \begin{tabular}{|l|} 
XS0304145351 \\
\end{tabular} & EUR & 18-Jun-2017 & $3,700,038$ & $74.0008 \%$ \\
\hline XS0306251967 & EUR & 18-Jun-2017 & $7,850,000$ & $100.0000 \%$ \\
\hline XS0305255407 & USD & 19-Jun-2017 & $14,301,222$ & $97.4771 \%$ \\
\hline XS0305338799 & USD & 26-Jun-2017 & 271,207 & $36.9709 \%$ \\
\hline \begin{tabular}{|l|} 
XS0280223107 \\
\end{tabular} & EUR & 4-Jul-2017 & $2,984,197$ & $74.6049 \%$ \\
\hline XS0308461176 & EUR & 5-Jul-2017 & 939,364 & $71.4345 \%$ \\
\hline \begin{tabular}{|l} 
XS0307663939 \\
\end{tabular} & EUR & 9-Jul-2017 & $4,830,531$ & $96.6106 \%$ \\
\hline \begin{tabular}{|l|} 
XS0308985240 \\
\end{tabular} & JPY & 10-Jul-2017 & 448,273 & $62.5386 \%$ \\
\hline \begin{tabular}{|l|} 
XS0309365319 \\
\end{tabular} & JPY & 12-Jul-2017 & 353,105 & $16.4205 \%$ \\
\hline XS0311765068 & EUR & 26-Jul-2017 & 824,120 & $60.5970 \%$ \\
\hline XS0310086623 & EUR & 27-Jul-2017 & $4,801,501$ & $96.0300 \%$ \\
\hline \begin{tabular}{|l|} 
XS0313198979 \\
\end{tabular} & EUR & 1-Aug-2017 & $15,152,570$ & $101.0171 \%$ \\
\hline \begin{tabular}{|l|} 
XS0313432329 \\
\end{tabular} & USD & 3-Aug-2017 & 189,116 & $37.3627 \%$ \\
\hline XS0313537002 & USD & 3-Aug-2017 & 482,737 & $78.3412 \%$ \\
\hline \begin{tabular}{|l}
$\mathrm{XS} 0225842433$ \\
\end{tabular} & EUR & 8-Aug-2017 & $9,586,785$ & $95.8678 \%$ \\
\hline XS0314999250 & EUR & 14-Aug-2017 & 522,856 & $42.0979 \%$ \\
\hline \begin{tabular}{|l|l} 
XS0226707510 \\
\end{tabular} & EUR & 15-Aug-2017 & $9,549,748$ & $95.4975 \%$ \\
\hline XS0315504323 & EUR & 16-Aug-2017 & $314,606,404$ & $104.8688 \%$ \\
\hline XS0315356039 & JPY & 17-Aug-2017 & $6,672,295$ & $93.0852 \%$ \\
\hline \begin{tabular}{|l|} 
XS0316264638 \\
\end{tabular} & USD & 22-Aug-2017 & 308,284 & $39.0933 \%$ \\
\hline \begin{tabular}{|l|} 
XS0317996279 \\
\end{tabular} & EUR & 31-Aug-2017 & 973,314 & $48.6657 \%$ \\
\hline XS0318943445 & EUR & 6-Sep-2017 & $90,000,000$ & $100.0000 \%$ \\
\hline \begin{tabular}{|l} 
XS0229979983 \\
\end{tabular} & EUR & 19-Sep-2017 & $11,113,994$ & $111.1399 \%$ \\
\hline XS0311446479 & EUR & 20-Sep-2017 & $14,048,620$ & $70.2431 \%$ \\
\hline \begin{tabular}{|l} 
XS0383779815 \\
\end{tabular} & AUD & 20-Sep-2017 & $8,094,439$ & $112.6326 \%$ \\
\hline XS0230911785 & EUR & 29-Sep-2017 & $12,784,939$ & $127.8494 \%$ \\
\hline \begin{tabular}{|l} 
XS0322779348 \\
\end{tabular} & EUR & 2-Oct-2017 & $16,273,816$ & $93.9326 \%$ \\
\hline XS0323412337 & EUR & 4-Oct-2017 & 134,355 & $22.3925 \%$ \\
\hline \begin{tabular}{|l|} 
XS0324058865 \\
\end{tabular} & ILS & $11-$ Oct-2017 & $186,260,808$ & $109.4136 \%$ \\
\hline XS0324446524 & $\mathrm{CHF}$ & 17-Oct-2017 & $10,252,208$ & $63.6703 \%$ \\
\hline XS0368669007 & EUR & $17-$ Oct-2017 & $7,919,514$ & $105.5935 \%$ \\
\hline XS0326823324 & JPY & 23-Oct-2017 & $2,188,038$ & $101.7511 \%$ \\
\hline \begin{tabular}{|l|} 
XS0299371509 \\
\end{tabular} & EUR & $25-O c t-2017$ & $19,823,150$ & $59.3634 \%$ \\
\hline XS0296589194 & EUR & 31-Oct-2017 & $1,097,180$ & $73.1453 \%$ \\
\hline XS0326598371 & USD & 31-Oct-2017 & $15,224,071$ & $75.4671 \%$ \\
\hline XS0327731096 & EUR & 2-Nov-2017 & 388,289 & $55.4699 \%$ \\
\hline \begin{tabular}{|l|} 
XS0326264917 \\
\end{tabular} & EUR & 7-Nov-2017 & $8,459,026$ & $84.5903 \%$ \\
\hline \begin{tabular}{|l|} 
XS0329877889 \\
\end{tabular} & USD & 21-Nov-2017 & $7,594,851$ & $103.5330 \%$ \\
\hline \begin{tabular}{|l|} 
XS0331249291 \\
\end{tabular} & EUR & 22-Nov-2017 & $5,499,867$ & $89.8671 \%$ \\
\hline XS0326826343 & EUR & 25-Nov-2017 & 486,682 & $48.6682 \%$ \\
\hline XS0323271170 & USD & 27-Nov-2017 & $3,720,928$ & $101.4474 \%$ \\
\hline XS0330837773 & EUR & 27-Nov-2017 & $34,142,121$ & $85.3553 \%$ \\
\hline \begin{tabular}{|l|} 
XS0331472281 \\
\end{tabular} & AUD & 27-Nov-2017 & 417,909 & $78.5043 \%$ \\
\hline XS0330834598 & EUR & 30-Nov-2017 & $2,570,314$ & $79.0866 \%$ \\
\hline \begin{tabular}{|l|} 
XS0332109221 \\
\end{tabular} & USD & 11-Dec-2017 & $3,830,784$ & $103.4084 \%$ \\
\hline \begin{tabular}{|l|} 
XS0334151411 \\
\end{tabular} & EUR & 11-Dec-2017 & $6,000,000$ & $100.0000 \%$ \\
\hline \begin{tabular}{|l} 
XS0336248322 \\
\end{tabular} & USD & 14-Dec-2017 & $2,047,574$ & $116.3022 \%$ \\
\hline XS0334788360 & EUR & 17-Dec-2017 & $7,727,293$ & $75.0223 \%$ \\
\hline XS0335243159 & EUR & 18-Dec-2017 & 159,101 & $22.7287 \%$ \\
\hline \begin{tabular}{|l|} 
XS0329879588 \\
\end{tabular} & AUD & 20-Dec-2017 & $17,291,530$ & $101.5067 \%$ \\
\hline \begin{tabular}{|l}
$\mathrm{XS} 0330133611$ \\
\end{tabular} & AUD & 20-Dec-2017 & $17,295,621$ & $101.5307 \%$ \\
\hline
\end{tabular}




\begin{tabular}{|c|c|c|c|c|}
\hline ISIN & Currency & $\begin{array}{c}\text { Maturity } \\
\text { date }\end{array}$ & $\begin{array}{c}\text { Admissible } \\
\text { Amount in EUR }\end{array}$ & $\begin{array}{c}\text { Admissible } \\
\text { Amount \% }\end{array}$ \\
\hline XS0330133702 & AUD & 20-Dec-2017 & $11,228,355$ & $65.9140 \%$ \\
\hline XS0330133967 & AUD & 20-Dec-2017 & $17,291,530$ & $101.5067 \%$ \\
\hline XS0330134007 & AUD & 20-Dec-2017 & $17,295,621$ & $101.5307 \%$ \\
\hline XS0334171799 & AUD & 20-Dec-2017 & $8,300,883$ & $91.7248 \%$ \\
\hline XS0334171872 & AUD & 20-Dec-2017 & $16,135,355$ & $91.8493 \%$ \\
\hline XS0334172094 & AUD & 20-Dec-2017 & $8,300,883$ & $91.7248 \%$ \\
\hline \begin{tabular}{|l|} 
XS0338656787 \\
\end{tabular} & USD & 20-Dec-2017 & $26,434,308$ & $90.0881 \%$ \\
\hline XS0338656860 & USD & 20-Dec-2017 & $19,825,731$ & $90.0881 \%$ \\
\hline XS0338657082 & USD & 20-Dec-2017 & $26,434,308$ & $90.0881 \%$ \\
\hline \begin{tabular}{|l} 
XS0338657165 \\
\end{tabular} & USD & 20-Dec-2017 & $26,434,308$ & $90.0881 \%$ \\
\hline XS0350507959 & USD & 20-Dec-2017 & $1,085,617$ & $8.0870 \%$ \\
\hline XS0356126705 & EUR & 20-Dec-2017 & 967,047 & $24.1762 \%$ \\
\hline \begin{tabular}{|l} 
XS0367282059 \\
\end{tabular} & USD & 20-Dec-2017 & $3,079,600$ & $41.9811 \%$ \\
\hline XS0368230628 & EUR & 20-Dec-2017 & - & $0.0000 \%$ \\
\hline IT0006578600 & EUR & 22-Dec-2017 & $13,536,197$ & $106.2663 \%$ \\
\hline \begin{tabular}{|l|} 
XS0311297021 \\
\end{tabular} & EUR & 27-Dec-2017 & $4,705,795$ & $122.7385 \%$ \\
\hline XS0336556146 & USD & 27-Dec-2017 & $6,521,136$ & $111.1202 \%$ \\
\hline \begin{tabular}{|l|} 
XS0338307936 \\
\end{tabular} & USD & 28-Dec-2017 & $4,414,126$ & $120.3467 \%$ \\
\hline \begin{tabular}{|l|} 
XS0307362656 \\
\end{tabular} & EUR & 30-Dec-2017 & $1,046,698$ & $104.6698 \%$ \\
\hline XS0336952337 & USD & 3-Jan-2018 & $6,867,470$ & $109.8795 \%$ \\
\hline XS0336410013 & USD & 7-Jan-2018 & $3,266,520$ & $104.2838 \%$ \\
\hline XS0336025027 & EUR & 10-Jan-2018 & $13,090,503$ & $65.4525 \%$ \\
\hline XS0340696466 & EUR & 21-Jan-2018 & $3,189,456$ & $83.9330 \%$ \\
\hline \begin{tabular}{|l|} 
XS0340031730 \\
\end{tabular} & EUR & 22-Jan-2018 & $9,856,808$ & $98.5681 \%$ \\
\hline XS0340461580 & USD & 23-Jan-2018 & 745,078 & $101.5690 \%$ \\
\hline XS0342406476 & USD & 23-Jan-2018 & $2,504,202$ & $113.7909 \%$ \\
\hline \begin{tabular}{|l|} 
XS0339480187 \\
\end{tabular} & USD & 24-Jan-2018 & $1,065,270$ & $103.7269 \%$ \\
\hline XS0339480344 & USD & 25-Jan-2018 & $6,094,415$ & $114.5918 \%$ \\
\hline XS0343088968 & USD & 25-Jan-2018 & $4,217,691$ & $114.9911 \%$ \\
\hline XS0340291722 & USD & 30-Jan-2018 & $7,013,683$ & $102.3667 \%$ \\
\hline XS0342194601 & EUR & 30-Jan-2018 & $1,614,224$ & $50.9219 \%$ \\
\hline \begin{tabular}{|l|} 
XS0339479841 \\
\end{tabular} & USD & 31-Jan-2018 & $4,133,887$ & $108.3714 \%$ \\
\hline \begin{tabular}{|l} 
XS0339479924 \\
\end{tabular} & USD & 31-Jan-2018 & 752,273 & $102.5499 \%$ \\
\hline XS0342489589 & USD & 31-Jan-2018 & $1,457,070$ & $110.3487 \%$ \\
\hline XS0344314850 & USD & 31-Jan-2018 & $1,126,017$ & $102.3324 \%$ \\
\hline XS0339480005 & USD & 1-Feb-2018 & $1,824,625$ & $118.4442 \%$ \\
\hline XS0340050284 & USD & 1-Feb-2018 & 457,680 & $103.9849 \%$ \\
\hline \begin{tabular}{|l} 
XS0342520094 \\
\end{tabular} & USD & 1-Feb-2018 & $4,251,745$ & $115.9196 \%$ \\
\hline XS0340461747 & USD & 6-Feb-2018 & $1,385,121$ & $102.0647 \%$ \\
\hline XS0341031275 & USD & 6-Feb-2018 & $1,365,405$ & $109.4894 \%$ \\
\hline \begin{tabular}{|l|} 
XS0343872734 \\
\end{tabular} & USD & 7-Feb-2018 & $4,222,745$ & $115.1289 \%$ \\
\hline \begin{tabular}{|l} 
XS0342733671 \\
\end{tabular} & EUR & 9-Feb-2018 & $6,000,000$ & $100.0000 \%$ \\
\hline XS0342095881 & USD & 11-Feb-2018 & $5,957,558$ & $108.2846 \%$ \\
\hline \begin{tabular}{|l|} 
XS0345213283 \\
\end{tabular} & USD & 11-Feb-2018 & $3,353,777$ & $101.5971 \%$ \\
\hline XS0344960058 & USD & 12-Feb-2018 & $1,995,588$ & $102.6561 \%$ \\
\hline XS0345205693 & EUR & 13-Feb-2018 & $1,038,623$ & $109.3288 \%$ \\
\hline XS0344086532 & USD & 14-Feb-2018 & $3,420,672$ & $93.2612 \%$ \\
\hline \begin{tabular}{|l|} 
XS0346470387 \\
\end{tabular} & USD & 14-Feb-2018 & $15,676,728$ & $106.8526 \%$ \\
\hline \begin{tabular}{|l|} 
XS0344829931 \\
\end{tabular} & USD & $15-F e b-2018$ & $7,299,420$ & $116.7907 \%$ \\
\hline XS0348560524 & EUR & $15-F e b-2018$ & $1,075,097$ & $107.5097 \%$ \\
\hline XS0364806298 & EUR & 15-Feb-2018 & $2,096,908$ & $104.8454 \%$ \\
\hline XS0346007080 & EUR & 18-Feb-2018 & $5,538,219$ & $110.7644 \%$ \\
\hline XS0347016015 & EUR & 19-Feb-2018 & $15,816,075$ & $105.4405 \%$ \\
\hline XS0345212806 & USD & 19-Feb-2018 & $3,487,550$ & $102.2415 \%$ \\
\hline \begin{tabular}{|l} 
XS0346073975 \\
\end{tabular} & USD & $19-F e b-2018$ & $8,562,193$ & $108.0739 \%$ \\
\hline XS0347451295 & USD & 20-Feb-2018 & $1,837,338$ & $100.1864 \%$ \\
\hline \begin{tabular}{|l|} 
XS0346508707 \\
\end{tabular} & USD & 21-Feb-2018 & $1,409,285$ & $101.1125 \%$ \\
\hline \begin{tabular}{|l} 
XS0344549067 \\
\end{tabular} & USD & 25-Feb-2018 & $4,644,365$ & $153.2978 \%$ \\
\hline XS0347938671 & EUR & 27-Feb-2018 & 268,876 & $53.7753 \%$ \\
\hline XS0348533984 & EUR & 28-Feb-2018 & $12,796,916$ & $102.3753 \%$ \\
\hline XS0346881252 & EUR & 3-Mar-2018 & $5,275,248$ & $105.5050 \%$ \\
\hline XS0347785312 & USD & 3-Mar-2018 & $4,651,638$ & $101.9472 \%$ \\
\hline XS0349506369 & EUR & 4-Mar-2018 & $1,382,930$ & $70.7020 \%$ \\
\hline XS0347769035 & JPY & 5-Mar-2018 & 833,343 & $116.2597 \%$ \\
\hline \begin{tabular}{|l|} 
XS0348934893 \\
\end{tabular} & USD & 5-Mar-2018 & $8,100,717$ & $88.3432 \%$ \\
\hline \begin{tabular}{|l|} 
XS0348442756 \\
\end{tabular} & USD & 6-Mar-2018 & 377,855 & $103.0185 \%$ \\
\hline \begin{tabular}{|l} 
XS0213454829 \\
\end{tabular} & EUR & 7-Mar-2018 & $21,579,194$ & $71.9306 \%$ \\
\hline XS0350419742 & USD & 10-Mar-2018 & 668,651 & $91.1505 \%$ \\
\hline XS0351358717 & USD & 10-Mar-2018 & $4,222,281$ & $102.2347 \%$ \\
\hline XS0347768813 & USD & 11-Mar-2018 & $8,012,477$ & $116.1980 \%$ \\
\hline XS0349442888 & USD & 11-Mar-2018 & $2,000,751$ & $102.9217 \%$ \\
\hline XS0351261127 & USD & 13-Mar-2018 & $2,303,015$ & $104.6490 \%$ \\
\hline XS0351261630 & USD & 13-Mar-2018 & $1,920,018$ & $104.6947 \%$ \\
\hline \begin{tabular}{|l} 
XS0350635875 \\
\end{tabular} & USD & 18-Mar-2018 & $4,405,991$ & $120.1249 \%$ \\
\hline $\begin{array}{l}\text { XS0352061674 } \\
\end{array}$ & USD & 18-Mar-2018 & 765,500 & $104.3529 \%$ \\
\hline XS0349442458 & USD & 19-Mar-2018 & $6,447,970$ & $110.1488 \%$ \\
\hline XS0350454905 & USD & 19-Mar-2018 & $2,987,947$ & $101.8292 \%$ \\
\hline XS0351983779 & JPY & 19-Mar-2018 & 697,519 & $97.3109 \%$ \\
\hline XS0352734924 & USD & 19-Mar-2018 & 766,745 & $104.5227 \%$ \\
\hline
\end{tabular}




\begin{tabular}{|c|c|c|c|c|}
\hline ISIN & Currency & $\begin{array}{c}\text { Maturity } \\
\text { date }\end{array}$ & $\begin{array}{c}\text { Admissible } \\
\text { Amount in EUR }\end{array}$ & $\begin{array}{c}\text { Admissible } \\
\text { Amount \% }\end{array}$ \\
\hline XS0342945002 & USD & 20-Mar-2018 & $10,477,959$ & $79.3531 \%$ \\
\hline XS0350115878 & USD & 20-Mar-2018 & $3,072,388$ & $116.3411 \%$ \\
\hline XS0353187478 & USD & 20-Mar-2018 & $1,591,834$ & $108.4994 \%$ \\
\hline XS0367279774 & USD & 20-Mar-2018 & $2,969,775$ & $40.4840 \%$ \\
\hline XS0367279931 & USD & 20-Mar-2018 & $3,030,436$ & $41.3109 \%$ \\
\hline XS0349506104 & USD & 21-Mar-2018 & $3,369,199$ & $102.0643 \%$ \\
\hline XS0350419403 & USD & 25-Mar-2018 & $3,426,527$ & $116.7760 \%$ \\
\hline XS0350116173 & USD & 26-Mar-2018 & $7,084,818$ & $104.9785 \%$ \\
\hline XS0351439046 & USD & 26-Mar-2018 & 389,544 & $106.2052 \%$ \\
\hline XS0352111289 & USD & 26-Mar-2018 & $4,669,117$ & $114.4773 \%$ \\
\hline XS0353780900 & USD & 26-Mar-2018 & $1,546,271$ & $105.3938 \%$ \\
\hline XS0352901507 & USD & 27-Mar-2018 & $2,457,217$ & $104.6775 \%$ \\
\hline XS0352061591 & SGD & 28-Mar-2018 & $1,065,368$ & $106.2598 \%$ \\
\hline XS0352111016 & USD & 28-Mar-2018 & $1,594,852$ & $108.7051 \%$ \\
\hline XS0353348666 & USD & 31-Mar-2018 & $13,058,562$ & $110.5679 \%$ \\
\hline XS0353349045 & USD & 31-Mar-2018 & $2,607,262$ & $105.1544 \%$ \\
\hline XS0353873408 & USD & 31-Mar-2018 & $1,437,229$ & $115.2489 \%$ \\
\hline XS0353875015 & USD & 31-Mar-2018 & $4,290,547$ & $116.9775 \%$ \\
\hline XS0351857551 & USD & 1-Apr-2018 & $4,746,985$ & $115.9693 \%$ \\
\hline XS0354397571 & USD & 1-Apr-2018 & $2,317,592$ & $105.3114 \%$ \\
\hline XS0352901689 & USD & 2-Apr-2018 & $5,311,314$ & $104.4788 \%$ \\
\hline XS0353157216 & USD & 3-Apr-2018 & $14,041,997$ & $110.3288 \%$ \\
\hline XS0353349631 & USD & 7-Apr-2018 & $2,575,132$ & $117.0140 \%$ \\
\hline XS0356447093 & EUR & 11-Apr-2018 & $9,314,405$ & $89.1331 \%$ \\
\hline XS0353349714 & USD & 14-Apr-2018 & $1,075,499$ & $104.7229 \%$ \\
\hline XS0359302642 & EUR & 14-Apr-2018 & $1,432,846$ & $89.5529 \%$ \\
\hline XS0356444660 & EUR & 18-Apr-2018 & $35,553,038$ & $104.5678 \%$ \\
\hline XS0356444827 & EUR & 18-Apr-2018 & $32,267,102$ & $107.5570 \%$ \\
\hline XS0358009487 & USD & 18-Apr-2018 & $2,413,425$ & $109.6660 \%$ \\
\hline XS0358689841 & GBP & 18-Apr-2018 & $7,400,920$ & $91.0328 \%$ \\
\hline XS0357393197 & USD & 22-Apr-2018 & $1,078,505$ & $113.9704 \%$ \\
\hline XS0358176468 & EUR & 25-Apr-2018 & $1,178,983$ & $104.3348 \%$ \\
\hline XS0358302601 & CZK & 25-Apr-2018 & $1,807,688$ & $99.4431 \%$ \\
\hline XS0356956564 & USD & 28-Apr-2018 & $2,124,482$ & $103.4319 \%$ \\
\hline XS0358118189 & USD & 29-Apr-2018 & $3,026,134$ & $82.5045 \%$ \\
\hline XS0358585551 & USD & 7-May-2018 & 766,274 & $90.0504 \%$ \\
\hline XS0218614567 & EUR & 16-May-2018 & $17,722,549$ & $88.6127 \%$ \\
\hline XS0342414819 & EUR & 16-May-2018 & $14,384,221$ & $82.6679 \%$ \\
\hline XS0364742543 & NZD & 21-May-2018 & 273,588 & $97.7486 \%$ \\
\hline XS0255600941 & CZK & 23-May-2018 & $8,763,035$ & $99.5448 \%$ \\
\hline XS0365026656 & USD & 25-May-2018 & $3,349,671$ & $102.6129 \%$ \\
\hline XS0366665106 & EUR & 28-May-2018 & $1,536,171$ & $68.3350 \%$ \\
\hline XS0366665791 & GBP & 28-May-2018 & $1,976,973$ & $65.3317 \%$ \\
\hline XS0366666096 & SEK & 28-May-2018 & $5,571,354$ & $67.2265 \%$ \\
\hline XS0366666419 & USD & 28-May-2018 & 925,298 & $68.9271 \%$ \\
\hline XS0363471631 & USD & 30-May-2018 & $2,522,791$ & $152.8475 \%$ \\
\hline XS0254946287 & EUR & 1-Jun-2018 & $66,979,780$ & $133.9596 \%$ \\
\hline XS0367519161 & USD & 12-Jun-2018 & 960,076 & $109.0647 \%$ \\
\hline XS0368783477 & SGD & 12-Jun-2018 & $2,649,043$ & $105.6862 \%$ \\
\hline XS0369274708 & EUR & 17-Jun-2018 & $3,103,268$ & $103.4423 \%$ \\
\hline XS0368699509 & USD & 18-Jun-2018 & 771,454 & $105.1646 \%$ \\
\hline XS0369333215 & $\mathrm{CHF}$ & 18-Jun-2018 & $1,293,184$ & $100.3899 \%$ \\
\hline XS0369868327 & USD & 20-Jun-2018 & 388,178 & $88.1941 \%$ \\
\hline 52519VAX4 & USD & 22-Jun-2018 & $3,779,250$ & $73.5982 \%$ \\
\hline XS0357601722 & GBP & 25-Jun-2018 & $3,275,689$ & $91.4194 \%$ \\
\hline XS0372300144 & AUD & 25-Jun-2018 & $2,588,118$ & $64.7708 \%$ \\
\hline XS0372359975 & AUD & 25-Jun-2018 & 600,193 & $64.7708 \%$ \\
\hline XS0359897229 & USD & 2-Jul-2018 & $11,895,397$ & $108.1054 \%$ \\
\hline XS0375441671 & NZD & 18-Jul-2018 & 389,834 & $98.3162 \%$ \\
\hline XS0366065505 & EUR & 31-Jul-2018 & $4,879,912$ & $119.0222 \%$ \\
\hline XS0379485864 & USD & 5-Aug-2018 & $3,995,630$ & $108.9368 \%$ \\
\hline XS0366298601 & EUR & 18-Aug-2018 & $1,393,573$ & $103.2276 \%$ \\
\hline XS0383284840 & USD & 25-Aug-2018 & 522,126 & $66.5821 \%$ \\
\hline XS0383284923 & SEK & 25-Aug-2018 & $7,560,999$ & $66.8143 \%$ \\
\hline XS0383285060 & EUR & $25-A u g-2018$ & $2,445,707$ & $67.7481 \%$ \\
\hline XS0383284766 & GBP & 26-Aug-2018 & 642,642 & $65.6364 \%$ \\
\hline XS0384072103 & USD & 27-Aug-2018 & $3,829,958$ & $104.4200 \%$ \\
\hline XS0382285954 & USD & 28-Aug-2018 & 309,391 & $105.4403 \%$ \\
\hline XS0209164192 & EUR & $1-$ Oct-2018 & $22,287,886$ & $89.1515 \%$ \\
\hline XS0209164275 & EUR & 8-Oct-2018 & $31,698,990$ & $126.7960 \%$ \\
\hline XS0209164358 & EUR & 15-Oct-2018 & $31,859,906$ & $127.4396 \%$ \\
\hline XS0270220220 & EUR & 18 -Oct-2018 & $8,805,481$ & $55.5902 \%$ \\
\hline XS0209164432 & EUR & 22-Oct-2018 & $35,485,460$ & $141.9418 \%$ \\
\hline XS0361641318 & EUR & 31-Oct-2018 & $2,492,704$ & $124.6352 \%$ \\
\hline XS0361641821 & EUR & 31-Oct-2018 & $1,246,352$ & $124.6352 \%$ \\
\hline XS0326476693 & GBP & 15-Dec-2018 & $17,804,850$ & $65.8991 \%$ \\
\hline XS0342489316 & USD & 21-Dec-2018 & $69,553,094$ & $62.7082 \%$ \\
\hline XS0384581756 & EUR & 31-Jan-2019 & $1,142,985$ & $114.2985 \%$ \\
\hline XS0384581913 & EUR & 31-Jan-2019 & $1,059,608$ & $105.9608 \%$ \\
\hline
\end{tabular}




\begin{tabular}{|c|c|c|c|c|}
\hline ISIN & Currency & $\begin{array}{c}\text { Maturity } \\
\text { date }\end{array}$ & $\begin{array}{c}\text { Admissible } \\
\text { Amount in EUR }\end{array}$ & $\begin{array}{c}\text { Admissible } \\
\text { Amount \% }\end{array}$ \\
\hline XS0293892419 & EUR & 29-Mar-2019 & $359,955,619$ & $102.8445 \%$ \\
\hline \begin{tabular}{|l|} 
XS0299086644 \\
\end{tabular} & USD & 9-May-2019 & $6,804,353$ & $106.3726 \%$ \\
\hline \begin{tabular}{|l} 
XS0323352095 \\
\end{tabular} & EUR & 1-Oct-2019 & $5,350,000$ & $100.0000 \%$ \\
\hline \begin{tabular}{|l} 
XS0327725528 \\
\end{tabular} & USD & 5-Nov-2019 & $1,505,966$ & $102.6467 \%$ \\
\hline $\begin{array}{l}\text { XS0329201528 } \\
\end{array}$ & USD & 5-Nov-2019 & 746,399 & $101.7491 \%$ \\
\hline \begin{tabular}{|l|} 
XS0329980030 \\
\end{tabular} & USD & 15-Nov-2019 & 322,242 & $109.8202 \%$ \\
\hline XS0332025120 & USD & 5-Dec-2019 & $2,620,506$ & $102.0650 \%$ \\
\hline \begin{tabular}{|l} 
XS0334732491 \\
\end{tabular} & USD & 3-Jan-2020 & $2,242,345$ & $101.8921 \%$ \\
\hline $\begin{array}{l}\text { XS0206245234 } \\
\end{array}$ & USD & 6-Jan-2020 & $6,019,273$ & $102.8255 \%$ \\
\hline XS0336623433 & USD & 8-Jan-2020 & $39,309,318$ & $104.8659 \%$ \\
\hline XS0338754525 & USD & 10-Jan-2020 & $1,505,378$ & $102.6066 \%$ \\
\hline XS0208689967 & USD & 11-Jan-2020 & $11,399,682$ & $105.2849 \%$ \\
\hline \begin{tabular}{|l} 
XS0207502781 \\
\end{tabular} & USD & 13-Jan-2020 & $2,135,487$ & $103.9677 \%$ \\
\hline XS0341714243 & USD & 18-Jan-2020 & $1,154,546$ & $100.8896 \%$ \\
\hline XS0340222750 & USD & 23-Jan-2020 & $1,799,734$ & $111.5181 \%$ \\
\hline \begin{tabular}{|l} 
XS0342489233 \\
\end{tabular} & USD & 28-Jan-2020 & $40,533,595$ & $106.4651 \%$ \\
\hline \begin{tabular}{|l} 
XS0320169013 \\
\end{tabular} & EUR & 31-Jan-2020 & $2,413,673$ & $80.4558 \%$ \\
\hline XS0211092316 & USD & 3-Feb-2020 & $3,838,766$ & $104.6601 \%$ \\
\hline \begin{tabular}{|l|} 
XS0340062883 \\
\end{tabular} & USD & 4-Feb-2020 & $2,227,917$ & $114.6074 \%$ \\
\hline XS0345633811 & USD & 6-Feb-2020 & 698,346 & $95.1985 \%$ \\
\hline XS0339215351 & USD & $15-F e b-2020$ & $2,188,069$ & $101.4549 \%$ \\
\hline \begin{tabular}{|l} 
XS0347925264 \\
\end{tabular} & USD & $27-F e b-2020$ & $2,578,693$ & $101.5975 \%$ \\
\hline XS0349757103 & USD & 7-Mar-2020 & $148,435,171$ & $103.6985 \%$ \\
\hline \begin{tabular}{|l|} 
XS0351984827 \\
\end{tabular} & USD & 18-Mar-2020 & $3,325,632$ & $105.1856 \%$ \\
\hline \begin{tabular}{|l|} 
XS0350635958 \\
\end{tabular} & USD & 28-Mar-2020 & $4,662,883$ & $102.1936 \%$ \\
\hline \begin{tabular}{|l} 
XS0342225769 \\
\end{tabular} & EUR & 31-Mar-2020 & $58,785,704$ & $101.3547 \%$ \\
\hline XS0341721453 & EUR & 1-Apr-2020 & $16,532,761$ & $82.6638 \%$ \\
\hline XS0216140094 & USD & 19-Apr-2020 & $3,749,153$ & $102.2169 \%$ \\
\hline \begin{tabular}{|l|} 
XS0361383192 \\
\end{tabular} & USD & 9-May-2020 & 806,677 & $103.7417 \%$ \\
\hline XS0362345638 & USD & 28-May-2020 & $38,809,419$ & $100.0000 \%$ \\
\hline XS0355227942 & EUR & 2-Jun-2020 & $10,674,659$ & $106.7466 \%$ \\
\hline XS0368710082 & USD & 9-Jun-2020 & $4,898,994$ & $95.4044 \%$ \\
\hline \begin{tabular}{|l} 
XS0365192078 \\
\end{tabular} & USD & 11-Jun-2020 & $23,513,791$ & $100.0000 \%$ \\
\hline XS0221851875 & USD & 1-Jul-2020 & $1,369,665$ & $91.0794 \%$ \\
\hline XS0365822435 & EUR & 2-Jul-2020 & $9,076,239$ & $90.7624 \%$ \\
\hline XS0371084640 & USD & 3-Jul-2020 & $2,613,033$ & $102.7723 \%$ \\
\hline XS0224536705 & EUR & 28-Jul-2020 & $5,222,981$ & $104.4596 \%$ \\
\hline XS0368926506 & EUR & 1-Aug-2020 & $15,071,112$ & $100.4741 \%$ \\
\hline \begin{tabular}{|l|} 
XS0225770857 \\
\end{tabular} & JPY & 5-Aug-2020 & 721,868 & $100.7078 \%$ \\
\hline \begin{tabular}{|l} 
XS0226995396 \\
\end{tabular} & EUR & $17-A u g-2020$ & $18,135,220$ & $120.9015 \%$ \\
\hline \begin{tabular}{|l|} 
XS0226956141 \\
\end{tabular} & EUR & 25-Aug-2020 & $4,218,993$ & $84.3799 \%$ \\
\hline \begin{tabular}{|l} 
XS0227573267 \\
\end{tabular} & JPY & 26 -Aug-2020 & $1,437,451$ & $100.2694 \%$ \\
\hline \begin{tabular}{|l|} 
XS0270984957 \\
\end{tabular} & EUR & 28 -Dec-2020 & $5,170,712$ & $103.4142 \%$ \\
\hline XS0335070032 & EUR & 28-Dec-2020 & $5,271,082$ & $105.4216 \%$ \\
\hline XS0249129494 & USD & 31-Dec-2020 & $13,420,033$ & $49.4438 \%$ \\
\hline XS0244530498 & EUR & 13-Mar-2021 & $1,727,249$ & $86.3624 \%$ \\
\hline \begin{tabular}{|l|} 
XS0255101353 \\
\end{tabular} & USD & 19-May-2021 & $1,772,579$ & $80.5460 \%$ \\
\hline XS0266833515 & EUR & 12-Sep-2021 & $7,318,877$ & $73.1888 \%$ \\
\hline \begin{tabular}{|l} 
XS0268364766 \\
\end{tabular} & JPY & 29-Sep-2021 & $1,425,257$ & $99.4188 \%$ \\
\hline XS0272080457 & JPY & $27-$ Oct-2021 & $6,842,964$ & $95.4662 \%$ \\
\hline \begin{tabular}{|l|} 
XS0289151879 \\
\end{tabular} & USD & 2-Mar-2022 & $1,638,044$ & $74.4327 \%$ \\
\hline XS0293179338 & USD & 24-Apr-2022 & $2,234,108$ & $101.5179 \%$ \\
\hline XS0297116070 & EUR & 2-May-2022 & $4,560,643$ & $91.2129 \%$ \\
\hline XS0293180344 & USD & 15-May-2022 & $2,366,561$ & $100.8155 \%$ \\
\hline \begin{tabular}{|l} 
XS0309870474 \\
\end{tabular} & EUR & 18-Jul-2022 & $9,243,307$ & $46.2165 \%$ \\
\hline XS0327725106 & USD & 1-Nov-2022 & 773,698 & $105.4705 \%$ \\
\hline \begin{tabular}{|l|} 
XS0329878770 \\
\end{tabular} & JPY & 16-Nov-2022 & $2,171,783$ & $100.9952 \%$ \\
\hline \begin{tabular}{|l} 
XS0331488014 \\
\end{tabular} & USD & 21-Nov-2022 & $1,900,042$ & $86.3379 \%$ \\
\hline $\begin{array}{l}\text { XS0331506369 } \\
\end{array}$ & EUR & $26-N o v-2022$ & $1,656,831$ & $84.4030 \%$ \\
\hline XS0336850762 & USD & 19-Dec-2022 & $1,801,805$ & $104.5200 \%$ \\
\hline XS0336373575 & USD & 24-Dec-2022 & 855,122 & $109.9720 \%$ \\
\hline XS0336617625 & USD & 24-Dec-2022 & $1,952,247$ & $109.5186 \%$ \\
\hline XS0342097747 & USD & 31-Jan-2023 & $6,240,021$ & $96.4991 \%$ \\
\hline XS0340461820 & USD & 6-Feb-2023 & $6,288,247$ & $117.4265 \%$ \\
\hline XS0343832605 & USD & 7-Feb-2023 & $5,599,449$ & $116.7151 \%$ \\
\hline \begin{tabular}{|l} 
XS0345439763 \\
\end{tabular} & USD & $14-F e b-2023$ & $1,660,488$ & $104.3123 \%$ \\
\hline \begin{tabular}{|l} 
XS0340592681 \\
\end{tabular} & USD & $15-F e b-2023$ & $22,463,293$ & $101.6665 \%$ \\
\hline \begin{tabular}{|l} 
XS0343197074 \\
\end{tabular} & USD & 15-Feb-2023 & $1,342,936$ & $101.7050 \%$ \\
\hline XS0346122343 & USD & $19-F e b-2023$ & $2,340,868$ & $106.3691 \%$ \\
\hline XS0346438657 & USD & $20-F e b-2023$ & $1,661,716$ & $113.2626 \%$ \\
\hline XS0342804365 & USD & $21-F e b-2023$ & $115,859,609$ & $101.1397 \%$ \\
\hline XS0347452855 & USD & $25-F e b-2023$ & $1,167,350$ & $106.0887 \%$ \\
\hline XS0346467326 & USD & $27-F e b-2023$ & $1,223,260$ & $101.0635 \%$ \\
\hline \begin{tabular}{|l} 
XS0347689274 \\
\end{tabular} & USD & $27-F e b-2023$ & $1,117,504$ & $101.5588 \%$ \\
\hline XS0348100362 & USD & $27-F e b-2023$ & $5,129,659$ & $120.5647 \%$ \\
\hline \begin{tabular}{|l|} 
XS0348391409 \\
\end{tabular} & USD & $27-F e b-2023$ & $12,801,035$ & $114.0547 \%$ \\
\hline XS0348391235 & USD & $28-F e b-2023$ & $2,252,138$ & $102.3371 \%$ \\
\hline XS0349911387 & EUR & 3-Mar-2023 & $57,458,091$ & $104.4693 \%$ \\
\hline \begin{tabular}{|l} 
XS0346689143 \\
\end{tabular} & USD & 4-Mar-2023 & $2,416,748$ & $98.9342 \%$ \\
\hline
\end{tabular}




\begin{tabular}{|c|c|c|c|c|}
\hline ISIN & Currency & $\begin{array}{l}\text { Maturity } \\
\text { date }\end{array}$ & $\begin{array}{c}\text { Admissible } \\
\text { Amount in EUR }\end{array}$ & $\begin{array}{c}\text { Admissible } \\
\text { Amount \% }\end{array}$ \\
\hline XS0347872128 & USD & 4-Mar-2023 & $7,742,644$ & $104.1932 \%$ \\
\hline XS0349092022 & USD & 4-Mar-2023 & $8,124,645$ & $101.3313 \%$ \\
\hline XS0350109475 & USD & 10-Mar-2023 & $3,707,591$ & $113.5773 \%$ \\
\hline XS0350187604 & EUR & 10-Mar-2023 & $4,291,600$ & $112.6404 \%$ \\
\hline XS0350764337 & USD & 12-Mar-2023 & $1,756,462$ & $117.3730 \%$ \\
\hline XS0351271514 & USD & 12-Mar-2023 & $1,566,581$ & $106.7781 \%$ \\
\hline XS0353301947 & USD & 17-Mar-2023 & $7,133,803$ & $110.3837 \%$ \\
\hline XS0349757442 & USD & 19-Mar-2023 & $3,800,794$ & $105.7396 \%$ \\
\hline XS0349904689 & USD & 25-Mar-2023 & $3,196,290$ & $106.2727 \%$ \\
\hline XS0353739187 & USD & 25-Mar-2023 & $1,301,474$ & $105.6053 \%$ \\
\hline XS0353180895 & USD & 27-Mar-2023 & $1,625,437$ & $119.7728 \%$ \\
\hline XS0353180978 & USD & 27-Mar-2023 & $2,190,708$ & $119.4549 \%$ \\
\hline XS0354608290 & JPY & 27-Mar-2023 & $5,516,401$ & $76.9593 \%$ \\
\hline XS0165086165 & EUR & 1-Apr-2023 & $10,725,575$ & $107.2557 \%$ \\
\hline XS0352061245 & USD & 1-Apr-2023 & 542,848 & $105.7158 \%$ \\
\hline XS0354197054 & USD & 3-Apr-2023 & $4,719,714$ & $116.9803 \%$ \\
\hline XS0356045707 & USD & 9-Apr-2023 & $7,295,668$ & $103.8148 \%$ \\
\hline XS0314254680 & EUR & 15-Apr-2023 & $1,978,339$ & $65.9446 \%$ \\
\hline XS0359405023 & USD & 28-Apr-2023 & $2,579,641$ & $102.5238 \%$ \\
\hline XS0360117690 & USD & 29-Apr-2023 & $14,129,566$ & $110.0653 \%$ \\
\hline XS0360994296 & USD & 27-May-2023 & $4,207,913$ & $102.4326 \%$ \\
\hline XS0366932407 & USD & 29-May-2023 & $4,242,744$ & $103.2805 \%$ \\
\hline XS0365475531 & USD & 30-May-2023 & $1,224,759$ & $104.3495 \%$ \\
\hline XS0366383387 & USD & 5-Jun-2023 & $4,839,040$ & $117.5861 \%$ \\
\hline XS0368699681 & USD & 12-Jun-2023 & $2,613,723$ & $103.5764 \%$ \\
\hline XS0368095237 & USD & 16-Jun-2023 & $3,064,685$ & $104.4445 \%$ \\
\hline XS0366386059 & JPY & 19-Jun-2023 & 450,649 & $62.8700 \%$ \\
\hline XS0379247504 & USD & 15-Aug-2023 & 354,471 & $107.3811 \%$ \\
\hline XS0317898186 & EUR & $28-O c t-2023$ & $2,234,585$ & $69.8308 \%$ \\
\hline XS0361886772 & EUR & 31-Oct-2023 & 850,034 & $85.0034 \%$ \\
\hline XS0239715260 & EUR & 30-Jan-2024 & $40,950,000$ & $100.0000 \%$ \\
\hline XS0186365499 & EUR & 1-Mar-2024 & $11,124,140$ & $111.2414 \%$ \\
\hline XS0317898004 & EUR & 30-Jul-2024 & $2,556,152$ & $63.9038 \%$ \\
\hline XS0224301571 & EUR & 1-Aug-2025 & $1,542,787$ & $75.7754 \%$ \\
\hline XS0232569086 & JPY & $27-O c t-2025$ & 659,149 & $91.9579 \%$ \\
\hline XS0234063906 & JPY & 10-Nov-2025 & 716,794 & $100.0000 \%$ \\
\hline XS0346438731 & USD & $27-F e b-2026$ & $4,590,879$ & $101.7608 \%$ \\
\hline XS0245162531 & EUR & 7-Mar-2026 & $5,200,310$ & $104.0062 \%$ \\
\hline XS0255434085 & EUR & 26-May-2026 & $21,317,489$ & $106.5874 \%$ \\
\hline XS0260592752 & EUR & 24-Jul-2026 & $6,478,804$ & $107.9801 \%$ \\
\hline XS0284375283 & EUR & 20-Dec-2026 & $26,167,913$ & $104.6717 \%$ \\
\hline XS0284376760 & EUR & 20-Dec-2026 & $20,933,065$ & $104.6653 \%$ \\
\hline XS0284379350 & EUR & 20-Dec-2026 & $36,630,648$ & $104.6590 \%$ \\
\hline XS0284381257 & EUR & 20-Dec-2026 & $36,641,725$ & $104.6906 \%$ \\
\hline XS0292221008 & JPY & 25-Mar-2027 & $1,400,768$ & $48.8553 \%$ \\
\hline XS0295094923 & JPY & 13-Apr-2027 & $1,059,169$ & $73.8823 \%$ \\
\hline XS0297097429 & EUR & 30-Apr-2027 & $10,703,913$ & $107.0391 \%$ \\
\hline US52519VAP13 & USD & 20-Dec-2027 & $13,408,624$ & $32.6404 \%$ \\
\hline US52519VAQ95 & USD & 20-Dec-2027 & $30,209,592$ & $77.7014 \%$ \\
\hline US52519VAS51 & USD & 20-Dec-2027 & $43,719,790$ & $77.4011 \%$ \\
\hline US52519VAU08 & USD & 20-Dec-2027 & $63,524,422$ & $103.0911 \%$ \\
\hline XS0327716881 & USD & 20-Dec-2027 & $13,170,660$ & $81.6102 \%$ \\
\hline XS0327717343 & USD & 20-Dec-2027 & $28,125,114$ & $79.0519 \%$ \\
\hline \begin{tabular}{|l} 
XS0327717855 \\
\end{tabular} & USD & 20-Dec-2027 & $13,170,660$ & $81.6102 \%$ \\
\hline XS0327717939 & USD & 20-Dec-2027 & $14,623,462$ & $90.6123 \%$ \\
\hline XS0337916406 & JPY & 11-Jan-2028 & 577,487 & $80.5653 \%$ \\
\hline XS0331053719 & USD & 15-May-2028 & 277,420 & $39.8083 \%$ \\
\hline XS0373960011 & EUR & 20-Jun-2028 & $20,817,620$ & $104.0881 \%$ \\
\hline XS0237558662 & EUR & 12-Dec-2030 & $5,353,603$ & $67.2563 \%$ \\
\hline XS0126813053 & EUR & 28-Mar-2031 & $18,085,380$ & $22.4638 \%$ \\
\hline XS0361015471 & EUR & 30-Jun-2031 & $10,588,411$ & $105.8841 \%$ \\
\hline XS0288702052 & EUR & 28-Feb-2032 & $1,458,643$ & $20.8378 \%$ \\
\hline XS0335394879 & JPY & 21-Dec-2032 & $2,660,867$ & $86.3297 \%$ \\
\hline XS0336192868 & JPY & 27-Dec-2032 & $1,375,014$ & $100.9622 \%$ \\
\hline XS0249942870 & EUR & 7-Jul-2033 & $29,115,684$ & $97.0523 \%$ \\
\hline XS0335156005 & EUR & 18-Dec-2034 & $9,266,500$ & $21.5500 \%$ \\
\hline XS0210433206 & EUR & 15-Feb-2035 & $58,616,223$ & $61.6967 \%$ \\
\hline XS0213416141 & EUR & 16-Mar-2035 & $58,141,836$ & $100.4836 \%$ \\
\hline XS0218304458 & EUR & 17-May-2035 & $70,180,500$ & $69.3011 \%$ \\
\hline XS0224442805 & JPY & 20-Jul-2035 & $1,064,884$ & $99.0414 \%$ \\
\hline XS0229584296 & EUR & 5-Oct-2035 & $155,188,255$ & $66.3711 \%$ \\
\hline XS0232364868 & EUR & 2-Nov-2035 & $67,412,854$ & $69.9144 \%$ \\
\hline XS0239265555 & JPY & 11-Jan-2036 & 750,662 & $104.7248 \%$ \\
\hline XS0253139843 & JPY & 16-May-2036 & $1,504,501$ & $104.9465 \%$ \\
\hline XS0253743800 & JPY & 23-May-2036 & $1,504,459$ & $104.9436 \%$ \\
\hline XS0256400127 & JPY & 20-Jun-2036 & 878,403 & $102.1217 \%$ \\
\hline XS0256520700 & JPY & 20-Jun-2036 & $1,098,004$ & $102.1217 \%$ \\
\hline XS0256731828 & JPY & 20-Jun-2036 & 732,003 & $102.1217 \%$ \\
\hline XS0256732800 & JPY & 20-Jun-2036 & 732,003 & $102.1217 \%$ \\
\hline
\end{tabular}




\begin{tabular}{|c|c|c|c|c|}
\hline ISIN & Currency & $\begin{array}{l}\text { Maturity } \\
\text { date }\end{array}$ & $\begin{array}{c}\text { Admissible } \\
\text { Amount in EUR }\end{array}$ & $\begin{array}{c}\text { Admissible } \\
\text { Amount \% } \\
\end{array}$ \\
\hline \begin{tabular}{|l|} 
XS0256932053 \\
\end{tabular} & JPY & 20-Jun-2036 & $1,683,606$ & $102.1217 \%$ \\
\hline XS0259838745 & JPY & 25-Jul-2036 & $1,363,396$ & $95.1037 \%$ \\
\hline \begin{tabular}{|l|l|}
$X S 0263507278$ \\
\end{tabular} & JPY & 11-Aug-2036 & $1,048,605$ & $97.5272 \%$ \\
\hline XS0266104867 & JPY & 12-Sep-2036 & $1,781,399$ & $82.8410 \%$ \\
\hline XS0266838407 & JPY & 12-Sep-2036 & 822,598 & $114.7606 \%$ \\
\hline XS0266912905 & JPY & 26-Sep-2036 & 228,631 & $31.8963 \%$ \\
\hline \begin{tabular}{|l|} 
XS0267300589 \\
\end{tabular} & JPY & 26-Sep-2036 & 660,937 & $92.2073 \%$ \\
\hline \begin{tabular}{|l|} 
XS0268241683 \\
\end{tabular} & JPY & 26-Sep-2036 & 538,485 & $75.1241 \%$ \\
\hline \begin{tabular}{|l|} 
XS0268364253 \\
\end{tabular} & JPY & 29-Sep-2036 & 729,082 & $101.7142 \%$ \\
\hline \begin{tabular}{|l|} 
XS0270328189 \\
\end{tabular} & JPY & $20-$ Oct-2036 & $2,113,041$ & $98.2634 \%$ \\
\hline \begin{tabular}{|l|}
$X S 0270820177$ \\
\end{tabular} & JPY & 24-Oct-2036 & 675,384 & $94.2228 \%$ \\
\hline \begin{tabular}{|l|l}
$X S 0270752313$ \\
\end{tabular} & EUR & $25-$ Oct-2036 & $2,722,113$ & $108.8845 \%$ \\
\hline \begin{tabular}{|l|}
$X S 0274755072$ \\
\end{tabular} & JPY & 28-Nov-2036 & 695,637 & $97.0483 \%$ \\
\hline \begin{tabular}{|l} 
XS0278981658 \\
\end{tabular} & EUR & 18-Dec-2036 & $10,804,253$ & $108.0425 \%$ \\
\hline \begin{tabular}{|l|} 
XS0279378532 \\
\end{tabular} & JPY & 18-Dec-2036 & $2,712,919$ & $92.3120 \%$ \\
\hline \begin{tabular}{|l|} 
XS0280508952 \\
\end{tabular} & JPY & 28-Dec-2036 & $2,546,506$ & $118.4210 \%$ \\
\hline XS0278290589 & JPY & 29-Dec-2036 & 555,372 & $77.4799 \%$ \\
\hline \begin{tabular}{|l|} 
XS0281179811 \\
\end{tabular} & JPY & 16-Jan-2037 & $12,279,190$ & $85.6535 \%$ \\
\hline \begin{tabular}{|l|} 
XS0185247912 \\
\end{tabular} & EUR & 29-Jan-2037 & $1,005,993$ & $53.0188 \%$ \\
\hline XS0286637144 & JPY & 23-Feb-2037 & 260,230 & $72.6095 \%$ \\
\hline \begin{tabular}{|l|} 
XS0287308299 \\
\end{tabular} & USD & 23-Feb-2037 & $1,046,472$ & $89.1594 \%$ \\
\hline XS0288782658 & JPY & 9-Mar-2037 & $2,968,029$ & $92.0155 \%$ \\
\hline \begin{tabular}{|l|} 
XS0289338948 \\
\end{tabular} & JPY & 9-Mar-2037 & 417,524 & $64.7208 \%$ \\
\hline \begin{tabular}{|l|} 
XS0290717486 \\
\end{tabular} & JPY & 13-Mar-2037 & $1,508,527$ & $105.2273 \%$ \\
\hline \begin{tabular}{|l|} 
XS0289536400 \\
\end{tabular} & JPY & 16-Mar-2037 & 716,794 & $100.0000 \%$ \\
\hline \begin{tabular}{|l|} 
XS0290093847 \\
\end{tabular} & JPY & 16-Mar-2037 & 559,978 & $78.1225 \%$ \\
\hline \begin{tabular}{|l|} 
XS0291873122 \\
\end{tabular} & JPY & 23-Mar-2037 & 287,095 & $80.1051 \%$ \\
\hline \begin{tabular}{|l|l|} 
XS0290716595 \\
\end{tabular} & JPY & 27-Mar-2037 & $1,129,273$ & $105.0299 \%$ \\
\hline \begin{tabular}{|l|} 
XS0291869955 \\
\end{tabular} & JPY & 27-Mar-2037 & $1,582,949$ & $92.0155 \%$ \\
\hline XS0292540019 & JPY & 27-Mar-2037 & 660,937 & $92.2073 \%$ \\
\hline XS0292305280 & JPY & 30-Mar-2037 & 831,535 & $116.0074 \%$ \\
\hline XS0293140553 & JPY & 5-Apr-2037 & 512,486 & $71.4969 \%$ \\
\hline \begin{tabular}{|l|} 
XS0293875083 \\
\end{tabular} & JPY & 13-Apr-2037 & $1,458,344$ & $101.7268 \%$ \\
\hline XS0293363858 & JPY & 17-Apr-2037 & 881,472 & $94.5955 \%$ \\
\hline \begin{tabular}{|l|} 
XS0297459868 \\
\end{tabular} & JPY & 15-May-2037 & $1,322,973$ & $92.2840 \%$ \\
\hline \begin{tabular}{|l|} 
XS0299876457 \\
\end{tabular} & JPY & 15-Мау-2037 & 681,698 & $95.1037 \%$ \\
\hline XS0302264535 & JPY & 12-Jun-2037 & $2,116,757$ & $92.2840 \%$ \\
\hline XS0302480230 & JPY & 12-Jun-2037 & 330,743 & $92.2840 \%$ \\
\hline XS0303531700 & JPY & 19-Jun-2037 & $3,296,089$ & $91.9675 \%$ \\
\hline XS0305103565 & JPY & 22-Jun-2037 & 228,600 & $63.7840 \%$ \\
\hline \begin{tabular}{|l|} 
XS0305127150 \\
\end{tabular} & JPY & 3-Jul-2037 & $1,190,676$ & $92.2840 \%$ \\
\hline XS0307008481 & JPY & 10-Jul-2037 & $1,318,435$ & $91.9675 \%$ \\
\hline \begin{tabular}{|l} 
XS0310885933 \\
\end{tabular} & JPY & 13-Jul-2037 & 704,531 & $98.2891 \%$ \\
\hline XS0307903830 & JPY & 17-Jul-2037 & 859,933 & $92.2840 \%$ \\
\hline XS0309227436 & JPY & 26-Jul-2037 & 403,152 & $56.2438 \%$ \\
\hline XS0312480196 & JPY & 2-Aug-2037 & $1,890,439$ & $64.7998 \%$ \\
\hline XS0312057432 & JPY & 7-Aug-2037 & 727,635 & $92.2840 \%$ \\
\hline \begin{tabular}{|l|} 
XS0313326646 \\
\end{tabular} & JPY & 10-Aug-2037 & 659,562 & $92.0155 \%$ \\
\hline \begin{tabular}{|l|} 
XS0313326729 \\
\end{tabular} & JPY & 14-Aug-2037 & 988,827 & $91.9675 \%$ \\
\hline \begin{tabular}{|l|} 
XS0314743963 \\
\end{tabular} & JPY & 17-Aug-2037 & 659,562 & $92.0155 \%$ \\
\hline \begin{tabular}{|l|} 
XS0313664459 \\
\end{tabular} & JPY & 21-Aug-2037 & 661,487 & $92.2840 \%$ \\
\hline \begin{tabular}{|l|l}
$X S 0314747105$ \\
\end{tabular} & AUD & 24-Aug-2037 & 492,284 & $84.0687 \%$ \\
\hline XS0315419134 & JPY & 24-Aug-2037 & 737,215 & $102.8489 \%$ \\
\hline XS0316169050 & JPY & 24-Aug-2037 & 957,679 & $60.7299 \%$ \\
\hline XS0317943586 & JPY & 24-Aug-2037 & 661,006 & $92.2169 \%$ \\
\hline XS0316953925 & JPY & 4-Sep-2037 & 430,995 & $60.1280 \%$ \\
\hline \begin{tabular}{|l|} 
XS0317981081 \\
\end{tabular} & JPY & 5-Sep-2037 & $2,657,159$ & $74.1400 \%$ \\
\hline XS0316953255 & AUD & 7-Sep-2037 & 447,510 & $84.0648 \%$ \\
\hline \begin{tabular}{|l} 
XS0318599056 \\
\end{tabular} & JPY & 14-Sep-2037 & $5,332,710$ & $104.7840 \%$ \\
\hline XS0319724851 & JPY & 14-Sep-2037 & 824,949 & $115.0886 \%$ \\
\hline \begin{tabular}{|l|} 
XS0321080912 \\
\end{tabular} & JPY & 19-Sep-2037 & $2,047,529$ & $95.2169 \%$ \\
\hline XS0319683990 & JPY & 25-Sep-2037 & $1,133,671$ & $98.8490 \%$ \\
\hline \begin{tabular}{|l} 
XS0328666119 \\
\end{tabular} & JPY & 30-Sep-2037 & $1,888,621$ & $109.7840 \%$ \\
\hline XS0321792151 & USD & 9-Oct-2037 & 652,358 & $88.9295 \%$ \\
\hline \begin{tabular}{|l|} 
XS0321396987 \\
\end{tabular} & JPY & 10-Oct-2037 & 850,351 & $98.8604 \%$ \\
\hline XS0325959285 & JPY & $18-$ Oct-2037 & 330,503 & $92.2169 \%$ \\
\hline \begin{tabular}{|l|} 
XS0324342582 \\
\end{tabular} & JPY & 23-Oct-2037 & $2,853,697$ & $104.7682 \%$ \\
\hline XS0327082854 & JPY & 6-Nov-2037 & $2,778,212$ & $104.7536 \%$ \\
\hline \begin{tabular}{|l|} 
XS0327082938 \\
\end{tabular} & JPY & 6-Nov-2037 & 661,830 & $92.3319 \%$ \\
\hline XS0328666036 & JPY & 6-Nov-2037 & $1,395,165$ & $97.3197 \%$ \\
\hline XS0330205625 & JPY & 16-Nov-2037 & 769,517 & $107.3554 \%$ \\
\hline XS0329067531 & JPY & 20-Nov-2037 & $1,878,967$ & $109.2228 \%$ \\
\hline \begin{tabular}{|l|} 
XS0330724229 \\
\end{tabular} & JPY & 20-Nov-2037 & 470,730 & $59.7014 \%$ \\
\hline \begin{tabular}{|l|} 
XS0329878267 \\
\end{tabular} & JPY & 27-Nov-2037 & $1,653,716$ & $92.2840 \%$ \\
\hline XS0333969706 & JPY & 7-Dec-2037 & 637,968 & $74.1691 \%$ \\
\hline XS0333106333 & JPY & 11-Dec-2037 & 661,830 & $92.3319 \%$ \\
\hline XS0333106416 & JPY & 11-Dec-2037 & $1,088,995$ & $101.2838 \%$ \\
\hline \begin{tabular}{|l|} 
XS0333106762 \\
\end{tabular} & JPY & 11-Dec-2037 & 860,926 & $92.3906 \%$ \\
\hline \begin{tabular}{|l|} 
XS0334885729 \\
\end{tabular} & JPY & 14-Dec-2037 & 661,830 & $92.3319 \%$ \\
\hline
\end{tabular}




\begin{tabular}{|c|c|c|c|c|}
\hline ISIN & Currency & $\begin{array}{c}\text { Maturity } \\
\text { date }\end{array}$ & $\begin{array}{c}\text { Admissible } \\
\text { Amount in EUR }\end{array}$ & $\begin{array}{l}\text { Admissible } \\
\text { Amount \% }\end{array}$ \\
\hline XS0333106259 & JPY & 18-Dec-2037 & $2,576,114$ & $105.7040 \%$ \\
\hline XS0333106507 & JPY & 18-Dec-2037 & $3,373,582$ & $92.2840 \%$ \\
\hline XS0335622253 & JPY & 18-Dec-2037 & $1,088,939$ & $101.2786 \%$ \\
\hline XS0336192942 & USD & 18-Dec-2037 & $1,112,088$ & $89.1764 \%$ \\
\hline XS0335621875 & JPY & 21-Dec-2037 & 221,607 & $30.9163 \%$ \\
\hline XS0336408462 & JPY & 21-Dec-2037 & 356,528 & $99.4785 \%$ \\
\hline XS0336409353 & JPY & 21-Dec-2037 & 661,830 & $92.3319 \%$ \\
\hline XS0320168718 & EUR & 31-Dec-2037 & $1,150,482$ & $46.0193 \%$ \\
\hline XS0336623516 & JPY & 8-Jan-2038 & 356,552 & $99.4852 \%$ \\
\hline XS0336851653 & JPY & 8-Jan-2038 & 142,927 & $33.2330 \%$ \\
\hline XS0338518128 & JPY & 8-Jan-2038 & 420,400 & $117.2999 \%$ \\
\hline XS0338677270 & JPY & 8-Jan-2038 & $5,858,112$ & $97.2935 \%$ \\
\hline XS0339677139 & USD & 11-Jan-2038 & $2,580,358$ & $17.5877 \%$ \\
\hline XS0338518391 & JPY & 15-Jan-2038 & $1,524,187$ & $101.2568 \%$ \\
\hline XS0338675571 & JPY & 15-Jan-2038 & $1,256,825$ & $92.2840 \%$ \\
\hline XS0339479684 & USD & 15-Jan-2038 & $1,242,806$ & $89.1681 \%$ \\
\hline XS0339479502 & JPY & 18-Jan-2038 & 727,455 & $101.4872 \%$ \\
\hline XS0338518045 & JPY & 19-Jan-2038 & 881,695 & $123.0053 \%$ \\
\hline XS0339480773 & JPY & 25-Jan-2038 & 772,864 & $107.8222 \%$ \\
\hline XS0339559287 & JPY & 25-Jan-2038 & 838,558 & $116.9872 \%$ \\
\hline XS0341031192 & JPY & 25-Jan-2038 & $1,252,747$ & $116.5138 \%$ \\
\hline XS0342155370 & JPY & 29-Jan-2038 & 838,388 & $116.9635 \%$ \\
\hline XS0340462042 & JPY & 5 -Feb-2038 & 529,189 & $92.2840 \%$ \\
\hline XS0343216809 & JPY & 5-Feb-2038 & $3,343,913$ & $93.3019 \%$ \\
\hline XS0343217104 & JPY & 5-Feb-2038 & $3,129,833$ & $87.3286 \%$ \\
\hline XS0343584602 & JPY & 5-Feb-2038 & $3,311,314$ & $92.3923 \%$ \\
\hline XS0342155297 & JPY & 12-Feb-2038 & 419,274 & $116.9860 \%$ \\
\hline XS0344830608 & JPY & 15-Feb-2038 & 206,216 & $28.7693 \%$ \\
\hline XS0343872577 & JPY & $22-F e b-2038$ & 726,829 & $101.3999 \%$ \\
\hline XS0346508616 & JPY & $26-F e b-2038$ & $1,786,014$ & $92.2840 \%$ \\
\hline XS0346509002 & JPY & $26-F e b-2038$ & $3,309,149$ & $92.3319 \%$ \\
\hline XS0348443135 & JPY & $26-F e b-2038$ & $1,171,154$ & $116.7055 \%$ \\
\hline XS0348444026 & JPY & $26-F e b-2038$ & $1,191,294$ & $92.3319 \%$ \\
\hline XS0346438814 & JPY & 4-Mar-2038 & $1,172,107$ & $116.8004 \%$ \\
\hline XS0349756980 & JPY & 4-Mar-2038 & 753,115 & $116.7412 \%$ \\
\hline XS0349442532 & JPY & 5-Mar-2038 & 707,918 & $98.7616 \%$ \\
\hline XS0350115951 & JPY & 11-Mar-2038 & 665,577 & $92.8546 \%$ \\
\hline XS0352061088 & JPY & 11-Mar-2038 & $1,264,145$ & $92.8215 \%$ \\
\hline XS0350190145 & JPY & 12-Mar-2038 & $5,308,062$ & $74.0528 \%$ \\
\hline XS0351650964 & JPY & 12-Mar-2038 & 877,394 & $30.6013 \%$ \\
\hline XS0349442615 & JPY & 18-Mar-2038 & $3,717,532$ & $129.6582 \%$ \\
\hline XS0349757368 & JPY & 18-Mar-2038 & $2,375,626$ & $114.2840 \%$ \\
\hline XS0351275341 & JPY & 18-Mar-2038 & 831,455 & $115.9963 \%$ \\
\hline XS0352062052 & JPY & 19-Mar-2038 & 426,093 & $99.0737 \%$ \\
\hline XS0352901416 & JPY & 19-Mar-2038 & 752,529 & $104.9854 \%$ \\
\hline XS0351439475 & JPY & 26-Mar-2038 & 921,072 & $128.4988 \%$ \\
\hline XS0352601024 & JPY & 26-Mar-2038 & 769,754 & $107.3884 \%$ \\
\hline XS0352601370 & USD & 26-Mar-2038 & 327,164 & $89.1980 \%$ \\
\hline XS0352601610 & JPY & 26-Mar-2038 & 806,489 & $112.5132 \%$ \\
\hline XS0352601701 & JPY & 26-Mar-2038 & 806,209 & $112.4742 \%$ \\
\hline XS0353348823 & JPY & 26-Mar-2038 & 934,690 & $86.9324 \%$ \\
\hline XS0353872939 & JPY & 26-Mar-2038 & 610,344 & $121.6416 \%$ \\
\hline XS0353873663 & JPY & 26-Mar-2038 & 891,593 & $124.3862 \%$ \\
\hline XS0354316241 & JPY & 26-Mar-2038 & 810,099 & $113.0169 \%$ \\
\hline XS0354483140 & JPY & 26-Mar-2038 & $2,963,521$ & $118.1259 \%$ \\
\hline XS0354496555 & JPY & 8-Apr-2038 & 618,255 & $123.2183 \%$ \\
\hline XS0353875106 & JPY & 9-Apr-2038 & $1,128,699$ & $131.2207 \%$ \\
\hline XS0355669614 & JPY & 15-Apr-2038 & 809,483 & $112.9309 \%$ \\
\hline XS0354482928 & JPY & 16-Apr-2038 & $3,701,854$ & $117.3740 \%$ \\
\hline XS0357773000 & JPY & 22-Apr-2038 & 906,614 & $140.5353 \%$ \\
\hline XS0358426244 & JPY & 22-Apr-2038 & 907,919 & $126.6637 \%$ \\
\hline XS0359279212 & JPY & 7-May-2038 & 409,430 & $114.2391 \%$ \\
\hline XS0362680695 & JPY & 13-May-2038 & 884,182 & $123.3522 \%$ \\
\hline XS0360775141 & JPY & 14-Мау-2038 & $1,242,715$ & $144.4759 \%$ \\
\hline XS0362376435 & JPY & 14-May-2038 & $1,608,802$ & $112.2220 \%$ \\
\hline XS0362680778 & JPY & 20-May-2038 & 804,329 & $112.2120 \%$ \\
\hline XS0362661398 & JPY & 28-May-2038 & $1,528,022$ & $112.1970 \%$ \\
\hline XS0363628982 & JPY & 28-May-2038 & 433,515 & $120.9593 \%$ \\
\hline XS0364649763 & JPY & 28-May-2038 & 831,776 & $116.0411 \%$ \\
\hline XS0364769314 & JPY & 28-May-2038 & $1,185,141$ & $110.2260 \%$ \\
\hline XS0364650183 & JPY & 3-Jun-2038 & $1,297,538$ & $120.6797 \%$ \\
\hline XS0364995240 & JPY & 3-Jun-2038 & $1,623,514$ & $113.2482 \%$ \\
\hline XS0364995323 & JPY & 3-Jun-2038 & 962,764 & $111.9293 \%$ \\
\hline XS0365299204 & JPY & 3-Jun-2038 & 455,332 & $127.0468 \%$ \\
\hline XS0364649250 & JPY & 4-Jun-2038 & 804,163 & $112.1887 \%$ \\
\hline XS0368576848 & JPY & 11-Jun-2038 & 765,936 & $106.8558 \%$ \\
\hline XS0368582812 & JPY & 17-Jun-2038 & 959,474 & $133.8562 \%$ \\
\hline XS0369334700 & JPY & 17-Jun-2038 & 490,698 & $68.4573 \%$ \\
\hline
\end{tabular}




\begin{tabular}{|l|c|r|r|r|}
\hline \multicolumn{1}{|c|}{ ISIN } & Currency & \multicolumn{1}{c|}{$\begin{array}{c}\text { Maturity } \\
\text { date }\end{array}$} & $\begin{array}{c}\text { Admissible } \\
\text { Amount in EUR }\end{array}$ & \multicolumn{1}{c|}{$\begin{array}{c}\text { Admissible } \\
\text { Amount } \%\end{array}$} \\
\hline XS0366374634 & JPY & 18-Jun-2038 & $1,845,038$ & $111.9136 \%$ \\
\hline XS0368882451 & JPY & 18-Jun-2038 & 880,880 & $122.8916 \%$ \\
\hline XS0368926092 & JPY & 25-Jun-2038 & 562,739 & $112.1539 \%$ \\
\hline XS0373147064 & JPY & 15-Jul-2038 & 736,763 & $102.7858 \%$ \\
\hline XS0374734480 & JPY & 15-Jul-2038 & $1,534,919$ & $107.0683 \%$ \\
\hline XS0376740956 & JPY & 30-Jul-2038 & 404,000 & $112.7240 \%$ \\
\hline XS0379987372 & JPY & 14-Aug-2038 & 458,099 & $53.2579 \%$ \\
\hline XS0384259866 & JPY & 3-Sep-2038 & $1,434,702$ & $153.9656 \%$ \\
\hline XS0320168809 & EUR & 21-Dec-2040 & $1,044,011$ & $41.7605 \%$ \\
\hline XS0237937171 & EUR & 12-Dec-2045 & $35,602,479$ & $107.8863 \%$ \\
\hline XS0258581403 & EUR & 22-Jun-2046 & $21,637,302$ & $105.5478 \%$ \\
\hline XS0311664543 & JPY & 25-Jul-2047 & 659,218 & $91.9675 \%$ \\
\hline
\end{tabular}

Total Admissible Amount EUR

$21,477,469,949$

\section{Amended ISINs}

The following ISINs have been amended since the last publication on the LBT Website of September 27, 2012

\begin{tabular}{|c|c|c|c|c|c|c|}
\hline ISIN & Currency & $\begin{array}{l}\text { Maturity } \\
\text { date }\end{array}$ & $\begin{array}{c}\text { Acceleration } \\
\text { date }\end{array}$ & $\begin{array}{c}8 \text { October } 2008 \\
\text { outstanding } \\
\text { nominal value in } \\
\text { EUR }\end{array}$ & $\begin{array}{c}\text { Amended } \\
\text { Admissible } \\
\text { Amount in EUR }\end{array}$ & $\begin{array}{c}\text { Amended } \\
\text { Admissible } \\
\text { Amount \% }\end{array}$ \\
\hline XS0372528165 & USD & 21-Jun-2013 & 4-Aug-2011 & $3,667,840$ & $4,376,467$ & $119.3200 \%$ \\
\hline \begin{tabular}{|l|} 
XS0290250454 \\
\end{tabular} & EUR & 13-Mar-2012 & & $2,650,000$ & $3,040,875$ & $114.7500 \%$ \\
\hline XS0205443764 & EUR & 25-Nov-2014 & 18-Sep-2008 & $15,000,000$ & $10,388,717$ & $69.2581 \%$ \\
\hline \begin{tabular}{|l|} 
XS0234443488 \\
\end{tabular} & EUR & 18-Nov-2013 & 18-Sep-2008 & $15,000,000$ & $11,546,558$ & $76.9771 \%$ \\
\hline XS0292542494 & $\mathrm{CHF}$ & 30-Mar-2013 & 23-Feb-2012 & $38,644,854$ & $48,145,491$ & $124.5845 \%$ \\
\hline \begin{tabular}{|l|} 
XS0284011599 \\
\end{tabular} & EUR & 7-Feb-2012 & & $10,000,000$ & $8,664,511$ & $86.6451 \%$ \\
\hline XS0358444734 & USD & 22-Apr-2010 & & $7,335,681$ & 437,177 & $5.9596 \%$ \\
\hline \begin{tabular}{|l|}
$\mathrm{XS} 0237558662$ \\
\end{tabular} & EUR & 12-Dec-2030 & 24-Jan-2012 & $7,960,000$ & $5,353,603$ & $67.2563 \%$ \\
\hline \begin{tabular}{|l} 
XS0299993336 \\
\end{tabular} & USD & 3-Jan-2012 & & $5,160,124$ & $7,381,323$ & $143.0455 \%$ \\
\hline
\end{tabular}

\section{Manifest Error Notifications}

The following ISINs are subject to unresolved Manifest Error Notifications as of December 5, 2012

\begin{tabular}{|l|c|r|r|r|}
\hline \multicolumn{1}{|c|}{ ISIN } & Currency & $\begin{array}{c}\text { Maturity } \\
\text { date }\end{array}$ & $\begin{array}{c}\text { Admissible } \\
\text { Amount in EUR }\end{array}$ & \multicolumn{1}{c|}{$\begin{array}{c}\text { Admissible } \\
\text { Amount \% }\end{array}$} \\
\hline XS0235648747 & USD & 20-Nov-2008 & $5,444,467$ & $49.4793 \%$ \\
\hline XS0336130835 & USD & 14-Dec-2008 & 10,441 & $0.0150 \%$ \\
\hline XS0336336960 & USD & $20-$-Dec-2008 & 40,040 & $3.6389 \%$ \\
\hline XS0354645227 & USD & $28-M a r-2009$ & 3,367 & $0.9180 \%$ \\
\hline XS0366314226 & USD & $28-M a y-2009$ & 106,176 & $26.3161 \%$ \\
\hline XS0347064924 & EUR & $29-$-Oct-2009 & 58,577 & $0.1025 \%$ \\
\hline XS0378810823 & USD & 5-Feb-2010 & - & $0.0000 \%$ \\
\hline XS0350390406 & EUR & 14-Mar-2011 & $7,033,456$ & $91.8086 \%$ \\
\hline XS0331333160 & EUR & 22-Nov-2011 & $17,884,430$ & $59.6148 \%$ \\
\hline XS0292542494 & CHF & 30-Mar-2013 & $48,145,491$ & $124.5845 \%$ \\
\hline XS0356126705 & EUR & $20-D e c-2017$ & 967,047 & $24.1762 \%$ \\
\hline XS0331053719 & USD & 15-May-2028 & 277,420 & $39.8083 \%$ \\
\hline
\end{tabular}


ANNEX VI 


\section{ANNEX VI - List of submitted Other Ordinary Creditors' claims}

\begin{tabular}{|c|c|c|c|c|c|c|c|}
\hline \multirow[b]{2}{*}{1} & \multirow{2}{*}{$\begin{array}{l}\text { Other Ordinary Creditor } \\
\text { (Stichting) Autoriteit Financiële } \\
\text { Markten (AFM) } \\
\end{array}$} & \multicolumn{2}{|r|}{ Claimed amount } & \multicolumn{2}{|c|}{$\begin{array}{l}\text { Provisionally } \\
\text { admitted amount }^{1}\end{array}$} & \multicolumn{2}{|c|}{$\begin{array}{l}\text { Provisionally } \\
\text { disputed amount }^{2}\end{array}$} \\
\hline & & EUR & $5,396.64$ & EUR & $4,665.00$ & EUR & 731.64 \\
\hline 2 & $\begin{array}{l}\text { Arenthals Grant Thornton } \\
\text { Accountants en Adviseurs B.V. }\end{array}$ & EUR & $6,138.91$ & EUR & $6,138.91$ & & 0 \\
\hline 3 & Austraclear Services Ltd. & AUD & $31,460.00$ & EUR & Pending & & Pending \\
\hline 4 & $\begin{array}{l}\text { Bundesanstalt für } \\
\text { Finanzdienstleistungsaufsicht } \\
\text { (BaFin) }\end{array}$ & EUR & $6,870.19$ & EUR & $6,575.00$ & EUR & 295.19 \\
\hline 5 & $\begin{array}{l}\text { Commissione Nazionale per le } \\
\text { Societa' e la Brosa (CONSOB) }\end{array}$ & EUR & $18,010.00$ & EUR & Pending & & Pending \\
\hline 6 & $\begin{array}{l}\text { Equity Trust Co. N.V. (TMF } \\
\text { Netherlands B.V.) }\end{array}$ & EUR & $29,817.35$ & EUR & $29,817.35$ & & 0 \\
\hline 7 & Irish Stock Exchange & EUR & $1,500.00$ & EUR & Pending & & Pending \\
\hline 8 & $\begin{array}{l}\text { (Claim formerly held by) Lehman } \\
\text { Brothers Bankhaus AG (in } \\
\text { administration) }\end{array}$ & EUR & $246,847.57$ & EUR & Pending & & Pending \\
\hline 9 & $\begin{array}{l}\text { Lehman Brothers Commodities } \\
\text { Services Inc. (in administration) }\end{array}$ & USD & $43,507,736.00$ & EUR & $31,915,886.15$ & & 0 \\
\hline 10 & $\begin{array}{l}\text { Lehman Brothers Finance (Japan) } \\
\text { Inc. }\end{array}$ & AUD & $25,922.07$ & EUR & Pending & & Pending \\
\hline 11 & $\begin{array}{l}\text { Lehman Brothers Finance (Japan) } \\
\text { Inc. }\end{array}$ & USD & $11,102.92$ & EUR & $8,144.75$ & & 0 \\
\hline 12 & Lehman Brothers Finance SA & USD & $3,816,016,451.61$ & EUR & Pending & & Pending \\
\hline 13 & $\begin{array}{l}\text { Lehman Brothers Limited (in } \\
\text { administration) }\end{array}$ & USD & $4,447,870.00$ & EUR & $3,262,815.43$ & & 0 \\
\hline 14 & $\begin{array}{l}\text { Lehman Brothers Special Financing } \\
\text { Inc. (in administration) }\end{array}$ & USD & $1,022,922,712.00$ & EUR & $750,434,794.48$ & & 0 \\
\hline 15 & London Stock Exchange Plc & GBP & $3,600.00$ & EUR & Pending & & Pending \\
\hline 16 & Lyreco Belgium S.A. & EUR & $1,240.53$ & EUR & 0 & EUR & $1,240.53$ \\
\hline 17 & Koninklijke TNT Post B.V. & EUR & 445.67 & EUR & 0 & EUR & 445.67 \\
\hline
\end{tabular}

\footnotetext{
${ }^{1}$ Pursuant to article 133 DBA, claims denominated in a foreign currency are to be converted to Euros at the rate applicable at the bankruptcy date. The Bankruptcy Trustees used the USD to EUR exchange rate of October 8, 2008 as determined by the Dutch Central Bank.

2 "Pending" in this column refers to submitted claims that are currently subject of further revision by the LBT estate and / or discussion between the LBT estate and the respective Other Ordinary Creditor.
} 